\title{
Bioactivity-Guided Discovery of Human Carboxylesterase Inhibitors from the Roots of Paeonia lactiflora
}

Jing-Fang Zhang ${ }^{\dagger}$, Wan-Chao Zhong ${ }^{\dagger}$, Yan-Cheng Li ${ }^{\dagger}$, Yun-Qing Song ${ }^{\ddagger}$, Gui-Yang Xia ${ }^{\dagger}$, , Gui-Hua Tian

*,§, Guang-Bo Ge**; and Sheng Lin $*, \dagger, \S$

${ }^{\dagger}$ State Key Laboratory of Bioactive Substance and Function of Natural Medicines, Institute of Materia Medica, Chinese Academy of Medical Sciences and Peking Union Medical College, Beijing, China

Institute of Interdisciplinary Integrative Medicine Research, Shanghai University of Traditional Chinese Medicine, Shanghai, China.

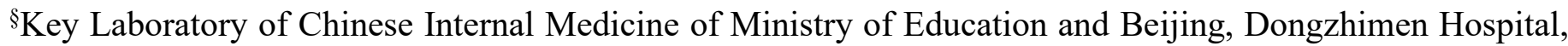
Beijing University of Chinese Medicine, Beijing, China.

\section{Supplementary Information}




\section{The List of Contents}

\begin{tabular}{|c|c|c|}
\hline no. & Contents & Page \\
\hline 1 & Figure S1. The UV Spectrum of Compound $\mathbf{1}$ in $\mathrm{MeOH}$ & 5 \\
\hline 2 & Figure S2. The CD Spectrum of Compound $\mathbf{1}$ in $\mathrm{MeOH}$ & 5 \\
\hline 3 & Figure S3. The HR-mass Spectrum of Compound 1 in $\mathrm{MeOH}$ & 6 \\
\hline 4 & Figure S4. The IR Spectrum of Compound 1 & 6 \\
\hline 5 & Figure S5. The ${ }^{1} \mathrm{H}$ NMR Spectrum of Compound 1 in $\mathrm{CDCl}_{3}(600 \mathrm{MHz})$ & 7 \\
\hline 6 & Figure S6. The ${ }^{13} \mathrm{C}$ NMR Spectrum of Compound 1 in $\mathrm{CDCl}_{3}(150 \mathrm{MHz})$ & 8 \\
\hline 7 & Figure S7. The ${ }^{1} \mathrm{H}^{-1} \mathrm{H}$ COSY Spectrum of Compound 1 in $\left.\mathrm{CDCl}_{3}(600 \mathrm{MHz})\right)$ & 9 \\
\hline 8 & Figure S8. The HSQC Spectrum of Compound 1 in $\mathrm{CDCl}_{3}(600 \mathrm{MHz})$ & 10 \\
\hline 9 & Figure S9. The HMBC Spectrum of Compound 1 in $\mathrm{CDCl}_{3}(600 \mathrm{MHz})$ & 11 \\
\hline 10 & Figure S10. The NOESY Spectrum of Compound 1 in $\mathrm{CDCl}_{3}(600 \mathrm{MHz})$ & 12 \\
\hline 11 & Figure S11. The X-ray Single Crystal Diffraction Data of Compound 1 & 13,14 \\
\hline 12 & Figure S12. The UV Spectrum of Compound 2 in $\mathrm{MeOH}$ & 15 \\
\hline 13 & Figure S13. The CD Spectrum of Compound 2 in $\mathrm{MeOH}$ & 15 \\
\hline 14 & Figure S14. The HR-mass Spectrum of Compound 2 in $\mathrm{MeOH}$ & 16 \\
\hline 15 & Figure S15. The IR Spectrum of Compound 2 & 16 \\
\hline 16 & Figure S16. The ${ }^{1} \mathrm{H}$ NMR Spectrum of Compound 2 in $\mathrm{MeOH}-d_{4}(500 \mathrm{MHz})$ & 17 \\
\hline 17 & Figure S17. The ${ }^{13} \mathrm{C}$ NMR Spectrum of Compound 2 in MeOH- $d_{4}(125 \mathrm{MHz})$ & 18 \\
\hline 18 & Figure S18. The ${ }^{1} \mathrm{H}-{ }^{1} \mathrm{H}$ COSY Spectrum of Compound 2 in $\mathrm{MeOH}-d_{4}(500 \mathrm{MHz})$ & 19 \\
\hline 19 & Figure S19. The HSQC Spectrum of Compound 2 in MeOH- $d_{4}(500 \mathrm{MHz})$ & 20 \\
\hline 20 & Figure S20. The HMBC Spectrum of Compound 2 in $\mathrm{MeOH}-d_{4}(500 \mathrm{MHz})$ & 21 \\
\hline 21 & Figure S21. The NOESY Spectrum of Compound 2 in $\mathrm{MeOH}-d_{4}(500 \mathrm{MHz})$ & 22 \\
\hline 22 & Figure S22. The UV Spectrum of Compound $\mathbf{3}$ in $\mathrm{MeOH}$ & 23 \\
\hline 23 & Figure S23. The CD Spectrum of Compound 3 in $\mathrm{MeOH}$ & 23 \\
\hline 24 & Figure S24. The HR-mass Spectrum of Compound 3 in $\mathrm{MeOH}$ & 23 \\
\hline 25 & Figure S25. The ${ }^{1} \mathrm{H}$ NMR Spectrum of Compound $\mathbf{3}$ in MeOH- $d_{4}(500 \mathrm{MHz})$ & 24 \\
\hline 26 & Figure S26. The ${ }^{13} \mathrm{C}$ NMR Spectrum of Compound 3 in MeOH- $d_{4}(125 \mathrm{MHz})$ & 25 \\
\hline 27 & Figure S27. The ${ }^{1} \mathrm{H}-{ }^{1} \mathrm{H}$ COSY Spectrum of Compound $\mathbf{3}$ in $\mathrm{MeOH}-d_{4}(500 \mathrm{MHz})$ & 26 \\
\hline 28 & Figure S28. The HSQC Spectrum of Compound 3 in $\mathrm{MeOH}-d_{4}(500 \mathrm{MHz})$ & 27 \\
\hline 29 & Figure S29. The HMBC Spectrum of Compound 3 in $\mathrm{MeOH}-d_{4}(500 \mathrm{MHz})$ & 28 \\
\hline 30 & Figure S30. The NOESY Spectrum of Compound 3 in MeOH- $d_{4}(500 \mathrm{MHz})$ & 29 \\
\hline 31 & Figure S31. The UV Spectrum of Compound 4 in $\mathrm{MeOH}$ & 30 \\
\hline 32 & Figure S32. The CD Spectrum of Compound 4 in $\mathrm{MeOH}$ & 30 \\
\hline 33 & Figure S33. The HR-mass Spectrum of Compound 4 in $\mathrm{MeOH}$ & 31 \\
\hline 34 & Figure S34. The IR Spectrum of Compound 4 & 31 \\
\hline 35 & Figure S35. The ${ }^{1} \mathrm{H}$ NMR Spectrum of Compound 4 in $\mathrm{CDCl}_{3}(500 \mathrm{MHz})$ & 32 \\
\hline 36 & Figure S36. The ${ }^{13} \mathrm{C}$ NMR Spectrum of Compound 4 in $\mathrm{CDCl}_{3}(125 \mathrm{MHz})$ & 33 \\
\hline 37 & Figure S37. The ${ }^{1} \mathrm{H}-{ }^{1} \mathrm{H}$ COSY Spectrum of Compound 4 in $\mathrm{CDCl}_{3}(500 \mathrm{MHz})$ & 34 \\
\hline 38 & Figure S38. The HSQC Spectrum of Compound 4 in $\mathrm{CDCl}_{3}(500 \mathrm{MHz})$ & 35 \\
\hline 39 & Figure S39. The HMBC Spectrum of Compound 4 in $\mathrm{CDCl}_{3}(500 \mathrm{MHz})$ & 36 \\
\hline 40 & Figure S40. The NOESY Spectrum of Compound 4 in $\mathrm{CDCl}_{3}(500 \mathrm{MHz})$ & 37 \\
\hline 41 & Figure S41. The UV Spectrum of Compound 5 in $\mathrm{MeOH}$ & 38 \\
\hline 42 & Figure S42. The CD Spectrum of Compound 5 in $\mathrm{MeOH}$ & 38 \\
\hline 43 & Figure S43. The HR-mass Spectrum of Compound 5 in MeOH & 39 \\
\hline
\end{tabular}




\begin{tabular}{|c|c|c|}
\hline 44 & Figure S44. The IR Spectrum of Compound 5 & 40 \\
\hline 45 & The ${ }^{1} \mathrm{H}$ NMR Spectrum of Compound 5 in $\mathrm{MeOH}-d_{4}(600 \mathrm{MHz})$ & 41 \\
\hline 46 & Figure S46. The ${ }^{13} \mathrm{C}$ NMR Spectrum of Compound 5 in $\mathrm{MeOH}-d_{4}(150 \mathrm{MHz})$ & 42 \\
\hline 47 & Figure S47. The ${ }^{1} \mathrm{H}-{ }^{1} \mathrm{H}$ COSY Spectrum of Compound 5 in MeOH- $d_{4}(600 \mathrm{MHz})$ & 43 \\
\hline 48 & Figure S48. The HSQC Spectrum of Compound 5 in MeOH- $d_{4}(600 \mathrm{MHz})$ & 44 \\
\hline 49 & Figure S49. The HMBC Spectrum of Compound 5 in $\mathrm{MeOH}-d_{4}(600 \mathrm{MHz})$ & 45 \\
\hline 50 & Figure S50. The NOESY Spectrum of Compound $\mathbf{5}$ in MeOH- $d_{4}(600 \mathrm{MHz})$ & 46 \\
\hline 51 & Figure S51. The UV Spectrum of Compound 7 in $\mathrm{MeOH}$ & 47 \\
\hline 52 & Figure S52. The CD Spectrum of Compound 7 in $\mathrm{MeOH}$ & 47 \\
\hline 53 & Figure S53. The HR-mass Spectrum of Compound 7 in $\mathrm{MeOH}$ & 48 \\
\hline 54 & Figure S54. $\quad$ The IR Spectrum of Compound 7 & 49 \\
\hline 55 & Figure S55. The ${ }^{1} \mathrm{H}$ NMR Spectrum of Compound 7 in $\mathrm{MeOH}-d_{4}(600 \mathrm{MHz})$ & 50 \\
\hline 56 & Figure S56. The ${ }^{13} \mathrm{C}$ NMR Spectrum of Compound 7 in MeOH- $d_{4}(150 \mathrm{MHz})$ & 51 \\
\hline 57 & Figure S57. The ${ }^{1} \mathrm{H}-{ }^{1} \mathrm{H}$ COSY Spectrum of Compound 7 in MeOH- $d_{4}(600 \mathrm{MHz})$ & 52 \\
\hline 58 & Figure S58. The HSQC Spectrum of Compound 7 in $\mathrm{MeOH}-d_{4}(600 \mathrm{MHz})$ & 53 \\
\hline 59 & Figure S59. The HMBC Spectrum of Compound 7 in $\mathrm{MeOH}-d_{4}(600 \mathrm{MHz})$ & 54 \\
\hline 60 & Figure S60. The NOESY Spectrum of Compound 7 in MeOH- $d_{4}(600 \mathrm{MHz})$ & 55 \\
\hline 61 & Figure S61. The UV Spectrum of Compound 8 in $\mathrm{MeOH}$ & 56 \\
\hline 62 & Figure S62. The CD Spectrum of Compound 8 in $\mathrm{MeOH}$ & 56 \\
\hline 63 & Figure S63. The HR-mass Spectrum of Compound 8 in $\mathrm{MeOH}$ & 57 \\
\hline 64 & Figure S64. The IR Spectrum of Compound 8 & 58 \\
\hline 65 & Figure S65. The ${ }^{1} \mathrm{H}$ NMR Spectrum of Compound 8 in $\mathrm{MeOH}-d_{4}(600 \mathrm{MHz})$ & 59 \\
\hline 66 & Figure S66. The ${ }^{13} \mathrm{C}$ NMR Spectrum of Compound 8 in MeOH- $d_{4}(150 \mathrm{MHz})$ & 60 \\
\hline 67 & Figure S67. The ${ }^{1} \mathrm{H}-{ }^{1} \mathrm{H}$ COSY Spectrum of Compound 8 in $\mathrm{MeOH}-d_{4}(600 \mathrm{MHz})$ & 61 \\
\hline 68 & Figure S68. The HSQC Spectrum of Compound 8 in MeOH- $d_{4}(600 \mathrm{MHz})$ & 62 \\
\hline 69 & Figure S69. The HMBC Spectrum of Compound 8 in MeOH- $d_{4}(600 \mathrm{MHz})$ & 63 \\
\hline 70 & Figure S70. The NOESY Spectrum of Compound 8 in MeOH- $d_{4}(600 \mathrm{MHz})$ & 64 \\
\hline 71 & Figure S71. The UV Spectrum of Compound 9 in $\mathrm{MeOH}$ & 65 \\
\hline 72 & Figure S72. The CD Spectrum of Compound 9 in $\mathrm{MeOH}$ & 65 \\
\hline 73 & Figure S73. The HR-mass Spectrum of Compound 9 in $\mathrm{MeOH}$ & 66 \\
\hline 74 & Figure S74. The IR Spectrum of Compound 9 & 67 \\
\hline 75 & Figure S75. The ${ }^{1} \mathrm{H}$ NMR Spectrum of Compound 9 in $\mathrm{MeOH}-d_{4}(600 \mathrm{MHz})$ & 68 \\
\hline 76 & Figure S76. The ${ }^{13} \mathrm{C}$ NMR Spectrum of Compound 9 in MeOH- $d_{4}(150 \mathrm{MHz})$ & 69 \\
\hline 77 & Figure S77. The ${ }^{1} \mathrm{H}-{ }^{1} \mathrm{H}$ COSY Spectrum of Compound 9 in $\mathrm{MeOH}-d_{4}(600 \mathrm{MHz})$ & 70 \\
\hline 78 & Figure S78. The HSQC Spectrum of Compound 9 in $\mathrm{MeOH}-d_{4}(600 \mathrm{MHz})$ & 71 \\
\hline 79 & Figure S79. The HMBC Spectrum of Compound 9 in MeOH- $d_{4}(600 \mathrm{MHz})$ & 72 \\
\hline 80 & Figure S80. The NOESY Spectrum of Compound 9 in MeOH- $d_{4}(600 \mathrm{MHz})$ & 73 \\
\hline 81 & Figure S81. The UV Spectrum of Compound 10 in $\mathrm{MeOH}$ & 74 \\
\hline 82 & Figure S82. The CD Spectrum of Compound $\mathbf{1 0}$ in $\mathrm{MeOH}$ & 74 \\
\hline 83 & Figure S83. The HR-mass Spectrum of Compound 10 in $\mathrm{MeOH}$ & 75 \\
\hline 84 & The IR Spectrum of Compound $\mathbf{1 0}$ & 76 \\
\hline 85 & Figure S85. The ${ }^{1} \mathrm{H}$ NMR Spectrum of Compound 10 in MeOH- $d_{4}(600 \mathrm{MHz})$ & 77 \\
\hline 86 & Figure S86. The ${ }^{13} \mathrm{C}$ NMR Spectrum of Compound 10 in $\mathrm{MeOH}-d_{4}(150 \mathrm{MHz})$ & 78 \\
\hline 87 & Figure S87. The ${ }^{1} \mathrm{H}-{ }^{1} \mathrm{H}$ COSY Spectrum of Compound 10 in $\mathrm{MeOH}-d_{4}(600 \mathrm{MHz})$ & 79 \\
\hline 88 & Figure S88. The HSQC Spectrum of Compound 10 in $\mathrm{MeOH}-d_{4}(600 \mathrm{MHz})$ & 80 \\
\hline 89 & The HMBC Spectrum of Compound $\mathbf{1 0}$ in $\mathrm{MeOH}-d_{4}(600 \mathrm{MHz})$ & 81 \\
\hline
\end{tabular}




\begin{tabular}{|c|c|c|}
\hline 90 & Figure S90. The NOESY Spectrum of Compound 10 in $\mathrm{MeOH}-d_{4}(600 \mathrm{MHz})$ & 82 \\
\hline 91 & Figure S91. The UV Spectrum of Compound 11 in $\mathrm{MeOH}$ & 83 \\
\hline 92 & Figure S92. The CD Spectrum of Compound $\mathbf{1 1}$ in $\mathrm{MeOH}$ & 83 \\
\hline 93 & Figure S93. The HR-mass Spectrum of Compound 11 in $\mathrm{MeOH}$ & 84 \\
\hline 94 & Figure S94. The IR Spectrum of Compound 11 & 84 \\
\hline 95 & Figure S95. The ${ }^{1} \mathrm{H}$ NMR Spectrum of Compound 11 in MeOH- $d_{4}(500 \mathrm{MHz})$ & 85 \\
\hline 96 & Figure S96. The ${ }^{13} \mathrm{C}$ NMR Spectrum of Compound 11 in MeOH- $d_{4}(125 \mathrm{MHz})$ & 86 \\
\hline 97 & Figure S97. The ${ }^{1} \mathrm{H}-{ }^{1} \mathrm{H}$ COSY Spectrum of Compound 11 in MeOH- $d_{4}(500 \mathrm{MHz})$ & 87 \\
\hline 98 & Figure S98. The HSQC Spectrum of Compound 11 in MeOH- $d_{4}(500 \mathrm{MHz})$ & 88 \\
\hline 99 & Figure S109. The HMBC Spectrum of Compound 11 in MeOH- $d_{4}(500 \mathrm{MHz})$ & 89 \\
\hline 100 & Figure S100. The NOESY Spectrum of Compound 11 in $\mathrm{MeOH}-d_{4}(500 \mathrm{MHz})$ & 90 \\
\hline 101 & Figure S101. The UV Spectrum of Compound 12 in $\mathrm{MeOH}$ & 91 \\
\hline 102 & Figure S102. The CD Spectrum of Compound 12 in $\mathrm{MeOH}$ & 91 \\
\hline 103 & Figure S103. The HR-mass Spectrum of Compound 12 in $\mathrm{MeOH}$ & 92 \\
\hline 104 & Figure S104. The IR Spectrum of Compound 12 & 92 \\
\hline 105 & Figure S105. The ${ }^{1} \mathrm{H}$ NMR Spectrum of Compound 12 in MeOH- $d_{4}(500 \mathrm{MHz})$ & 93 \\
\hline 106 & Figure S106. The ${ }^{13} \mathrm{C}$ NMR Spectrum of Compound 12 in MeOH- $d_{4}(125 \mathrm{MHz})$ & 94 \\
\hline 107 & Figure S107. The ${ }^{1} \mathrm{H}-{ }^{1} \mathrm{H}$ COSY Spectrum of Compound 12 in MeOH- $d_{4}(500 \mathrm{MHz})$ & 95 \\
\hline 108 & Figure S108. The HSQC Spectrum of Compound 12 in MeOH- $d_{4}(500 \mathrm{MHz})$ & 96 \\
\hline 109 & Figure S109. The HMBC Spectrum of Compound 12 in MeOH- $d_{4}(500 \mathrm{MHz})$ & 97 \\
\hline 110 & Figure S110. The NOESY Spectrum of Compound 12 in MeOH- $d_{4}(500 \mathrm{MHz})$ & 98 \\
\hline 111 & Figure S111. The UV Spectrum of Compound 26 in $\mathrm{MeOH}$ & 99 \\
\hline 112 & Figure S112. The CD Spectrum of Compound 26 in $\mathrm{MeOH}$ & 99 \\
\hline 113 & Figure S113. The HR-mass Spectrum of Compound 26 in MeOH & 100 \\
\hline 114 & Figure S114. The IR Spectrum of Compound 26 & 100 \\
\hline 115 & Figure S115. The ${ }^{1} \mathrm{H}$ NMR Spectrum of Compound 26 in $\mathrm{CDCl}_{3}(600 \mathrm{MHz})$ & 101 \\
\hline 116 & Figure S116. The ${ }^{13} \mathrm{C}$ NMR Spectrum of Compound 26 in $\mathrm{CDCl}_{3}(150 \mathrm{MHz})$ & 102 \\
\hline 117 & Figure S117. The DEPT Spectrum of Compound 26 in $\mathrm{CDCl}_{3}(150 \mathrm{MHz})$ & 103 \\
\hline 118 & Figure S118. The ${ }^{1} \mathrm{H}-{ }^{1} \mathrm{H}$ COSY Spectrum of Compound 26 in $\left.\mathrm{CDCl}_{3}(600 \mathrm{MHz})\right)$ & 104 \\
\hline 119 & Figure S119. The HSQC Spectrum of Compound 26 in $\mathrm{CDCl}_{3}(600 \mathrm{MHz})$ & 105 \\
\hline 120 & Figure S120. The HMBC Spectrum of Compound 26 in $\mathrm{CDCl}_{3}(600 \mathrm{MHz})$ & 106 \\
\hline 121 & Figure S121. The NOESY Spectrum of Compound 26 in $\mathrm{CDCl}_{3}(600 \mathrm{MHz})$ & 107 \\
\hline 122 & In silico prediction of ECD Spectrum & 108 \\
\hline 123 & Figure S122. Low-energy Conformers of 1-5 in $\mathrm{MeOH}$ & 109 \\
\hline 124 & Figure S123. Low-energy Conformers of 7-12 in $\mathrm{MeOH}$ & 109 \\
\hline 125 & Figure S124. Low-energy Conformers of 26 in $\mathrm{MeOH}$ & 110 \\
\hline 126 & $\begin{array}{l}\text { Table S1. Relative Energies, Equilibrium Populations, Extracted heats and weighting } \\
\text { factors of the optimized conformers of } \mathbf{1 - 5 , 7 - 1 2} \text {, and } \mathbf{2 6} \text { at B3LYP/6-311+G }(\mathrm{d}, \mathrm{p}) \text { level in } \\
\text { MeOH with PCM }\end{array}$ & 110 \\
\hline 127 & Figure S125. Experimental and calculated ECD data of compounds $\mathbf{2 - 5}$ and 26 & 111 \\
\hline 128 & General Experimental Procedures & 112 \\
\hline 129 & Table S2. The Inhibitory Activity of Fractions A-J Against hCEs & 113 \\
\hline 130 & Table S3. IC $\mathrm{IC}_{50}$ Values of $\mathbf{1}, \mathbf{6}, \mathbf{1 0}, \mathbf{1 1}, \mathbf{1 3 - 1 5}, \mathbf{1 8 - 2 0}, \mathbf{2 2}$, and 24-26 on hCES2A1 & 113 \\
\hline 131 & Table S4. IC $_{50}$ Values of $\mathbf{1 8}-\mathbf{2 6}$ on hCES1A1 & 113 \\
\hline
\end{tabular}




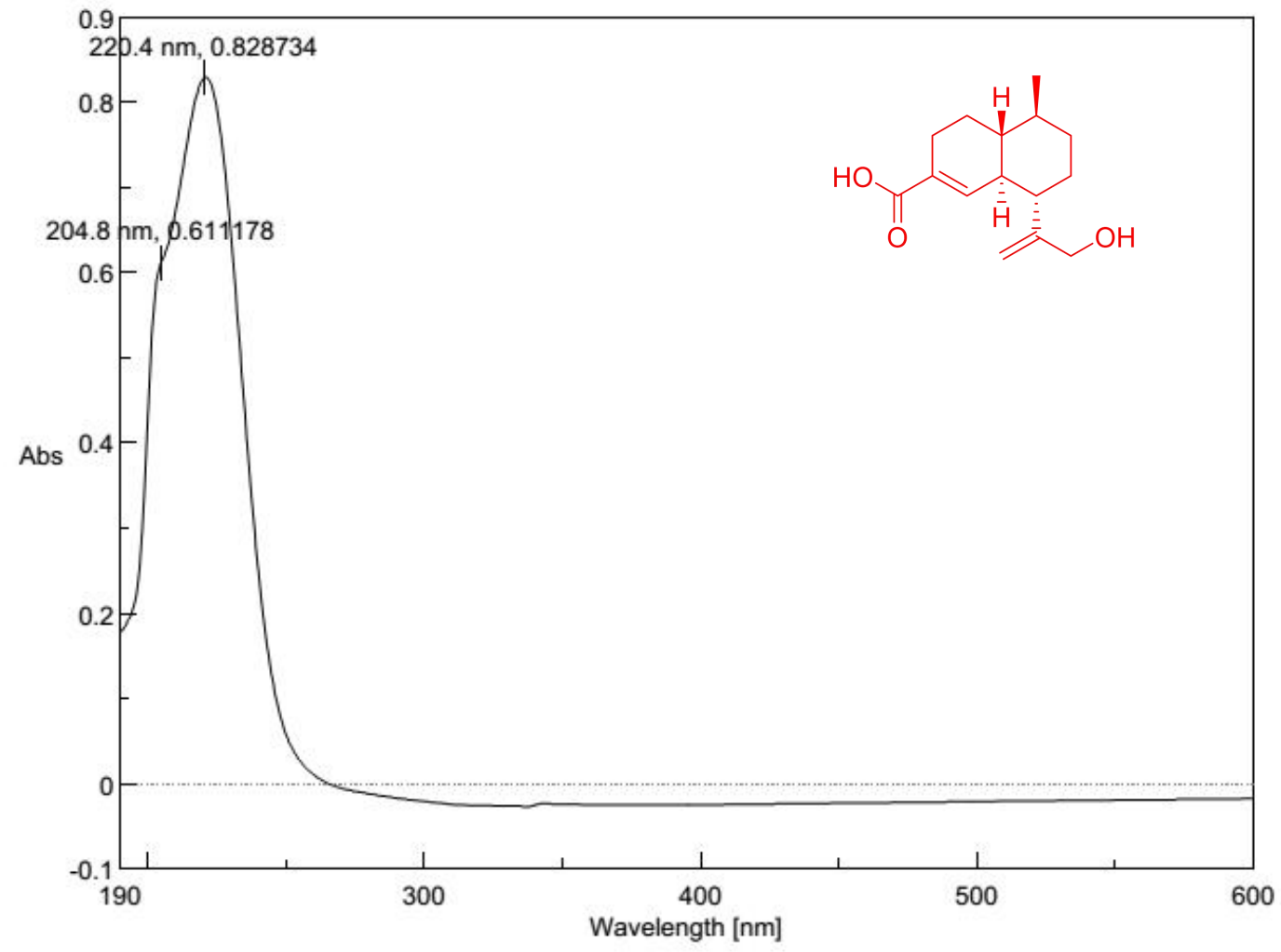

Figure S1. The UV Spectrum of Compound 1 in $\mathrm{MeOH}$

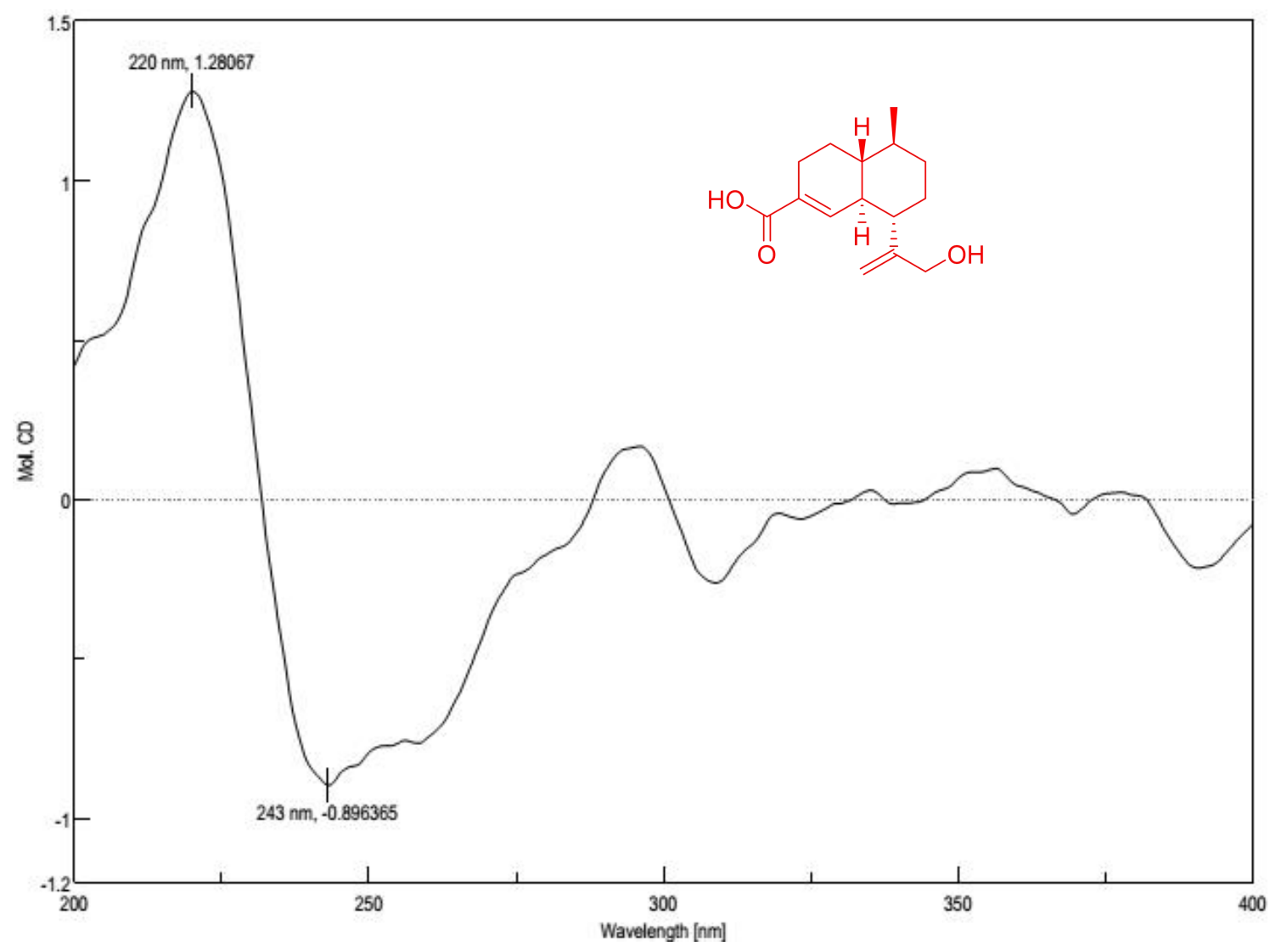

Figure S2. The CD Spectrum of Compound 1 in $\mathrm{MeOH}$ 


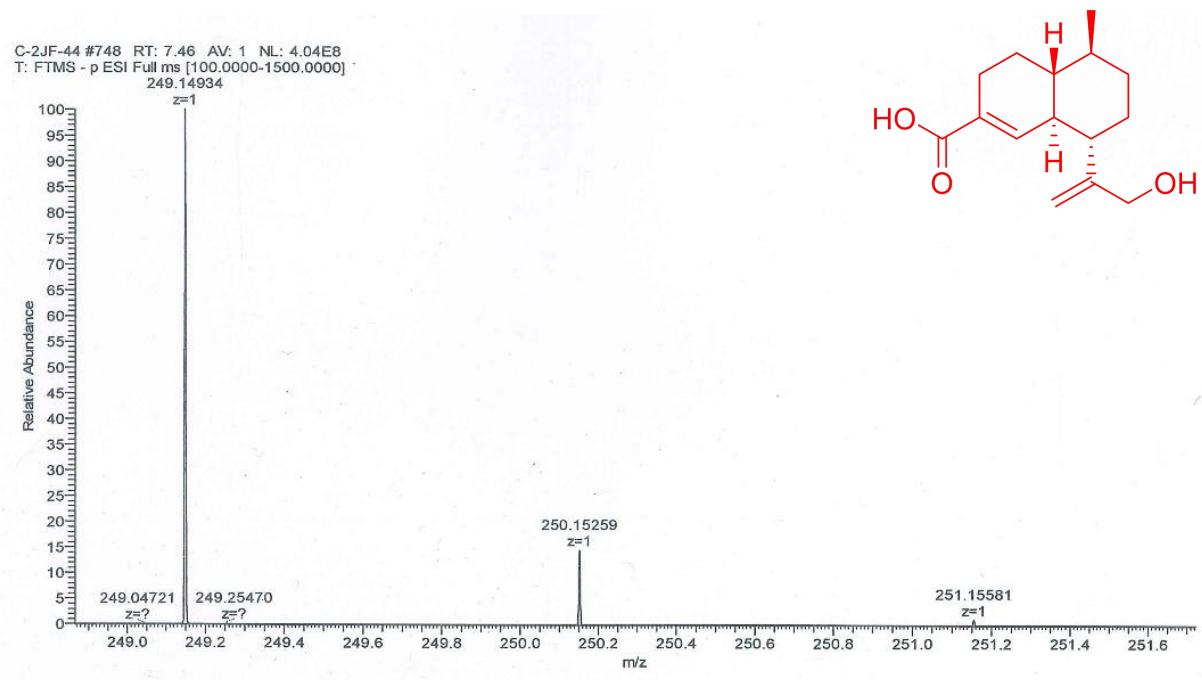

\begin{tabular}{|l|r|r|r|l|l|}
\hline $\mathrm{m} / \mathrm{z}$ & Theo. Mass & Delta (ppm) & RDB equiv. & Composition & \\
\hline & & & & & \\
\hline 249.14934 & 249.14962 & -1.12 & 5.5 & $\mathrm{C} 15 \mathrm{H} 21 \mathrm{O} 3$ & $\mathrm{M}-\mathrm{H}$ \\
\hline
\end{tabular}

Figure S3. The HR-mass Spectrum of Compound 1 in $\mathrm{MeOH}$

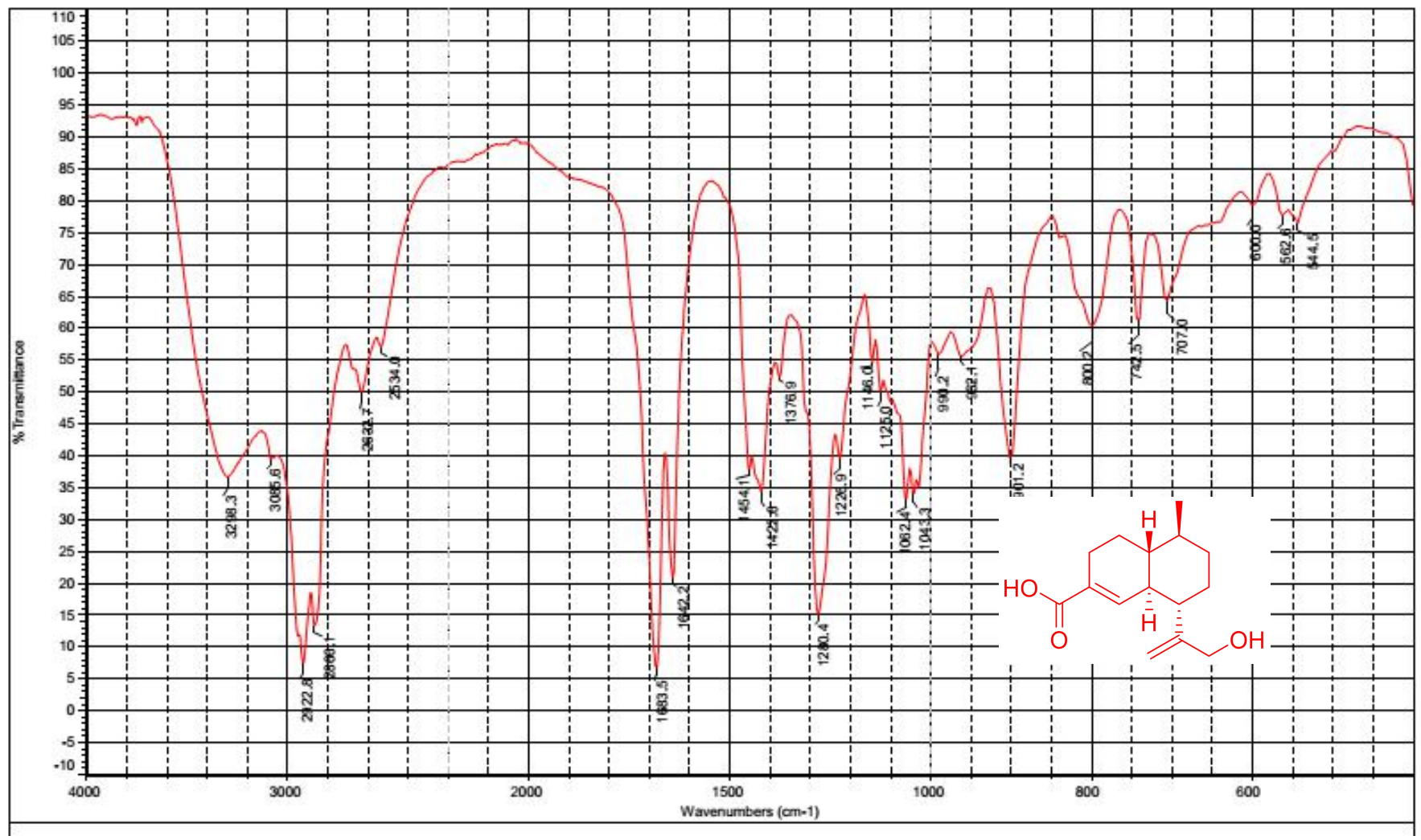

Figure S4. The IR Spectrum of Compound 1 

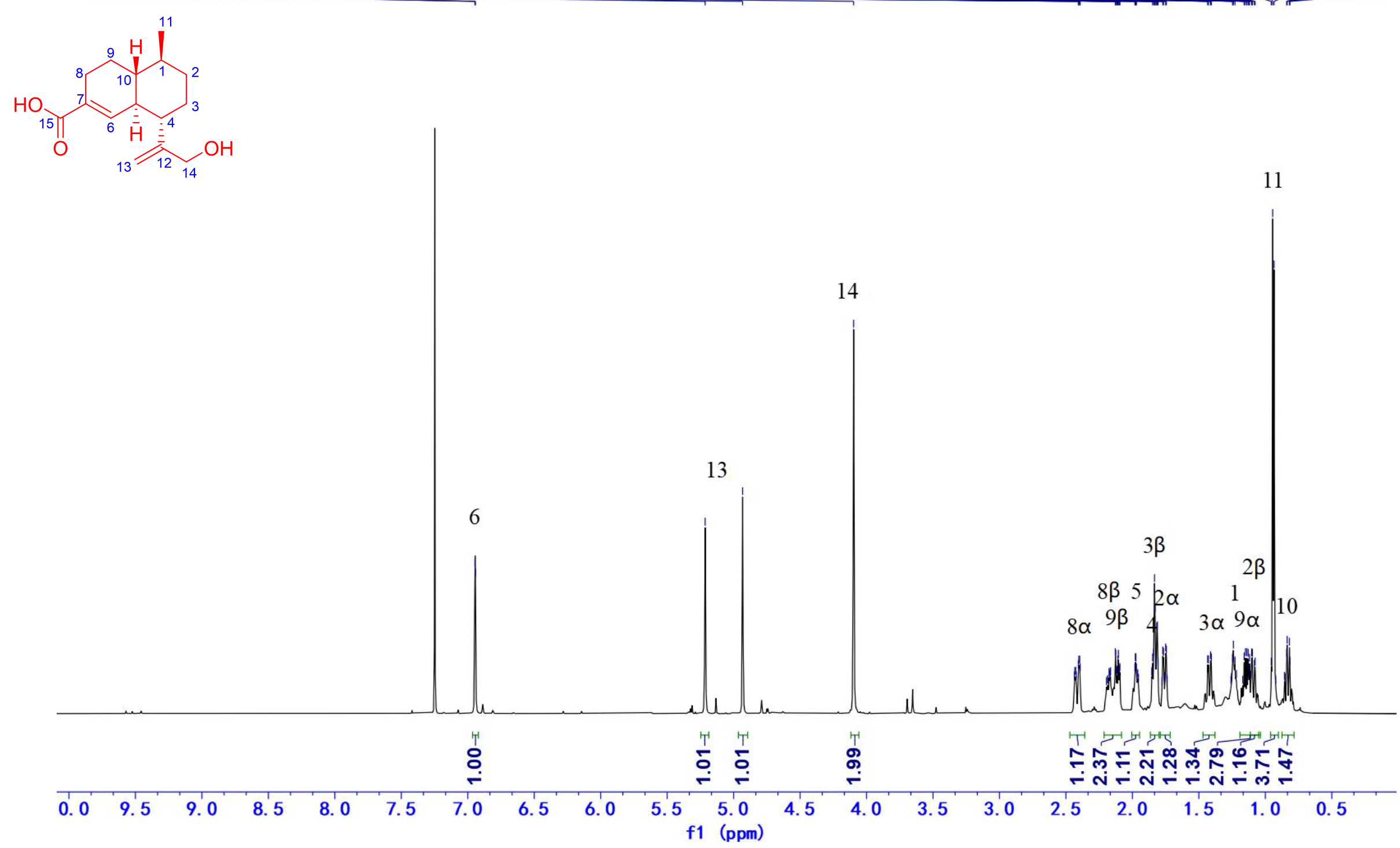

Figure S5. The ${ }^{1} \mathrm{H}$ NMR Spectrum of Compound 1 in $\mathrm{CDCl}_{3}(600 \mathrm{MHz})$ 

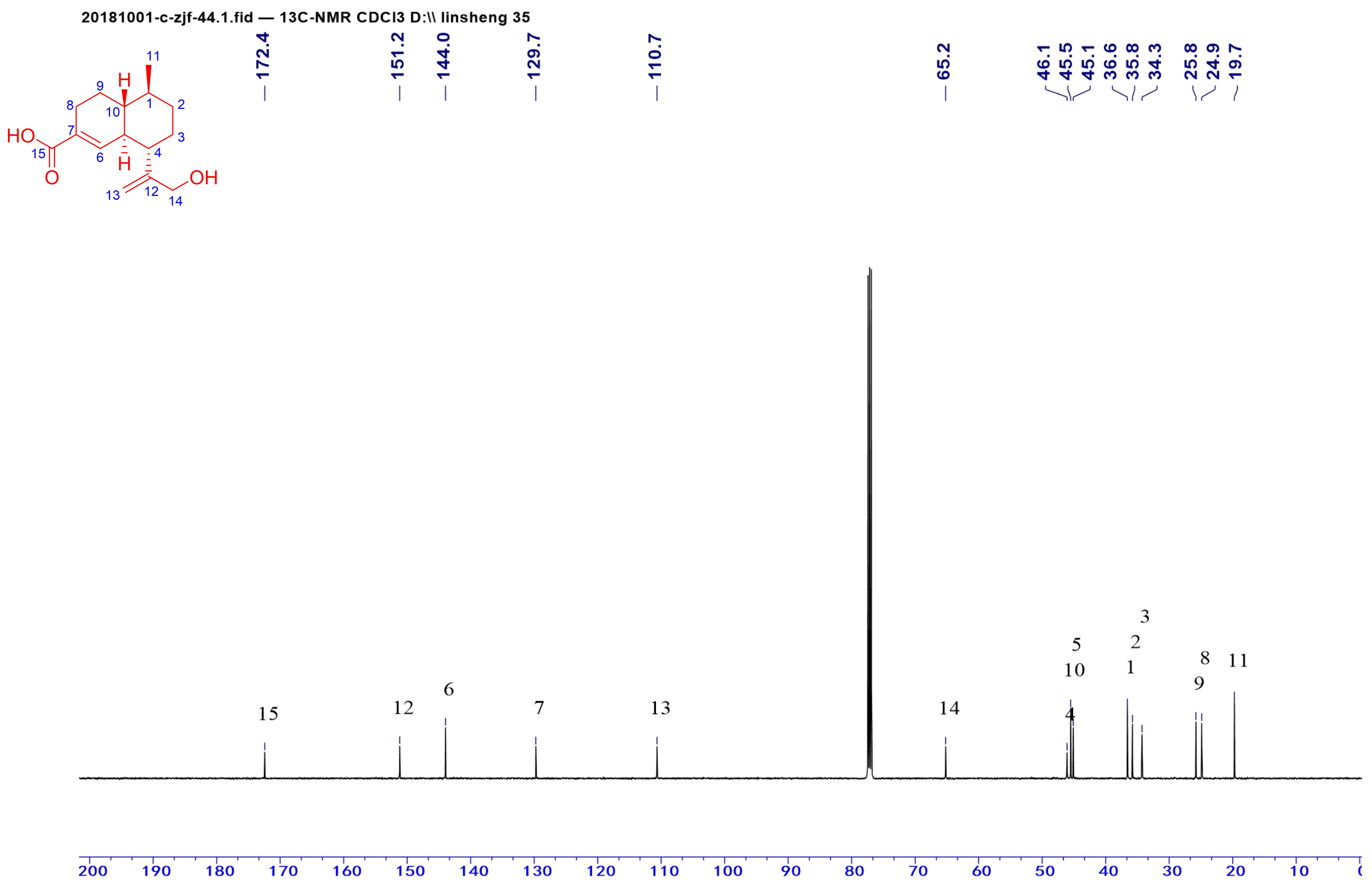

100

80
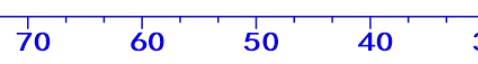

Figure S6. The ${ }^{13} \mathrm{C}$ NMR Spectrum of Compound 1 in $\mathrm{CDCl}_{3}(150 \mathrm{MHz})$ 
20181023 c-zjf-44.2.ser — Bruker AVIII HD 600 — COSY_MQF CDCI3 D:II DATA2018 7
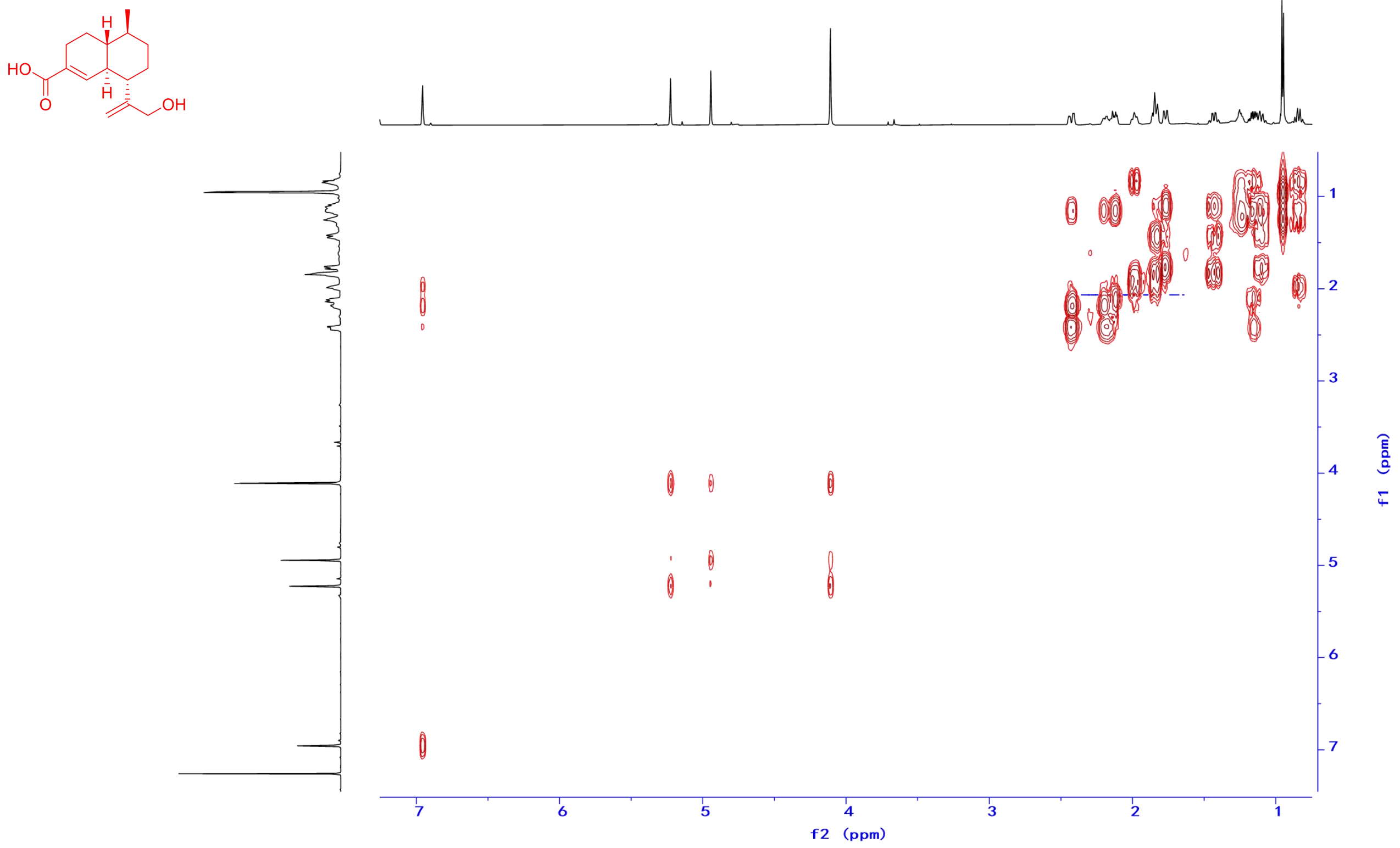

Figure S7. The ${ }^{1} \mathrm{H}-{ }^{1} \mathrm{H}$ COSY Spectrum of Compound 1 in $\mathrm{CDCl}_{3}(600 \mathrm{MHz})$ 
20181023 c-zjf-44.4.ser — Bruker AVIII HD 600 — \{HSQC_(phase sensitive)\} CDCI3 D:II DATA2018 7
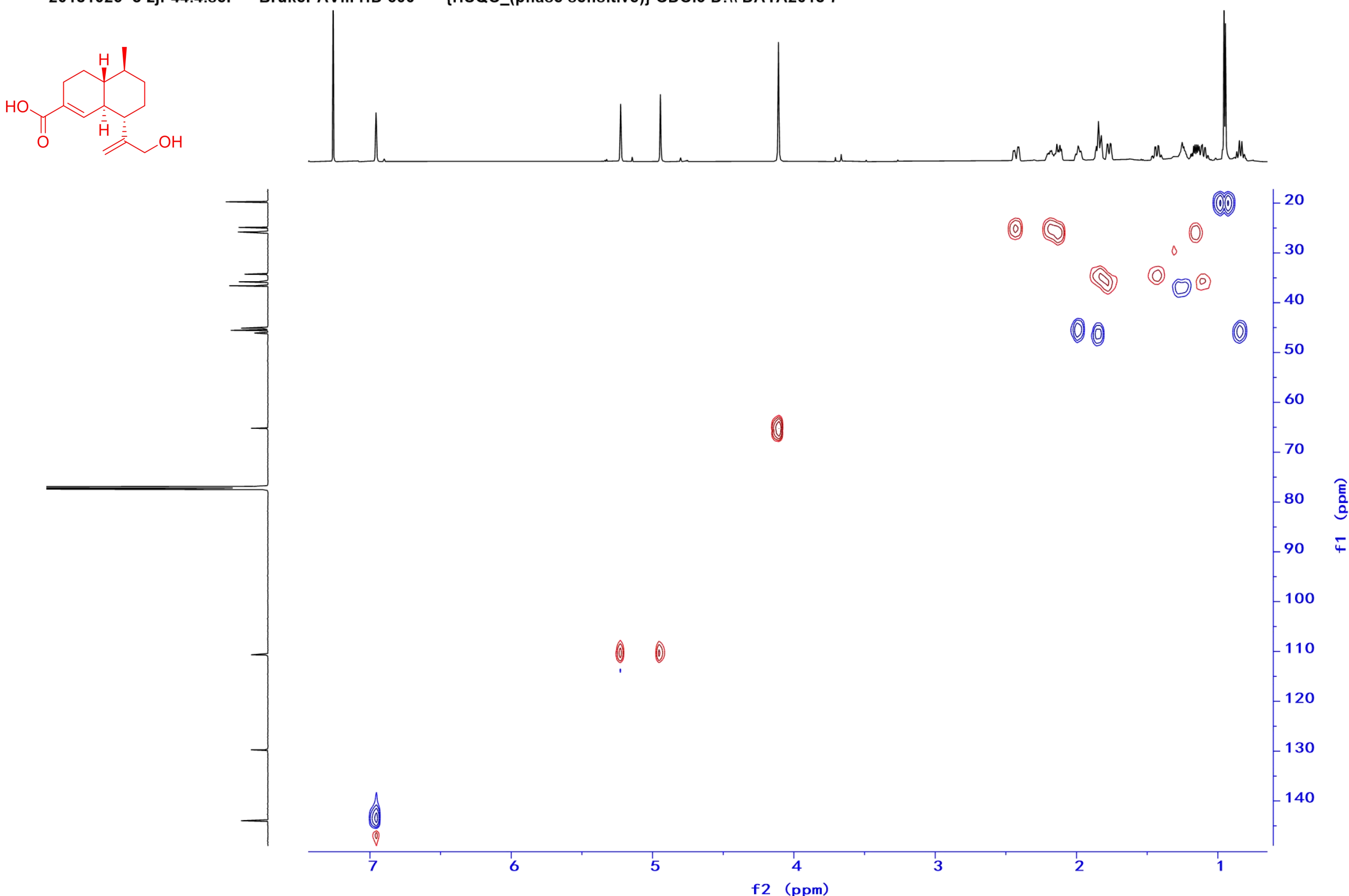

Figure S8. The HSQC Spectrum of Compound 1 in $\mathrm{CDCl}_{3}(600 \mathrm{MHz})$ 
20181023 c-zjf-44.5.ser — Bruker AVIII HD 600 — HMBC CDCI3 D:II DATA2018 7

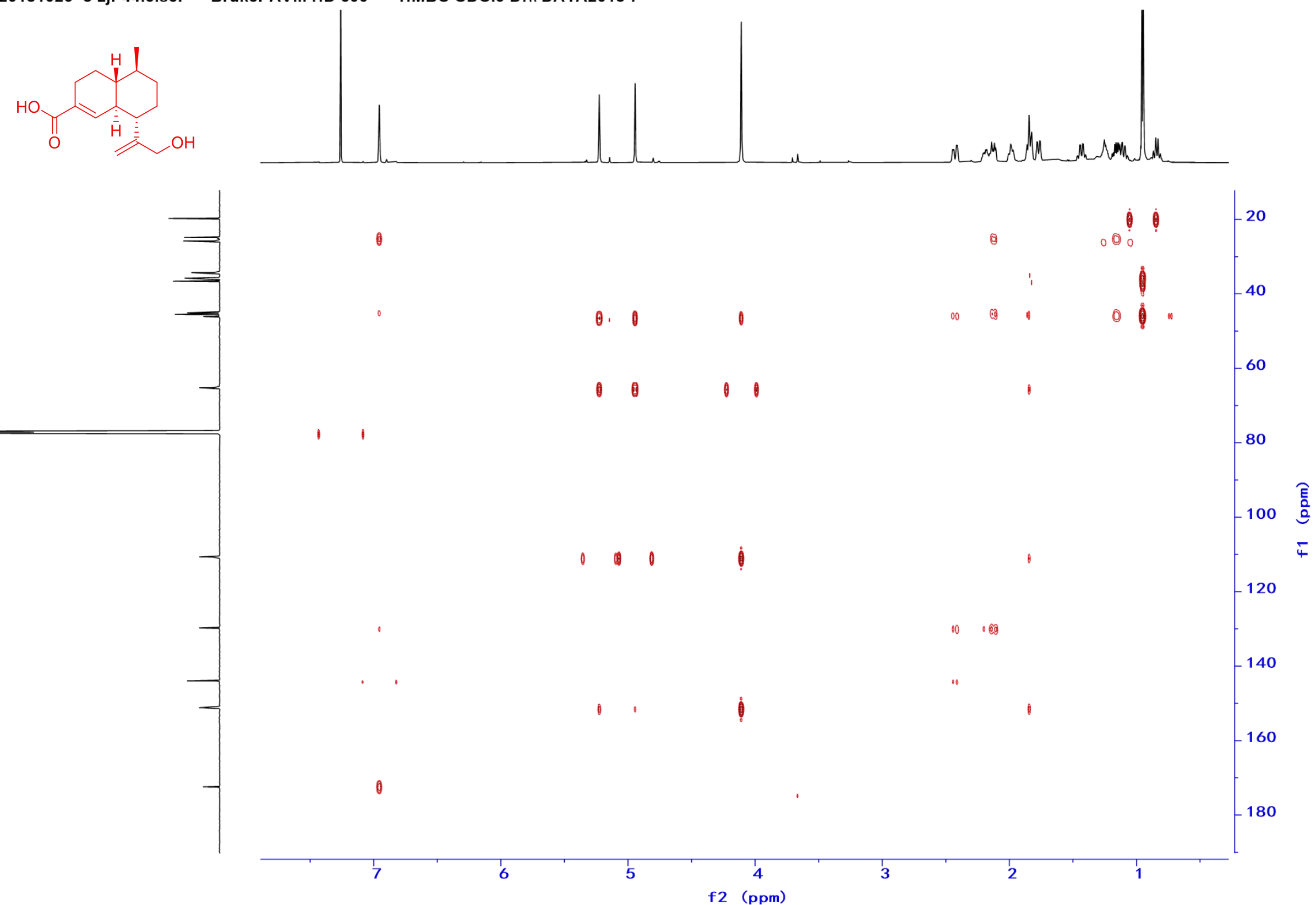

Figure S9. The HMBC Spectrum of Compound 1 in $\mathrm{CDCl}_{3}(600 \mathrm{MHz})$ 


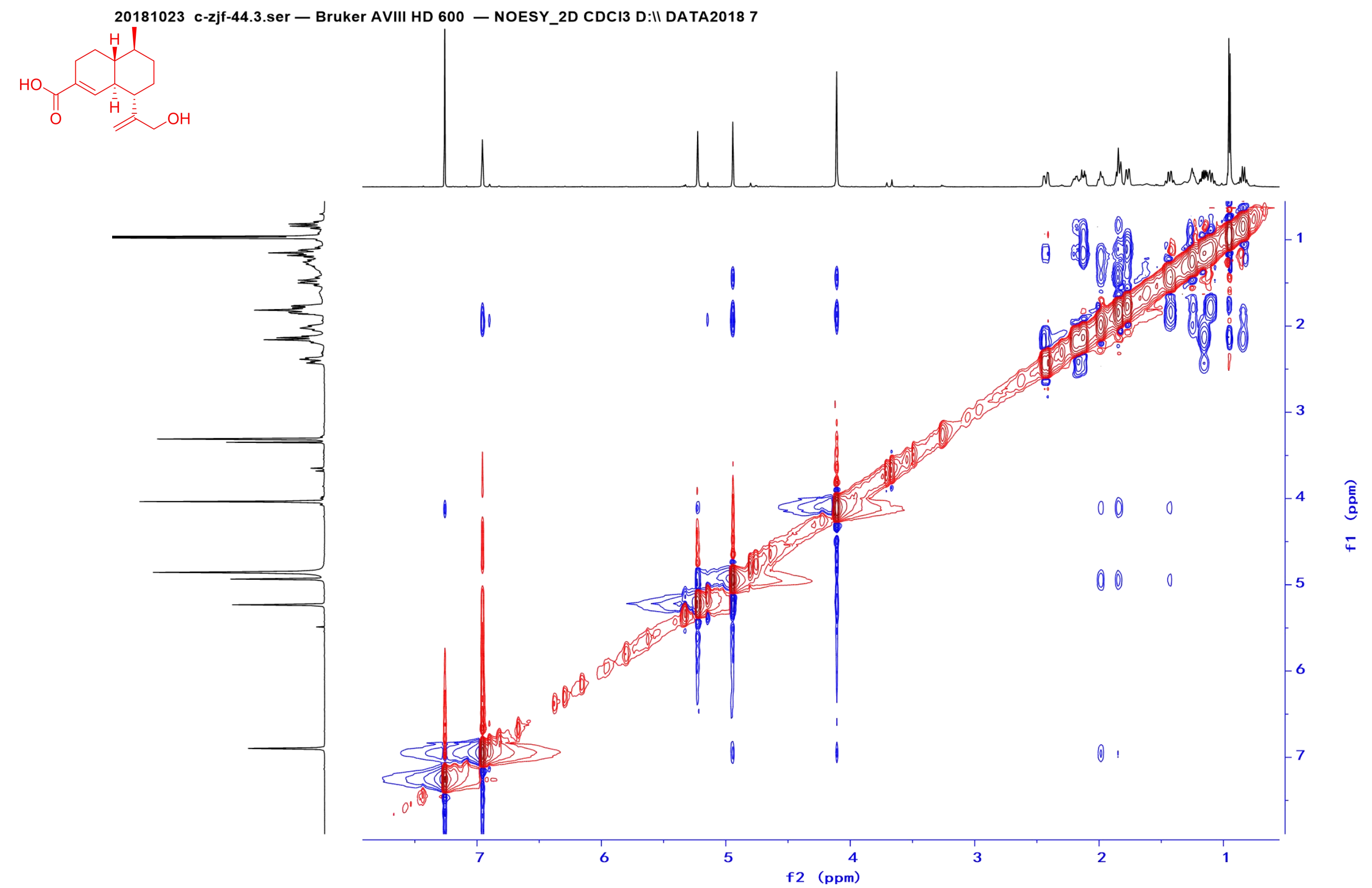

Figure S10. The NOESY Spectrum of Compound 1 in $\mathrm{CDCl}_{3}(600 \mathrm{MHz})$ 
Table 1. Crystal data and structure refinement for mj19144.

Identification code

Empirical formula

Formula weight

Temperature

Wavelength

Crystal system

Space group

Unit cell dimensions

Volume

Z

Density (calculated)

Absorption coefficient

$\mathrm{F}(000)$

Crystal size

Theta range for data collection

Index ranges

Reflections collected

Independent reflections

Completeness to theta $=53.594^{\circ}$

Absorption correction

Max. and min. transmission

Refinement method

Data / restraints / parameters

Goodness-of-fit on $\mathrm{F}^{2}$

Final $R$ indices $[\mathrm{I}>2 \operatorname{sigma}(\mathrm{I})]$

$\mathrm{R}$ indices (all data)

Absolute structure parameter

Extinction coefficient

Largest diff. peak and hole mj 19144

C15 H22 O3

250.32

$170.02 \mathrm{~K}$

$1.34139 \AA$

Triclinic

P1

$\begin{array}{ll}\mathrm{a}=8.6358(13) \AA & \alpha=74.596(6)^{\circ} . \\ \mathrm{b}=9.3834(15) \AA & \beta=86.938(9)^{\circ} . \\ \mathrm{c}=9.8633(15) \AA & \gamma=68.597(9)^{\circ} .\end{array}$

$716.6(2) \AA^{3}$

2

$1.160 \mathrm{Mg} / \mathrm{m}^{3}$

$0.408 \mathrm{~mm}^{-1}$

272

$0.12 \times 0.03 \times 0.02 \mathrm{~mm}^{3}$

4.049 to $55.232^{\circ}$

$-10<=\mathrm{h}<=10,-11<=\mathrm{k}<=11,-12<=\mathrm{l}<=11$

16803

$5215[\mathrm{R}(\mathrm{int})=0.0529]$

$99.6 \%$

Semi-empirical from equivalents

0.7508 and 0.5594

Full-matrix-block least-squares on $\mathrm{F}^{2}$

$5215 / 7 / 339$

1.053

$\mathrm{R} 1=0.0666, \mathrm{wR} 2=0.1808$

$\mathrm{R} 1=0.0724, \mathrm{wR} 2=0.1881$

$0.00(19)$

$\mathrm{n} / \mathrm{a}$

0.444 and -0.296 e. $\AA^{-3}$ 
Table 2. Atomic coordinates $\left(\times 10^{4}\right)$ and equivalent isotropic displacement parameters $\left(\AA^{2} \times 10^{3}\right)$ for mj19144. $\mathrm{U}(\mathrm{eq})$ is defined as one third of the trace of the orthogonalized $\mathrm{U}^{\mathrm{ij}}$ tensor.

\begin{tabular}{|c|c|c|c|c|}
\hline & $\mathrm{x}$ & $\mathrm{y}$ & $\mathrm{z}$ & $\mathrm{U}(\mathrm{eq})$ \\
\hline $\mathrm{O}(1)$ & $16079(5)$ & $-7715(4)$ & $1634(3)$ & 66 \\
\hline $\mathrm{O}(2)$ & $15370(5)$ & $-6265(4)$ & $3165(3)$ & 64 \\
\hline $\mathrm{O}(3)$ & $16252(4)$ & $-6109(3)$ & $8946(3)$ & 56 \\
\hline$C(1)$ & $19051(5)$ & $-13240(5)$ & $7439(5)$ & 49 \\
\hline$C(2)$ & $19727(6)$ & $-12802(5)$ & $8607(5)$ & 50 \\
\hline$C(3)$ & $18424(5)$ & $-11425(5)$ & $9057(4)$ & 48 \\
\hline$C(4)$ & $17770(5)$ & $-9955(4)$ & $7811(4)$ & 39 \\
\hline$C(5)$ & $17066(4)$ & $-10367(4)$ & $6627(4)$ & 38 \\
\hline$C(6)$ & $16405(4)$ & $-8962(4)$ & $5361(4)$ & 38 \\
\hline$C(7)$ & $16485(5)$ & $-9065(5)$ & $4035(4)$ & 39 \\
\hline$C(8)$ & $17218(5)$ & $-10621(5)$ & $3655(4)$ & 46 \\
\hline $\mathrm{C}(9)$ & $17621(5)$ & $-12048(5)$ & $4944(5)$ & 47 \\
\hline$C(10)$ & $18384(5)$ & $-11772(5)$ & $6187(4)$ & 41 \\
\hline$C(11)$ & $20398(7)$ & $-14634(6)$ & $7036(6)$ & 66 \\
\hline$C(12)$ & $16543(5)$ & $-8552(5)$ & $8283(4)$ & 41 \\
\hline$C(13)$ & $15017(5)$ & $-8430(6)$ & $8619(5)$ & 52 \\
\hline$C(14)$ & $17287(6)$ & $-7363(5)$ & $8386(4)$ & 48 \\
\hline$C(15)$ & $15949(5)$ & $-7631(5)$ & $2834(4)$ & 45 \\
\hline $\mathrm{O}(1 \mathrm{~A})$ & $14046(4)$ & $-2171(4)$ & $8369(3)$ & 53 \\
\hline $\mathrm{O}(2 \mathrm{~A})$ & $14427(4)$ & $-3727(4)$ & $6940(3)$ & 55 \\
\hline$O(3 A)$ & $15198(4)$ & $-3777(3)$ & $1074(3)$ & 52 \\
\hline$C(1 \mathrm{~A})$ & $10045(5)$ & $2977(5)$ & $2583(4)$ & 44 \\
\hline$C(2 A)$ & $10753(6)$ & $2860(5)$ & $1141(4)$ & 51 \\
\hline$C(3 A)$ & $11268(5)$ & $1206(5)$ & $949(4)$ & 46 \\
\hline$C(4 A)$ & $12498(5)$ & $-63(4)$ & $2128(4)$ & 38 \\
\hline$C(5 \mathrm{~A})$ & $11697(4)$ & $65(4)$ & $3554(4)$ & 37 \\
\hline$C(6 A)$ & $12697(5)$ & $-1229(4)$ & 4793(4) & 38 \\
\hline$C(7 A)$ & $12851(5)$ & $-1003(4)$ & $6042(4)$ & 39 \\
\hline$C(8 \mathrm{~A})$ & $12058(5)$ & $585(5)$ & $6352(4)$ & 44 \\
\hline$C(9 A)$ & $10710(5)$ & $1741(4)$ & $5248(4)$ & 41 \\
\hline$C(10 A)$ & $11302(4)$ & $1721(4)$ & $3750(4)$ & 37 \\
\hline$C(11 A)$ & $9548(7)$ & $4661(5)$ & $2733(6)$ & 62 \\
\hline$C(12 A)$ & $12988(5)$ & $-1693(5)$ & $1869(4)$ & 43 \\
\hline$C(11 A)$ & $9548(7)$ & $4661(5)$ & $2733(6)$ & 62 \\
\hline $\mathrm{C}(12 \mathrm{~A})$ & $12988(5)$ & $-1693(5)$ & $1869(4)$ & 43 \\
\hline$C(13 A)$ & $11938(6)$ & $-2408(6)$ & $1861(5)$ & 56 \\
\hline $\mathrm{C}(14 \mathrm{~A})$ & $14786(5)$ & $-2382(5)$ & $1544(4)$ & 47 \\
\hline$C(15 A)$ & $13843(5)$ & $-2363(5)$ & $7223(4)$ & 40 \\
\hline
\end{tabular}

Figure S11. X-ray single crystal diffraction data of compound 1 


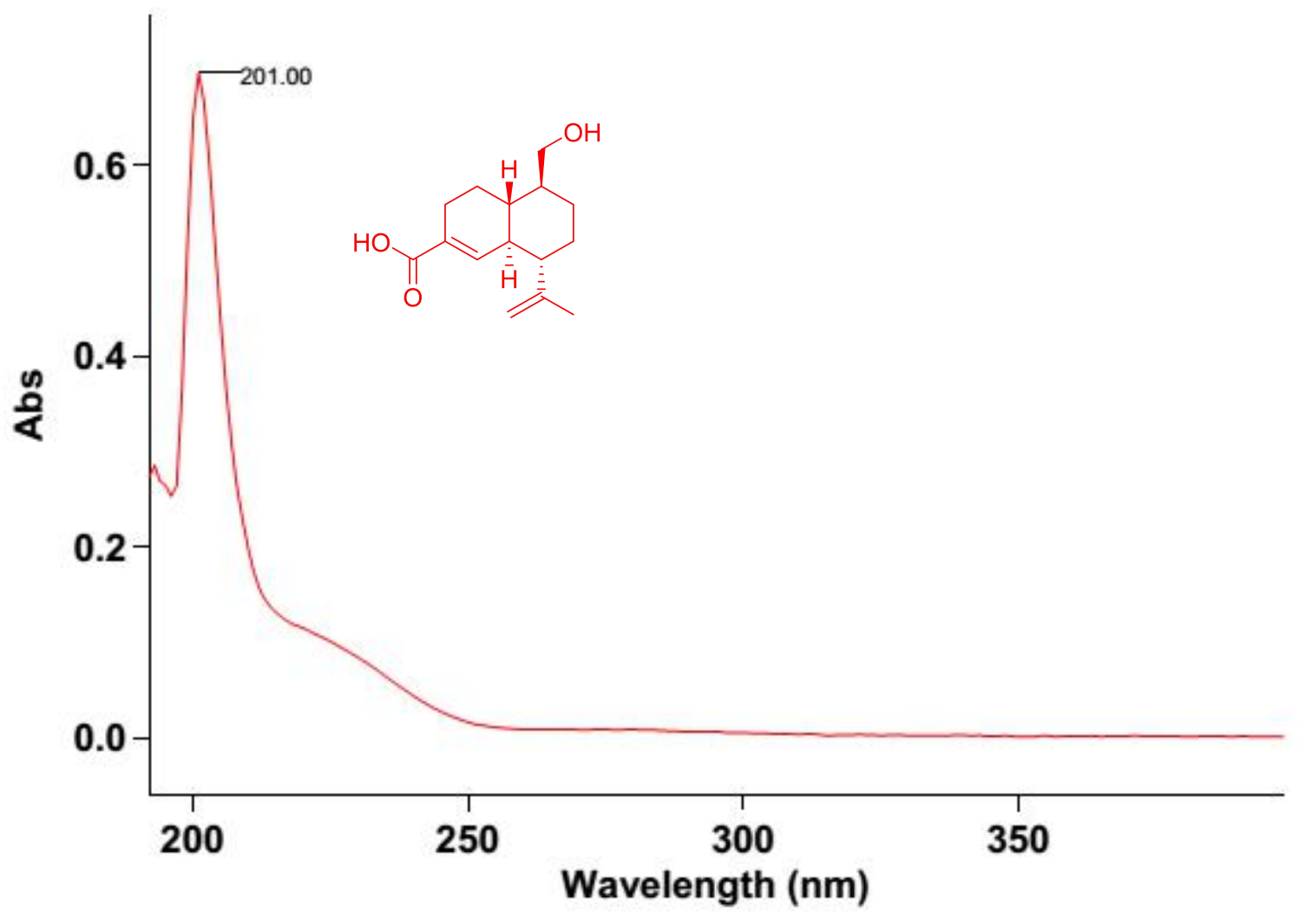

Figure S12. The UV Spectrum of compound 2 in $\mathrm{MeOH}$

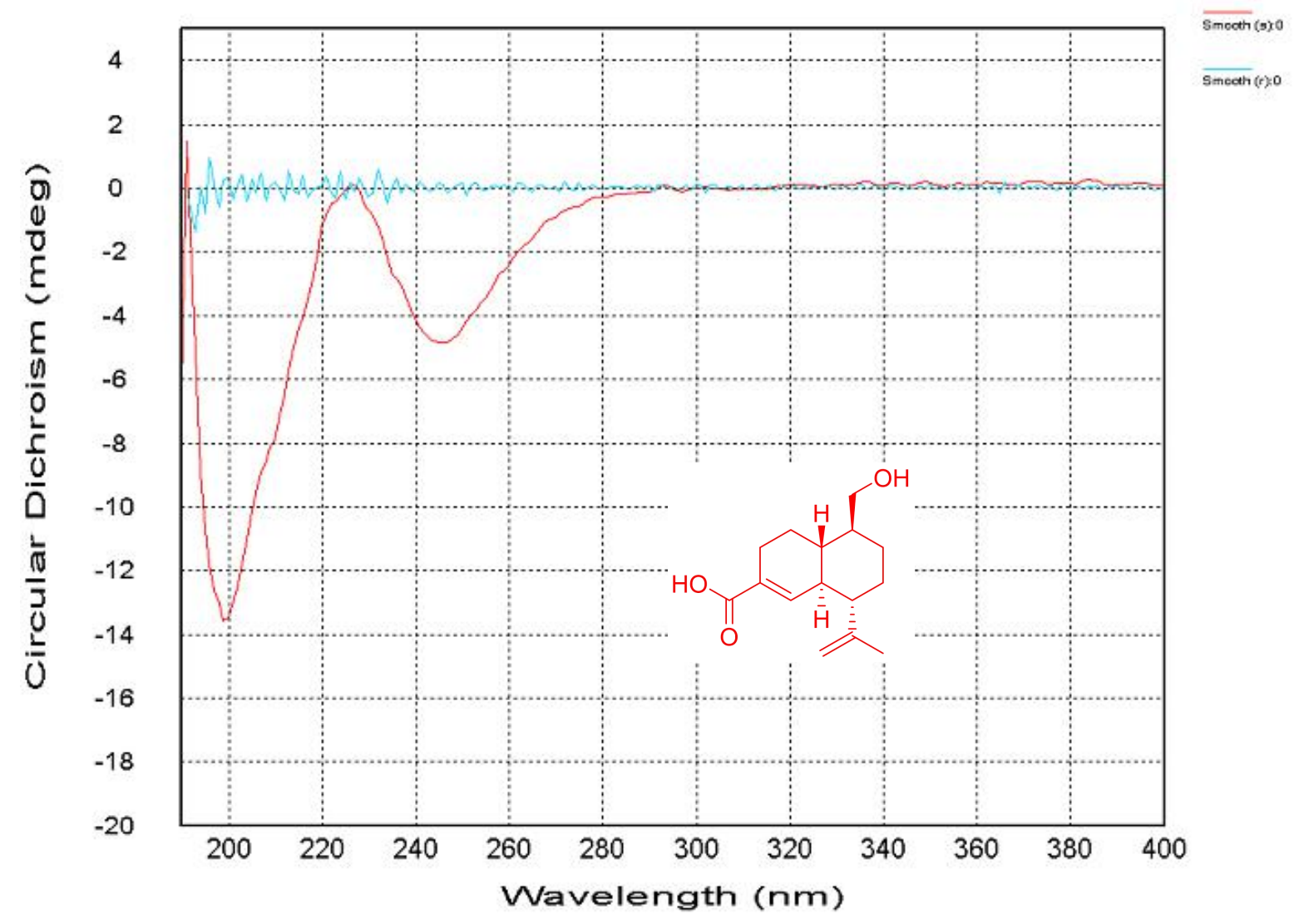

Figure S13. The CD Spectrum of compound 2 in 
Compound N0:C-ZJF-11

Method: 20190108-ZJF-NEG

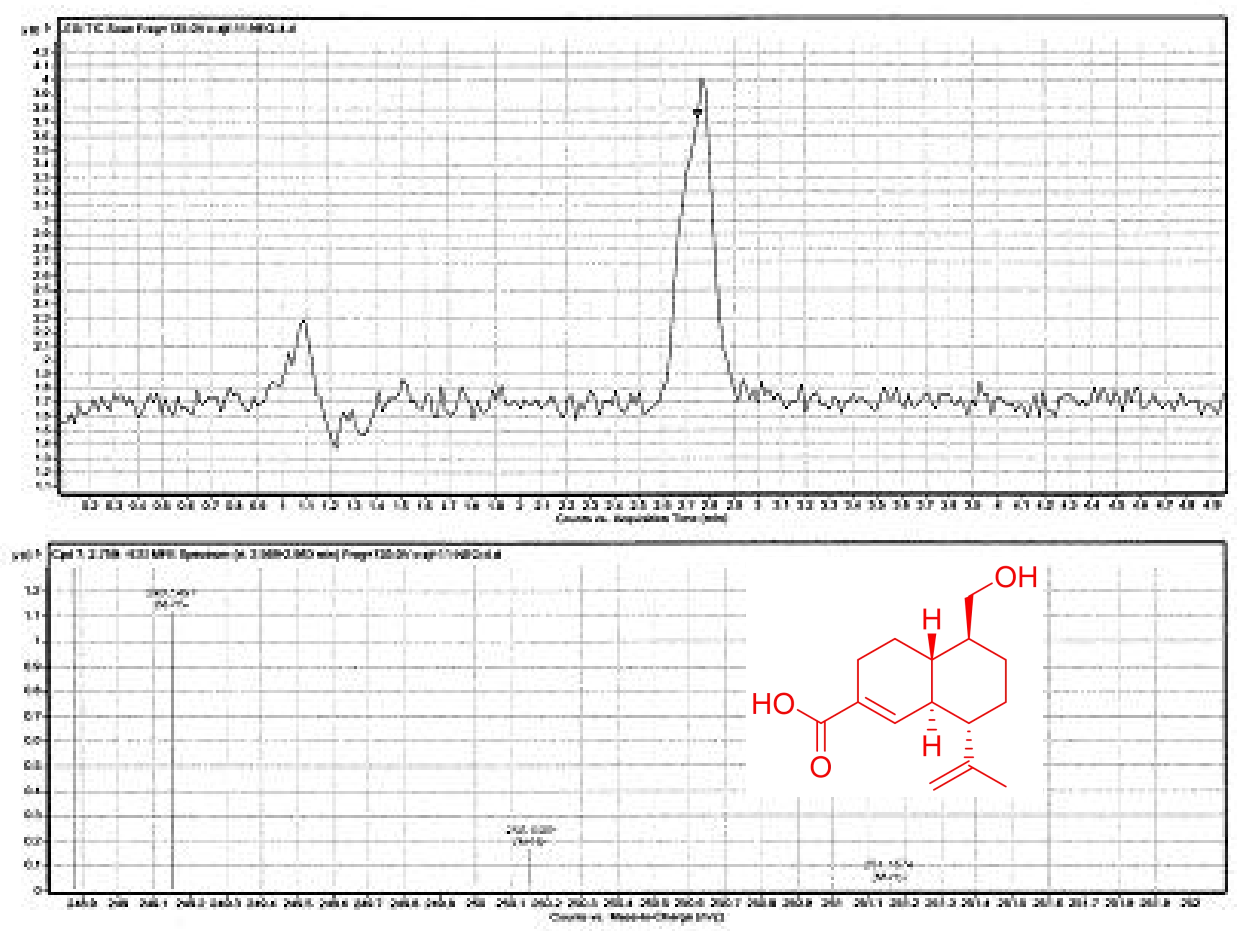

\begin{tabular}{|c|c|c|c|c|}
\hline Formula $(M)$ & Ion Formula & Mass (MFG) & n/z (Calc) & Diff (pon) \\
\hline C15 H22 O3 & C15 H2l 03 & 250.1569 & 249.1496 & 2.07 \\
\hline
\end{tabular}

\section{$\mathrm{MeOH}$}

Figure S14. The HR-mass Spectrum of Compound 2 in $\mathrm{MeOH}$

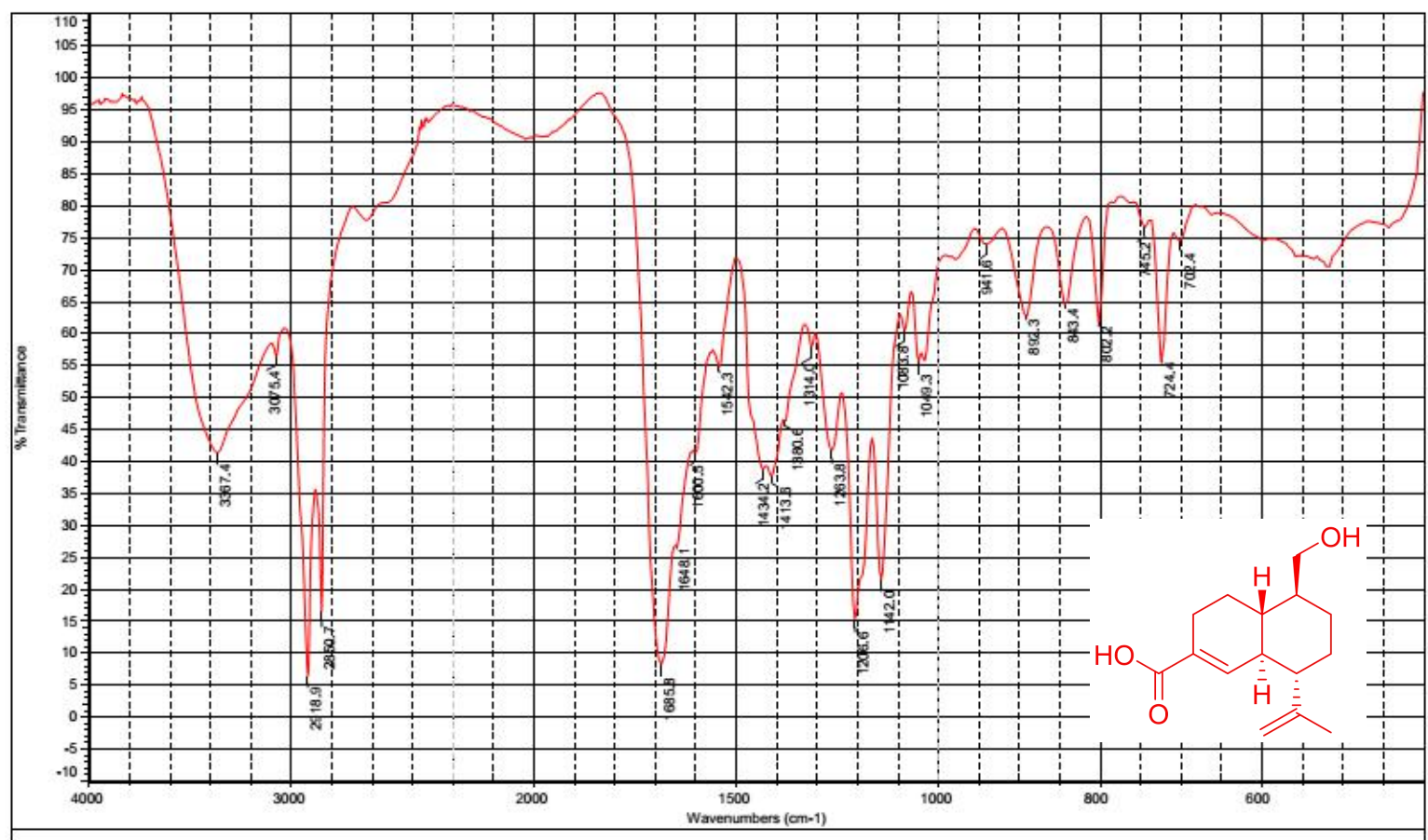

Figure S15. The IR Spectrum of Compound 2 
ZJF-C-ZJF-11.1.fid - ZJF-C-ZJF-11 1H NMR

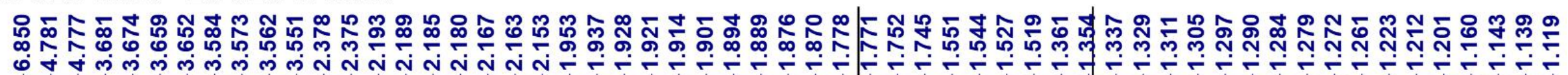
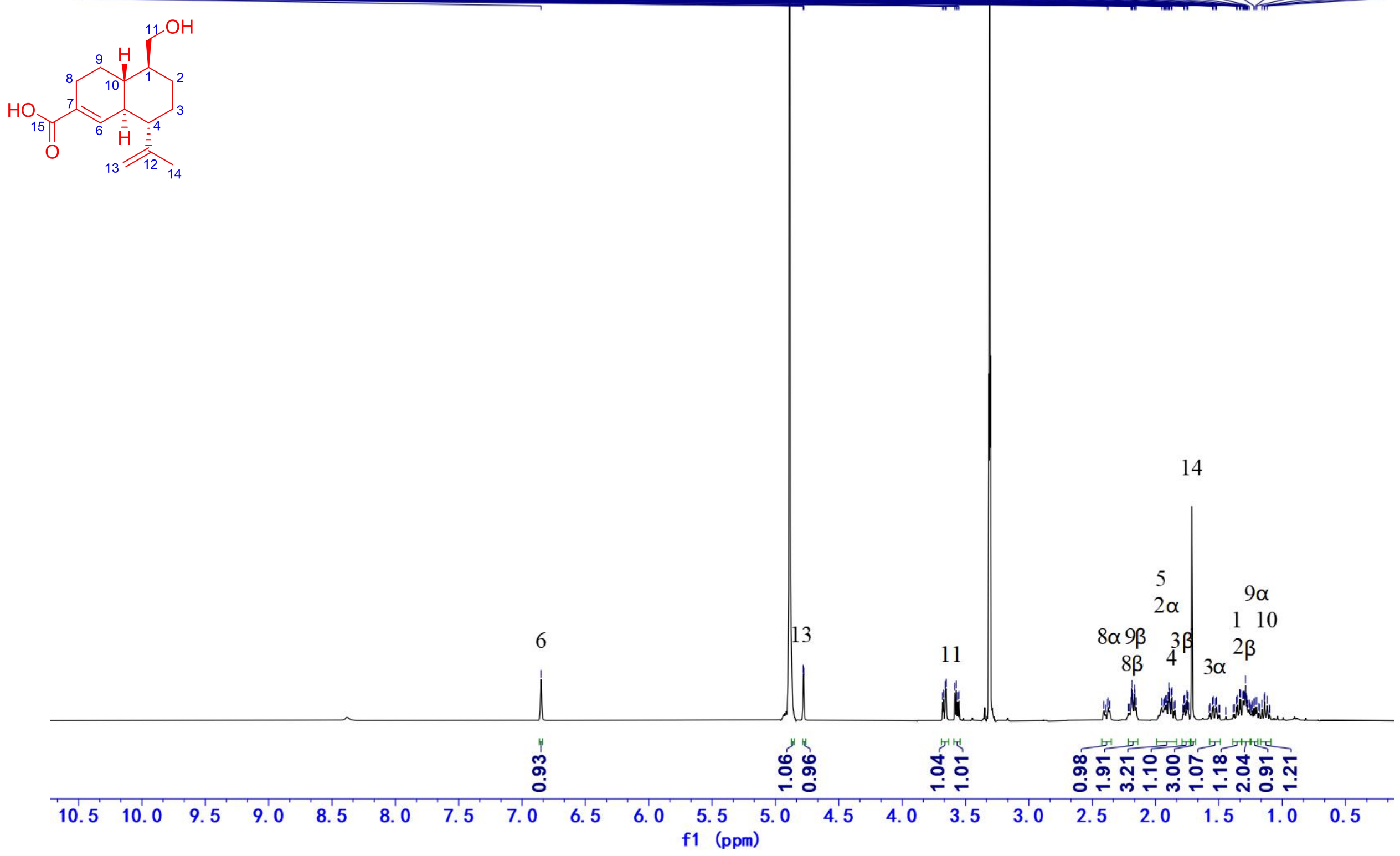

Figure S16. The ${ }^{1} \mathrm{H}$ NMR Spectrum of Compound 2 in $\mathrm{MeOH}_{-} d_{4}(500 \mathrm{MHz})$ 
20180917 c-zjf-11.1.fid - Bruker AVIII HD 600 - C13 CD3OD D:II DATA2018 17

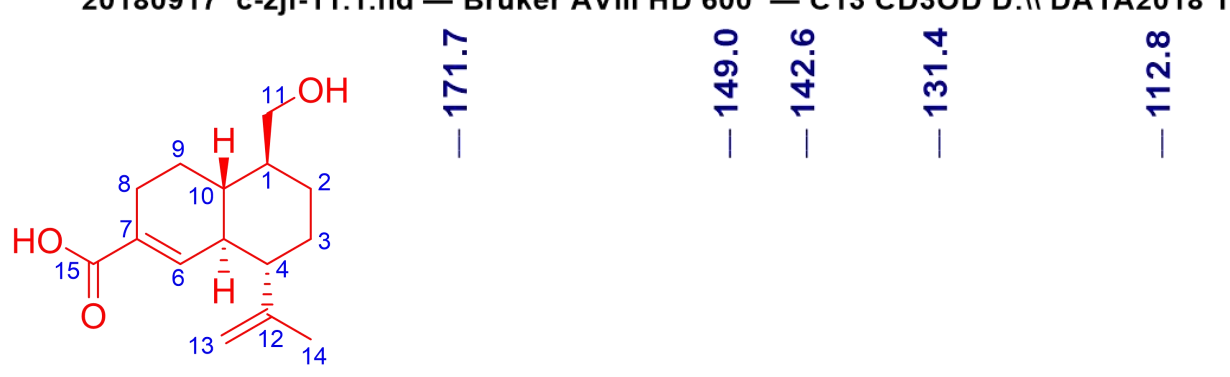

ᄃ)

13

Figure S17. The ${ }^{13} \mathrm{C}$ NMR Spectrum of Compound 2 in $\mathrm{MeOH}-d_{4}(125 \mathrm{MHz})$ 
ZJF-C-ZJF-11.4.ser - ZJF-C-ZJF-11 1H 1H CosY

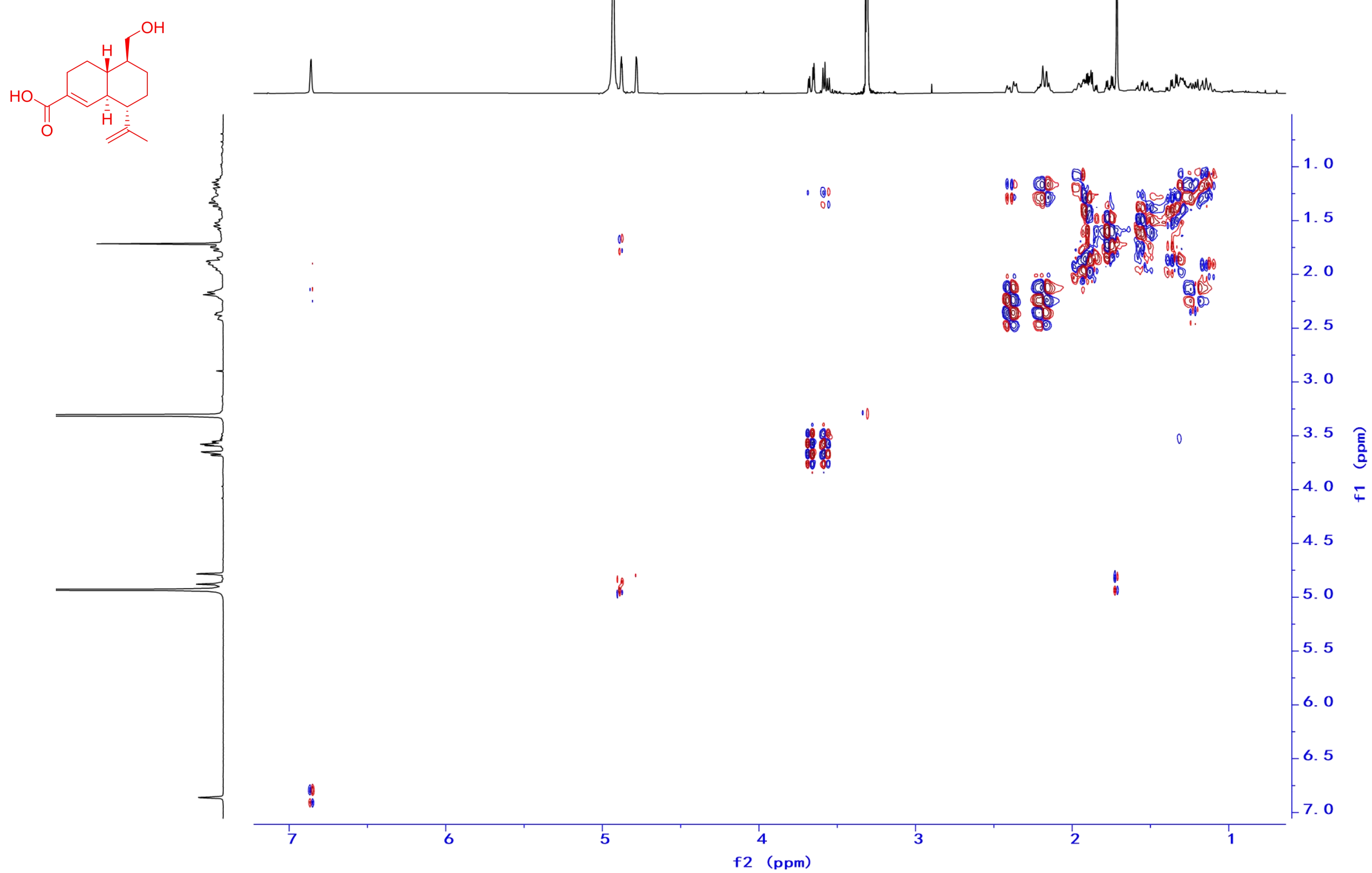

Figure S18. The ${ }^{1} \mathrm{H}-{ }^{1} \mathrm{H}$ COSY Spectrum of Compound 2 in $\mathrm{MeOH}-d_{4}(500 \mathrm{MHz})$ 
ZJF-C-ZJF-11.5.ser - ZJF-C-ZJF-11 HSQC
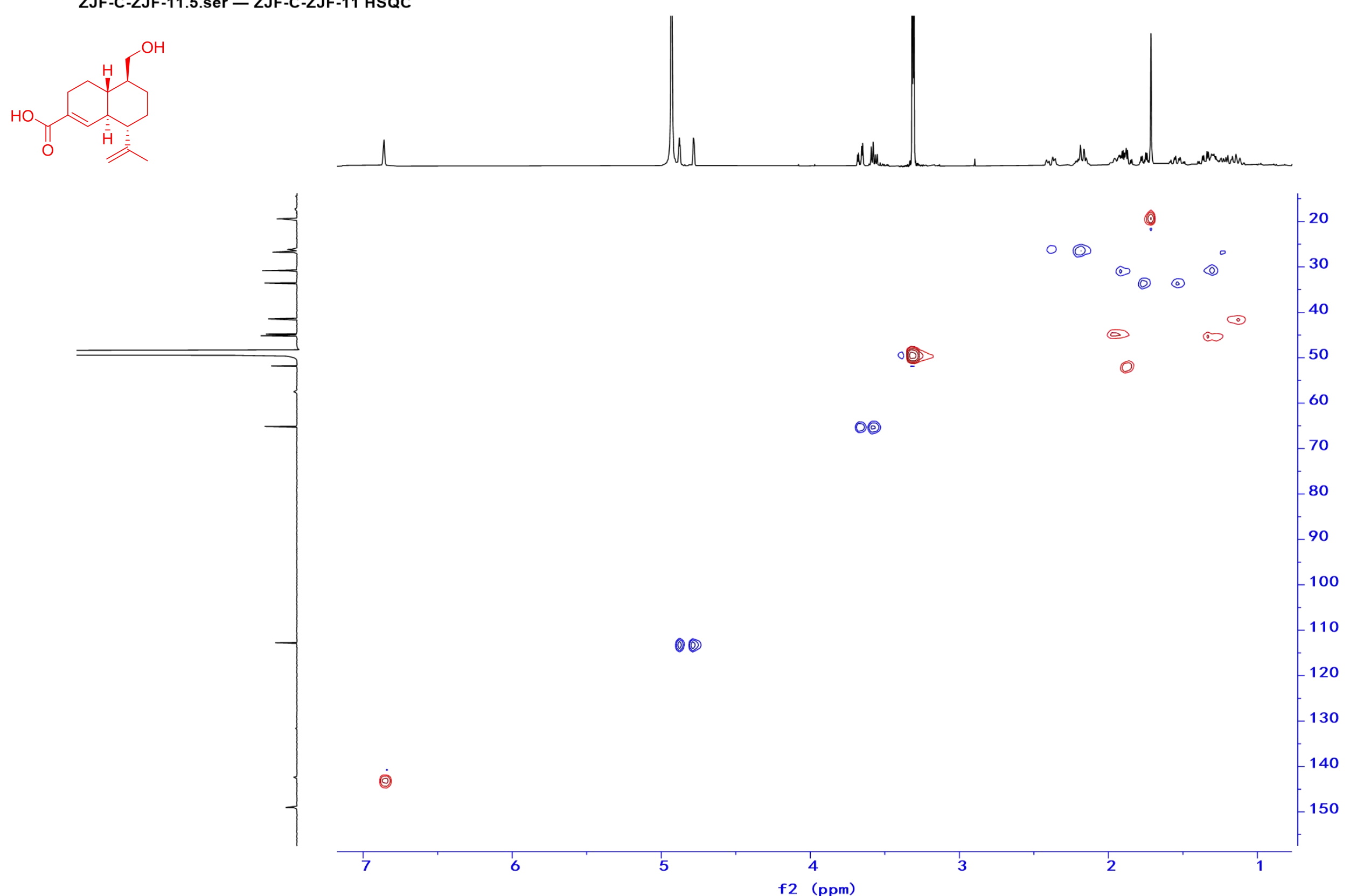

Figure S19. The HSQC Spectrum of Compound 2 in $\mathrm{MeOH}-d_{4}(500 \mathrm{MHz})$ 
ZJF-C-ZJF-11.6.ser - ZJF-C-ZJF-11 HMBC
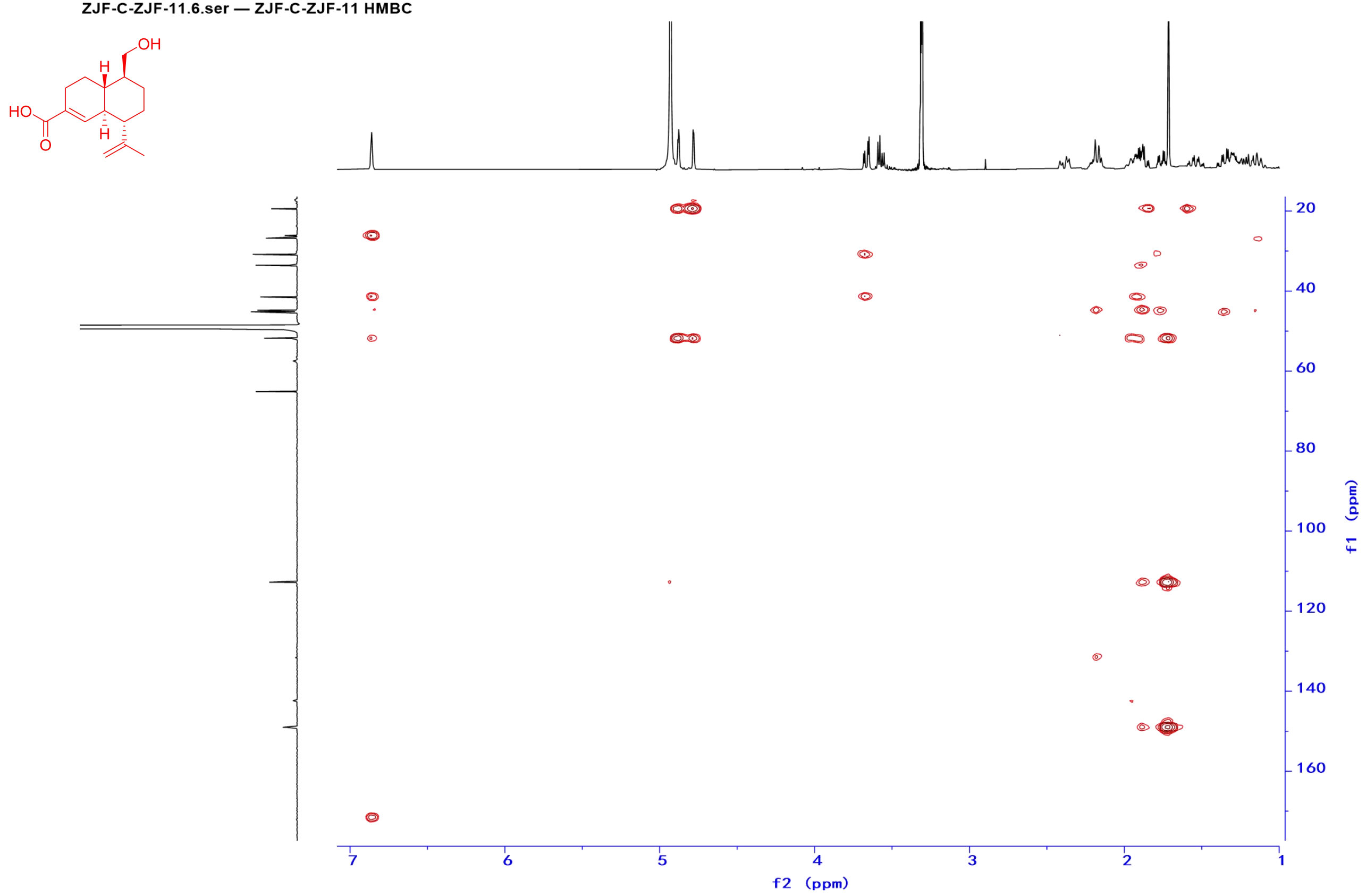

Figure S20. The HMBC Spectrum of Compound 2 in MeOH-d $(500 \mathrm{MHz})$ 


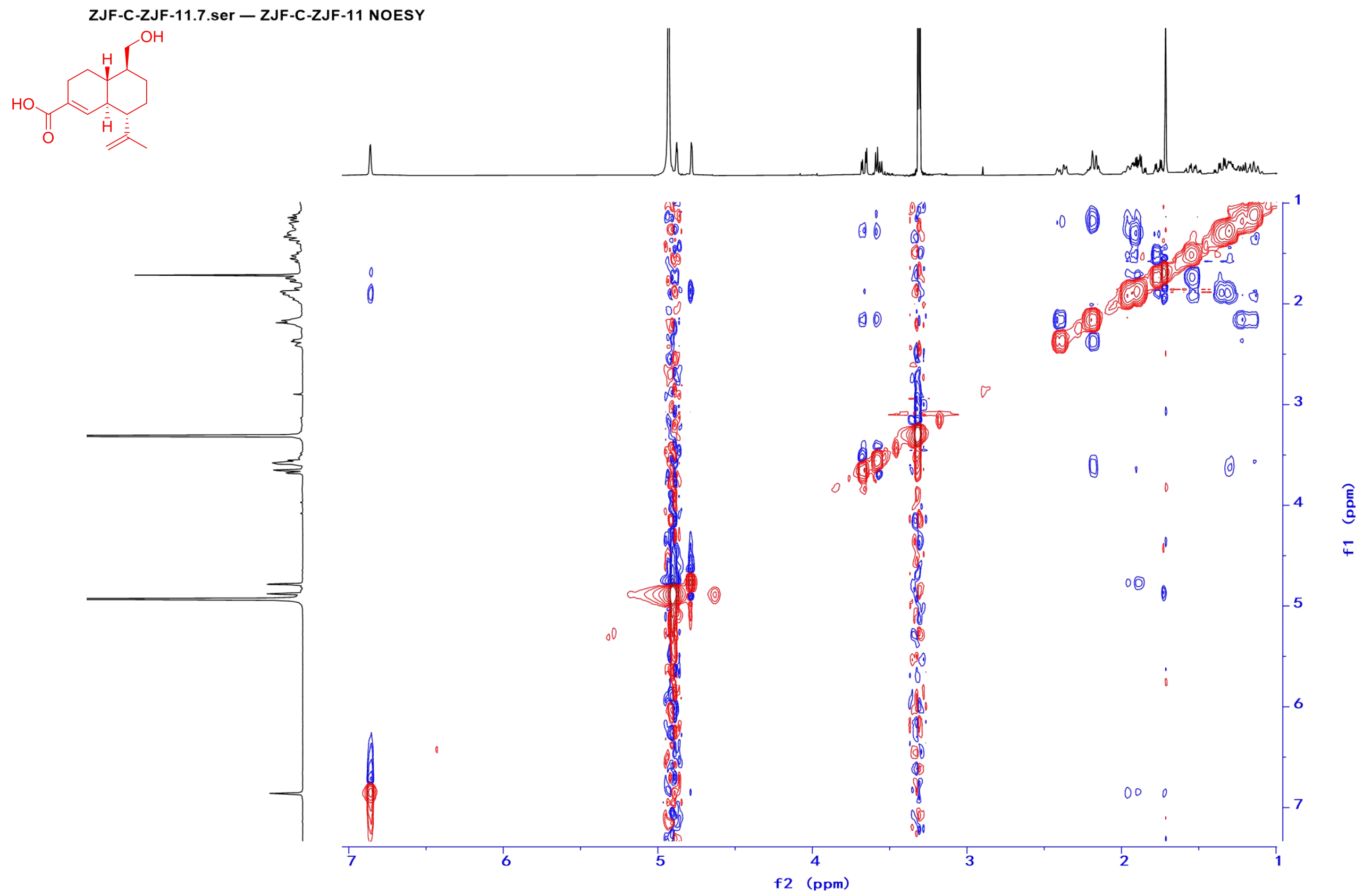

Figure S21. The NOESY Spectrum of Compound 2 in $\mathrm{MeOH}-d_{4}(500 \mathrm{MHz})$ 


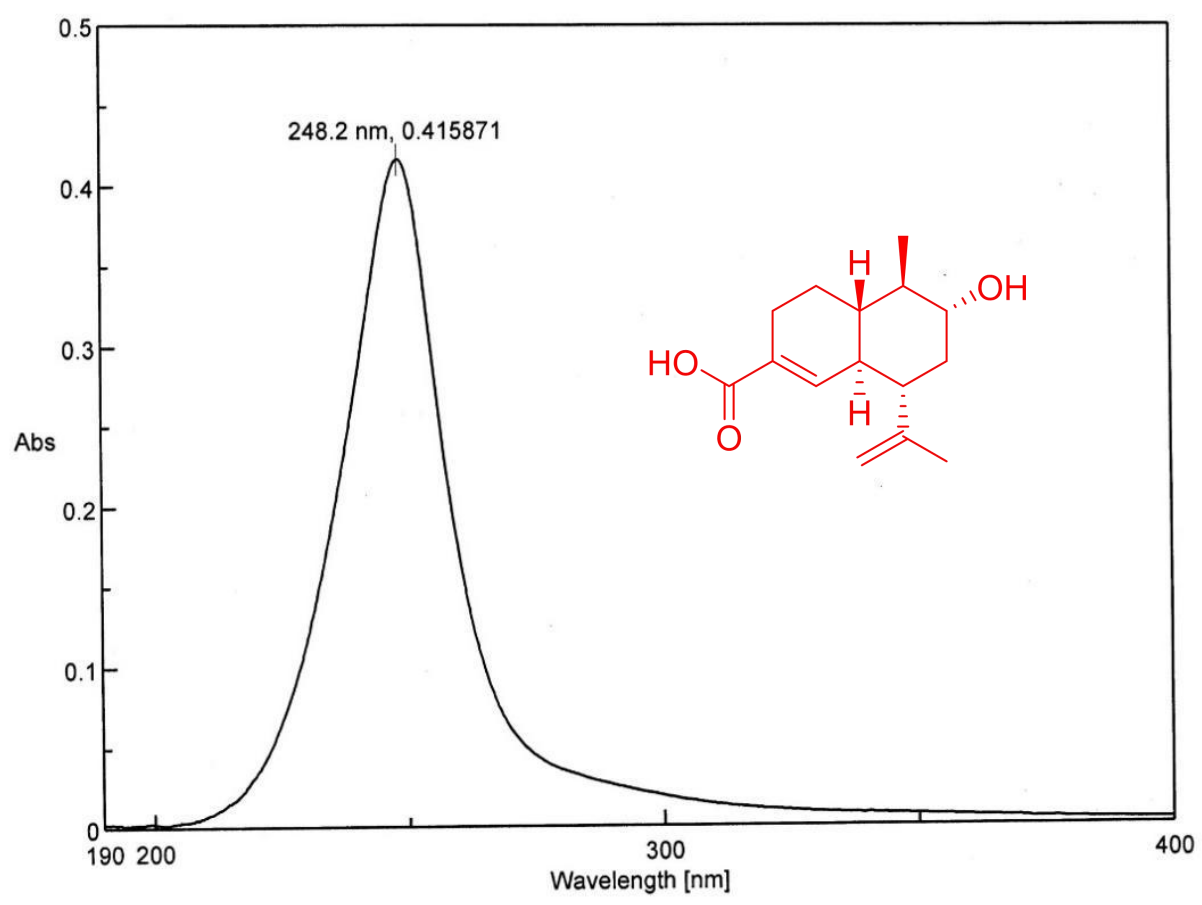

Figure S22. The UV Spectrum of Compound 3 in $\mathrm{MeOH}$

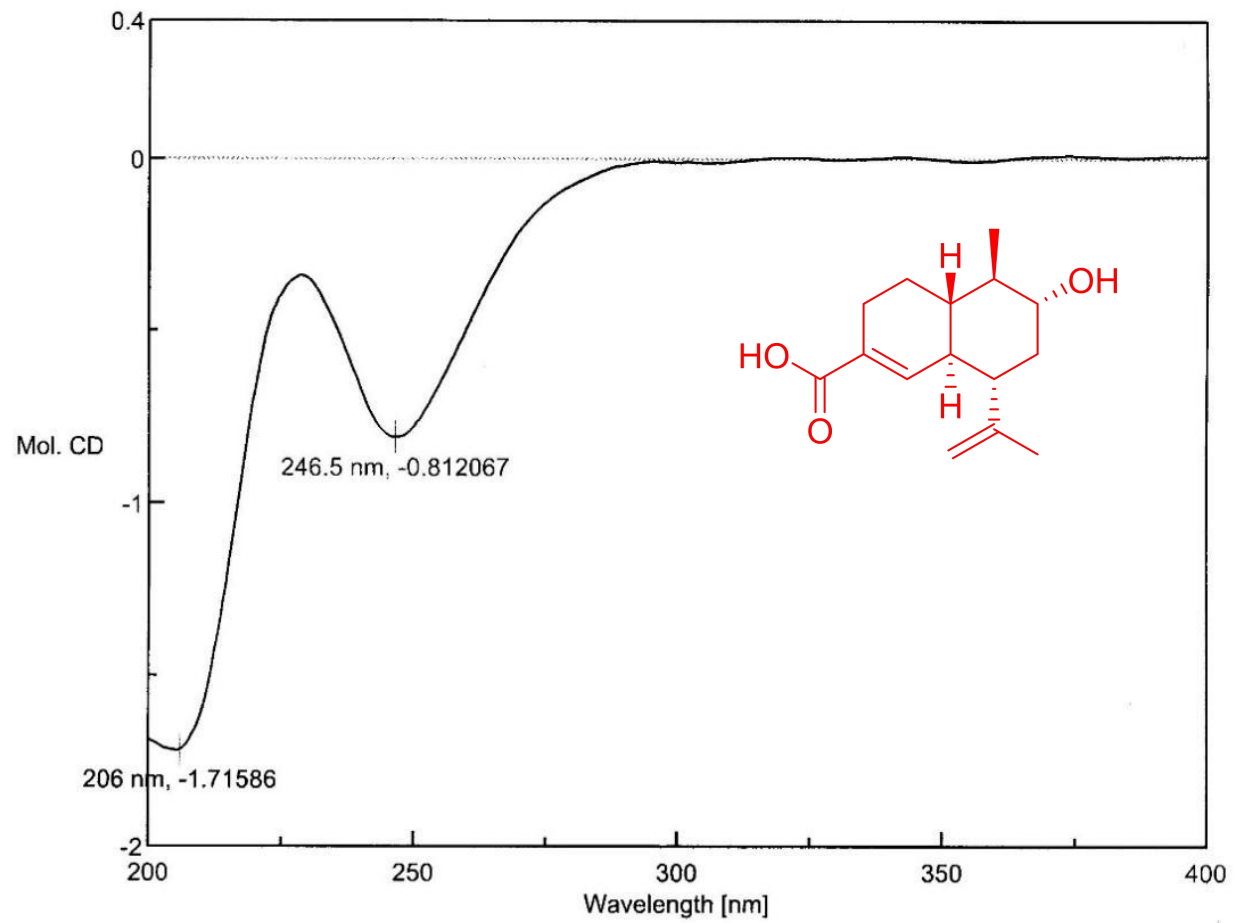

Figure S23. The CD Spectrum of Compound 3 in $\mathrm{MeOH}$

MS Formula Results: + Scan (6.441 min) Sub (2016052001.d)

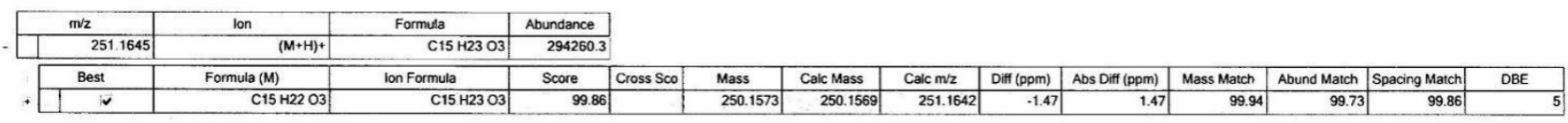

Figure S24. The HR-mass Spectrum of Compound 3 in $\mathrm{MeOH}$ 

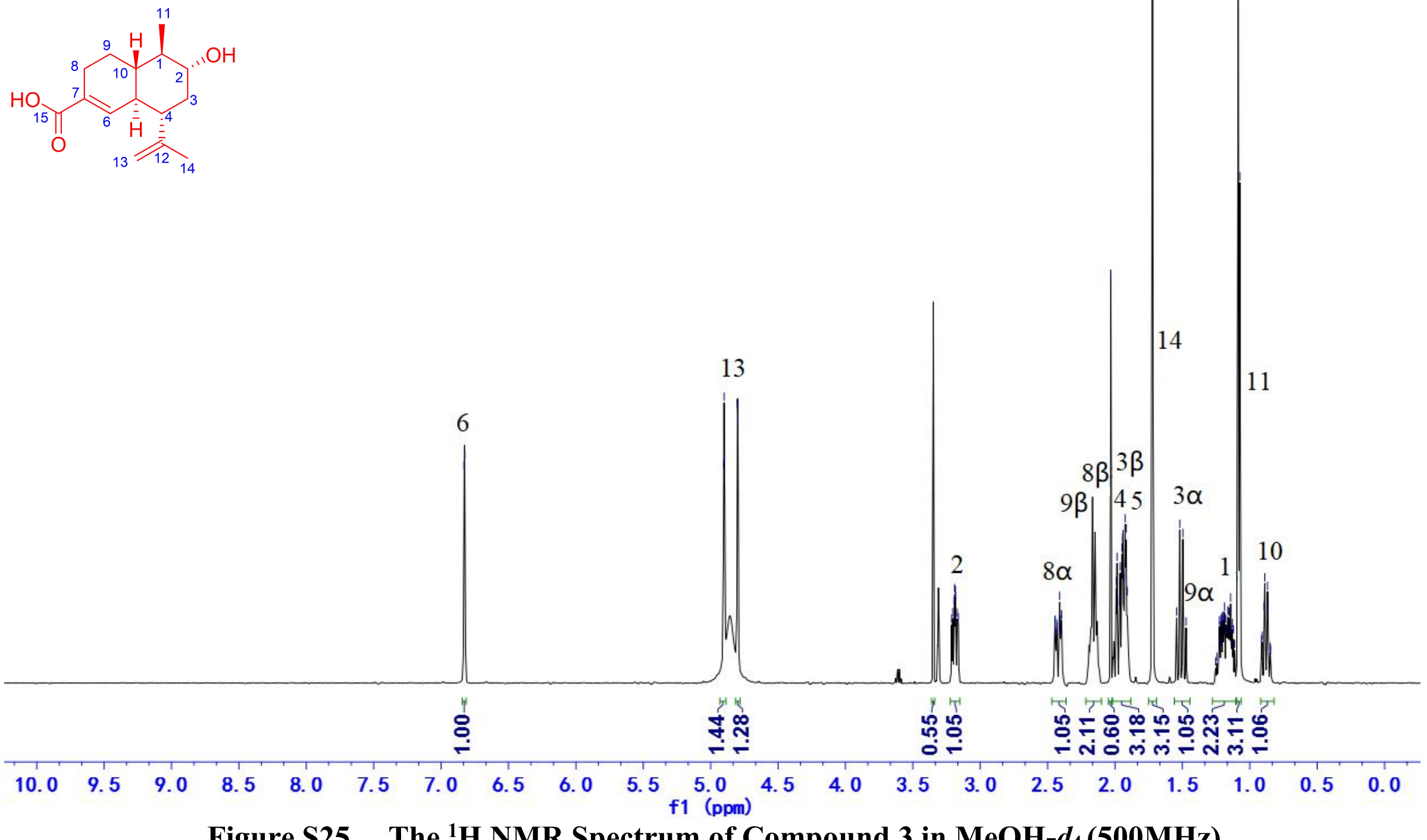
CARBON_01 - DD2-500 CARBON LYC-C26 IN cd3od May 102016 sw -

\begin{tabular}{|c|c|c|c|c|c|c|c|c|}
\hline$\frac{N}{\pi}$ & $\underset{\text { 广 }}{\stackrel{\infty}{+}}$ & $\frac{\mathfrak{N}}{\text { ホ }}$ & $\frac{n}{\frac{m}{m}}$ & $\stackrel{m}{\stackrel{m}{\sigma}}$ & $\underset{\mid}{\infty}$ & 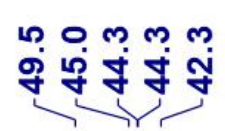 & 它 & $\stackrel{\text { ஸे }}{i}$ \\
\hline
\end{tabular}
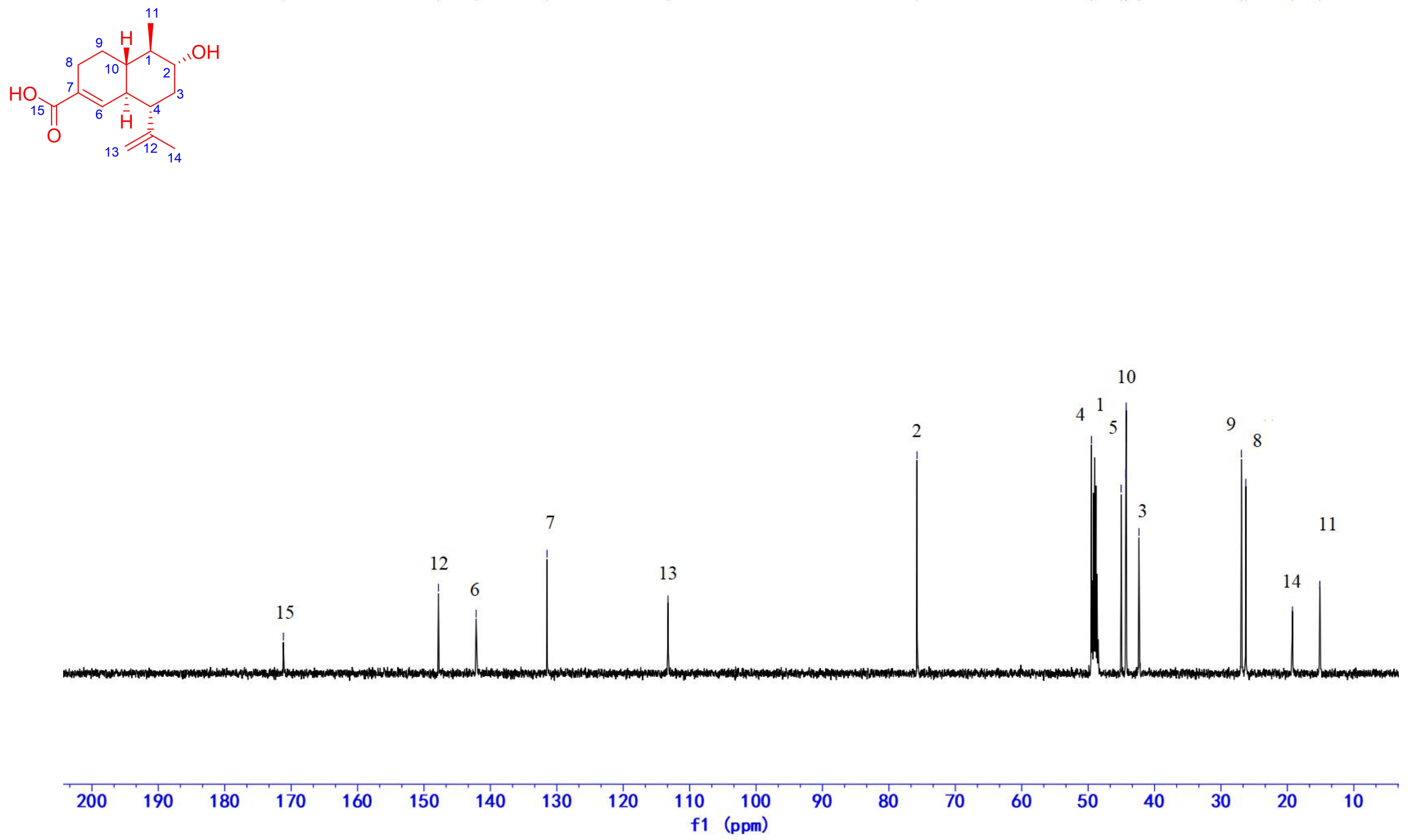

Figure S26. The ${ }^{13} \mathrm{C}$ NMR Spectrum of Compound 3 in $\mathrm{MeOH}-d_{4}(125 \mathrm{MHz})$ 
gCOSY_01 - DD2-500 LYC-C26 IN cd3od sw-Probe -
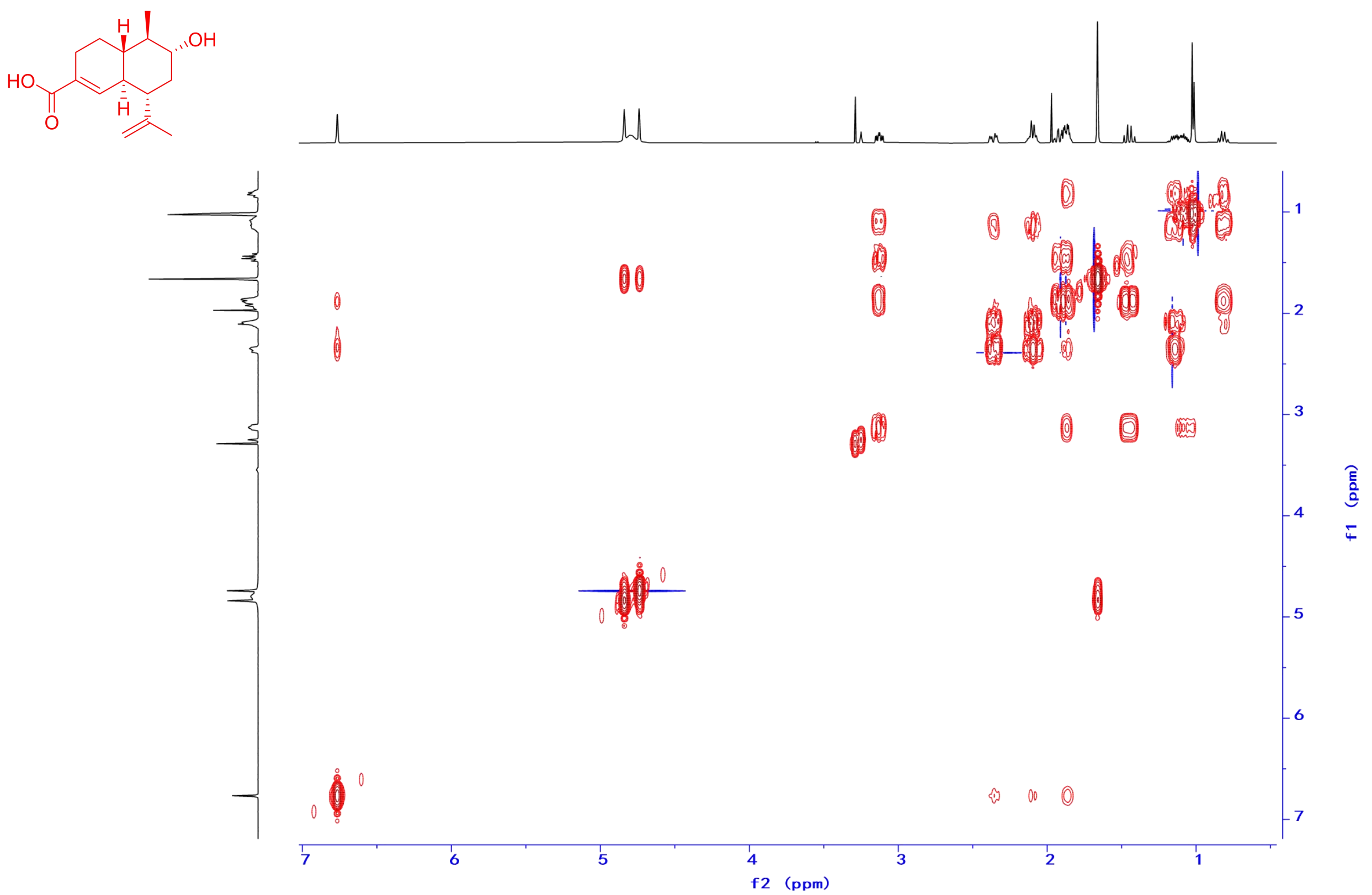

Figure27. The ${ }^{1} \mathrm{H}-{ }^{1} \mathrm{H}$ COSY Spectrum of Compound 3 in $\mathrm{MeOH}-d_{4}(500 \mathrm{MHz})$ 
gHSQCAD_01 - DD2-500 LYC-C26 IN cd3od sw-Probe -
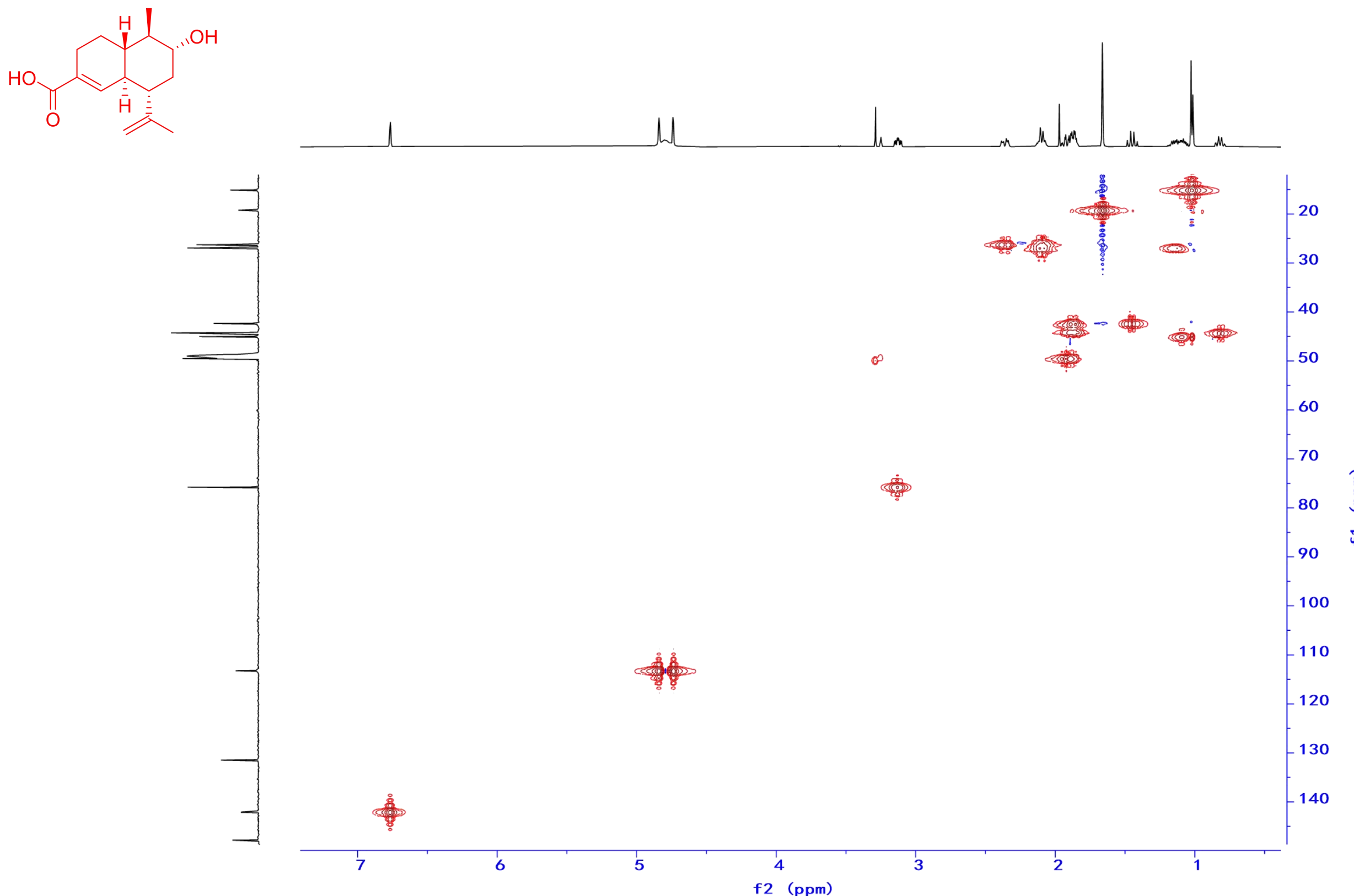

Figure S28. The HSQC Spectrum of Compound 3 in MeOH- $d_{4}(500 \mathrm{MHz})$ 
gHMBCAD_01 - DD2-500 LYC-C26 IN cd3od sw-Probe -
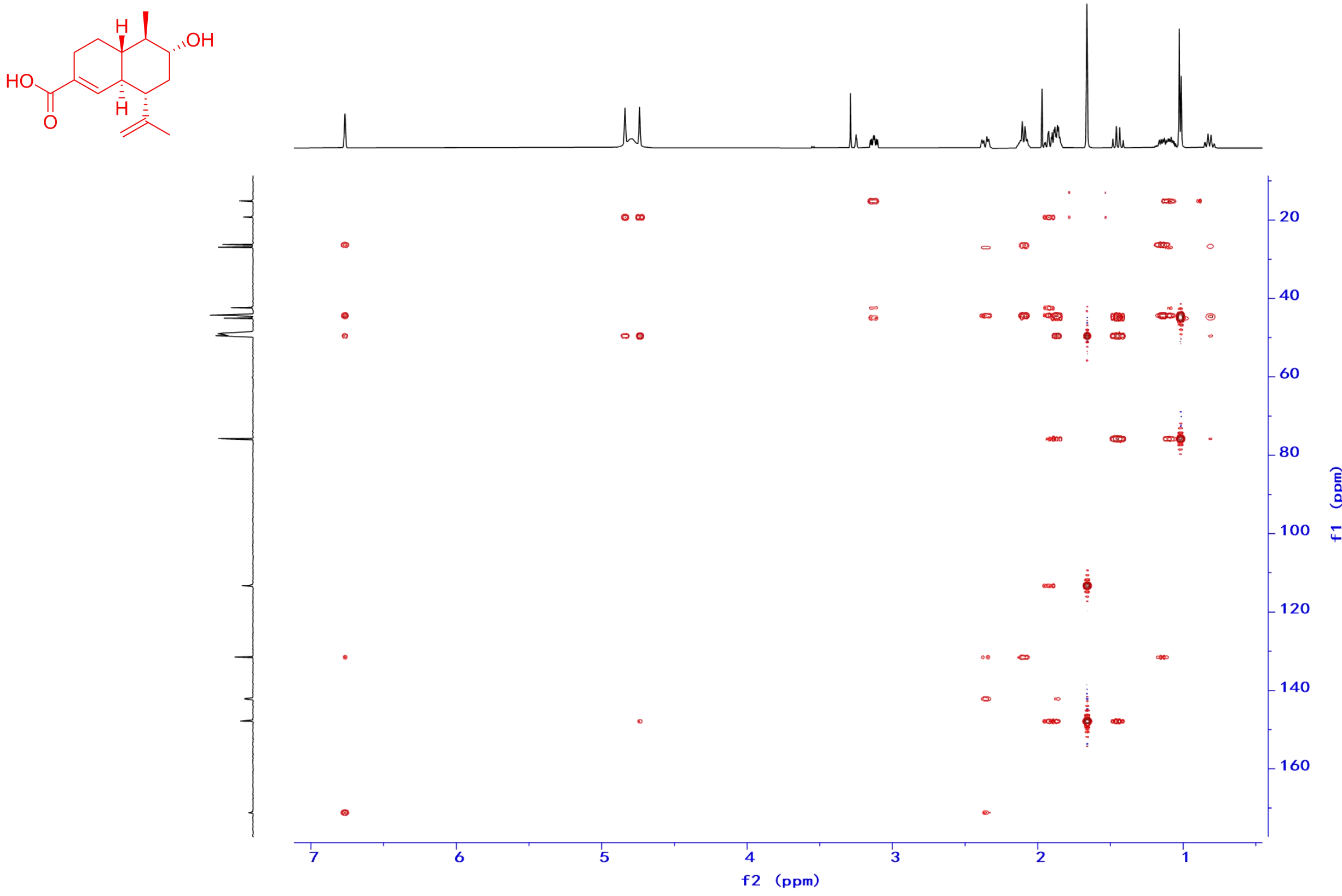

Figure S29. The HMBC Spectrum of Compound 3 in $\mathrm{MeOH}-d_{4}(500 \mathrm{MHz})$ 


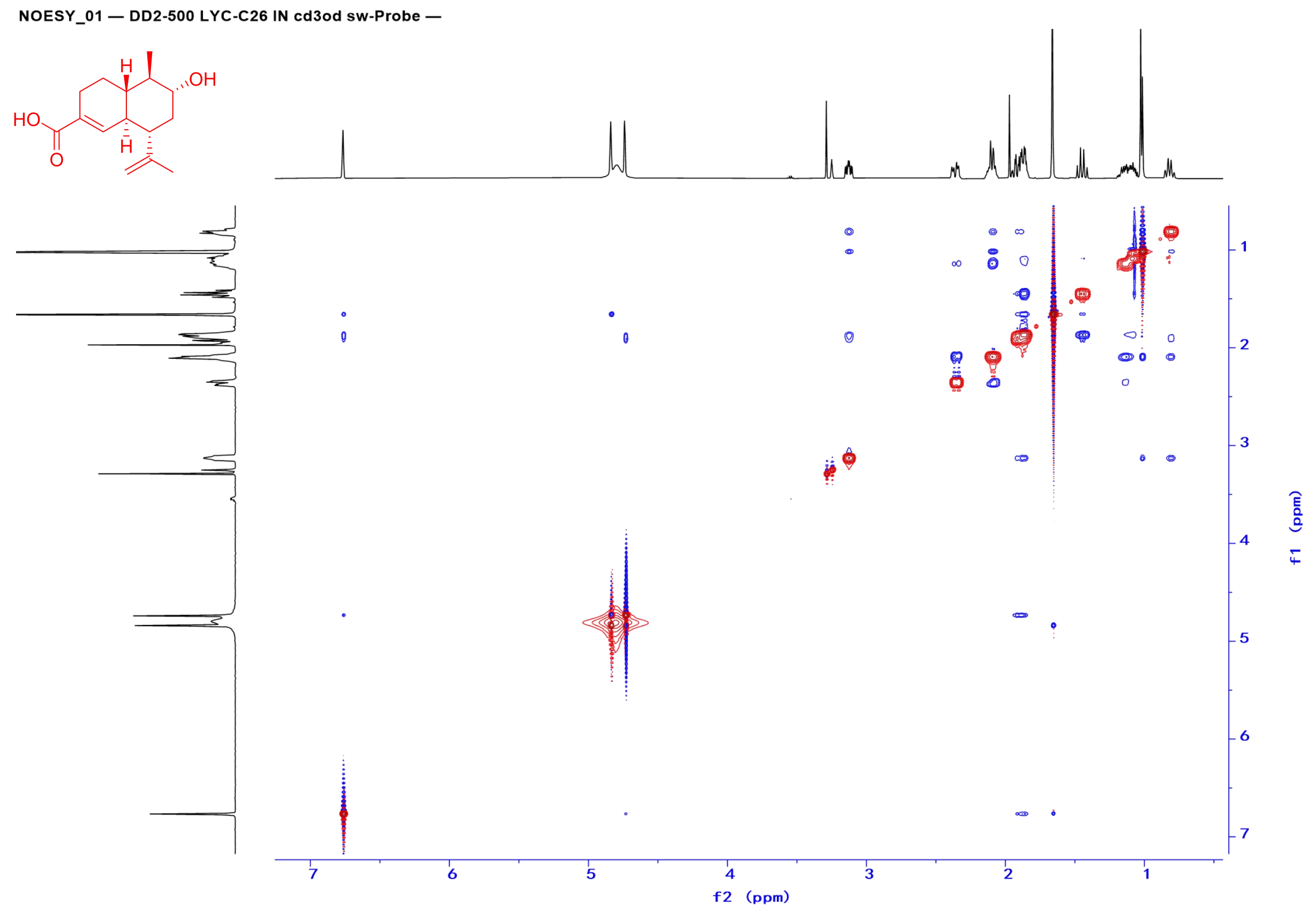

Figure S30. The NOESY Spectrum of Compound 3 in MeOH-d $\mathrm{M}_{4}(500 \mathrm{MHz})$ 


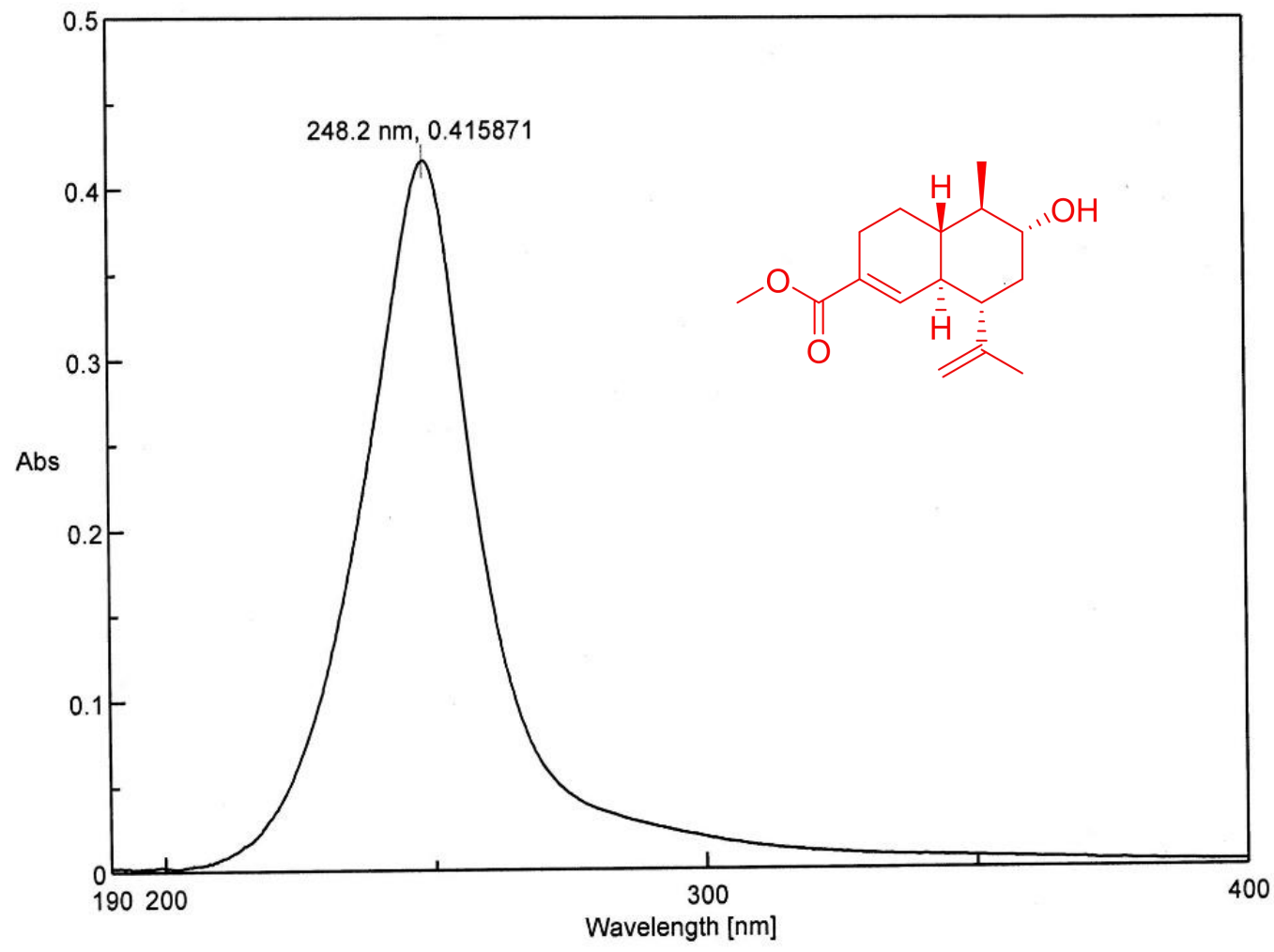

Figure S31. The UV Spectrum of Compound 4 in $\mathrm{MeOH}$

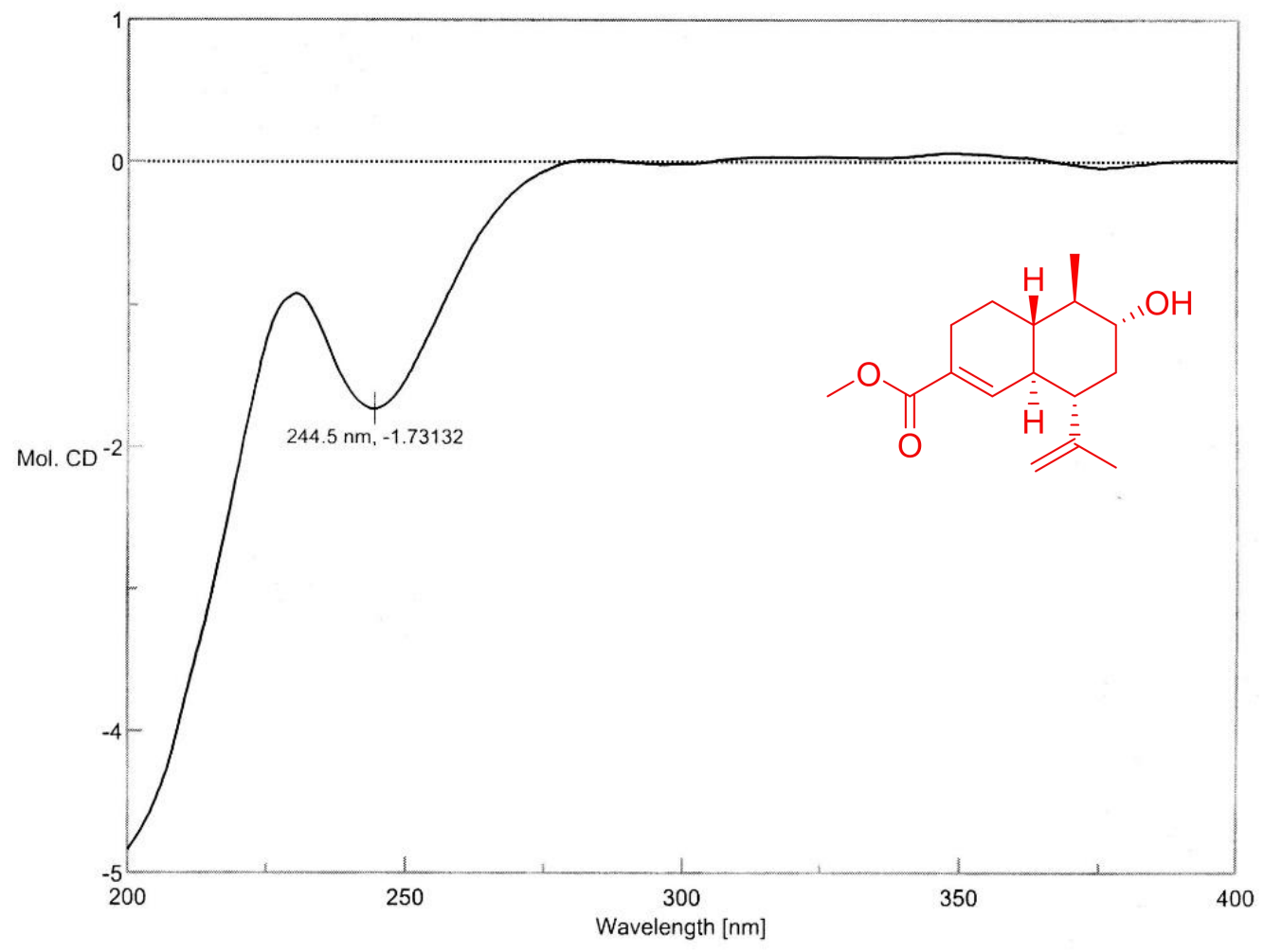

Figure S32. The CD Spectrum of Compound 4 in $\mathrm{MeOH}$ 
MS Formula Results: + Scan (7.367 min) Sub (2016031002.d)

\begin{tabular}{|c|c|c|c|c|c|c|c|c|c|c|c|c|c|c|}
\hline \multicolumn{2}{|r|}{$\mathrm{m} / \mathrm{z}$} & ion & Formula & Abundance & & & & & & & & & & \\
\hline & 265.1804 & $(M+H)+$ & $\mathrm{C} 16 \mathrm{H} 25 \mathrm{O} 3$ & 393274.3 & & & & & & & & & & \\
\hline & Best & Formula (M) & Ion Formula & Score & Cross Sco & Mass & Calc Mass & Calc $m / z$ & Diff (ppm) & Abs Diff (ppm) & Mass Match & Abund Match & Spacing Match & DBE \\
\hline + & $\sqrt{v}$ & $\mathrm{C} 16 \mathrm{H} 24 \mathrm{O} 3$ & $\mathrm{C} 16 \mathrm{H} 25 \mathrm{O}$ & 99.68 & & 264.1731 & 264.1725 & 265.1798 & -2.18 & 2.18 & 99.86 & 99.72 & 99.28 & 5 \\
\hline +. & $\Gamma$ & $\mathrm{C} 11 \mathrm{H} 24 \mathrm{~N} 2 \mathrm{O}$ & $\mathrm{C} 11 \mathrm{H} 25 \mathrm{~N} 2 \mathrm{O}$ & 94.43 & & 264.1731 & 264.1685 & 265.1758 & -17.41 & 17.41 & 91.31 & \begin{tabular}{|c|}
95.38 \\
\end{tabular} & 99.51 & 1 \\
\hline+ & 5 & $\mathrm{C} 18 \mathrm{H} 20 \mathrm{~N} 2$ & $\mathrm{C} 18 \mathrm{H} 21 \mathrm{~N} 2$ & 81.84 & & 264.1731 & 264.1626 & 265.1699 & -39.64 & 39.64 & 62.43 & 99.65 & 99.3 & 10 \\
\hline . & $r$ & $\mathrm{C} 15 \mathrm{H} 24 \mathrm{~N} 2 \mathrm{O} 2$ & $\mathrm{C} 15 \mathrm{H} 25 \mathrm{~N} 2 \mathrm{O} 2$ & 81.34 & & 264.1731 & 264.1838 & 265.1911 & 40.34 & 40.34 & 61.4 & 99.53 & 99.39 & 5 \\
\hline & $\Gamma$ & $\mathrm{C} 20 \mathrm{H} 24$ & $\mathrm{C} 20 \mathrm{H} 25$ & 70.77 & & 264.1731 & 264.1878 & 265.1951 & 55.57 & 55.57 & 39.63 & 99.02 & 99.16 & 9 \\
\hline
\end{tabular}

Figure S33. The HR-mass Spectrum of Compound 4 in $\mathrm{MeOH}$

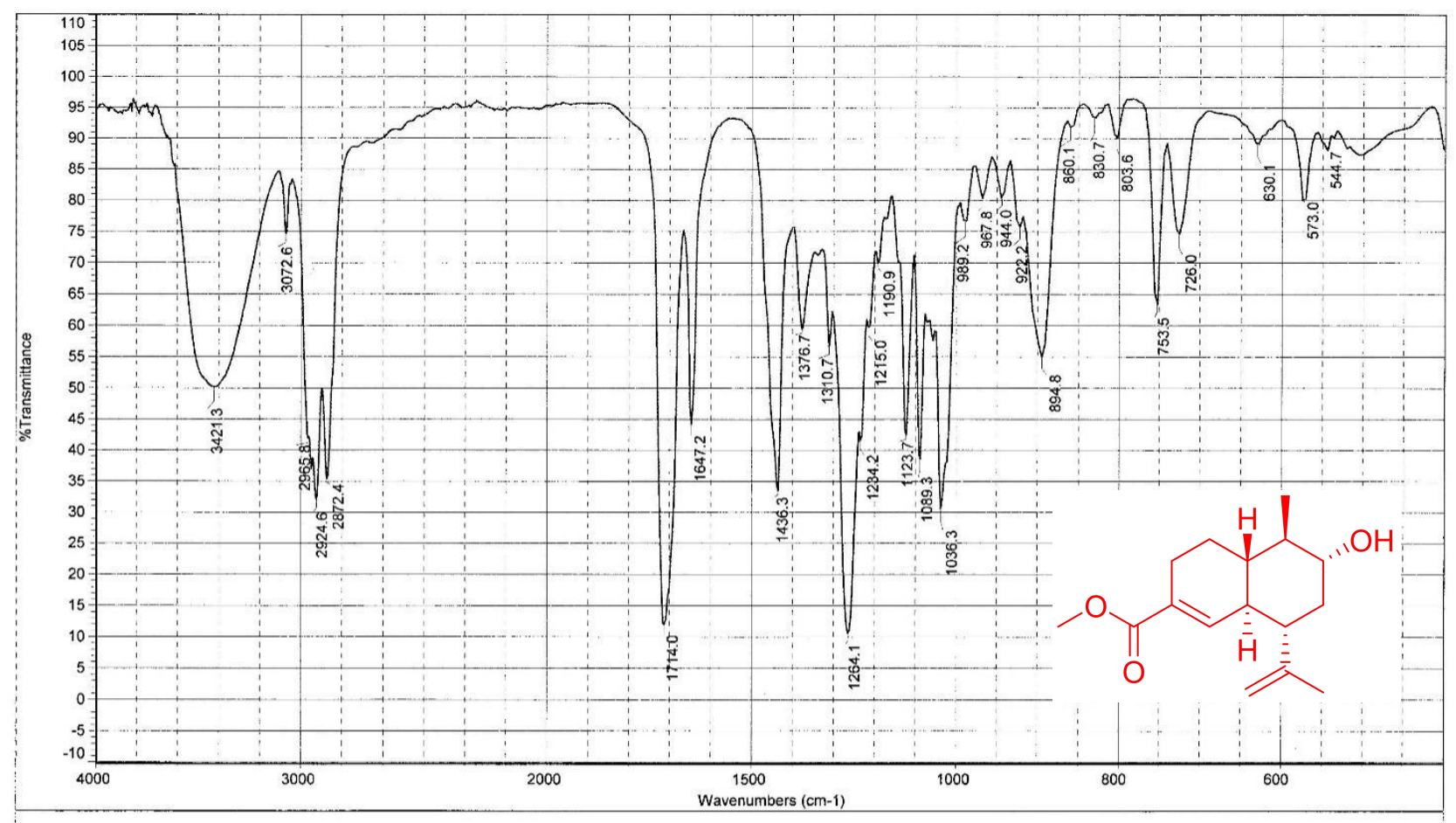

日期: 星期三 7月 01 09:32:42 2015 (GMT+08:0Sample Name: LYC - 8E（显微镜透射法 FT- IR Microscope Transmission)

扫描次数: 100

傅里叶变换显微镜红外(FT-IR Microscope): Centaur $\mu$ s

分辨率: 8.000

美国热电公司(Thermo)傅里叶变换红外光谱仪:Nicolet 5700

Figure S34. The IR Spectrum of Compound 4 
PROTON_01 - DD2-500 LYC-8E IN cdcl3 sw-Probe -

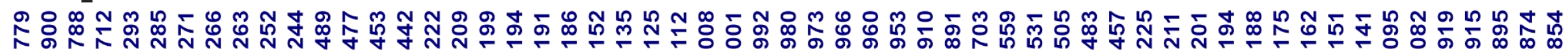

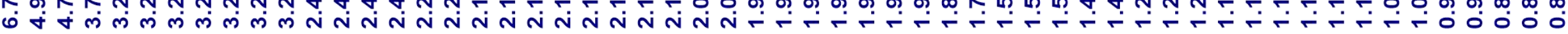

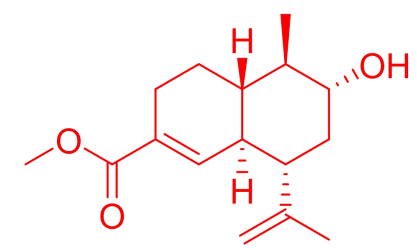

$\mathrm{OMe}$

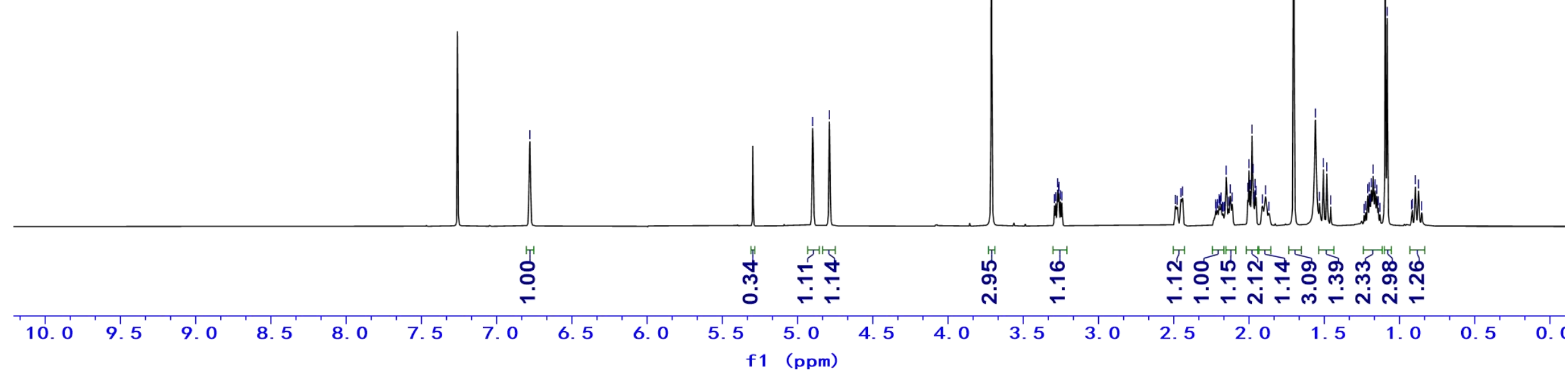

Figure S35. The $1 \mathrm{H}$ NMR Spectrum of Compound 4 in $\mathrm{CDCl}_{3}(500 \mathrm{MHz})$ 
CARBON_01 - DD2-500 LYC-8E IN cdcl3 sw-Probe -

焉
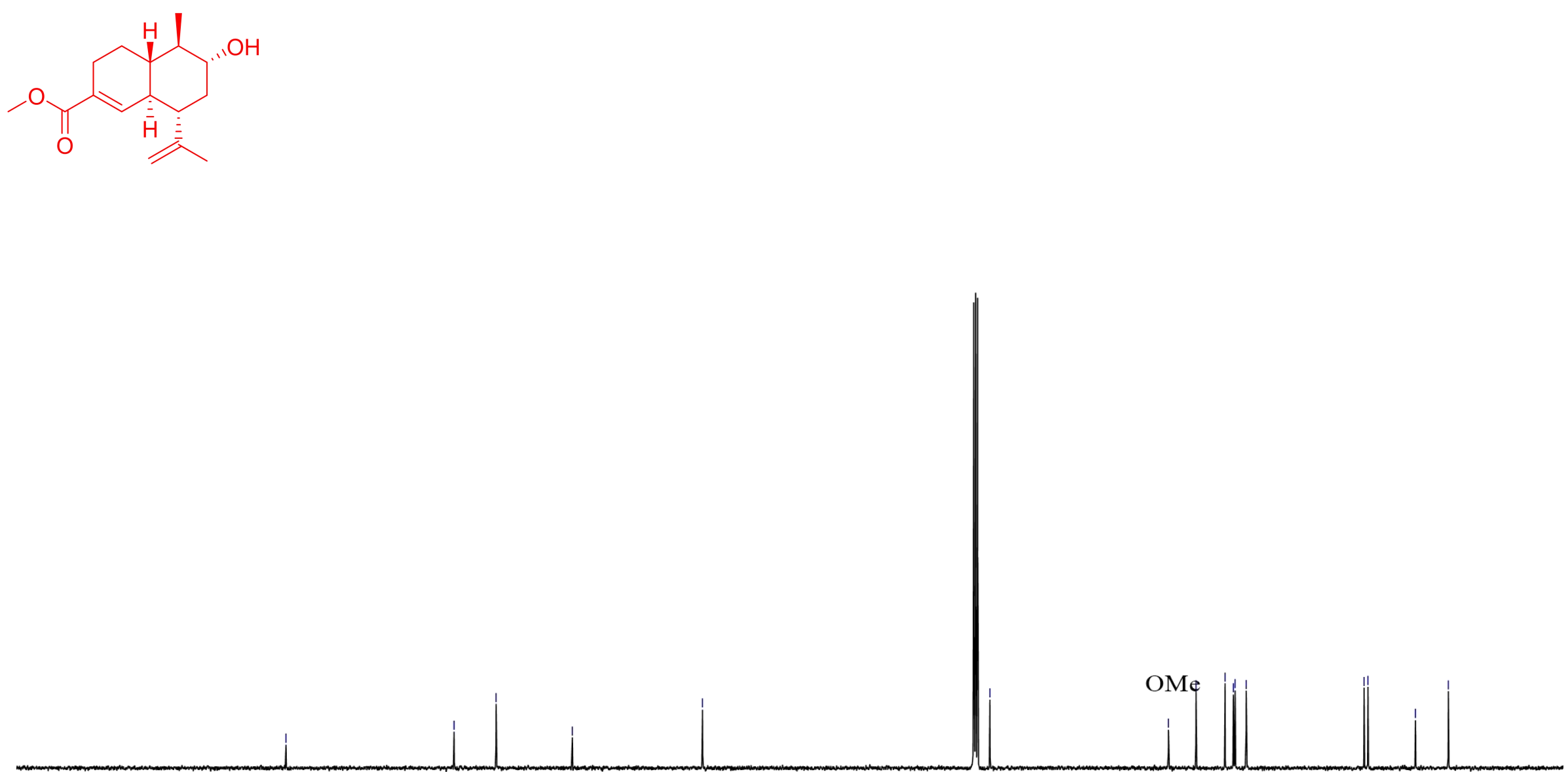

Figure S36. The ${ }^{13} \mathrm{C}$ NMR Spectrum of Compound 4 in $\mathrm{CDCl}_{3}(125 \mathrm{MHz})$ 


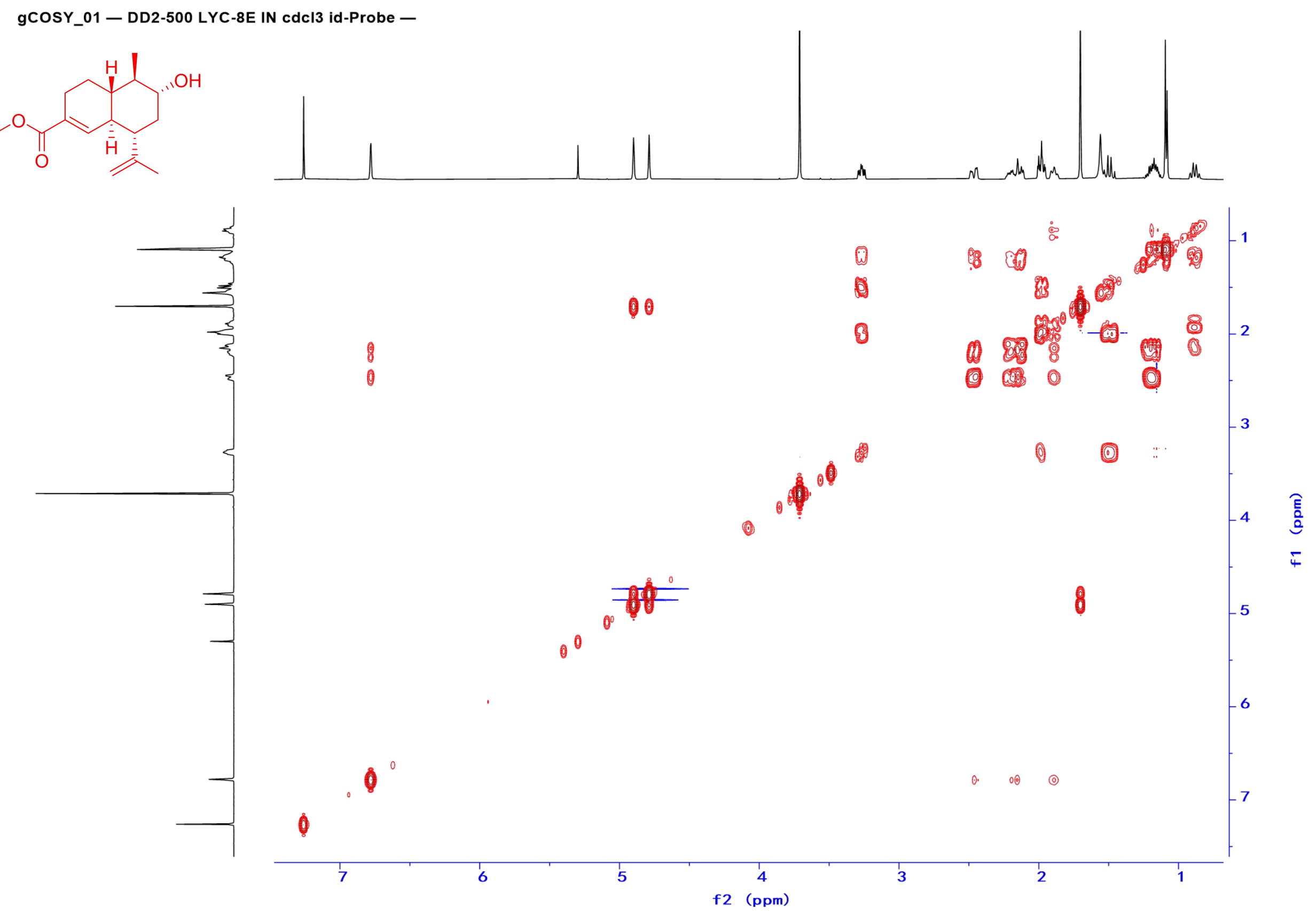

Figure S37. The ${ }^{1} \mathrm{H}-{ }^{1} \mathrm{H}$ COSY Spectrum of Compound 4 in $\mathrm{CDCl}_{3}(500 \mathrm{MHz})$ 
gHSQCAD_01 - DD2-500 LYC-8E IN cdcl3 id-Probe -

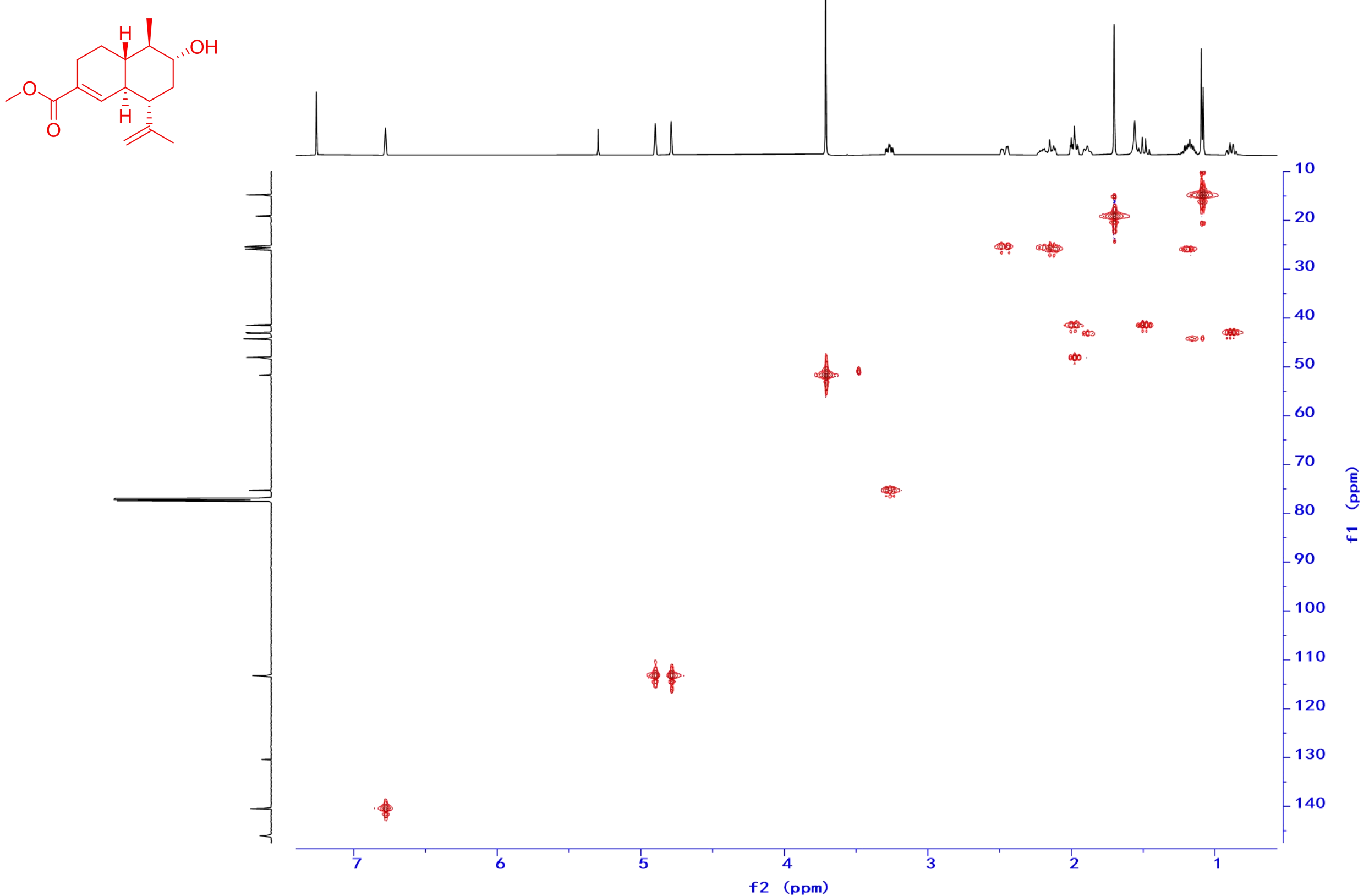

Figure S38. The HSQC Spectrum of Compound 4 in $\mathrm{CDCl}_{3}(500 \mathrm{MHz})$ 


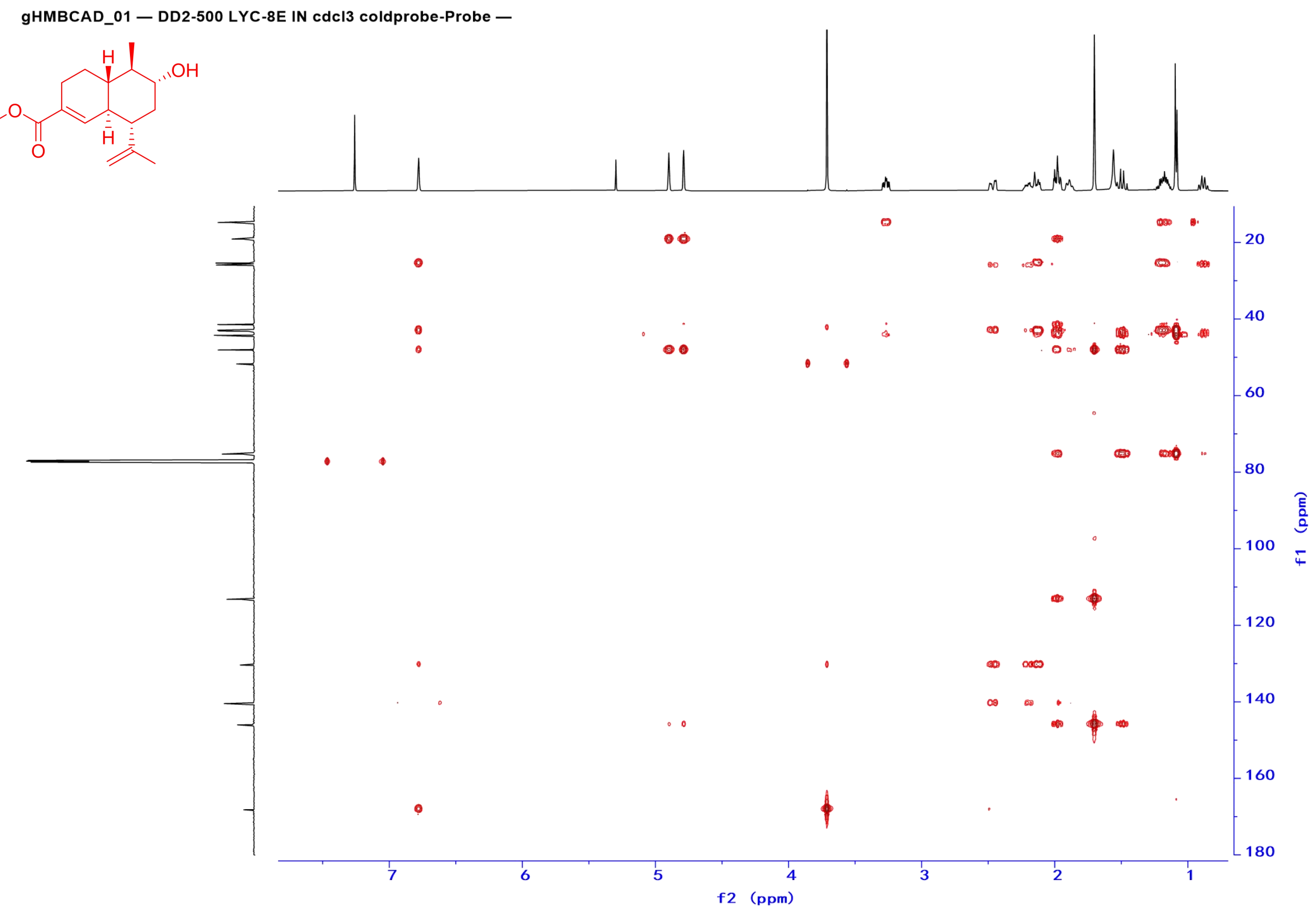

Figure S39. The HMBC Spectrum of Compound 4 in $\mathrm{CDCl}_{3}(500 \mathrm{MHz})$ 
20160302 LYC-8E — Bruker AVIIIHD 60020160302 — NOESY_2D CDCI3 D:II DATA2016 3 —
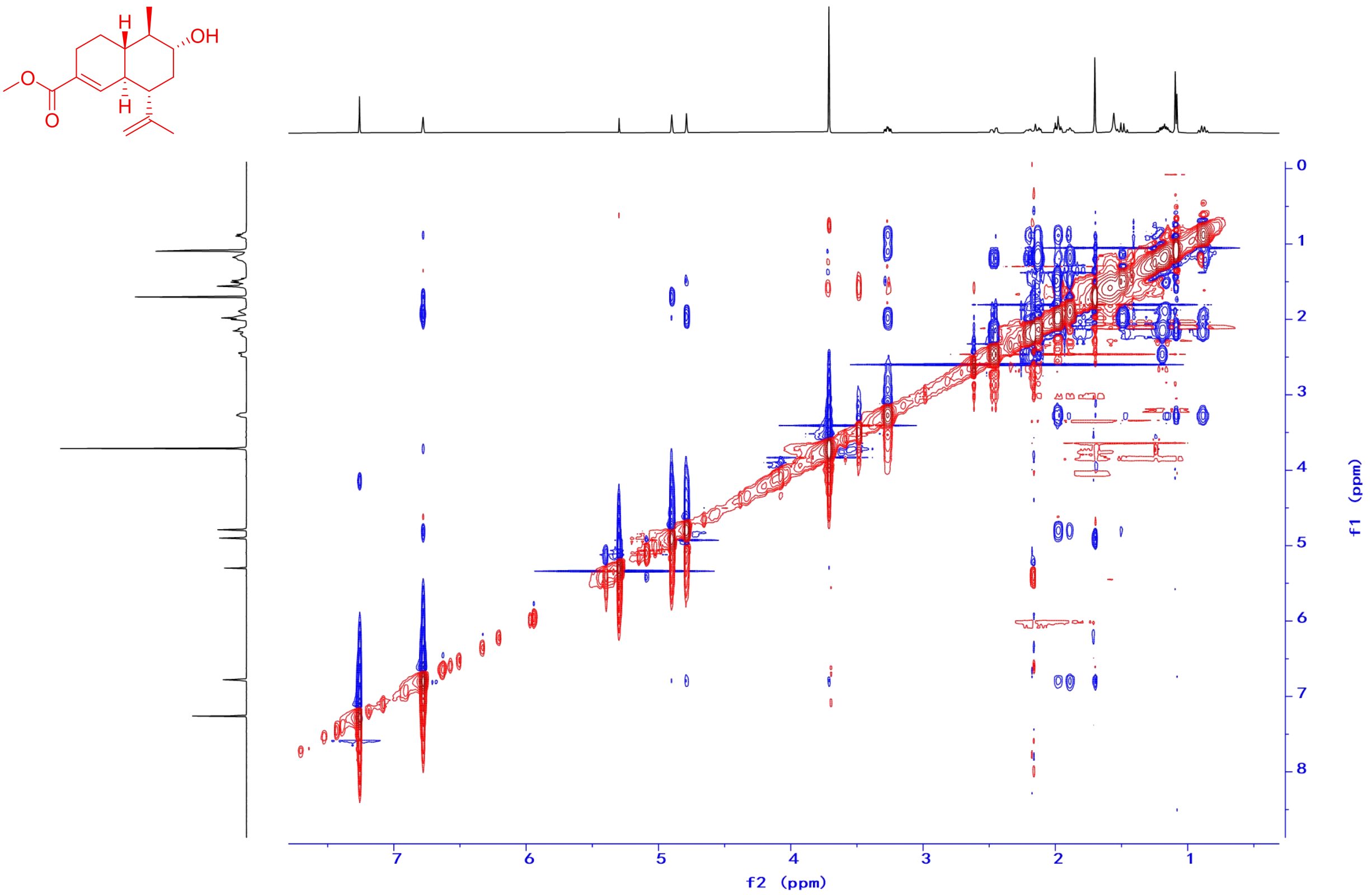

Figure S40. The NOESY Spectrum of Compound 4 in $\mathrm{CDCl}_{3}(500 \mathrm{MHz})$ 


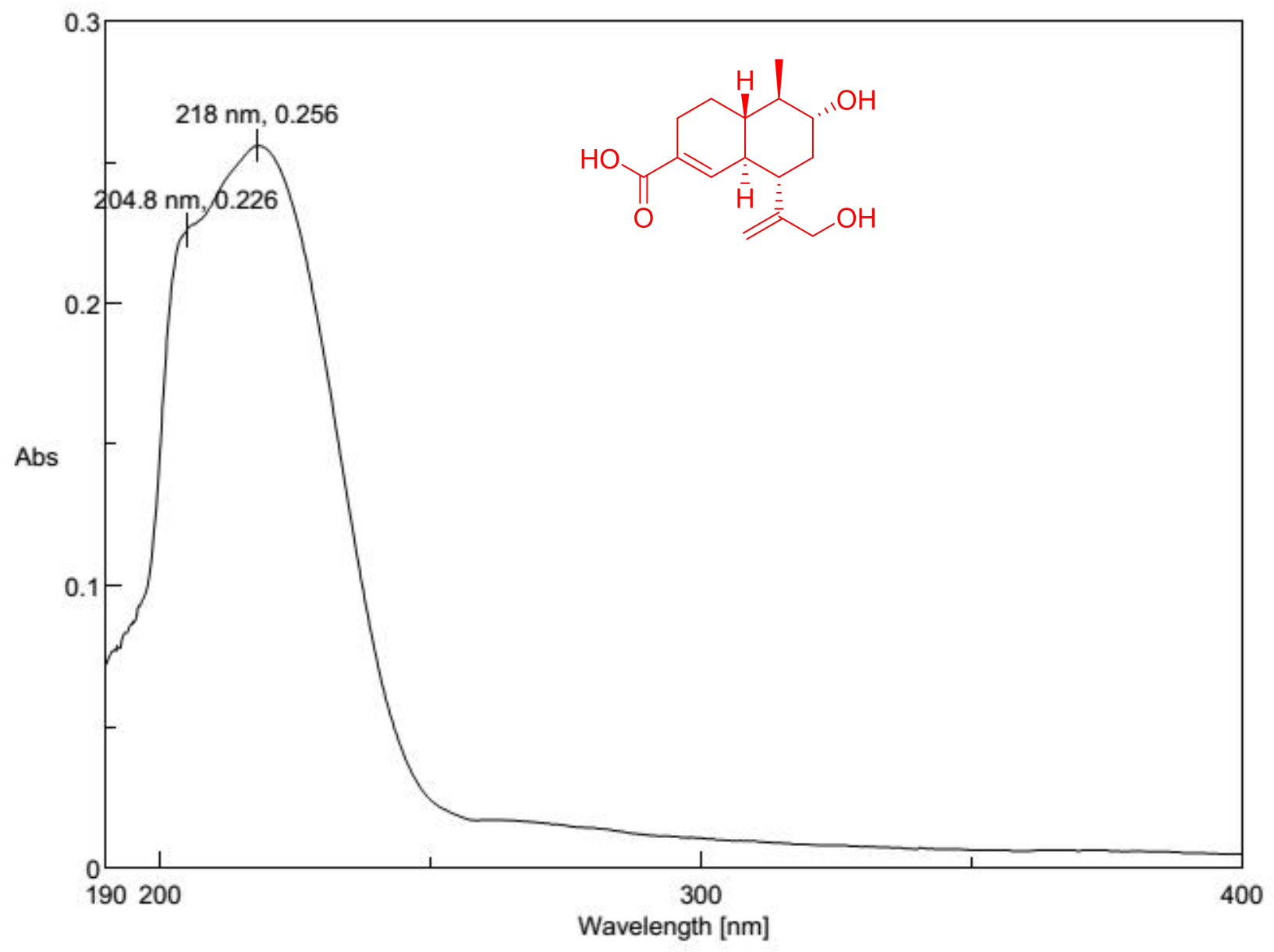

Figure S41. The UV Spectrum of Compound 5 in $\mathrm{MeOH}$

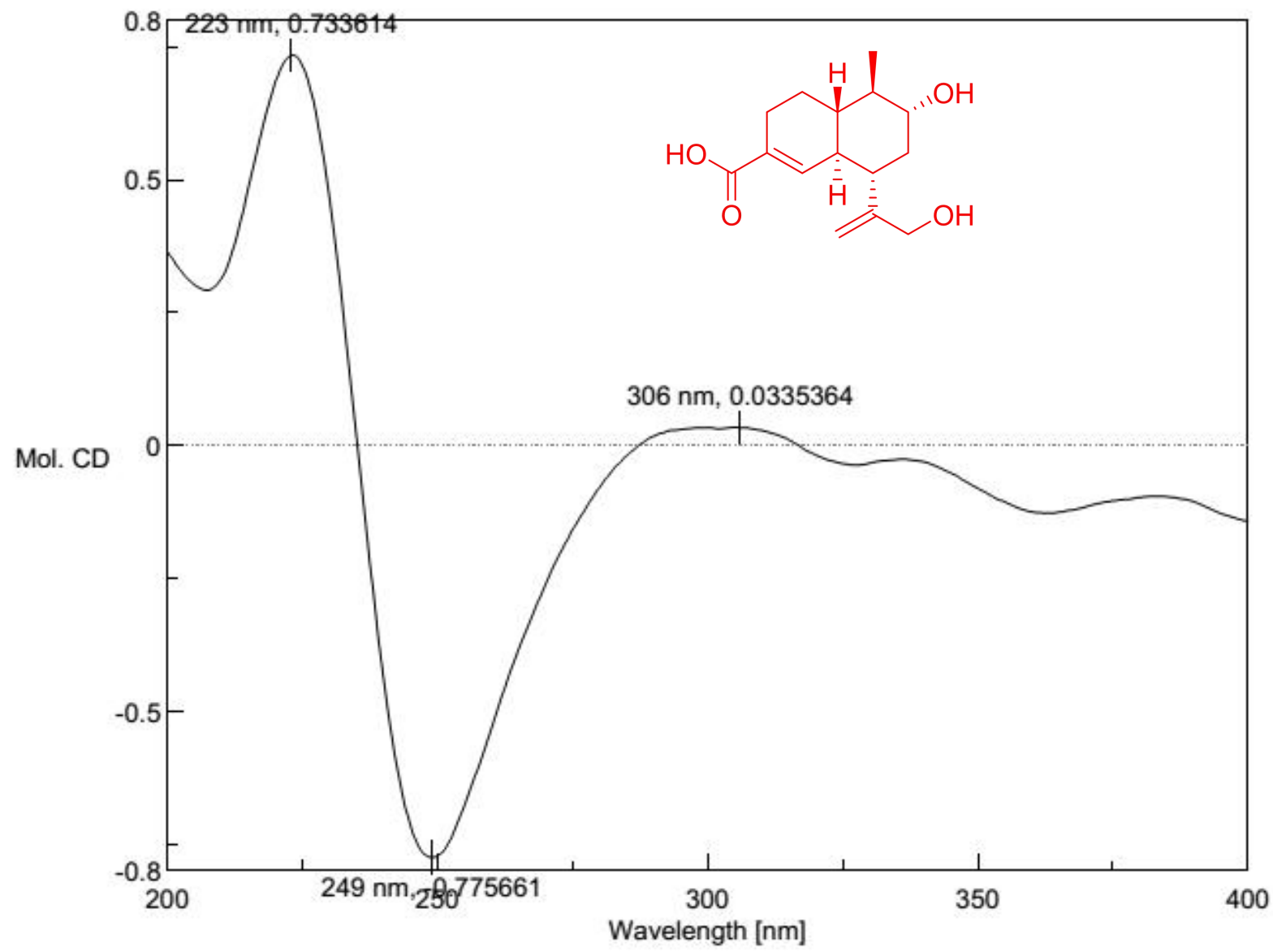

Figure S42. The CD Spectrum of Compound 5 in $\mathrm{MeOH}$ 
compound NO. : 2WC5

Method :

LCMS(compound)-low

RT: $0.00-15.01$ SM: $7 \mathrm{G}$

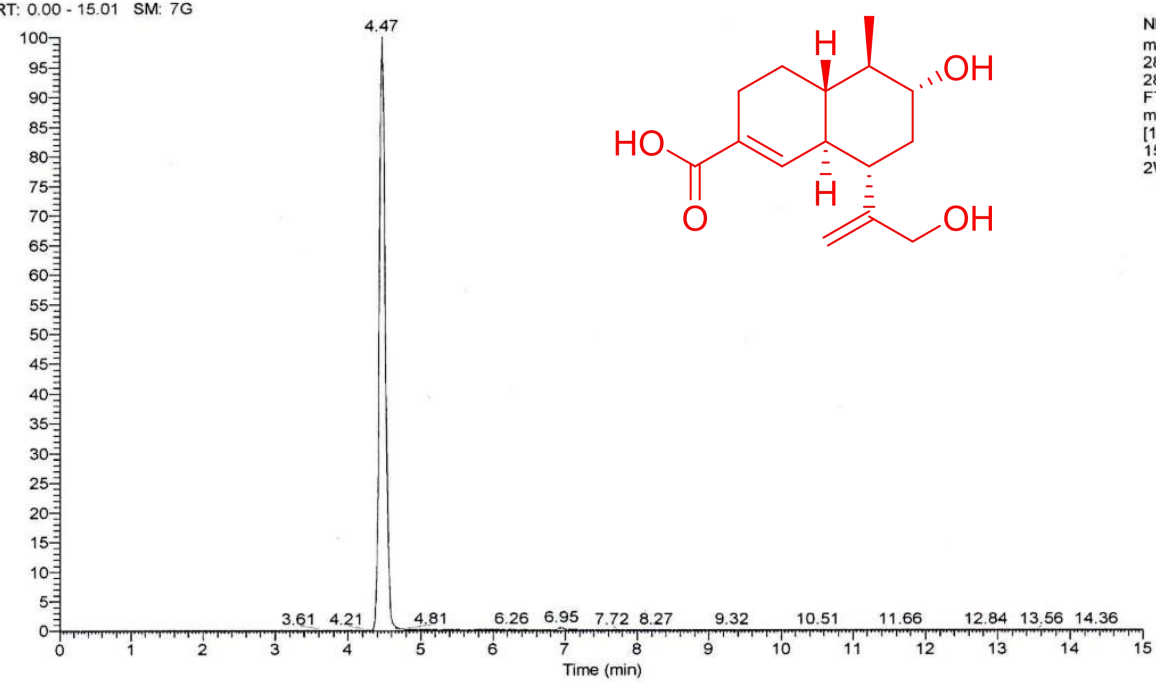

4.51E7

$\mathrm{m} / \mathrm{Z}=$
$289.13918-$

FTMS + p ESI Full

ms 100.000

$1500.0000] \mathrm{MS}$

$\begin{array}{llll}\text { 2WC5 \#447 } & \text { RT: } 4.47 \quad \text { AV: } 1 \quad \text { NL: } 5.52 E 7 \\ \text { T: FTMS + p ESI Full ms [100.0000-1500.0000 }\end{array}$

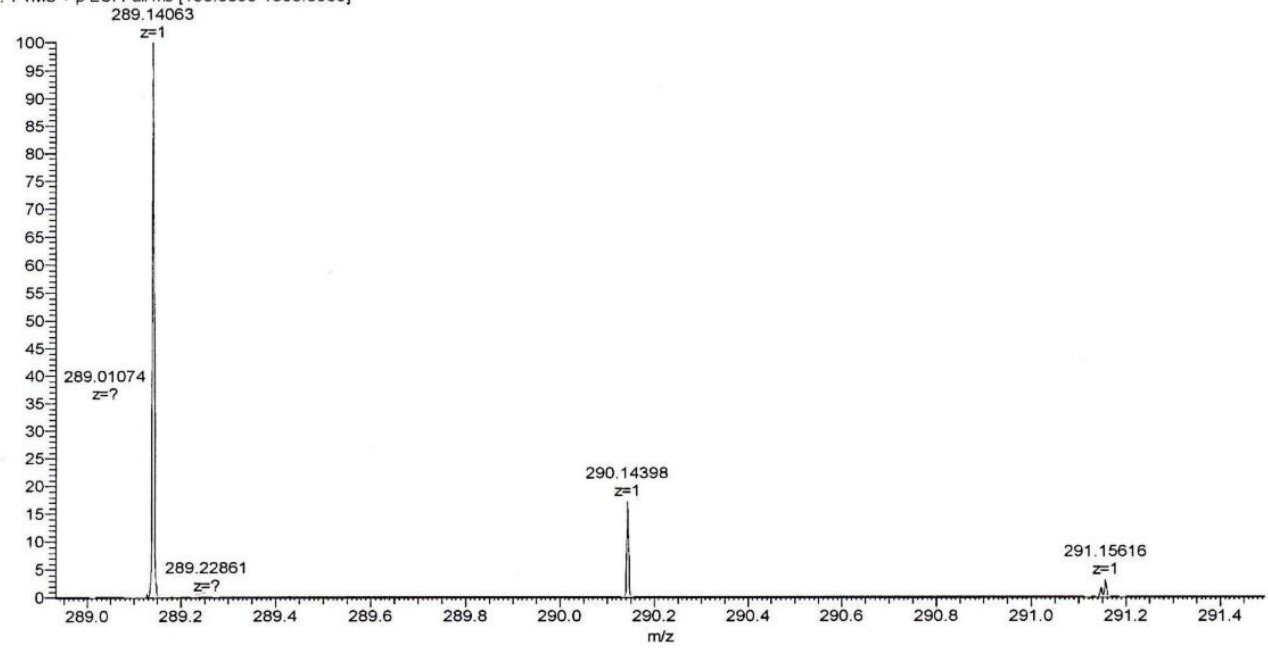

\begin{tabular}{|l|r|r|r|l|l|}
\hline $\mathrm{m} / \mathrm{z}$ & Theo. Mass & Delta (ppm) & RDB equiv. & Composition & \\
\hline & & & & & \\
\hline 289.14063 & 289.14103 & -1.38 & 4.5 & $\mathrm{C} 15 \mathrm{H} 22 \mathrm{O} 4 \mathrm{Na}$ & $\mathrm{M}+\mathrm{Na}$ \\
\hline
\end{tabular}

Figure S43. The HR-mass Spectrum of Compound 5 in $\mathrm{MeOH}$ 


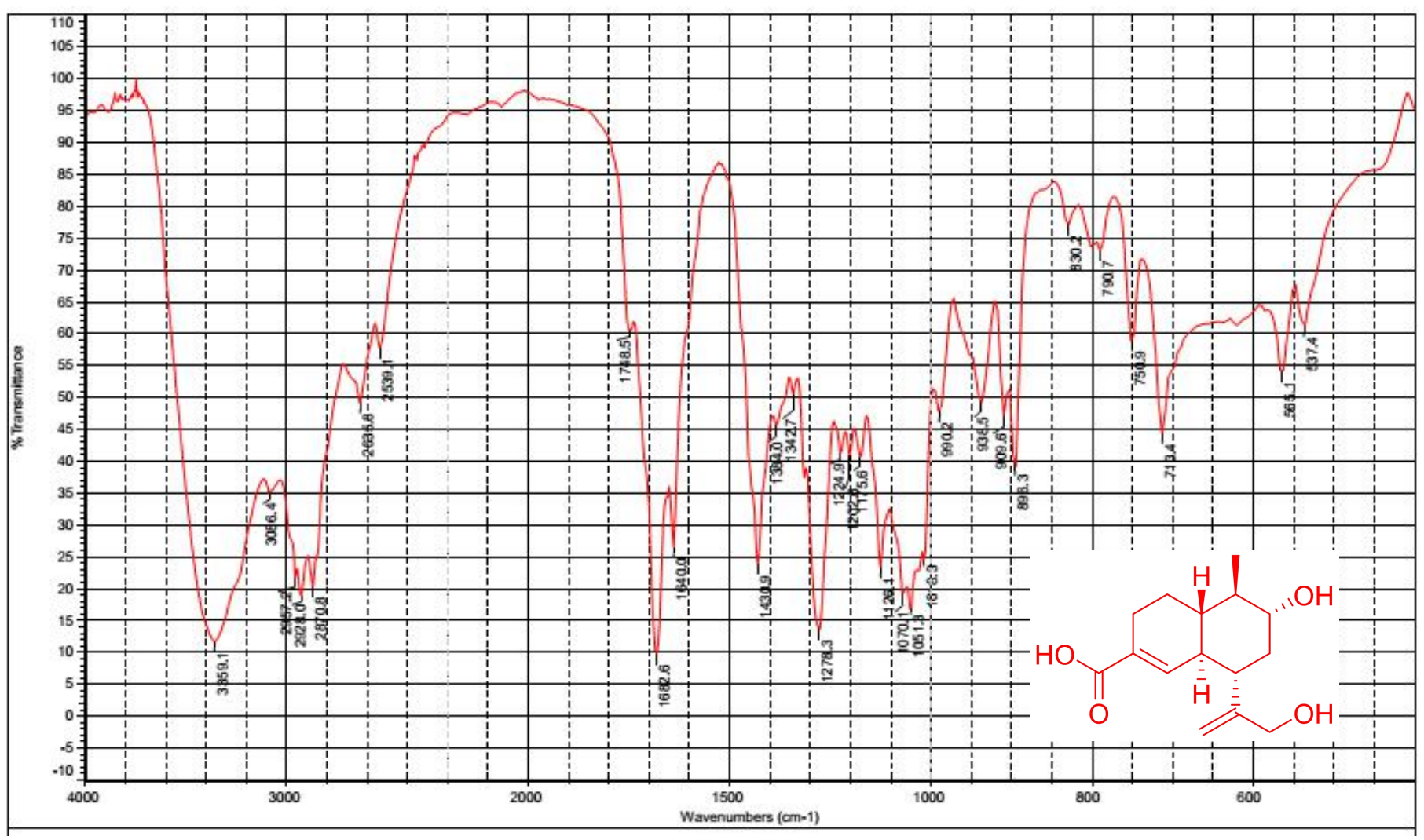

Figure S44. The IR Spectrum of Compound 5 
20180708 A9-2-3-2.1.fid - Bruker AVIII HD 600 - PROTON CD3OD D:II DATA2018 49

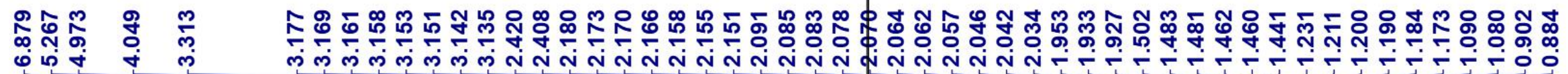

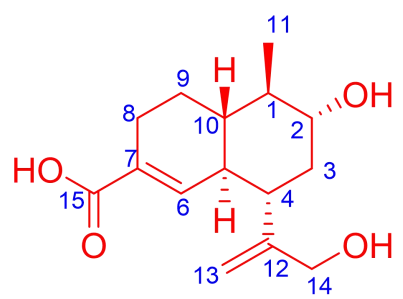
(1)
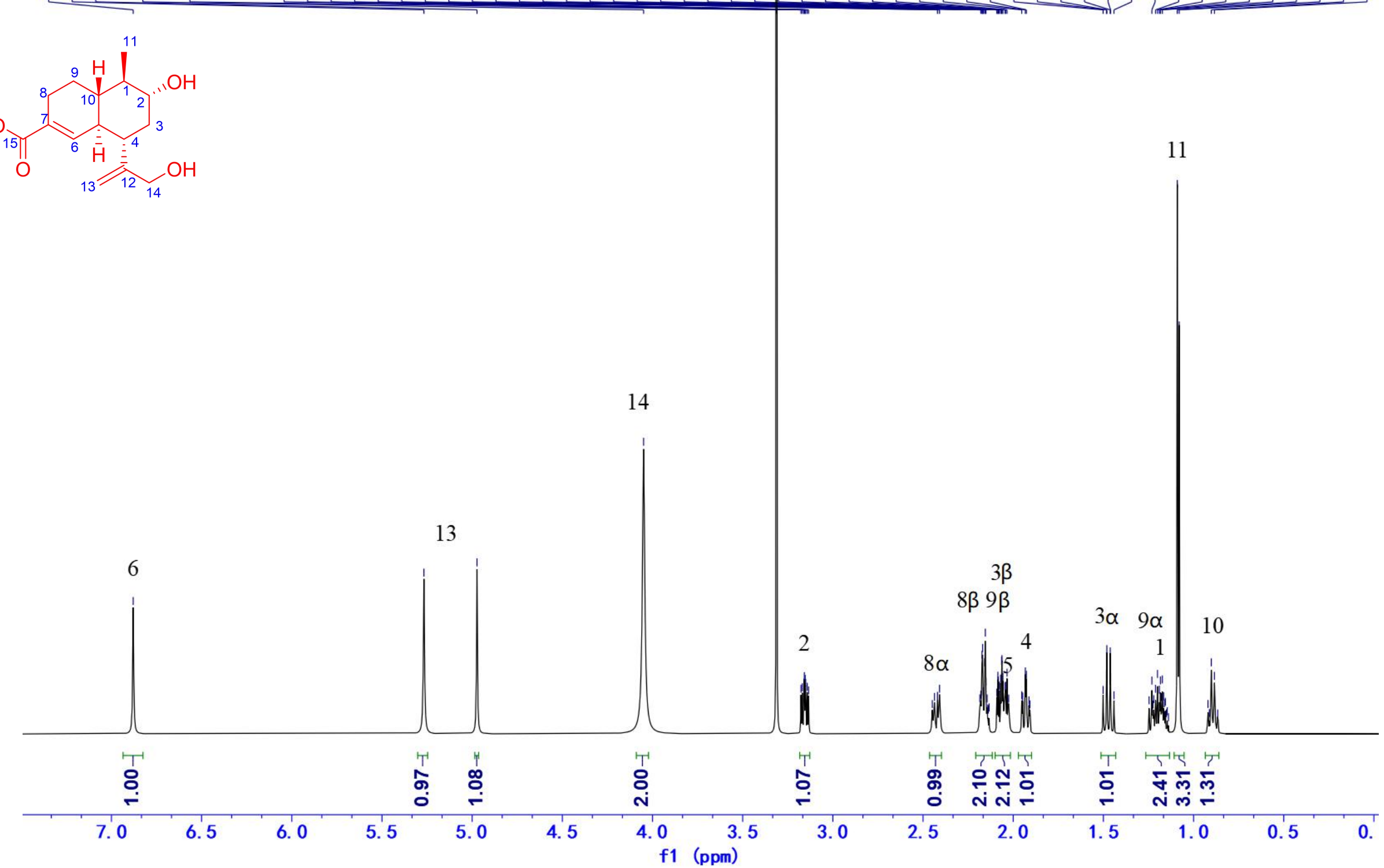

Figure S45. The ${ }^{1} \mathrm{H}$ NMR Spectrum of Compound 5 in $\mathrm{MeOH}_{-} d_{4}(600 \mathrm{MHz})$ 
20180730 A9-2-3-2.1.fid - Bruker AVIII HD 600 - C13 CD3OD D:II DATA2018 17

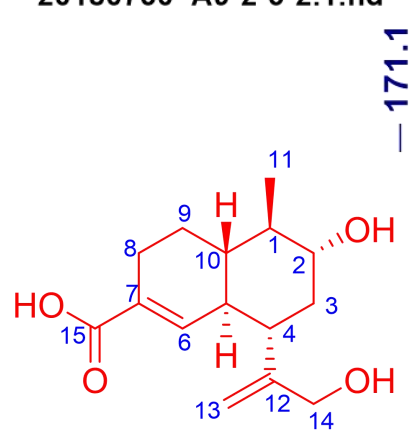

Figure S46. The ${ }^{13} \mathrm{C}$ NMR Spectrum of Compound 5 in $\mathrm{MeOH}-d_{4}(150 \mathrm{MHz})$ 
20180730 A9-2-3-2.3.ser — Bruker AVIII HD 600 — COSY_MQF CD3OD D:II DATA2018 37

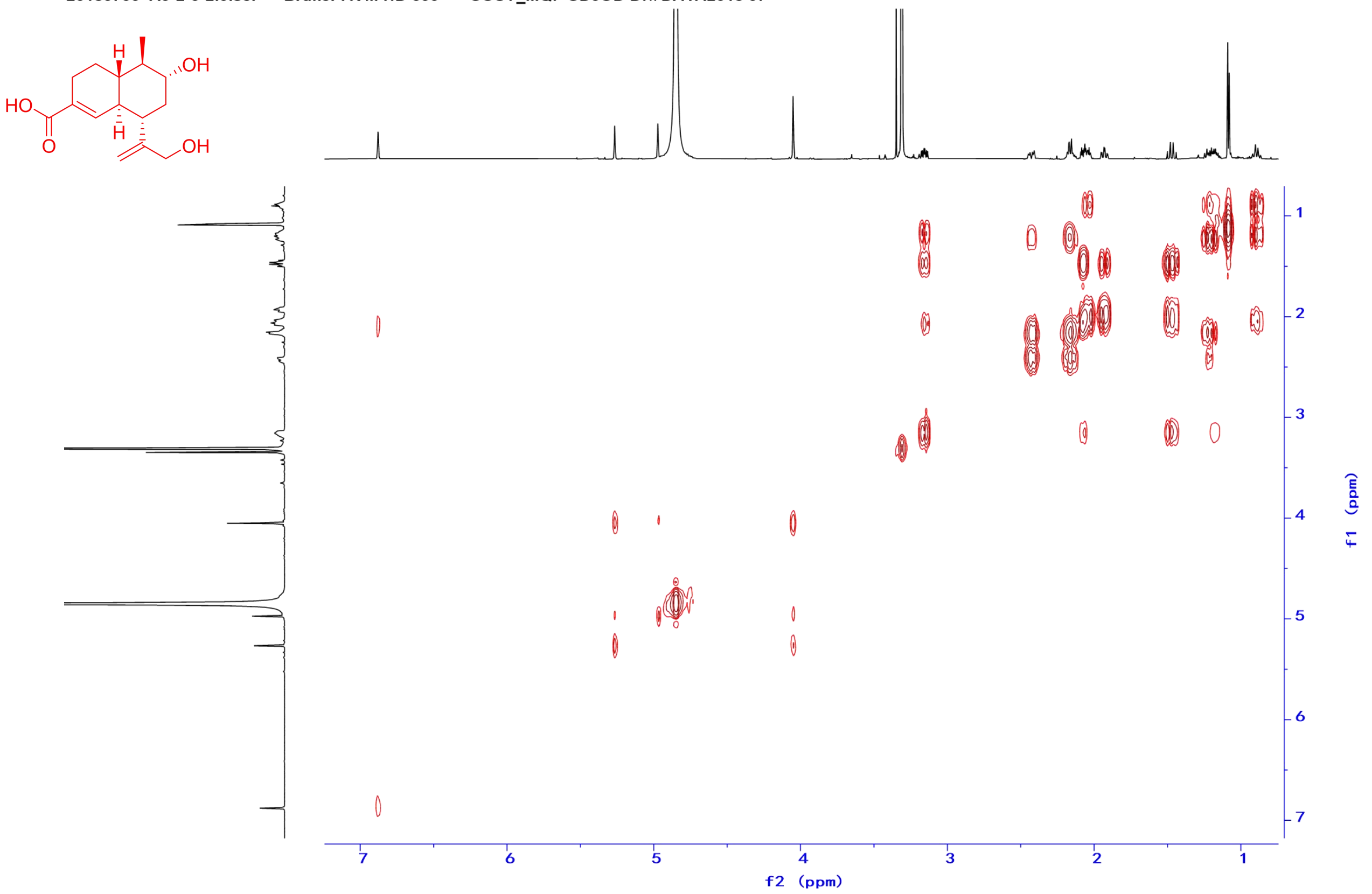

Figure S47. The ${ }^{1} \mathrm{H}^{-1} \mathrm{H}$ COSY Spectrum of Compound 5 in MeOH-d $\mathbf{M}_{4}(600 \mathrm{MHz})$ 
20180730 A9-2-3-2.4.ser — Bruker AVIII HD 600 — \{HSQC_(phase sensitive)\} CD3OD D:II DATA2018 37
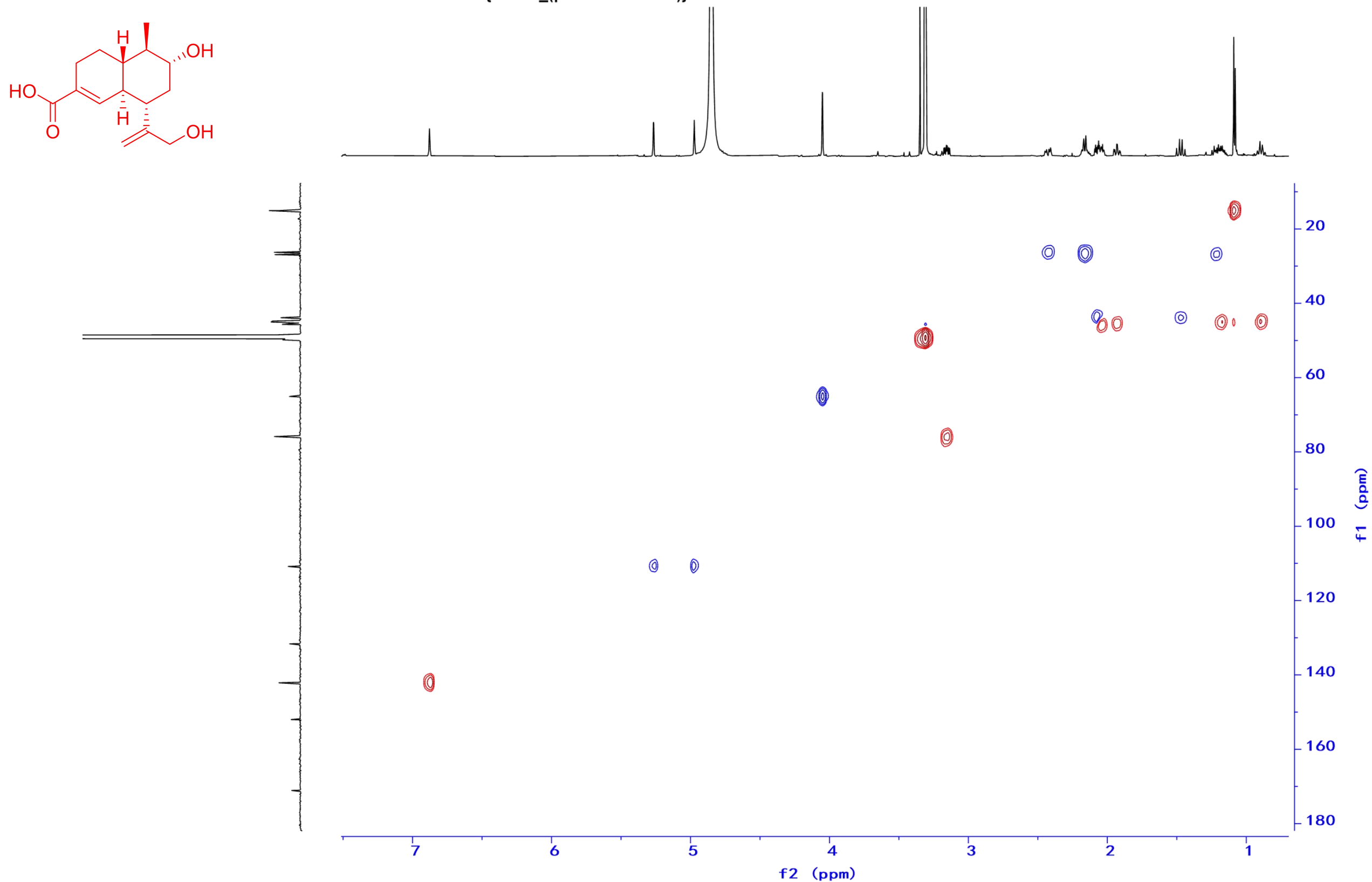

Figure S48. The HSQC Spectrum of Compound 5 in $\mathrm{MeOH}-d_{4}(600 \mathrm{MHz})$ 
20180730 A9-2-3-2.5.ser - Bruker AVIII HD 600 - HMBC CD3OD D:II DATA2018 37

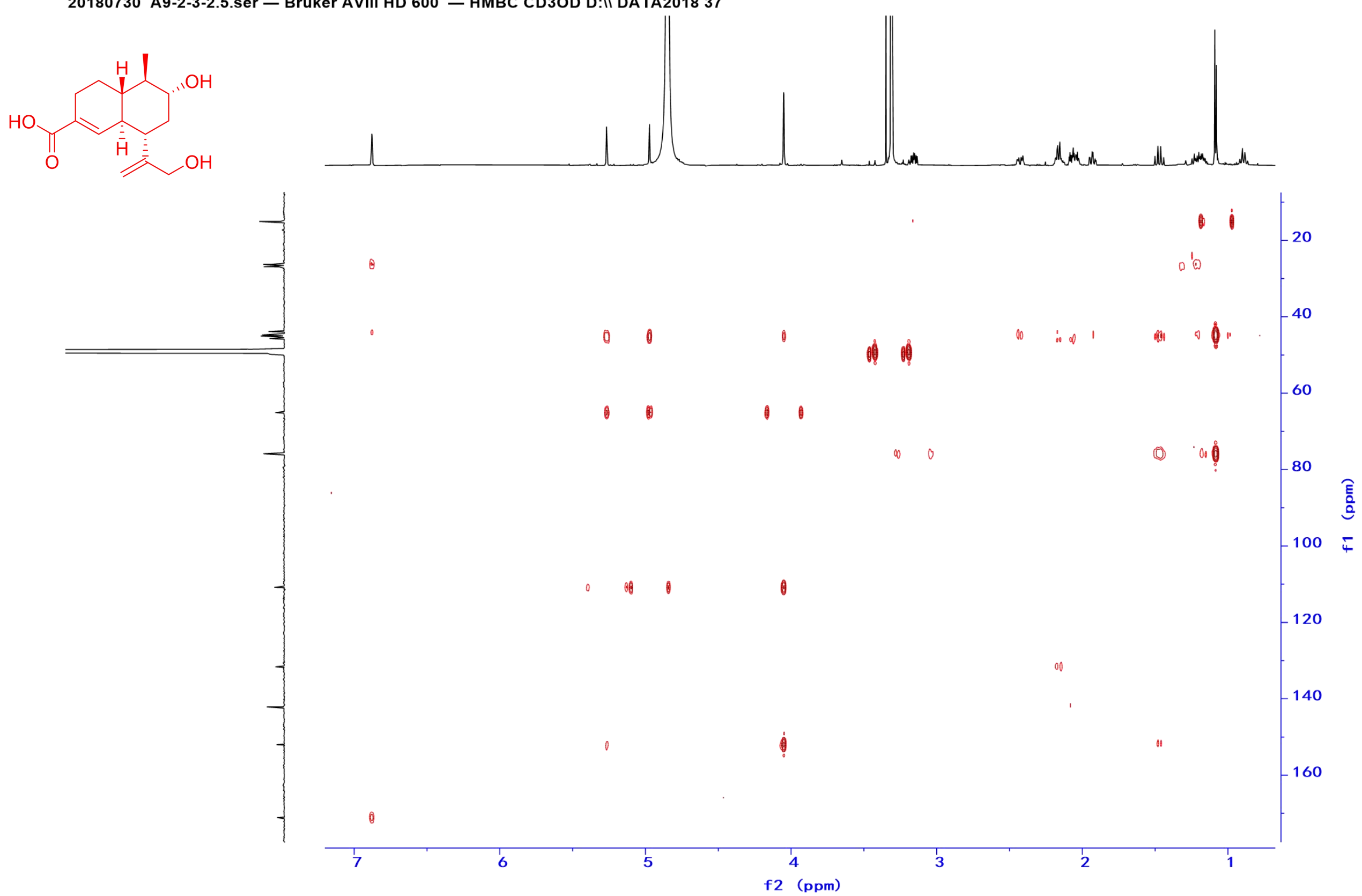

Figure S49. The HMBC Spectrum of Compound 5 in MeOH- $d_{4}(600 \mathrm{MHz})$ 
20190627 A9-2-3-2.2.ser — Bruker AVIII HD 600 — ROESY CD3OD D:II DATA2019 1
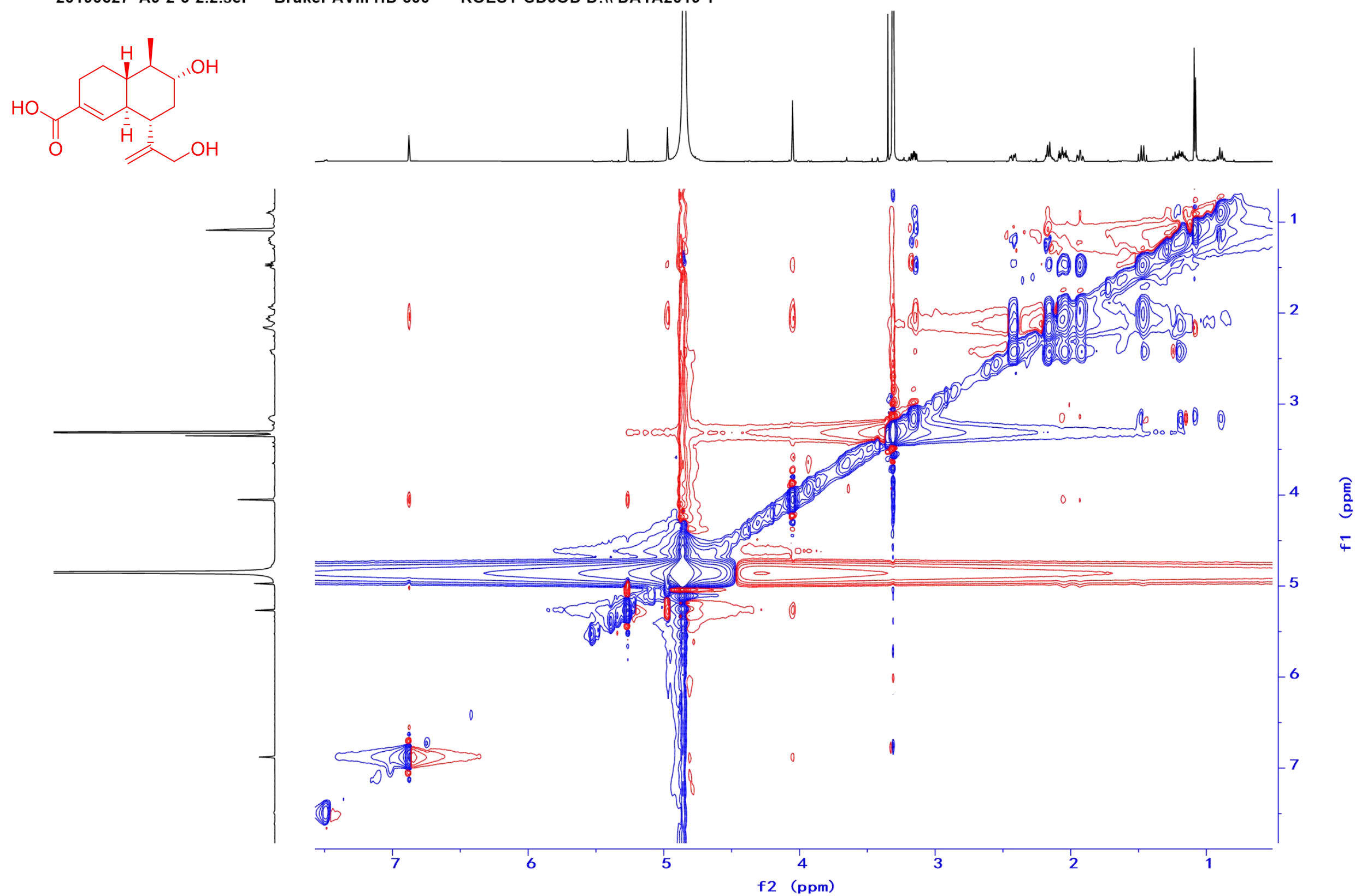

Figure S50. The NOESY Spectrum of Compound 5 in MeOH-d $d_{4}(600 \mathrm{MHz})$ 


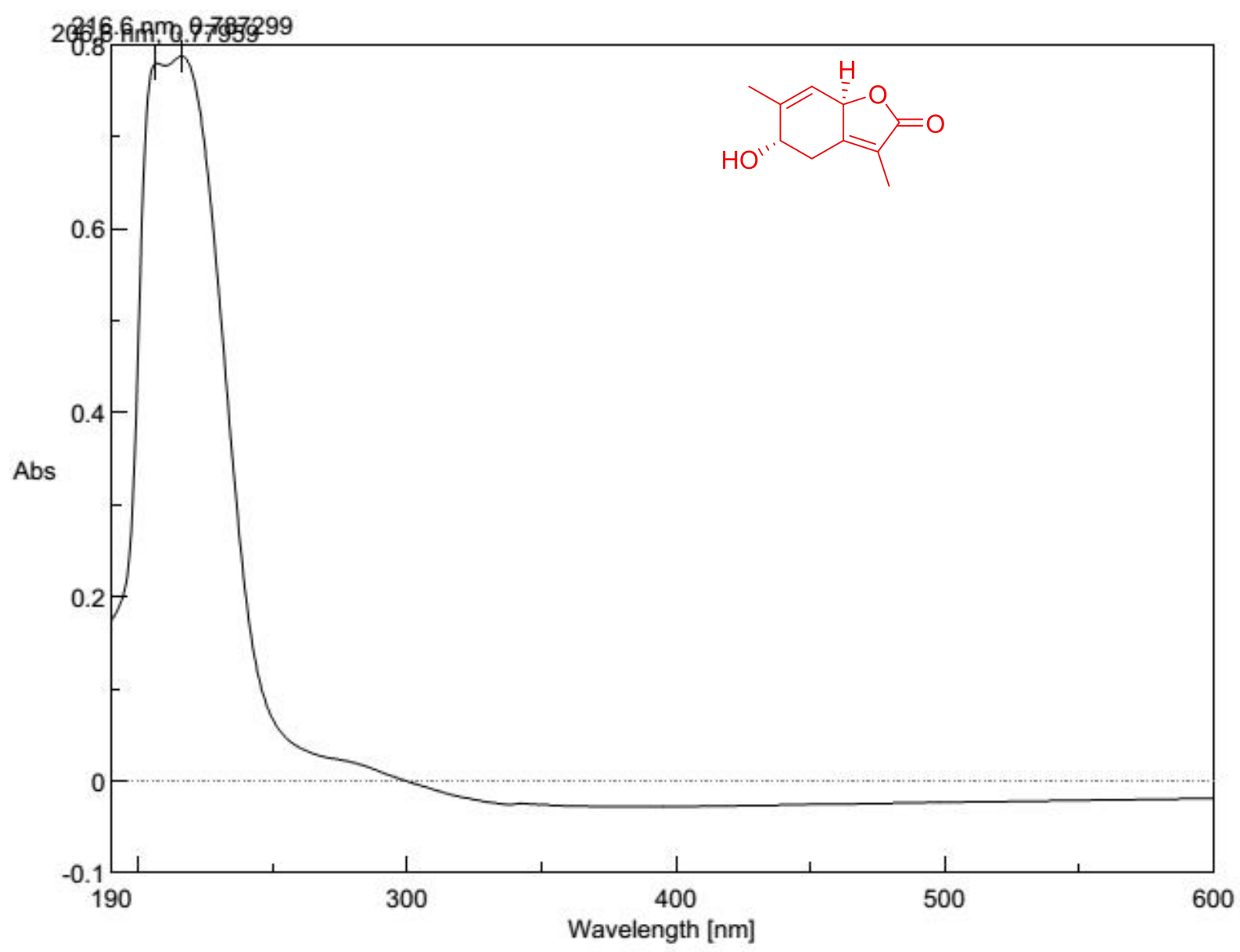

Figure S51. The UV Spectrum of Compound 7 in $\mathrm{MeOH}$

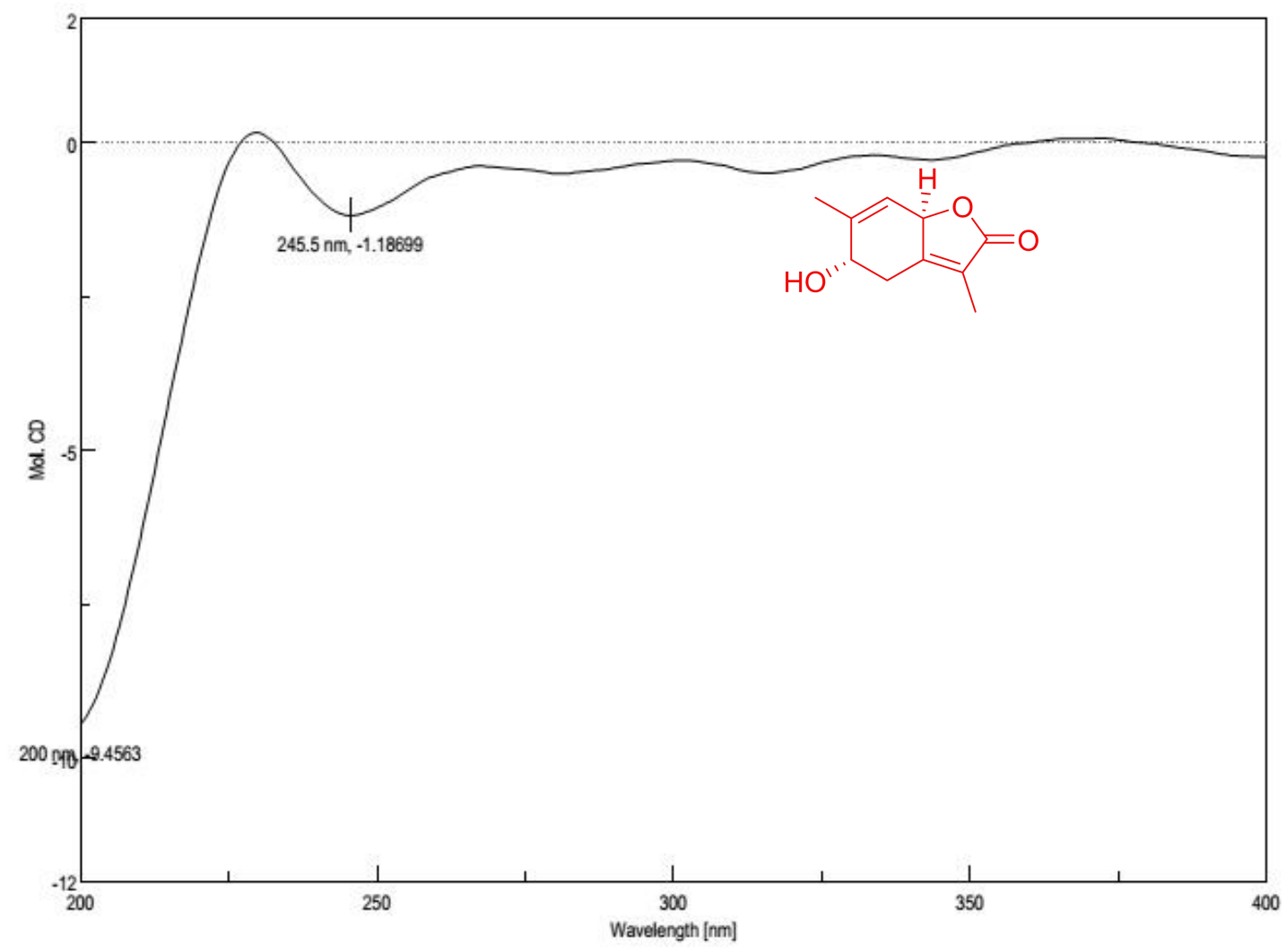

Figure S52. The CD Spectrum of Compound 7 in $\mathrm{MeOH}$ 


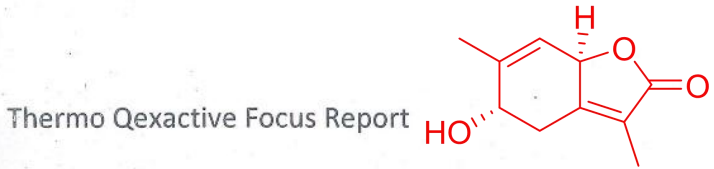

$\begin{array}{ll}\text { compound NO. : } & \text { C-2JF-21 } \\ \text { Method : } & \text { LCMS(compound)-low }\end{array}$

RT: $0.00-15.01$ SM: $7 G$

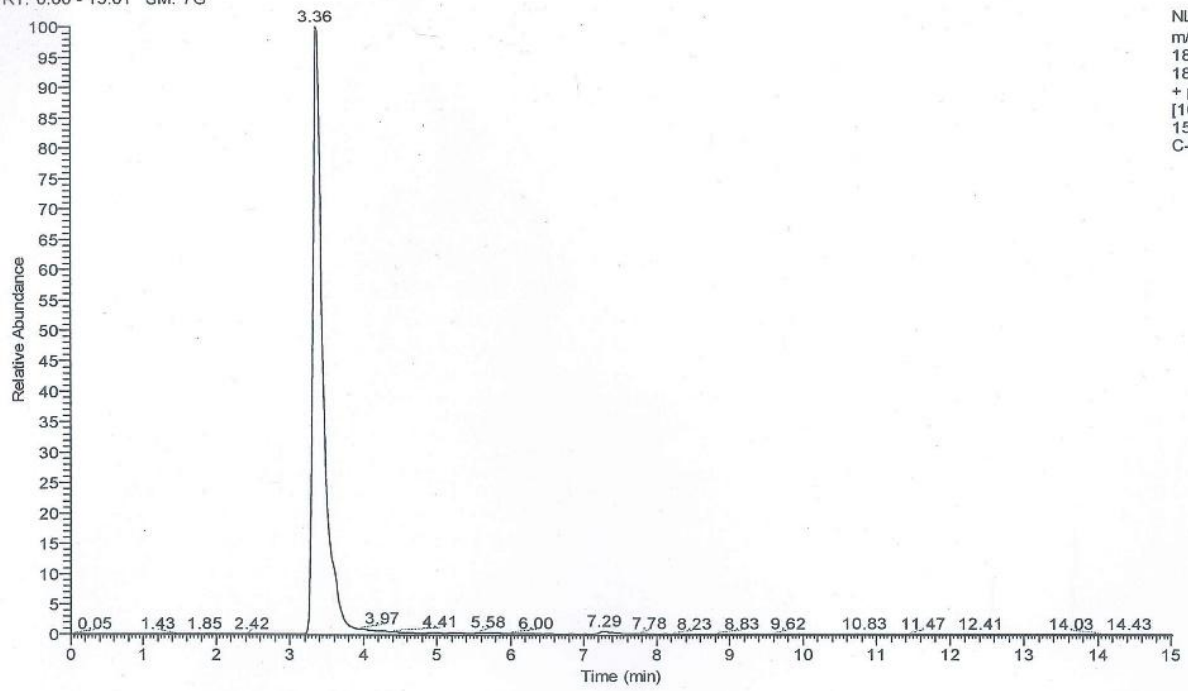

C-2.JF-21 \#339 RT: 3.36 AV: 1 NL: $1.02 E 8$

T: FTMS + p ESI Full ms [100.0000-1500.0000

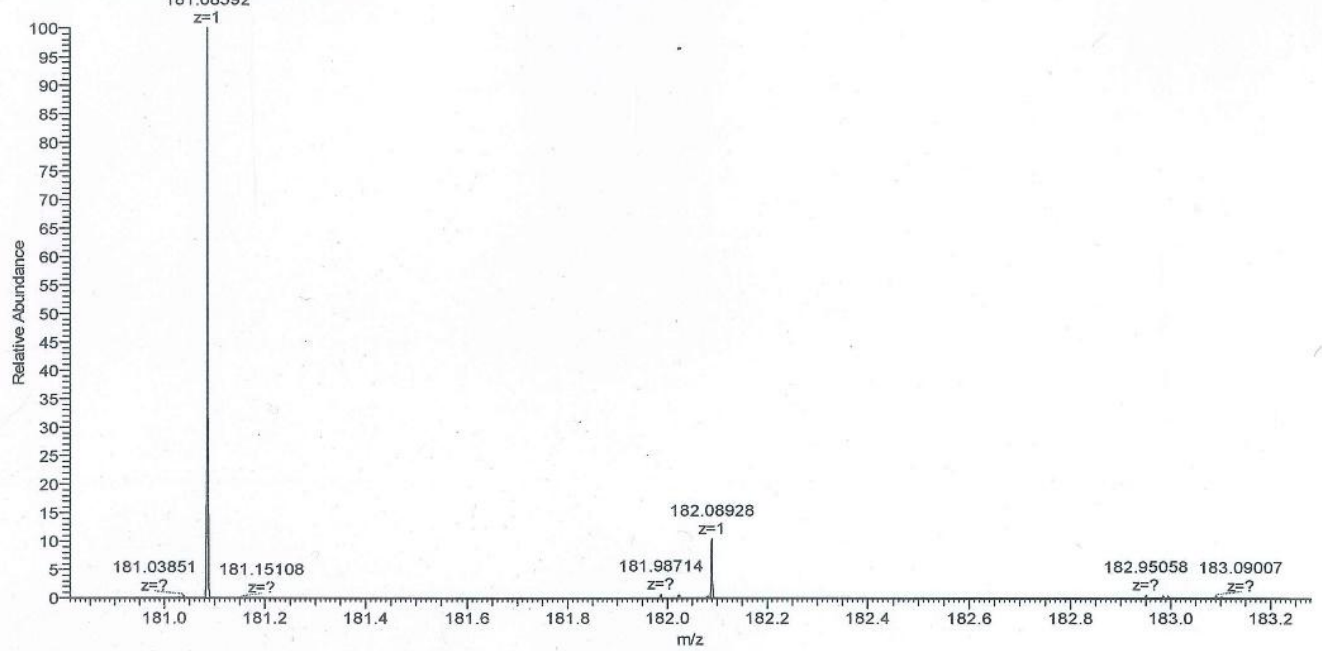

\begin{tabular}{|l|l|l|l|l|l|}
\hline $\mathrm{m} / \mathrm{z}$ & Theo. Mass & Delta $(\mathrm{ppm})$ & RDB equiv. & Composition & \\
\hline & & & & & \\
\hline 181.08592 & 181.08592 & 0 & 4.5 & $\mathrm{C} 10 \mathrm{H} 13 \mathrm{O} 3$ & $\mathrm{M}+\mathrm{H}$ \\
\hline
\end{tabular}

Figure S53. The HR-mass Spectrum of Compound 7 in $\mathrm{MeOH}$ 


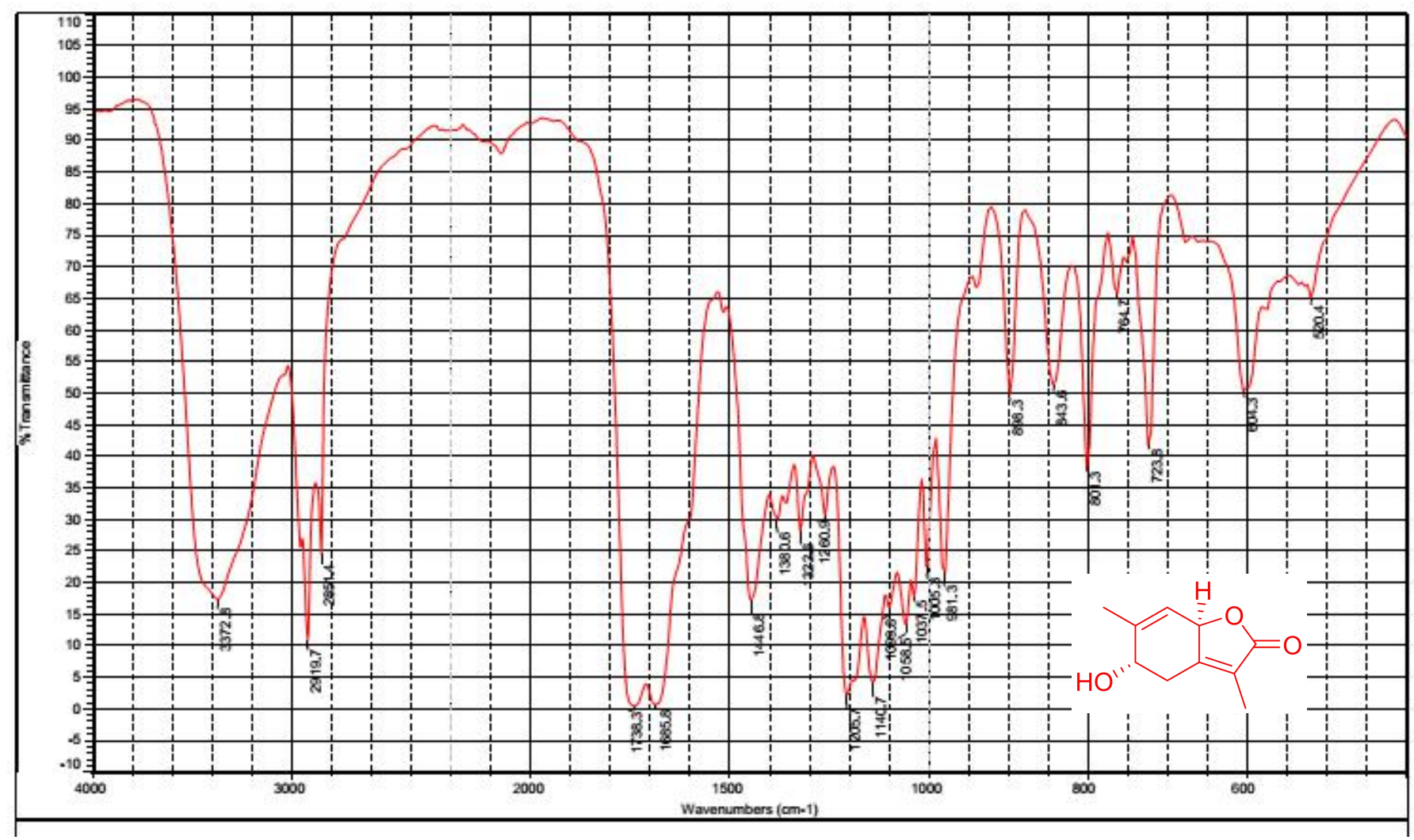

Figure S54. The IR Spectrum of Compound 7 
20181023 c-zjf-21.1.fid — Bruker AVIII HD 600 — PROTON MeOD D:II DATA2018 11

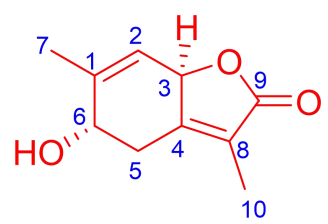

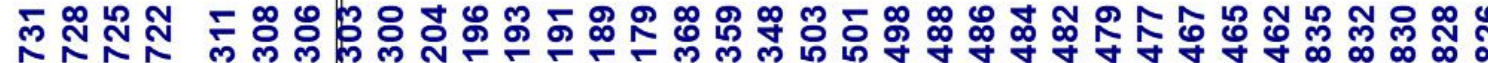
किं

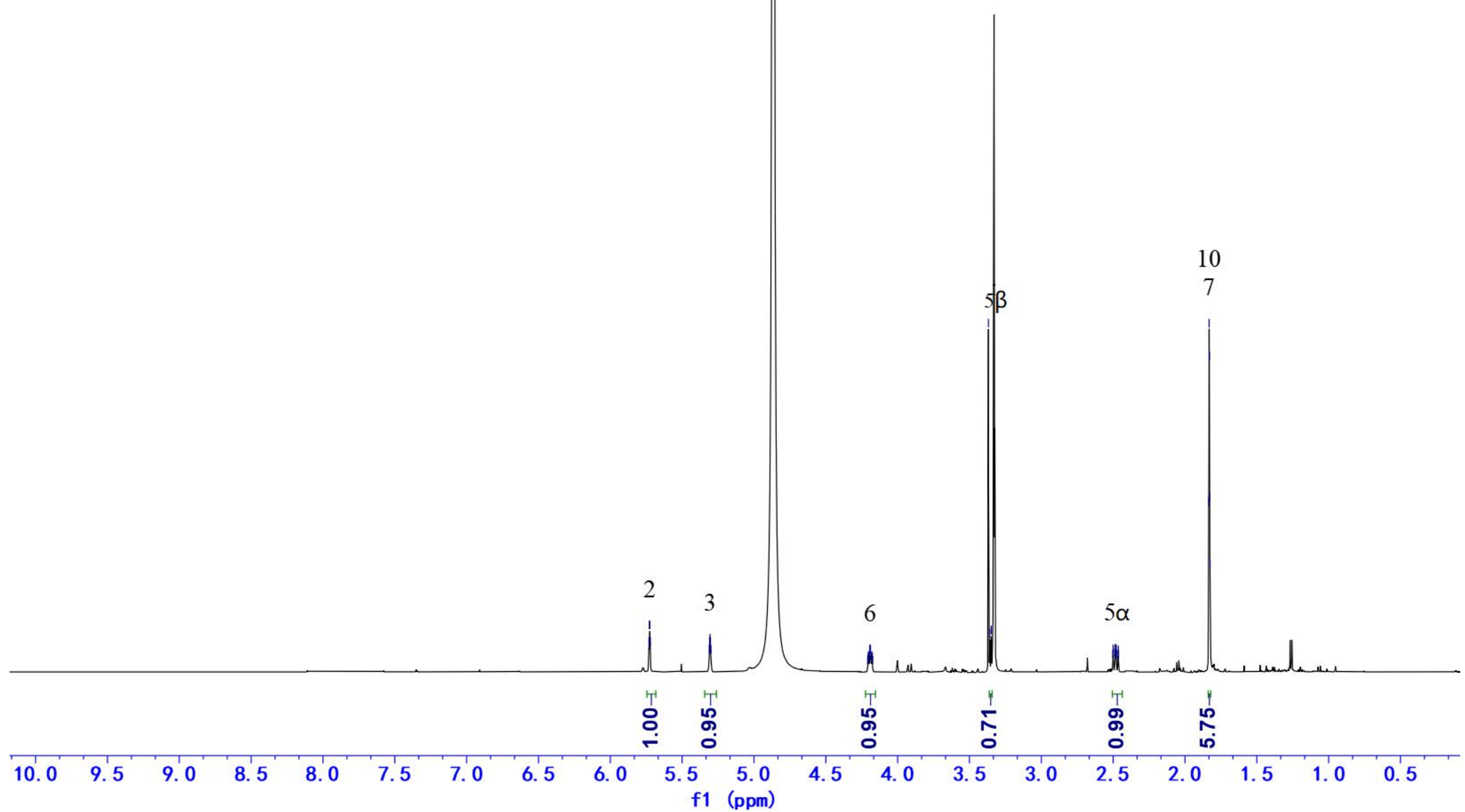

Figure S55. The ${ }^{1} \mathrm{H}$ NMR Spectrum of Compound 7 in $\mathrm{MeOH}-d_{4}(600 \mathrm{MHz})$ 

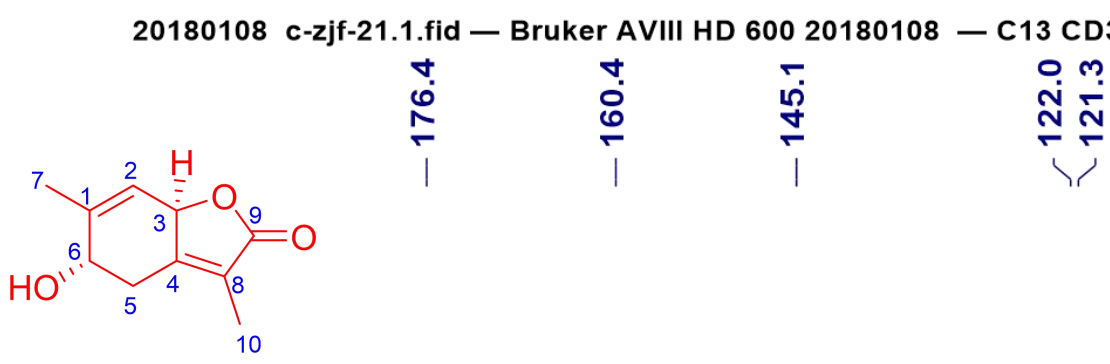

$$
\stackrel{0}{\stackrel{0}{9}} \underset{1}{\stackrel{N}{N}}
$$

జ̊ำ

$\stackrel{\infty}{\infty}$

9

4

1

36

5

10

100
$\mathrm{f1} \quad$ (ppm)

Figure S56. The ${ }^{13} \mathrm{C}$ NMR Spectrum of Compound 7 in MeCH- $d_{4}(150 \mathrm{MHz})$

51 
20181023 c-zjf-21.2.ser — Bruker AVIII HD 600 — COSY_MQF MeOD D:II DATA2018 11
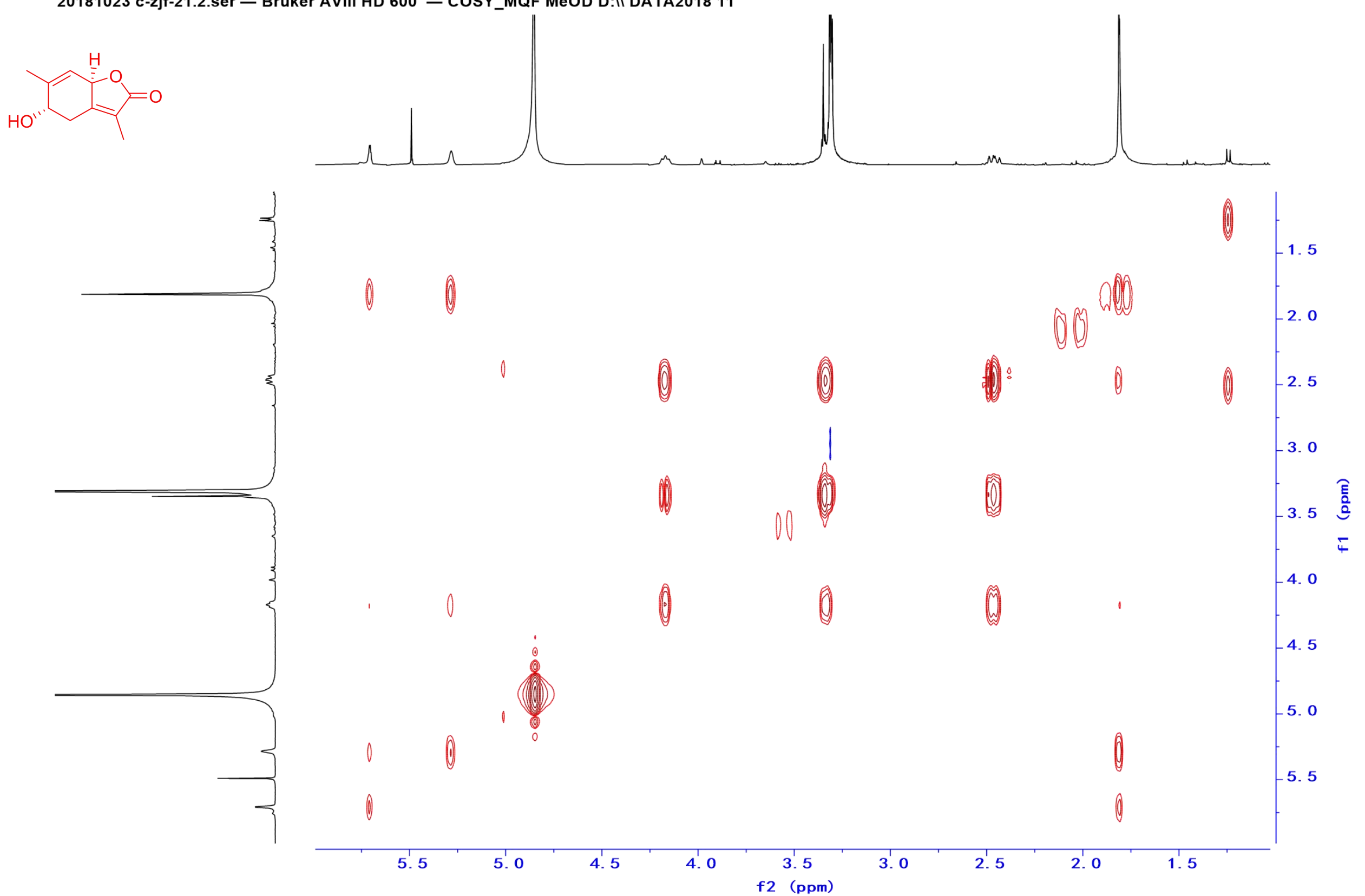

Figure S57. The ${ }^{1} \mathrm{H}-{ }^{1} \mathrm{H}$ COSY Spectrum of Compound 7 in $\mathrm{MeOH}-d_{4}(600 \mathrm{MHz})$ 
20181023 c-zjf-21.3.ser — Bruker AVIII HD 600 — SHSQC (phase sensitive)\} MeOD D:II DATA2018 11
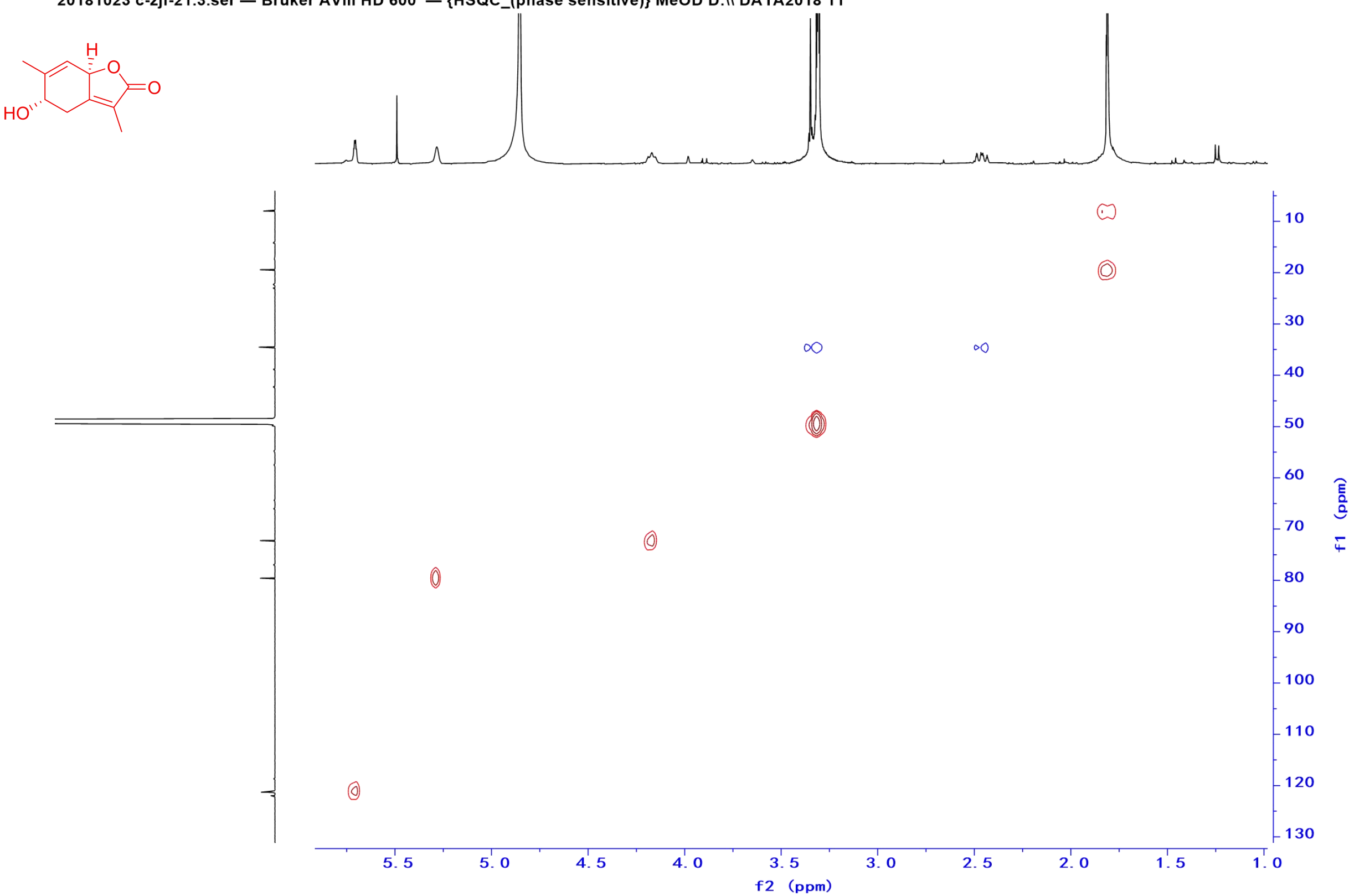

Figure S58. The HSQC Spectrum of Compound 7 in $\mathrm{MeOH}-d_{4}(600 \mathrm{MHz})$ 
20181023 c-zjf-21.4.ser — Bruker AVIII HD 600 — HMBC MeOD D:II DATA2018 11
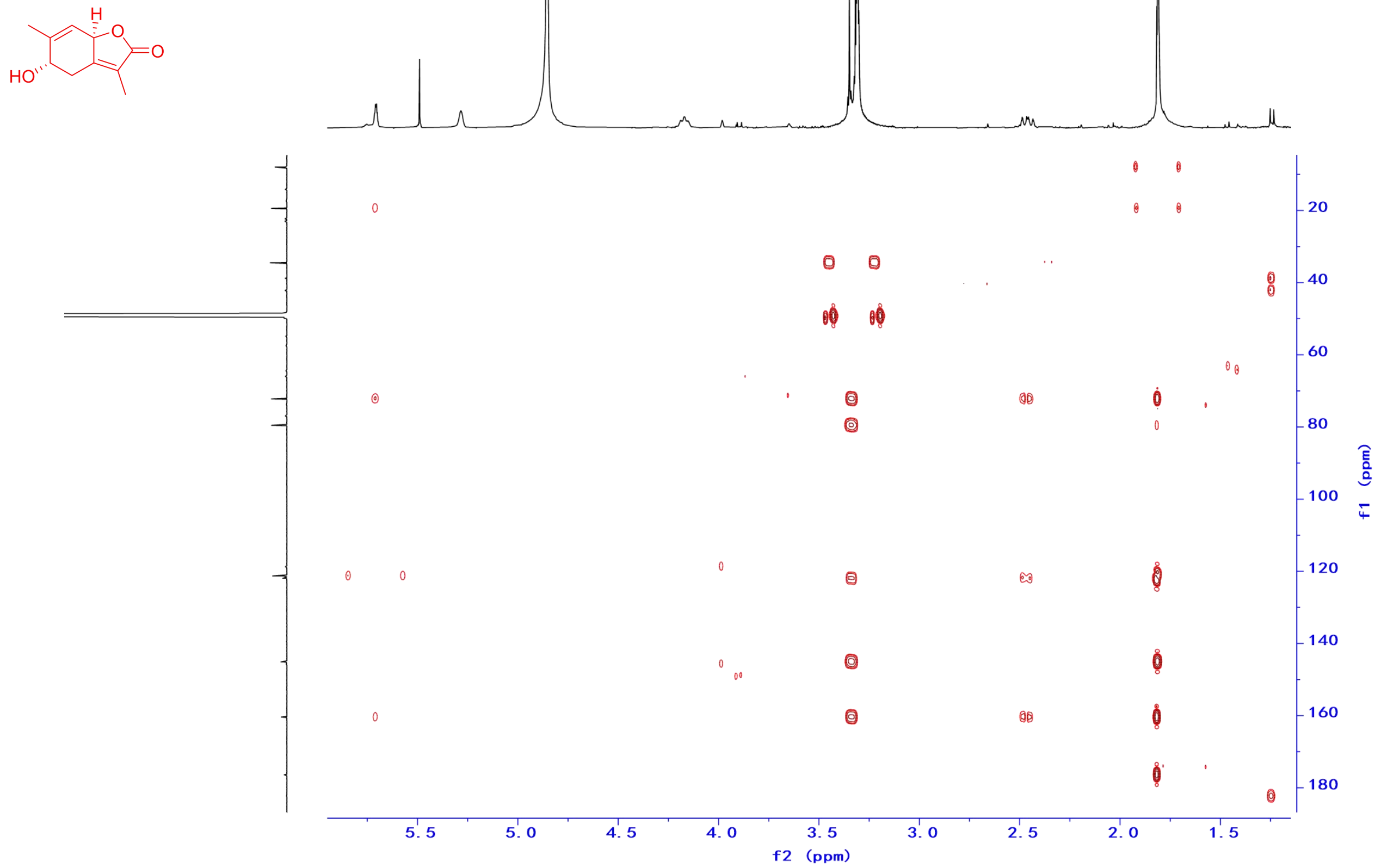

Figure S59. The HMBC Spectrum of Compound 7 in $\mathrm{MeOH}-d_{4}(600 \mathrm{MHz})$ 


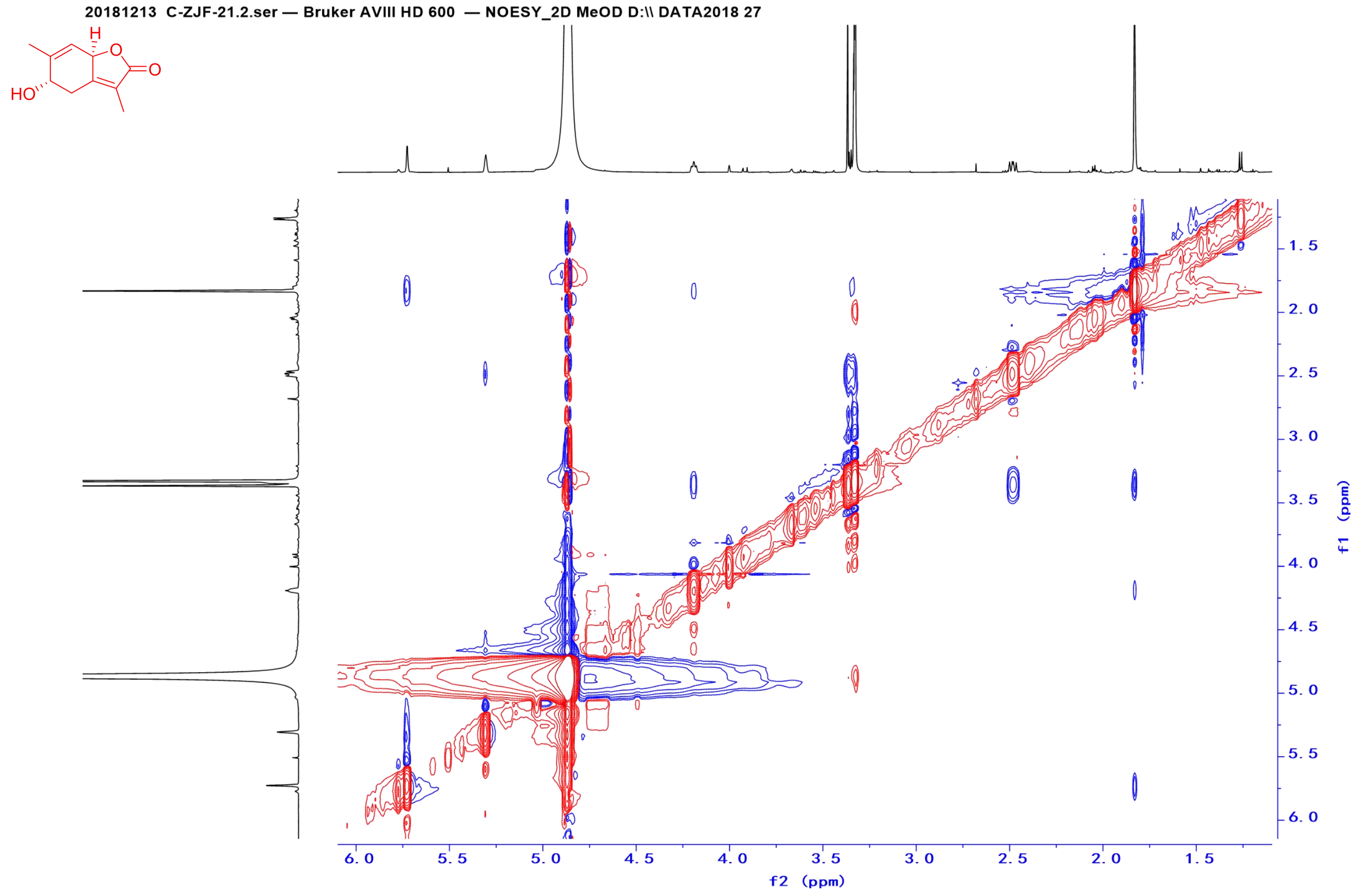

Figure S60. The NOESY Spectrum of Compound 7 in $\mathrm{MeOH}-d_{4}(600 \mathrm{MHz})$ 


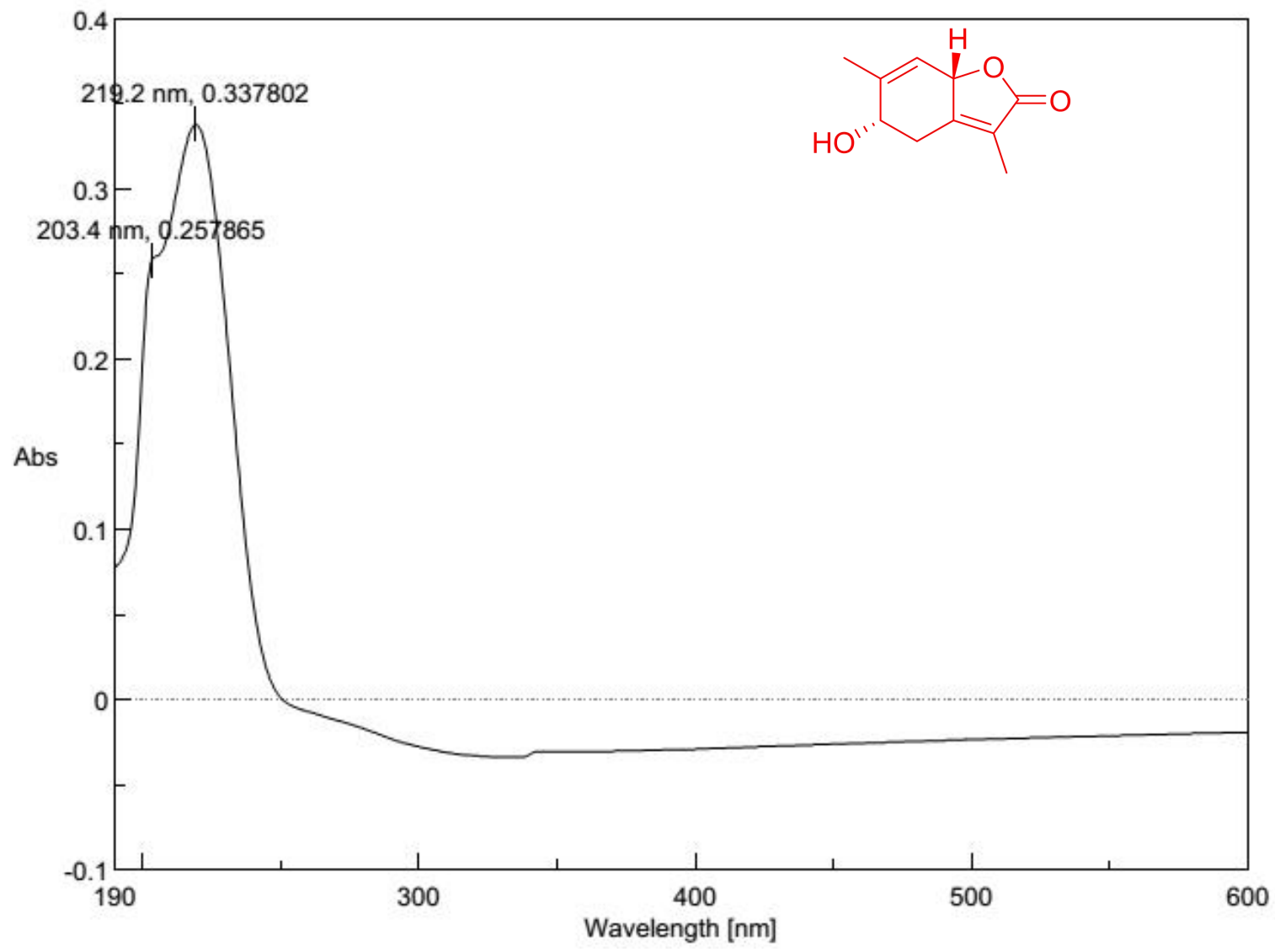

Figure S61. The UV Spectrum of Compound 8 in $\mathrm{MeOH}$

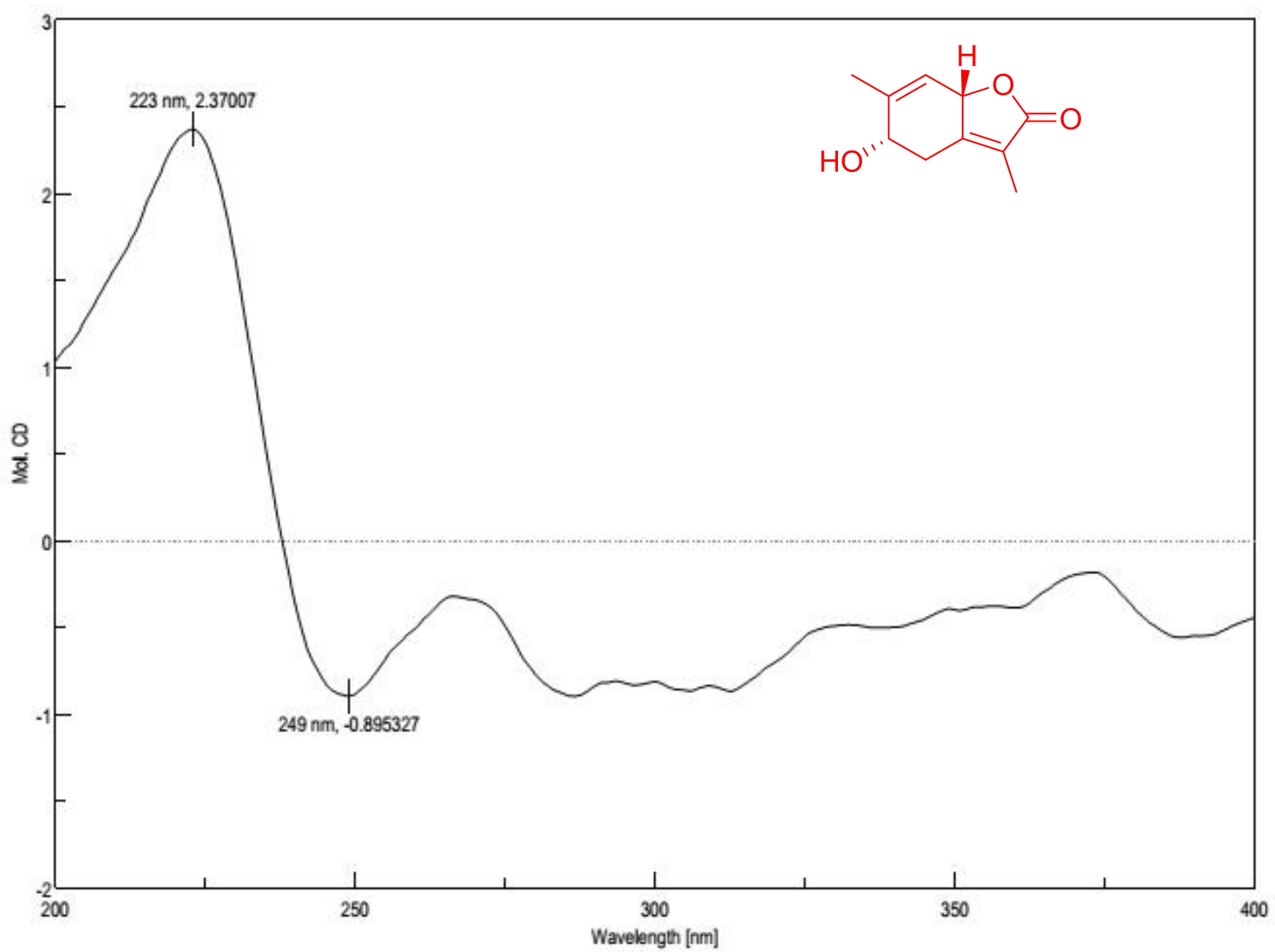

Figure S62. The CD spectrum of Compound 8 in $\mathrm{MeOH}$ 

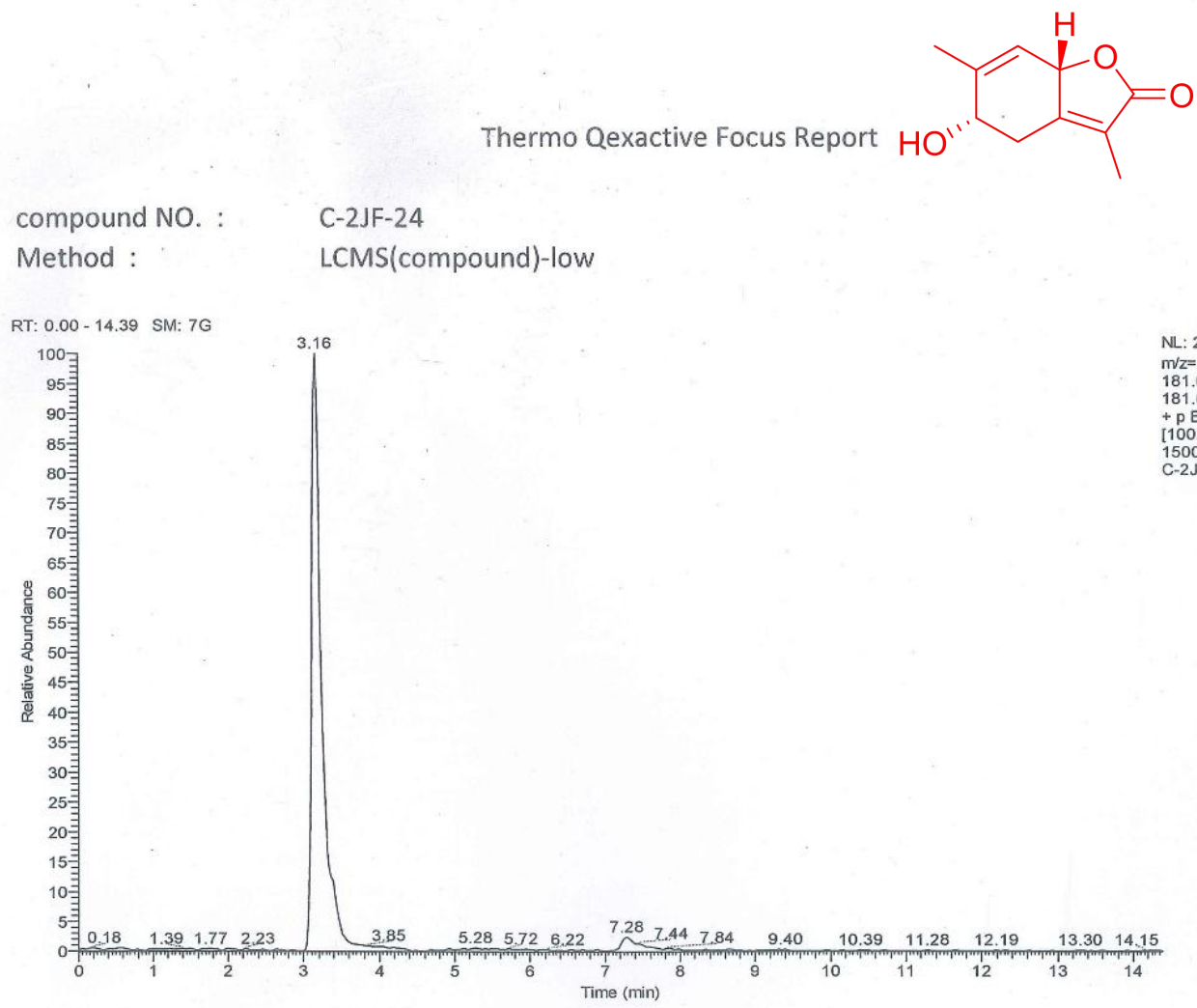

C-2JF-24 \#321 RT: 3.18 AV: 1 NL: $2.18 E 7$

T: FTMS + p ESI Full ms [100.0000-1500.0000]

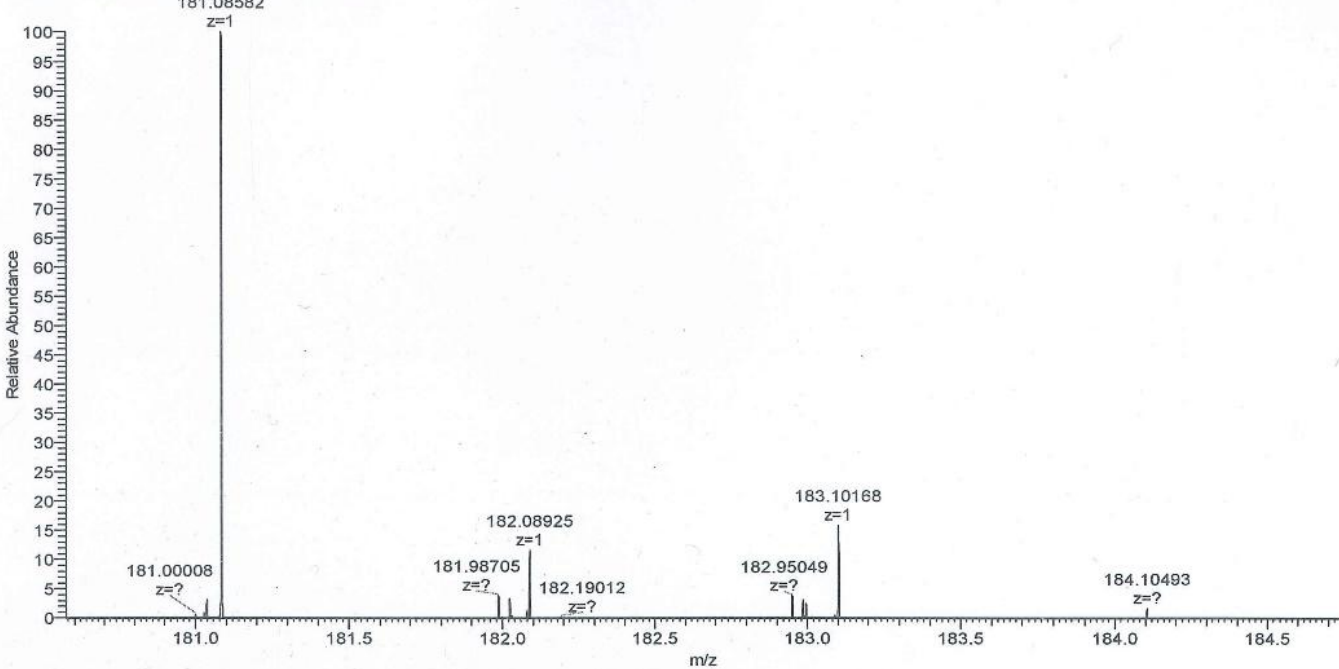

\begin{tabular}{|l|r|r|r|l|l|}
\hline $\mathrm{m} / \mathrm{z}$ & Theo. Mass & Delta $(\mathrm{ppm})$ & RDB equiv. & Composition & \\
\hline & & & & & \\
\hline 181.08582 & 181.08592 & -0.56 & 4.5 & $\mathrm{C} 10 \mathrm{H} 13 \mathrm{O} 3$ & $\mathrm{M}+\mathrm{H}$ \\
\hline
\end{tabular}

Figure S63. The HR-mass Spectrum of Compound 8 in MeOH 


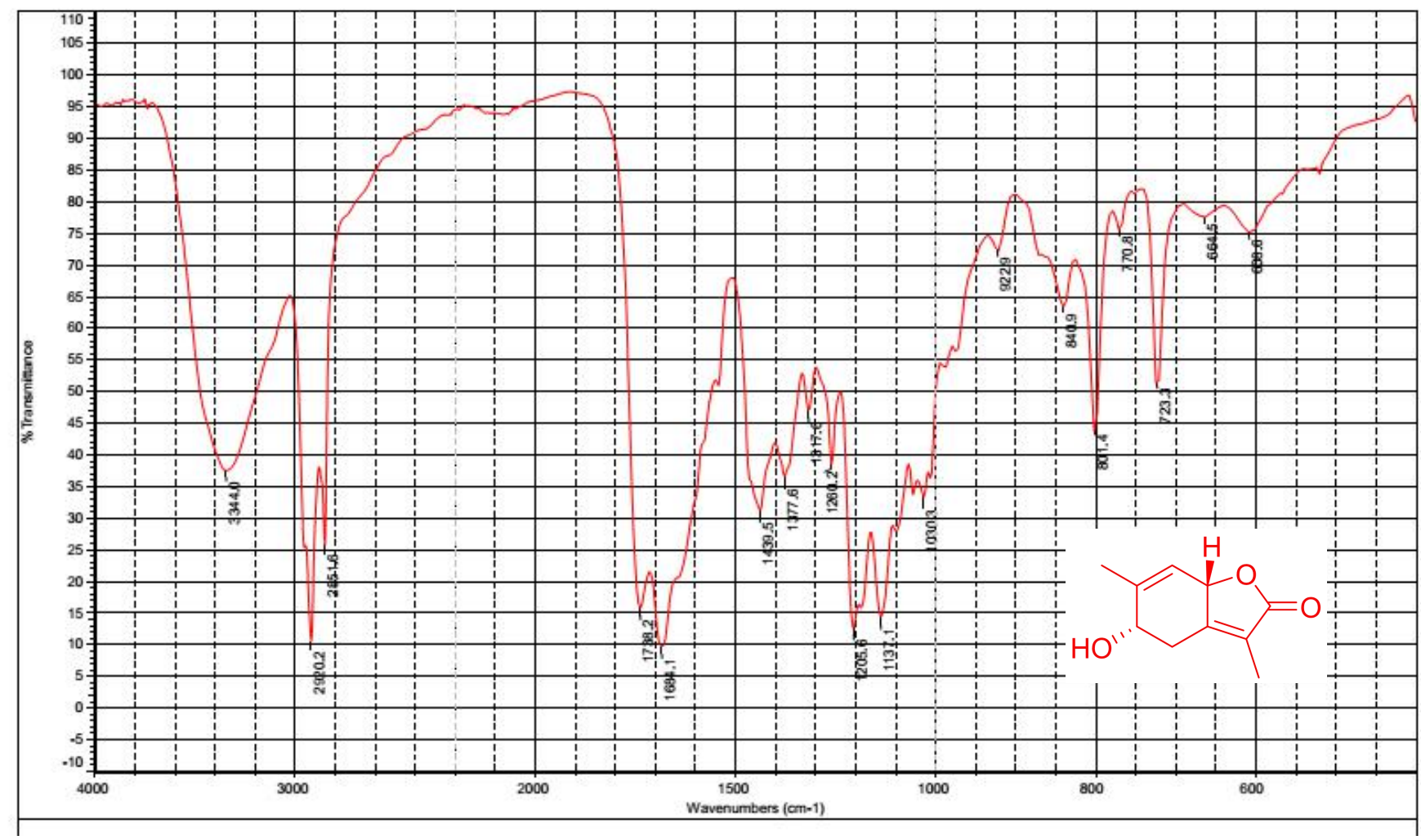

Figure S64. The IR Spectrum of Compound 8 


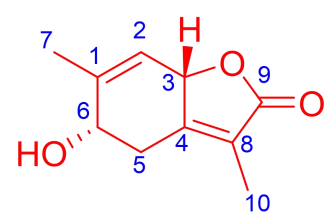

10
10

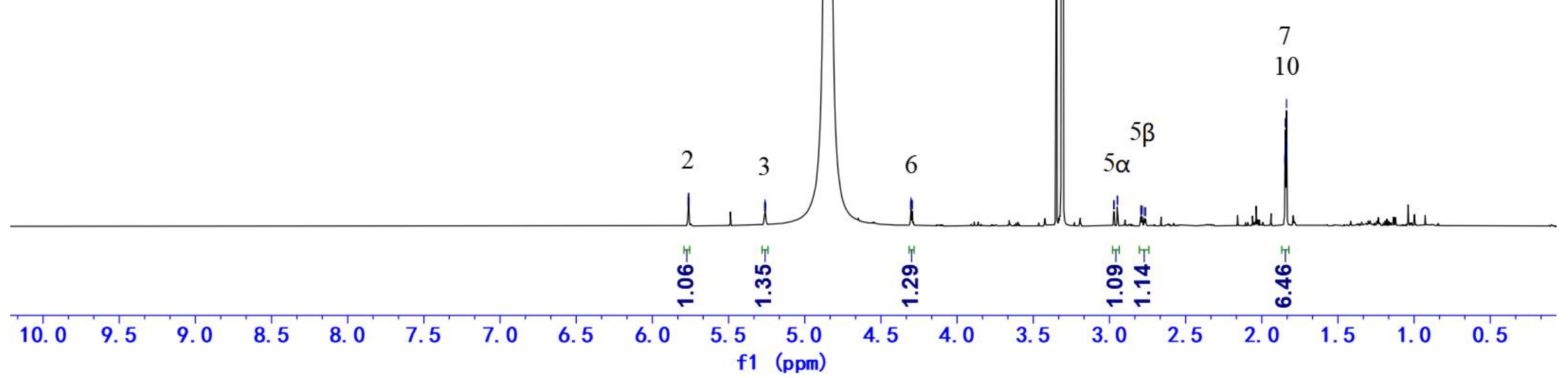

Figure S65. The ${ }^{1} \mathrm{H}$ NMR Spectrum of Compound 8 in $\mathrm{MeOH}-d_{4}(600 \mathrm{MHz})$ 
20180108 c-zjf-24.1.fid — Bruker AVIII HD 60020180108 — C13 CD3OD D:II DATA2018 47

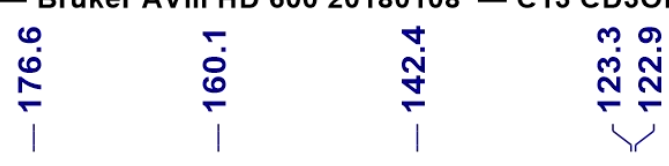

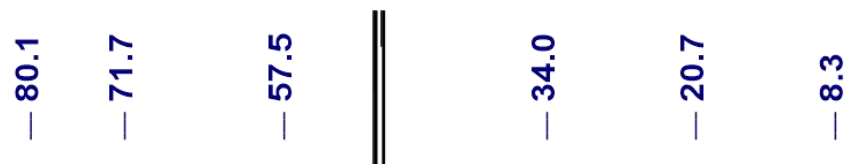

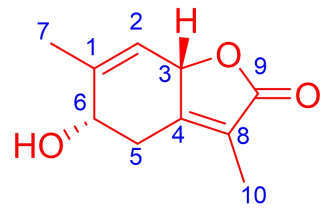

$200 \quad 190 \quad 180$
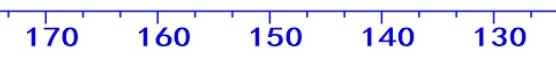

Figure S66. The ${ }^{13} \mathrm{C}$ NMR Spectrum of Compound 8 in $\mathrm{MeOH}-d_{4}(150 \mathrm{MHz})$ 


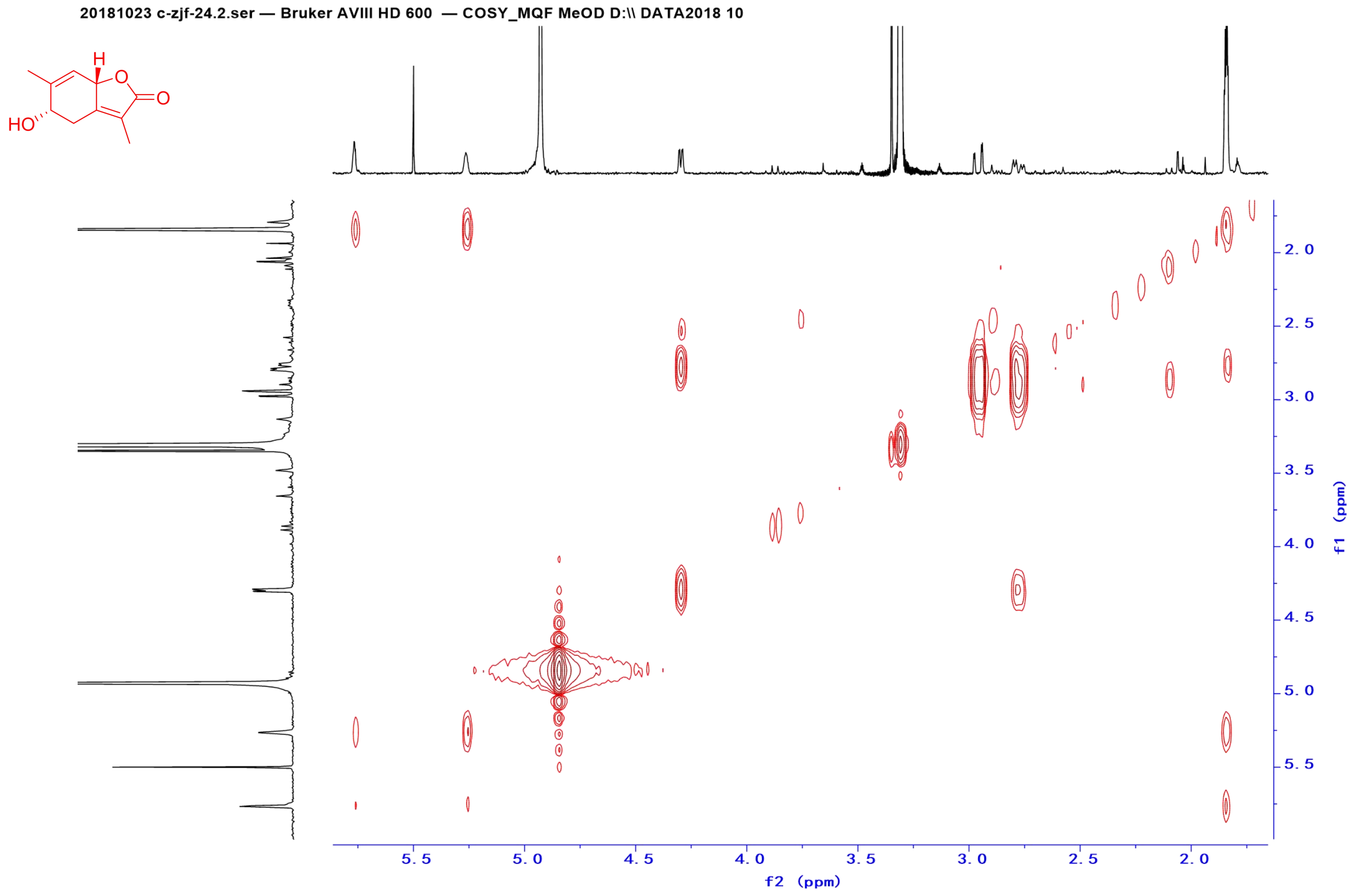

Figure S67. The ${ }^{1} \mathrm{H}-{ }^{1} \mathrm{H}$ COSY Spectrum of Compound 8 in $\mathrm{MeOH}-d_{4}(600 \mathrm{MHz})$ 


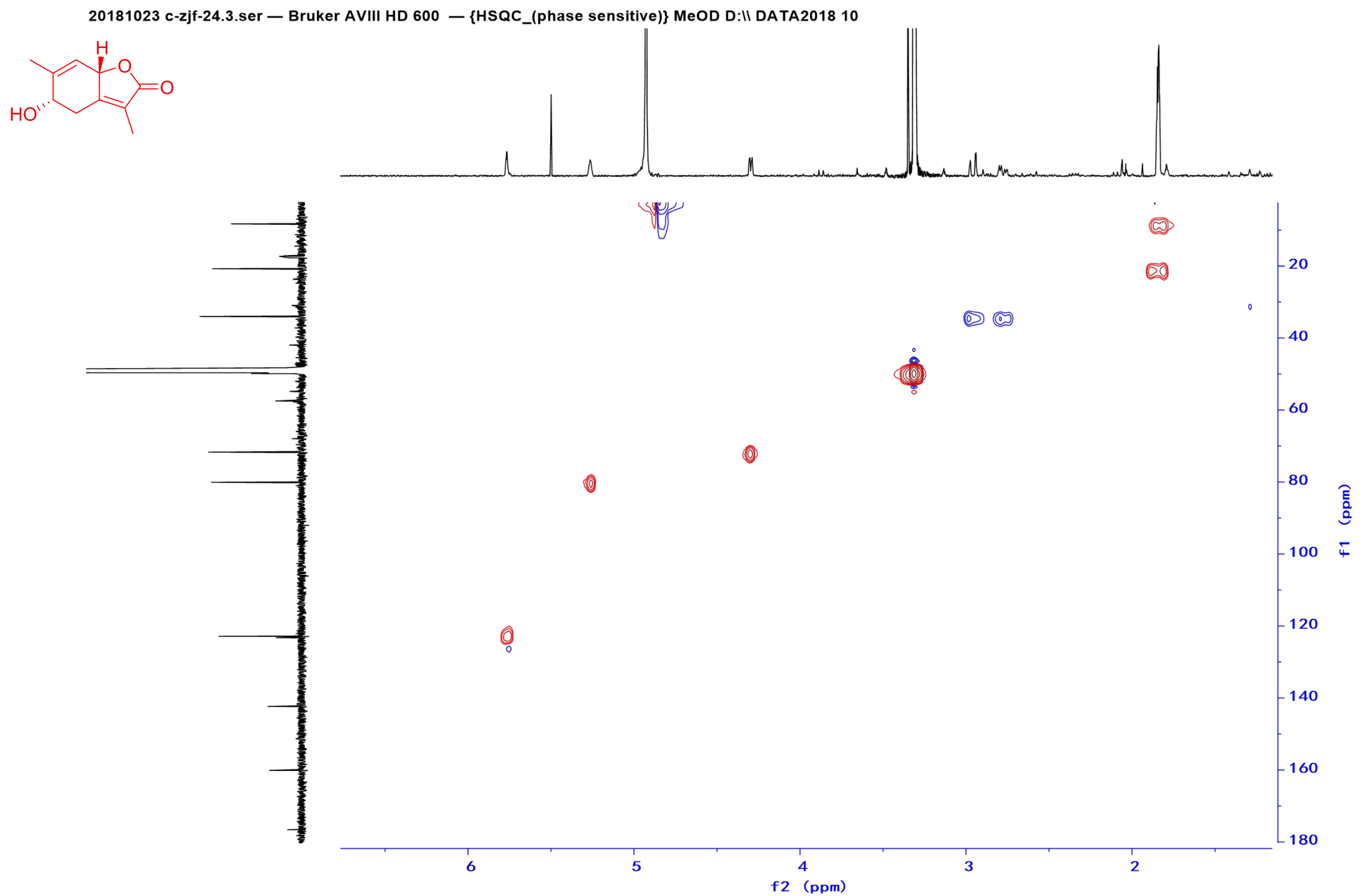

Figure S68. The HSQC Spectrum of Compound 8 in MeOH- $d_{4}(600 \mathrm{MHz})$ 


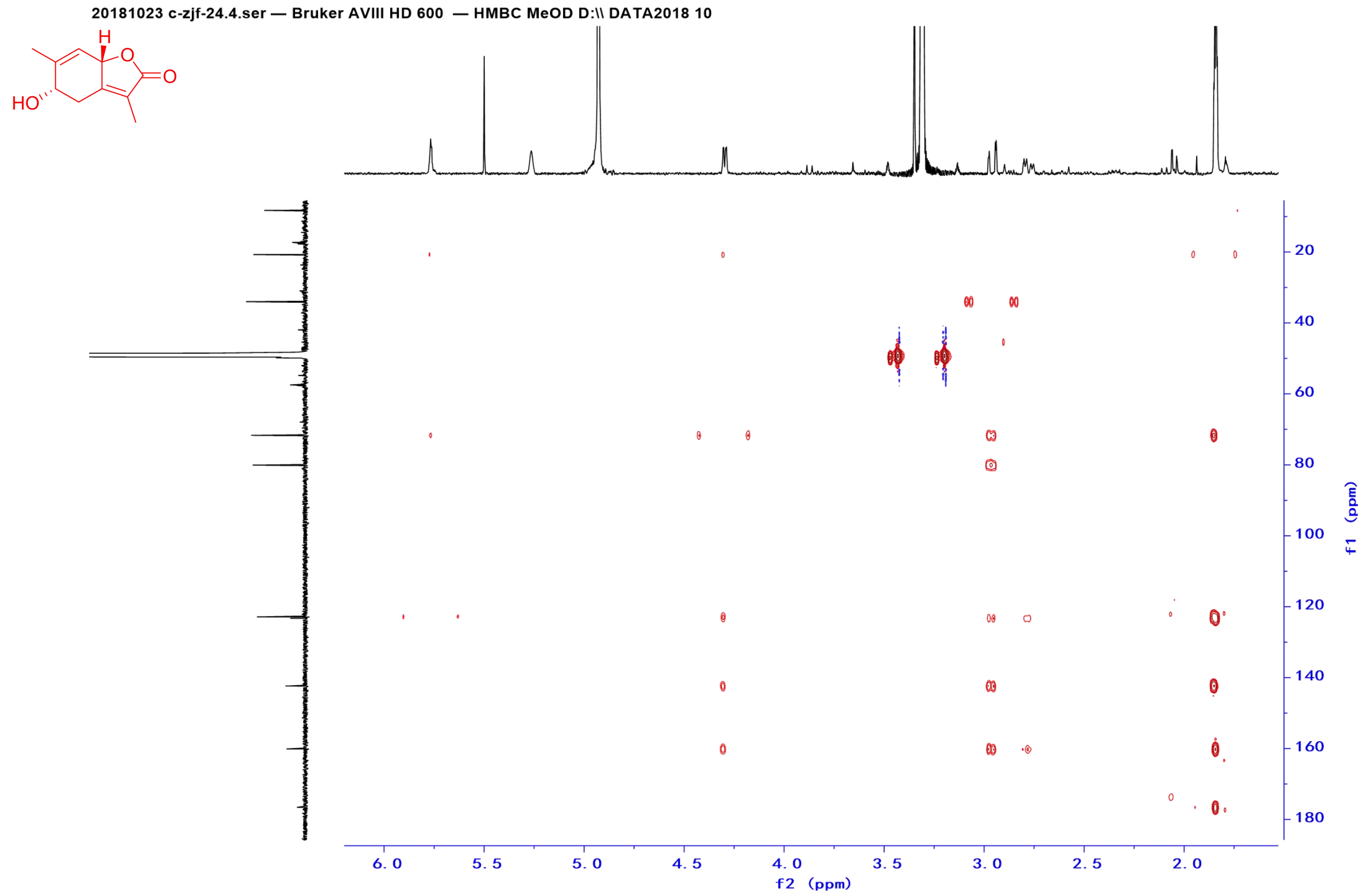

Figure S69. The HMBC Spectrum of Compound 8 in $\mathrm{MeOH}-d_{4}(600 \mathrm{MHz})$ 
20181213 C-ZJF-24.2.ser - Bruker AVIII HD 600 - NOESY_2D MeOD D:II DATA2018 28
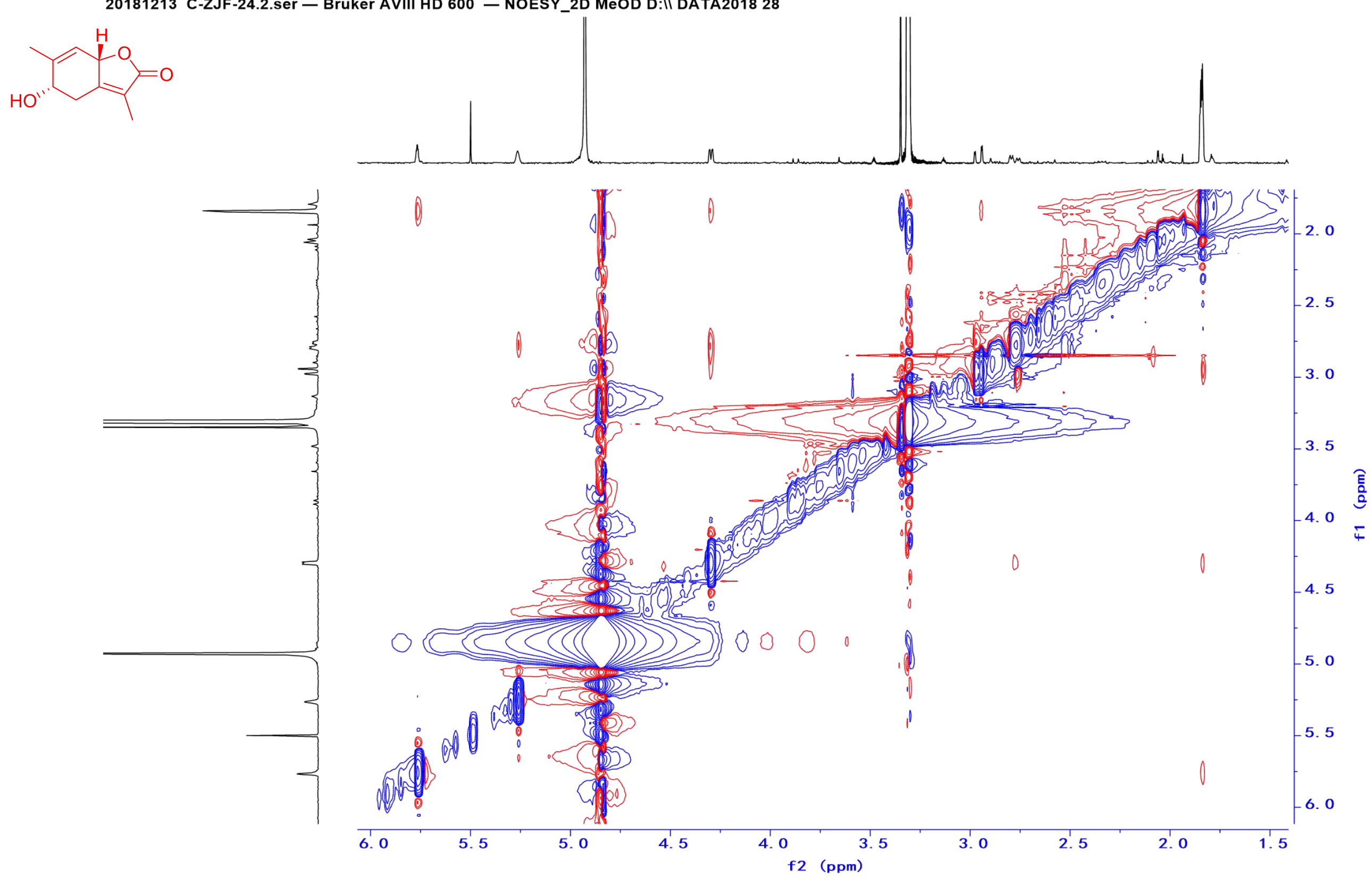

Figure S70. The NOESY Spectrum of Compound 8 in $\mathrm{MeOH}_{-} d_{4}(600 \mathrm{MHz})$ 


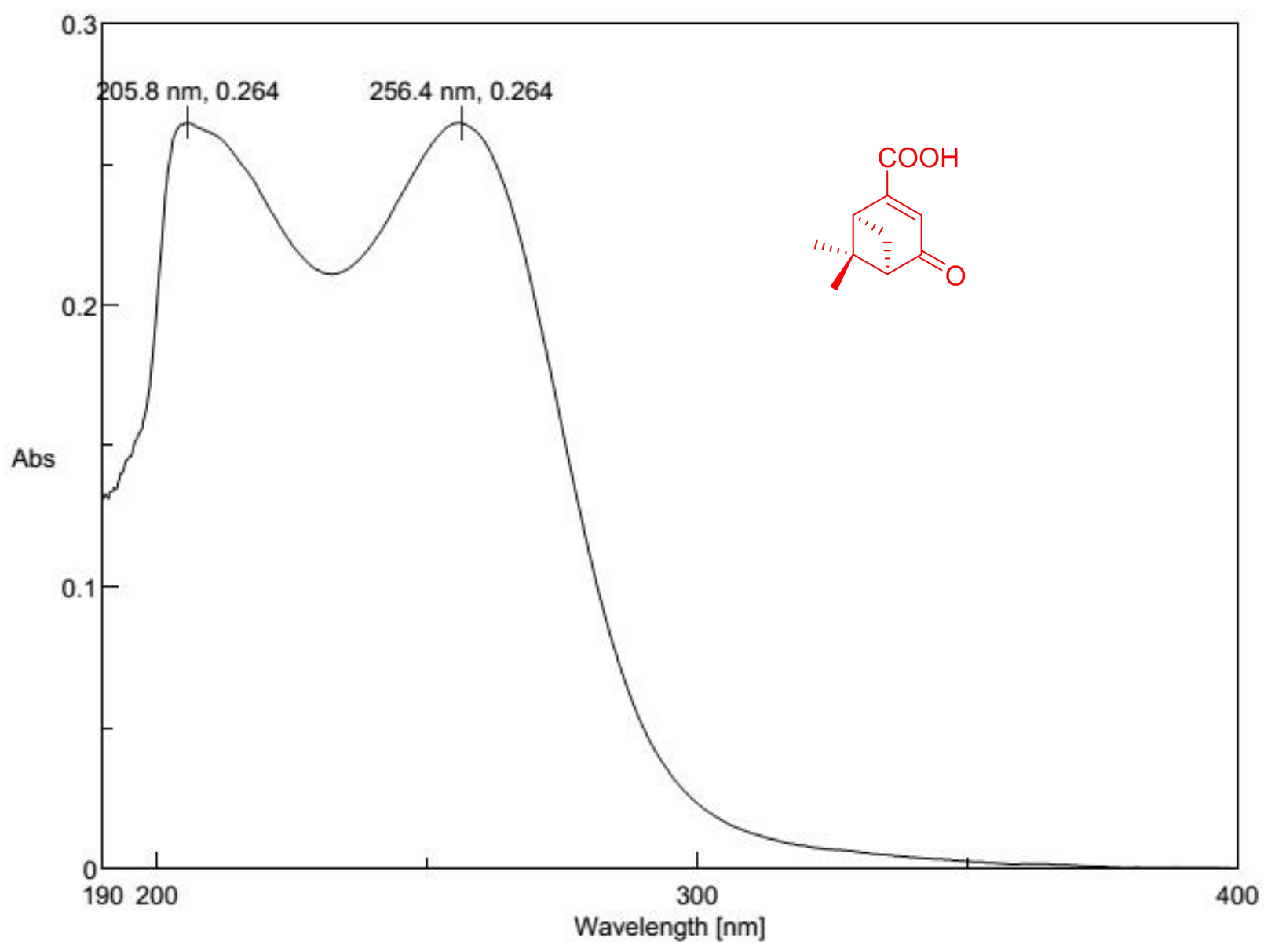

Figure S71. The UV Spectrum of Compound 9 in $\mathrm{MeOH}$

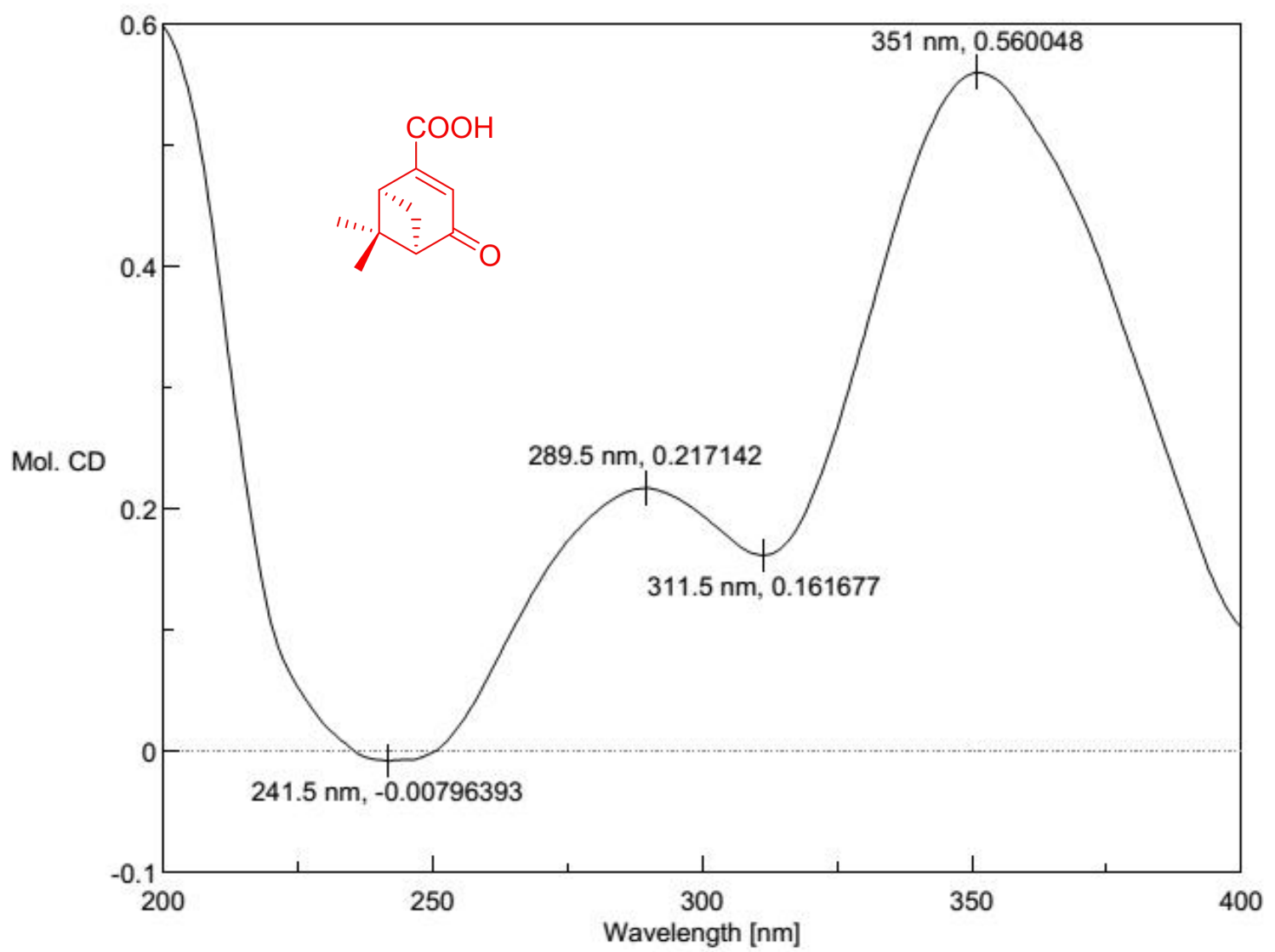

Figure S72. The CD Spectrum of Compound 9 in $\mathrm{MeOH}$ 
compound NO. : $2 \mathrm{WC2}$

Method :

LCMS(compound)-low

RT: $0.00-15.02$ SM: $7 G$

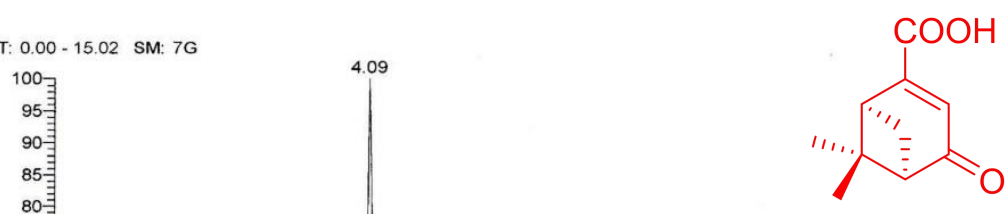

$\mathrm{NL}: 1.78 \mathrm{E} 8$

$\mathrm{m} / \mathrm{z}=$
179.07043

FTMS - P ESI Ful

[100.0000-

2WC2

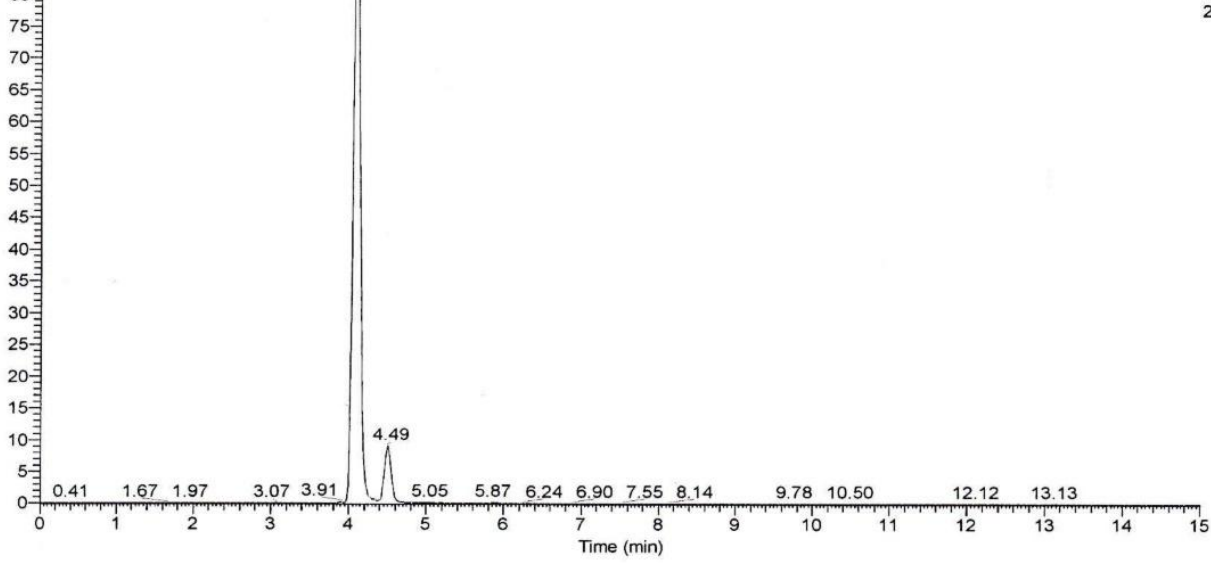

$2 W C 2 \# 406$ RT: 4.07 AV: 1 NL: $2.00 E 8$

2WC2 \#406 RT: 4.07 AV: $1 \quad$ NL: $2.00 E 8$
T: FTMS - p ESI Full ms [100.0000-1500.0000]

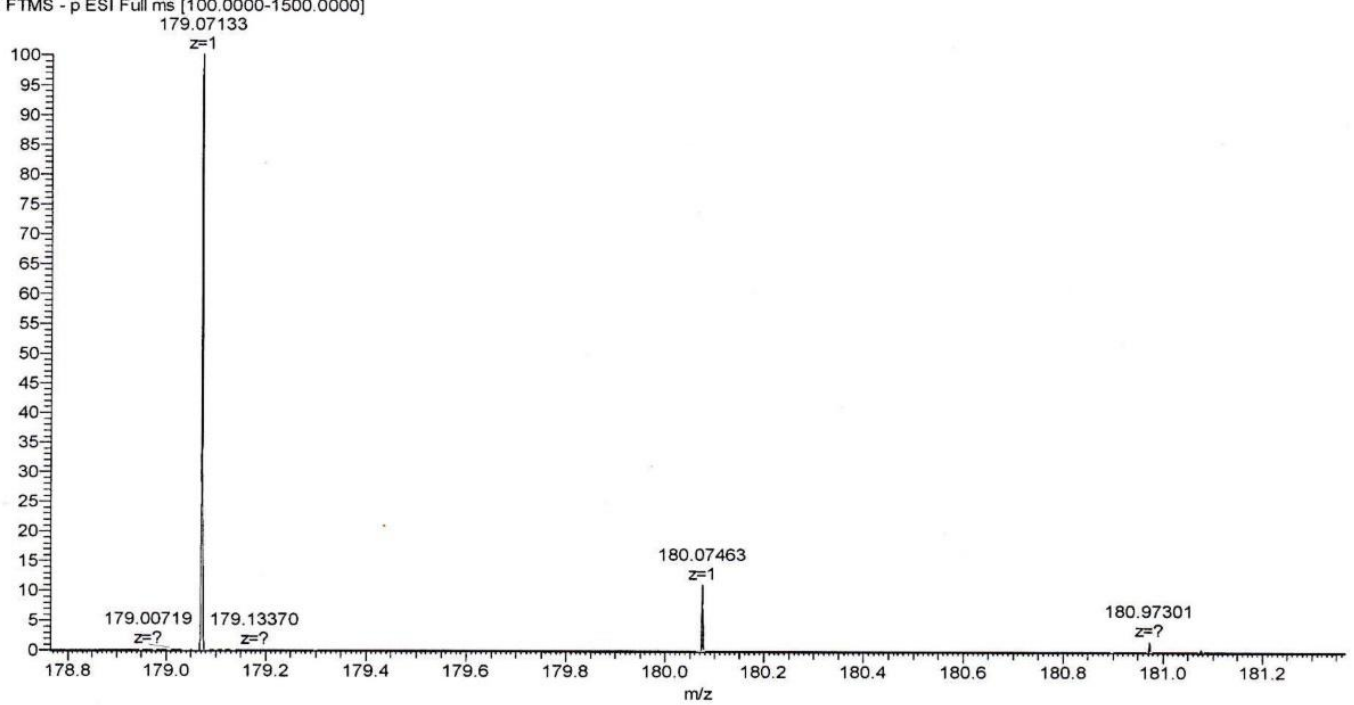

\begin{tabular}{|l|l|r|r|l|l|}
\hline $\mathrm{m} / \mathrm{z}$ & Theo. Mass & Delta (ppm) & RDB equiv. & Composition & \\
\hline & & & & & \\
\hline 179.07133 & 179.07137 & -0.21 & 5.5 & $\mathrm{C} 10 \mathrm{H} 11 \mathrm{O} 3$ & M-H \\
\hline
\end{tabular}

Figure S73. The HR-mass Spectrum of Compound 9 in $\mathrm{MeOH}$ 


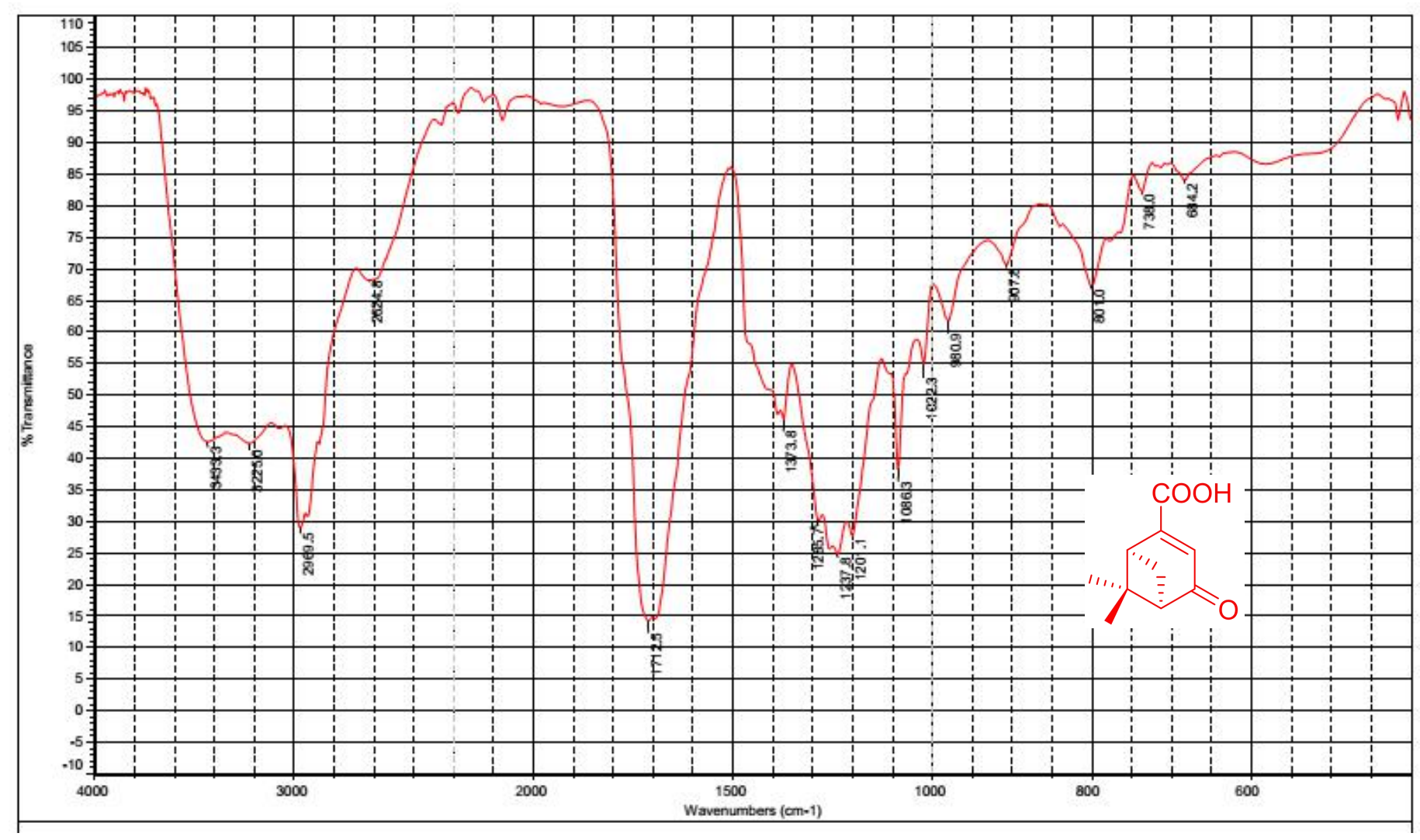

Figure S74. The IR Spectrum of Compound 9 
20180906 D3-1-1-4-1.1.fid — Bruker AVIII HD 600 — PROTON CD3OD D:II DATA2018 16

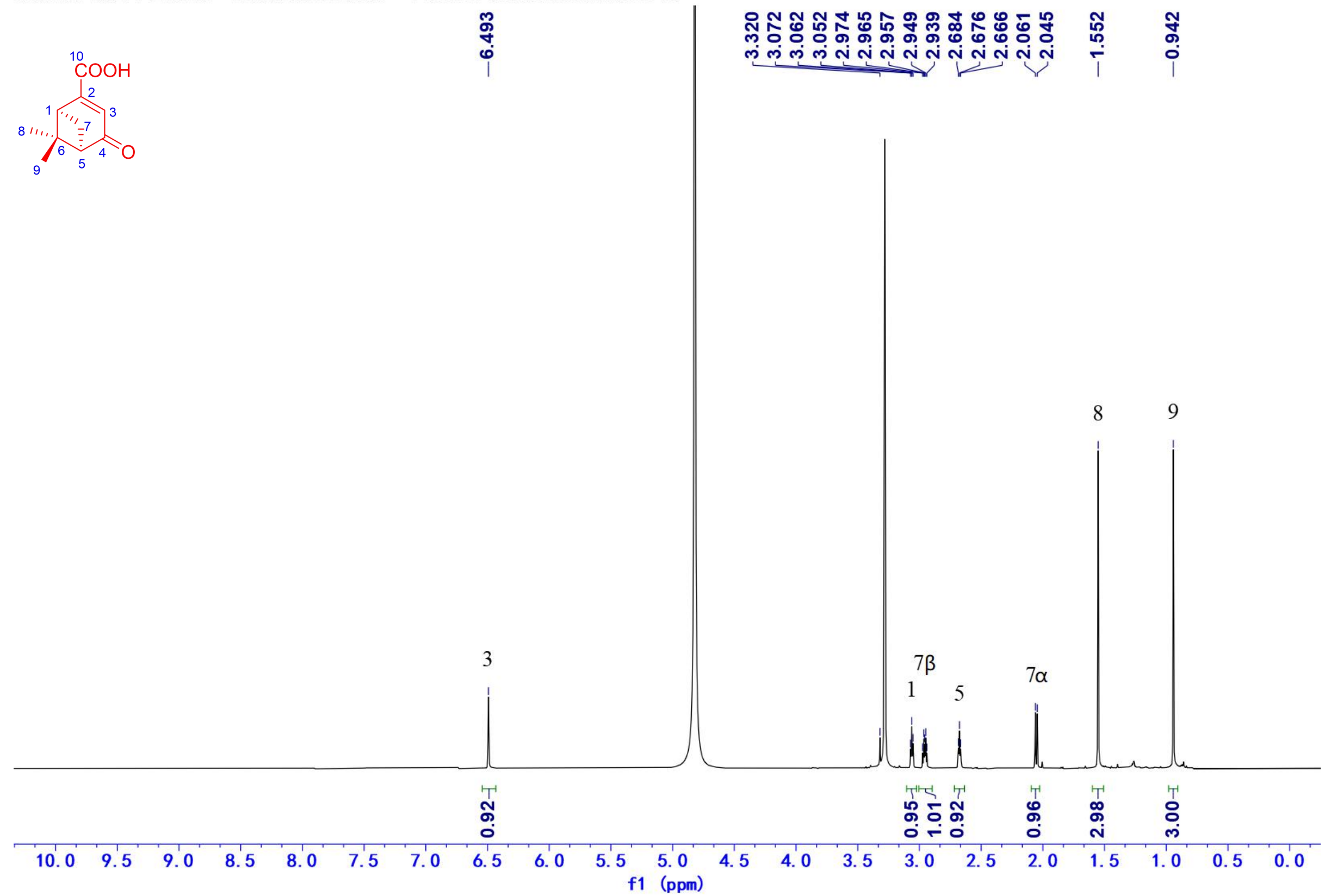

Figure S75. The ${ }^{1} \mathrm{H}$ NMR Spectrum of Compound 9 in $\mathrm{MeOH}-d_{4}(600 \mathrm{MHz})$ 
20180925 D3-1-1-4-1.1.fid - Bruker AVIII HD 600 - C13 CD3OD D:II DATA2018 26

in

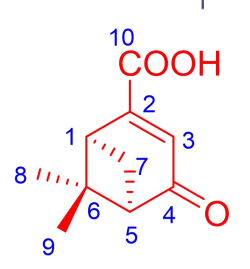

స్

0 ก

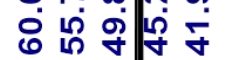

$\infty$ m

ก ก

| I

3

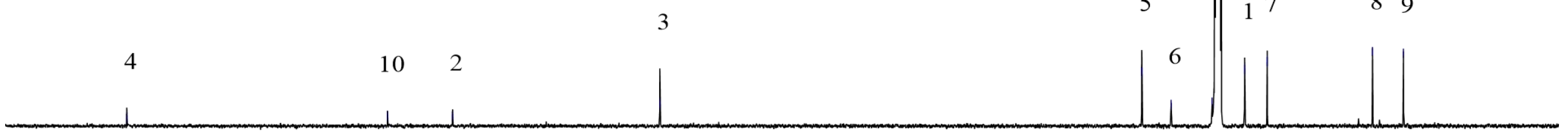

$220 \quad 210^{\prime} \quad 200 \quad 190 \quad 180$

Figure S76. The ${ }^{13} \mathrm{C}$ NMR Spectrum of Compound 9 in $\mathrm{MeOH}-d_{4}(150 \mathrm{MHz})$ 
20190426 D3-1-1-4-1.2.ser - Bruker AVIII HD 600 — COSY MQF CD3OD D:II DATA2019 27
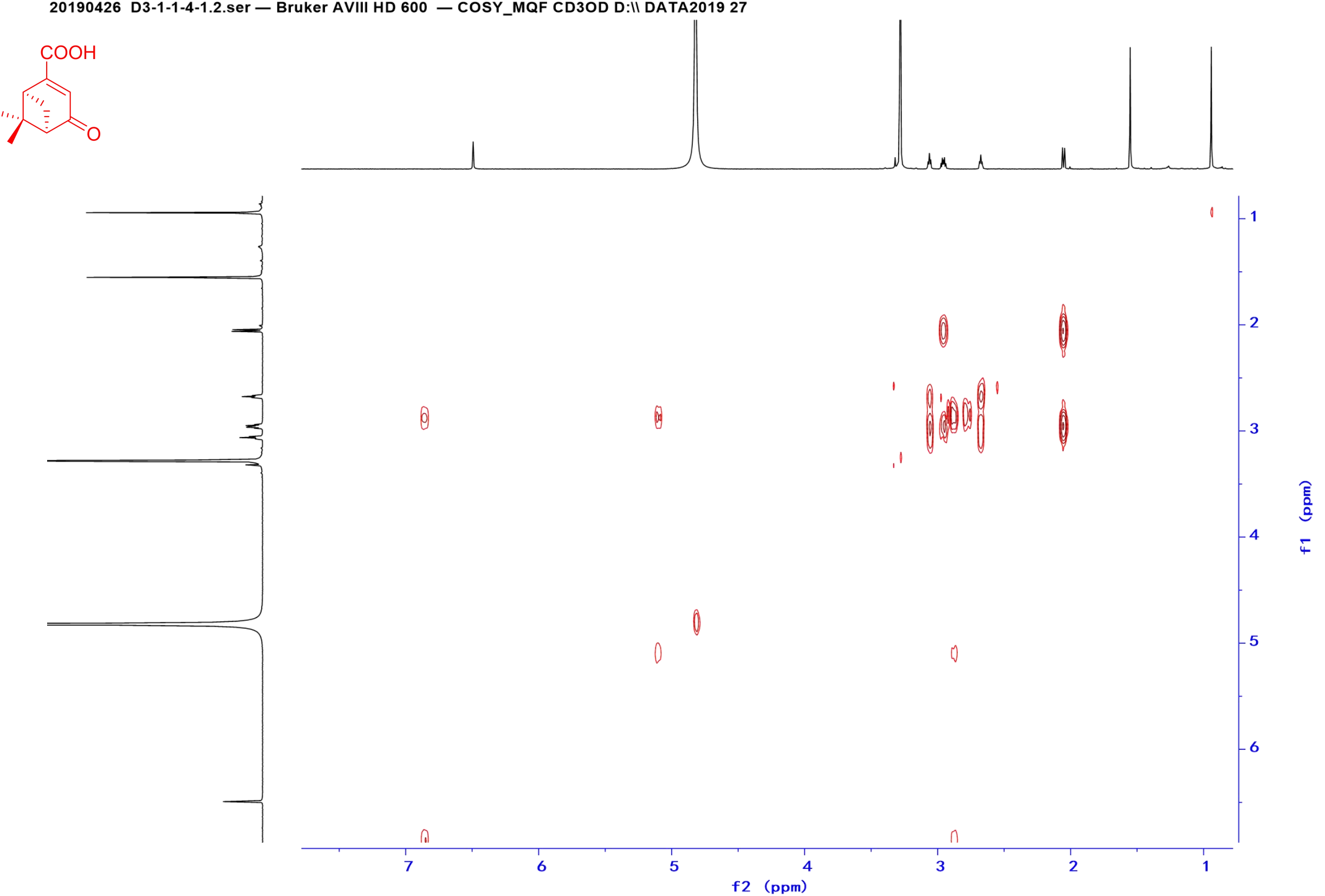

Figure S77. The ${ }^{1} \mathrm{H}-{ }^{1} \mathrm{H}$ COSY Spectrum of Compound 9 in $\mathrm{MeOH}_{-} d_{4}(600 \mathrm{MHz})$ 
20190426 D3-1-1-4-1.3.ser — Bruker AVIII HD 600 — \{HSQC_(phase sensitive)\} CD3OD D:II DATA2019 27<smiles>O=C(O)C1CC2CCC(C1)C2C(=O)O</smiles>
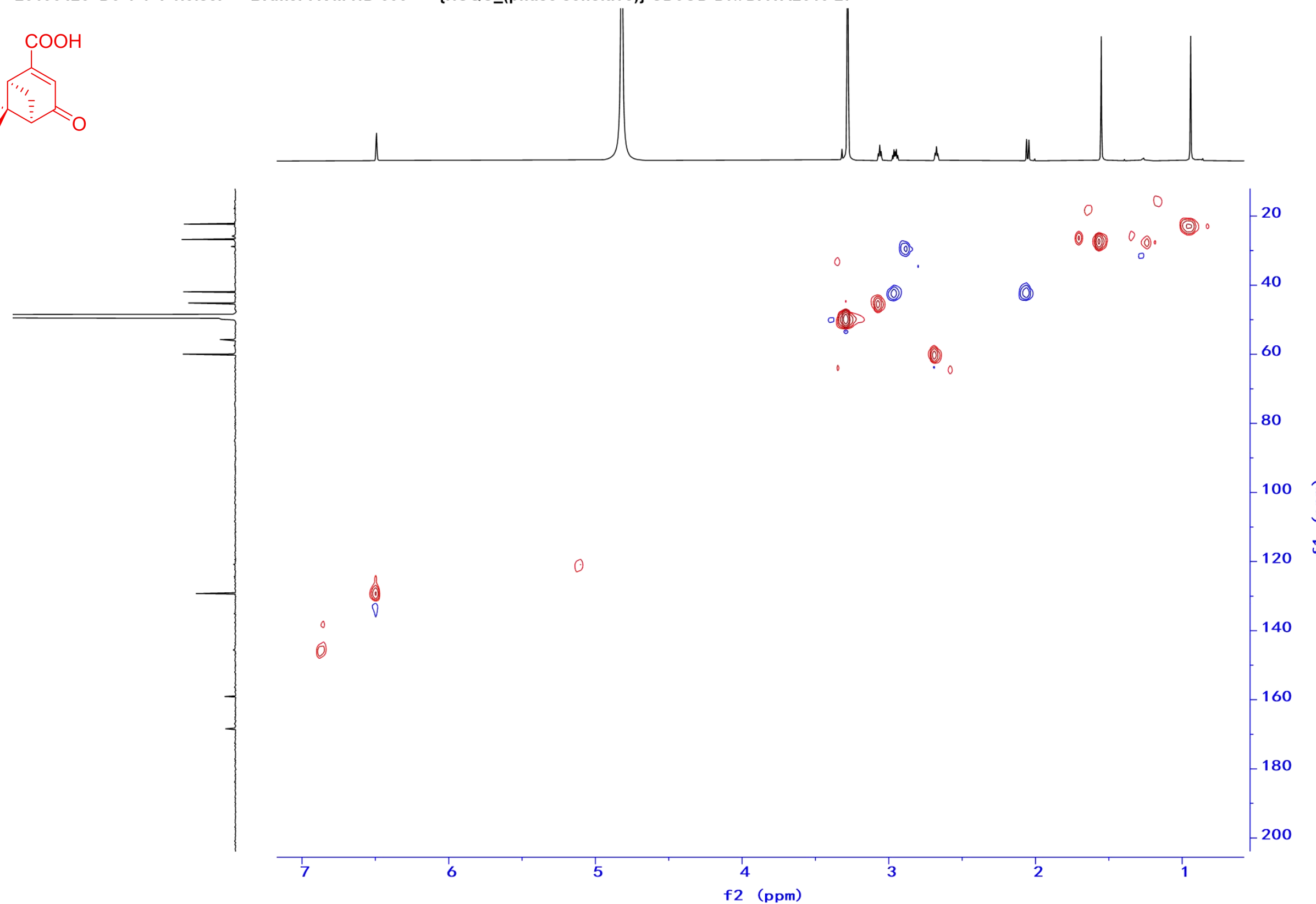

Figure S78. The HSQC Spectrum of Compound 9 in MeOH- $d_{4}(600 \mathrm{MHz})$ 
20190426 D3-1-1-4-1.4.ser - Bruker AVIII HD 600 — HMBC CD3OD D:II DATA2019 27
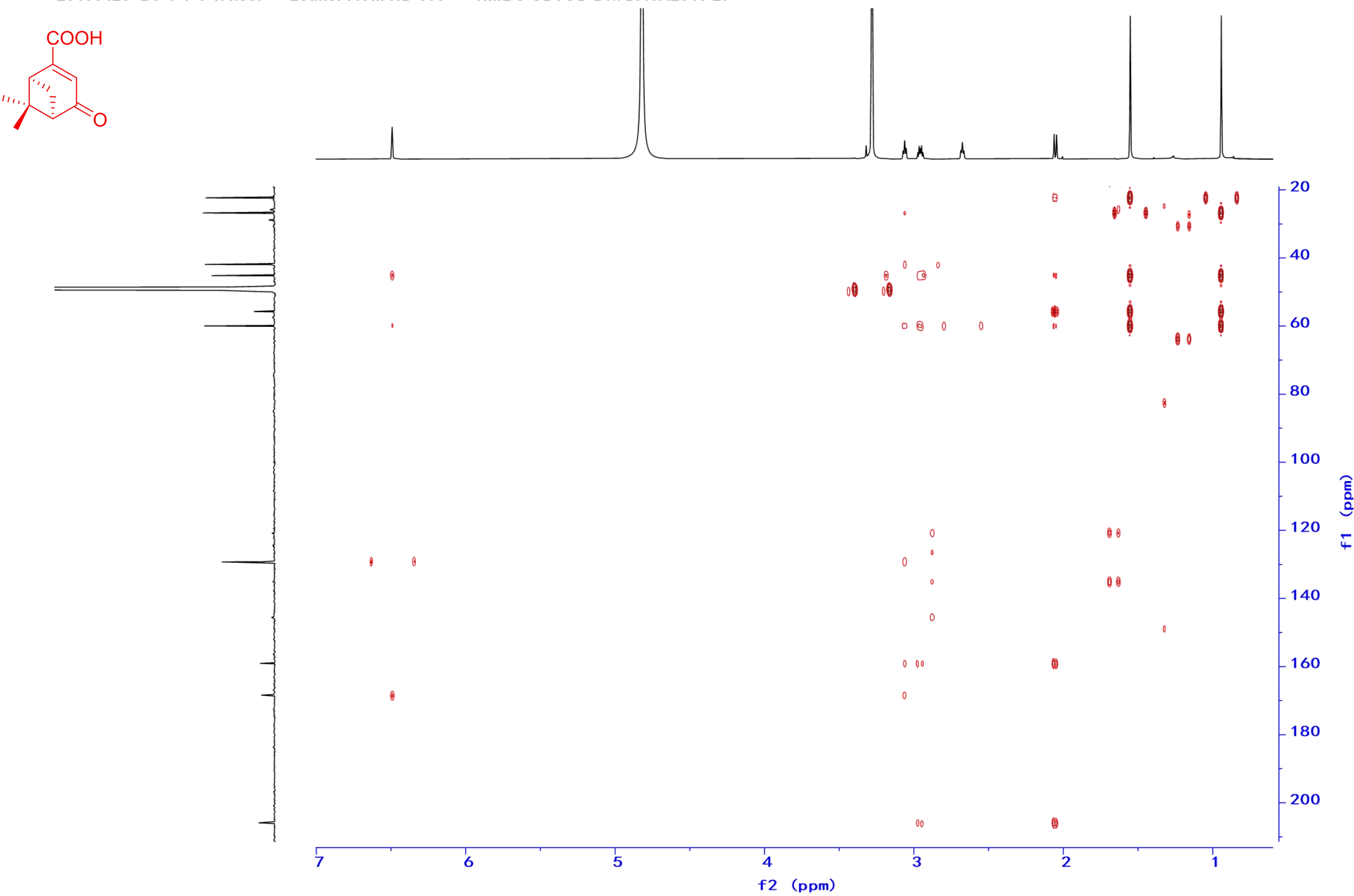

Figure S79. The HMBC Spectrum of Compound 9 in $\mathrm{MeOH}-d_{4}(600 \mathrm{MHz})$ 
20190426 D3-1-1-4-1.5.ser — Bruker AVIII HD 600 — ROESY CD3OD D:II DATA2019 27<smiles>CC1(C)CC(C(=O)O)C2C(=O)C=CC1C21CC1</smiles>
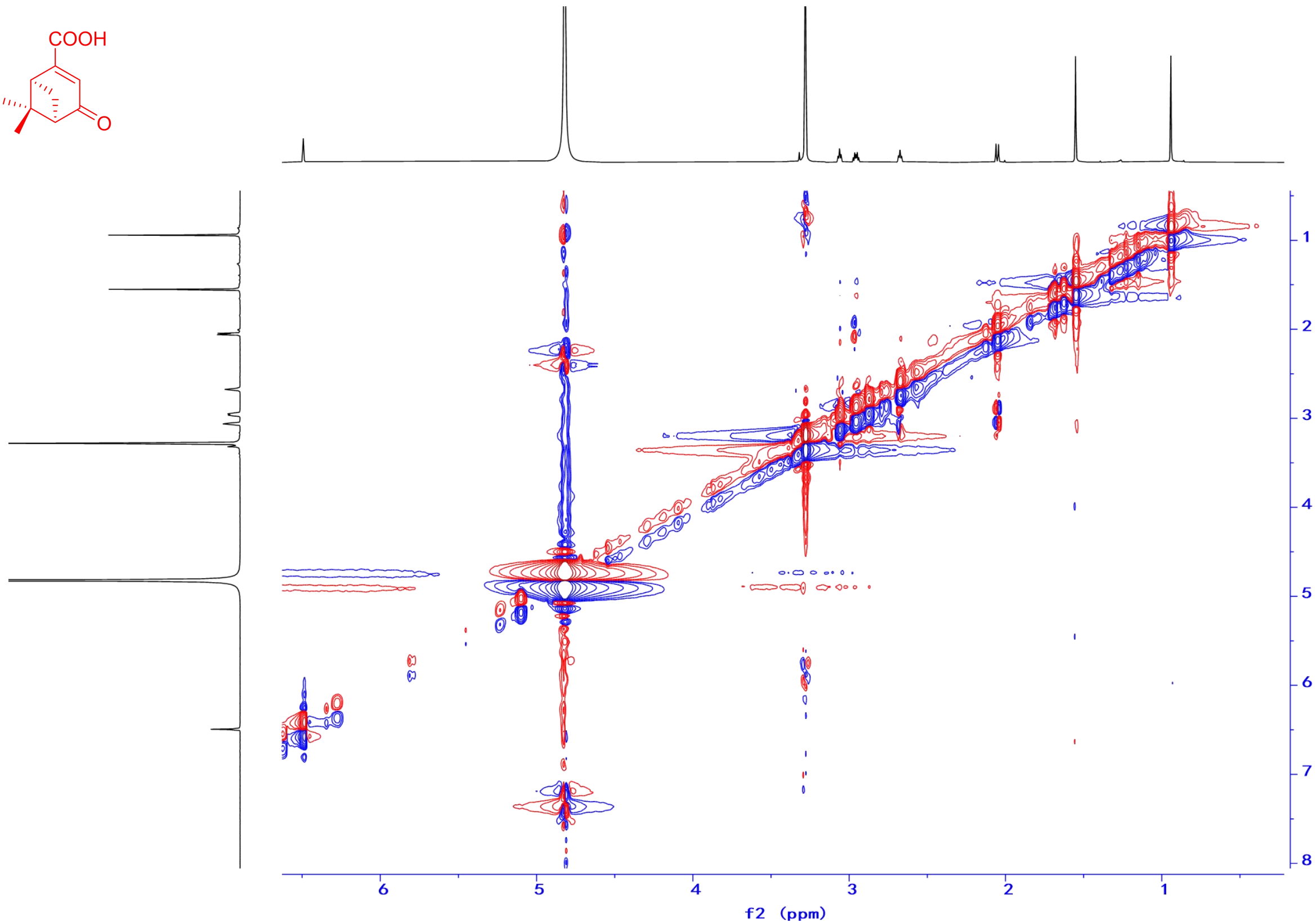

Figure S80. The NOESY Spectrum of Compound 9 in $\mathrm{MeOH}-d_{4}(600 \mathrm{MHz})$ 


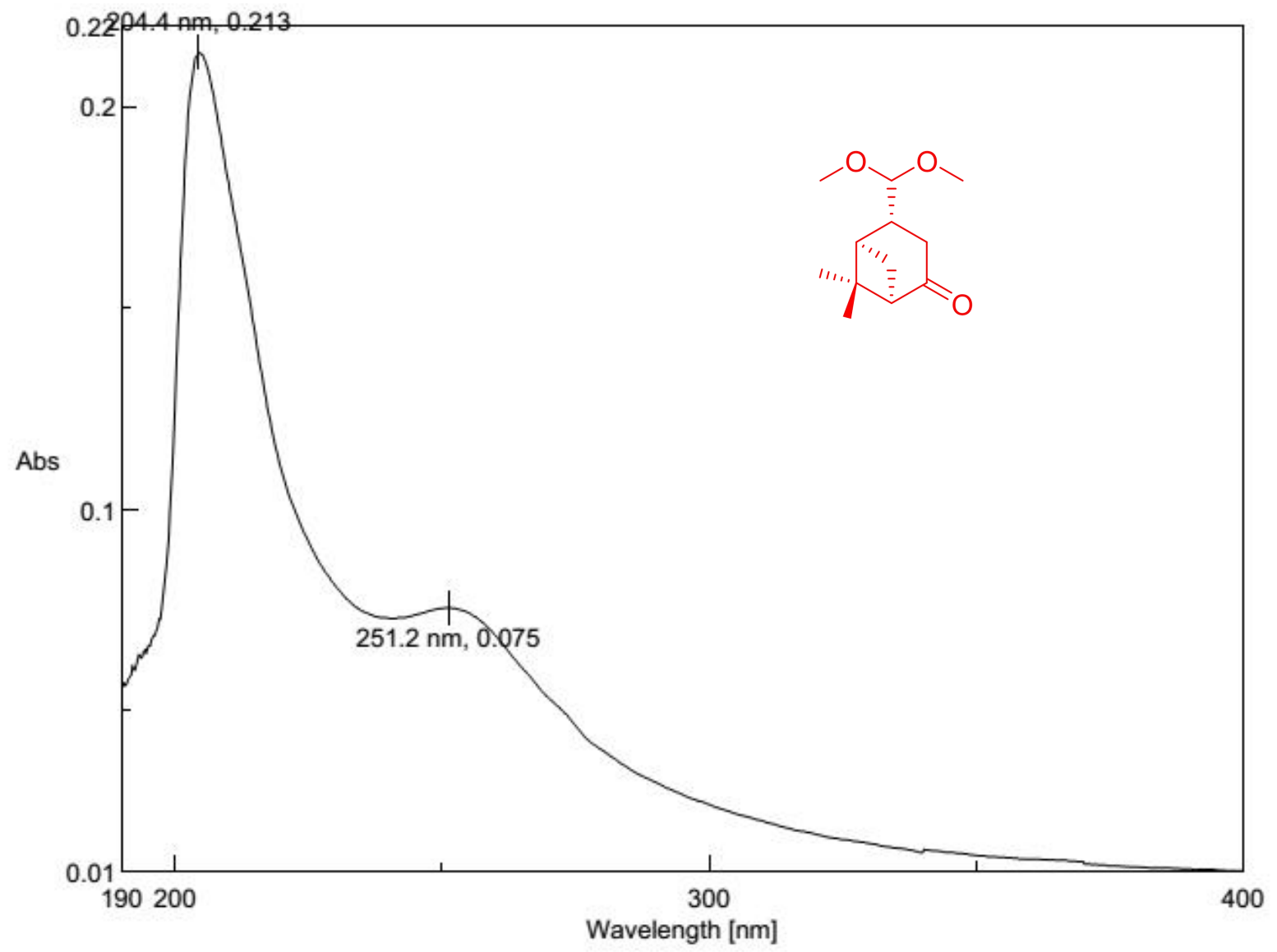

Figure S81. The UV Spectrum of Compound 10 in $\mathrm{MeOH}$

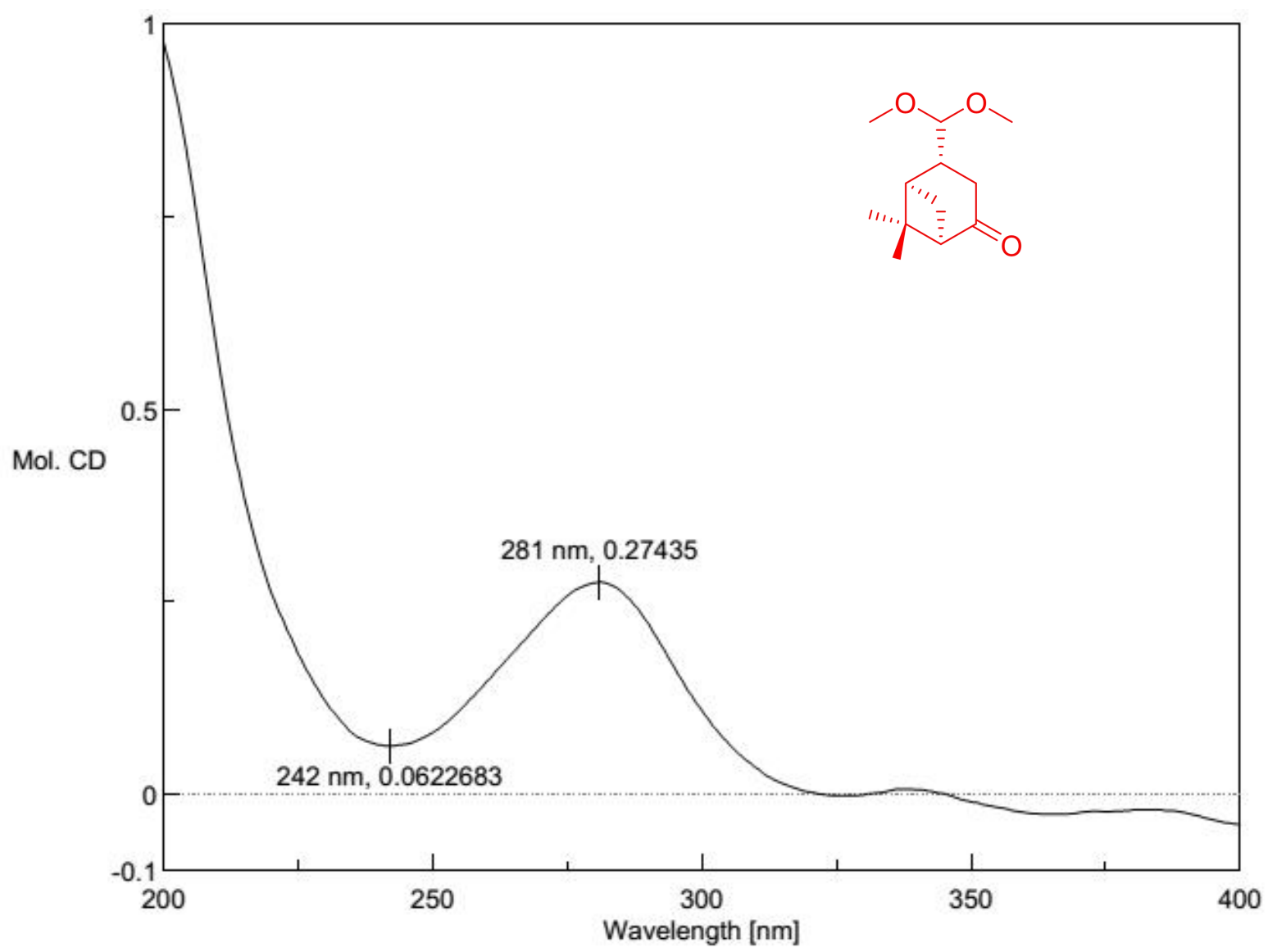

Figure S82. The CD spectrum of Compound 10 in $\mathrm{MeOH}$ 
compound NO. : 2WC1

Method :

LCMS(compound)-low

RT: $0.00-15.02$ SM: $7 G$

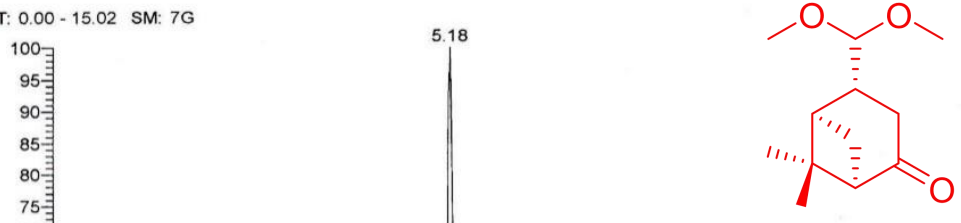

NL: $3.00 E 8$

235.12981-

FTMS + p ESI Fu

$\mathrm{ms}$

$1500.0000)$ MS

2WC1

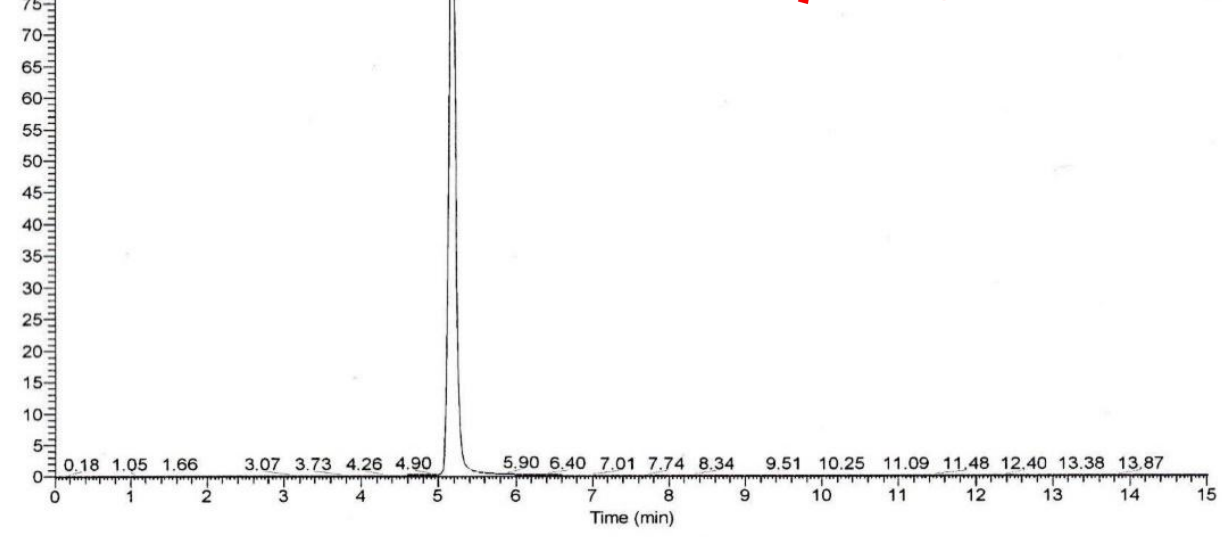

2WC1 \#517 RT: 5.18 AV: 1 NL: $3.68 E 8$

T: FTMS + p ESI Full ms [100.0000-1500.0000]

235.13033

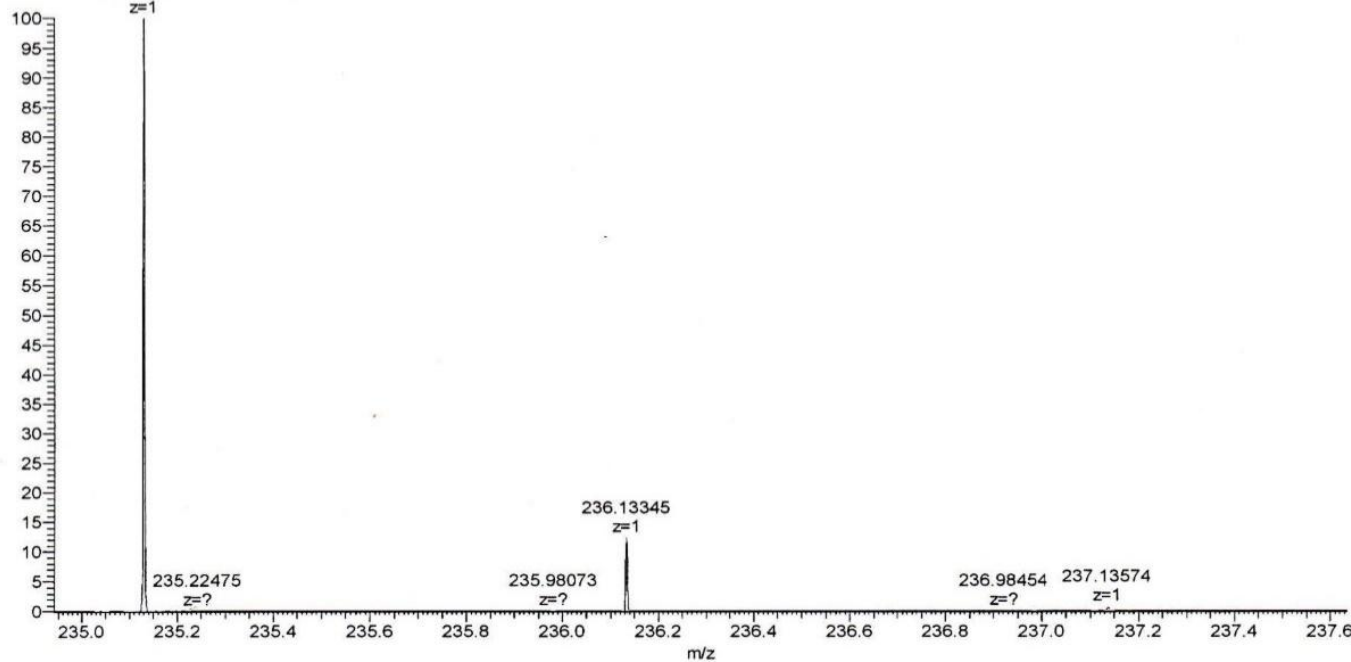

\begin{tabular}{|l|l|l|l|l|l|}
\hline $\mathrm{m} / \mathrm{z}$ & Theo. Mass & Delta (ppm) & RDB equiv. & Composition & \\
\hline & & & & & \\
\hline 235.13033 & 235.13047 & -0.58 & 2.5 & $\mathrm{C} 12 \mathrm{H} 20 \mathrm{O} 3 \mathrm{Na}$ & $\mathrm{M}+\mathrm{Na}$ \\
\hline
\end{tabular}

Figure S83. The HR-mass Spectrum of Compound 10 in $\mathrm{MeOH}$ 


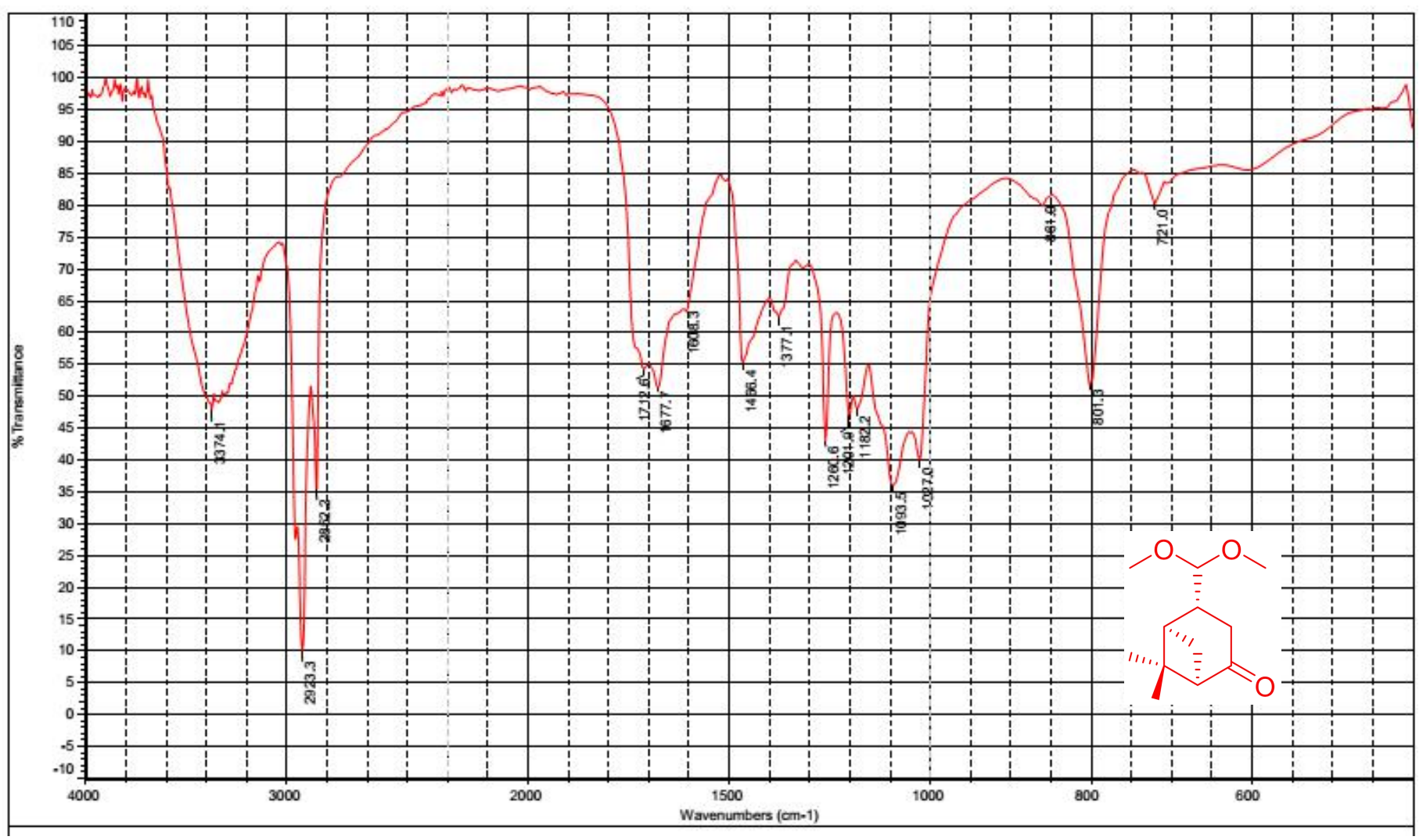

Figure S84. The IR Spectrum of Compound 10 


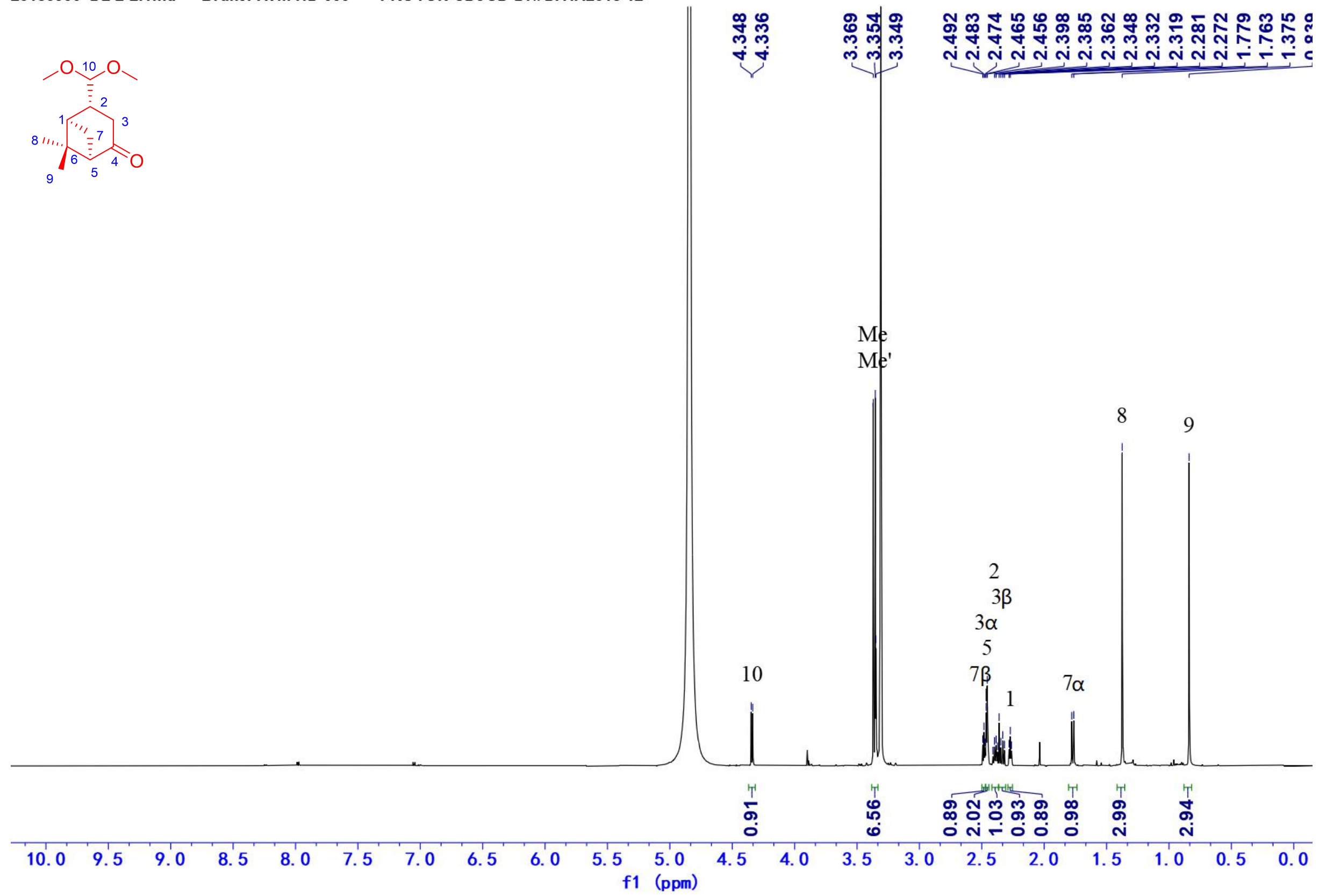

Figure S85. The ${ }^{1} \mathrm{H}$ NMR Spectrum of Compound 10 in $\mathrm{MeOH}_{-} d_{4}(600 \mathrm{MHz})$ 
20180925 D2-2-2.1.fid - Bruker AVIII HD 600 - C13 CD3OD D:II DATA2018 24 ஸे

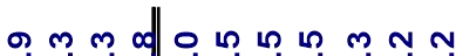

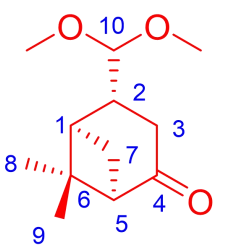

10
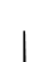

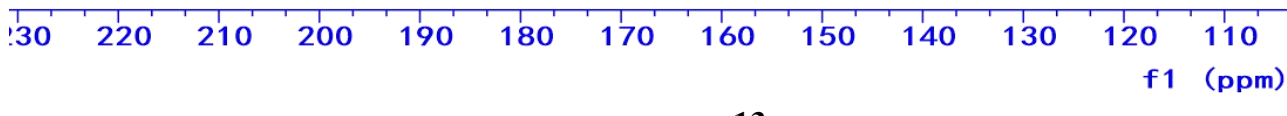

Figure S86. The ${ }^{13} \mathrm{C}$ NMR Spectrum of Compound 10 in $\mathrm{MeOH}-d_{4}(150 \mathrm{MHz})$ 
20190426 D2-2-2.2.ser — Bruker AVIII HD 600 — COSY_MQF CD3OD D:II DATA2019 28
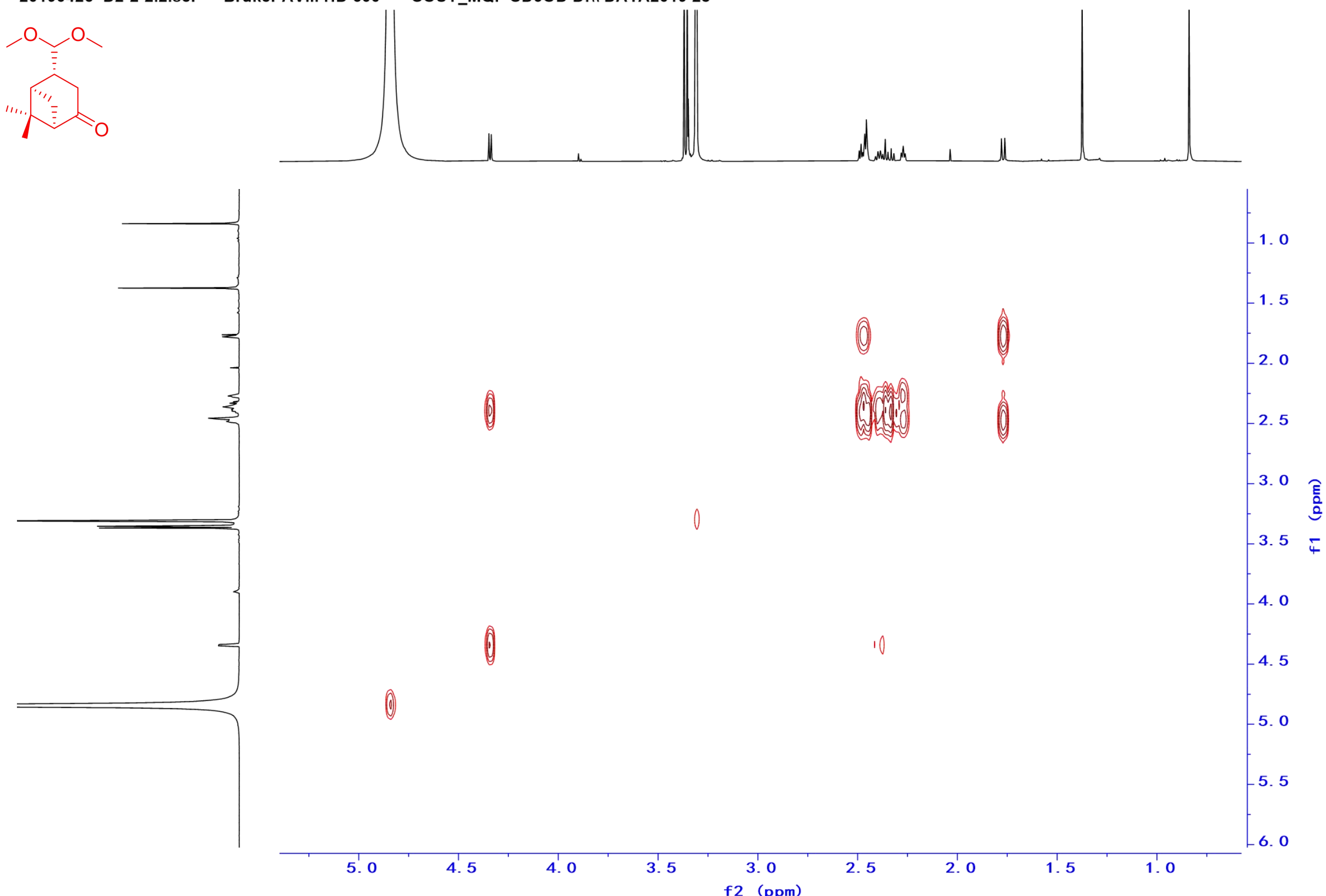

Figure S87. The ${ }^{1} \mathrm{H}-{ }^{1} \mathrm{H}$ COSY Spectrum of Compound 10 in $\mathrm{MeOH}-d_{4}(600 \mathrm{MHz})$ 


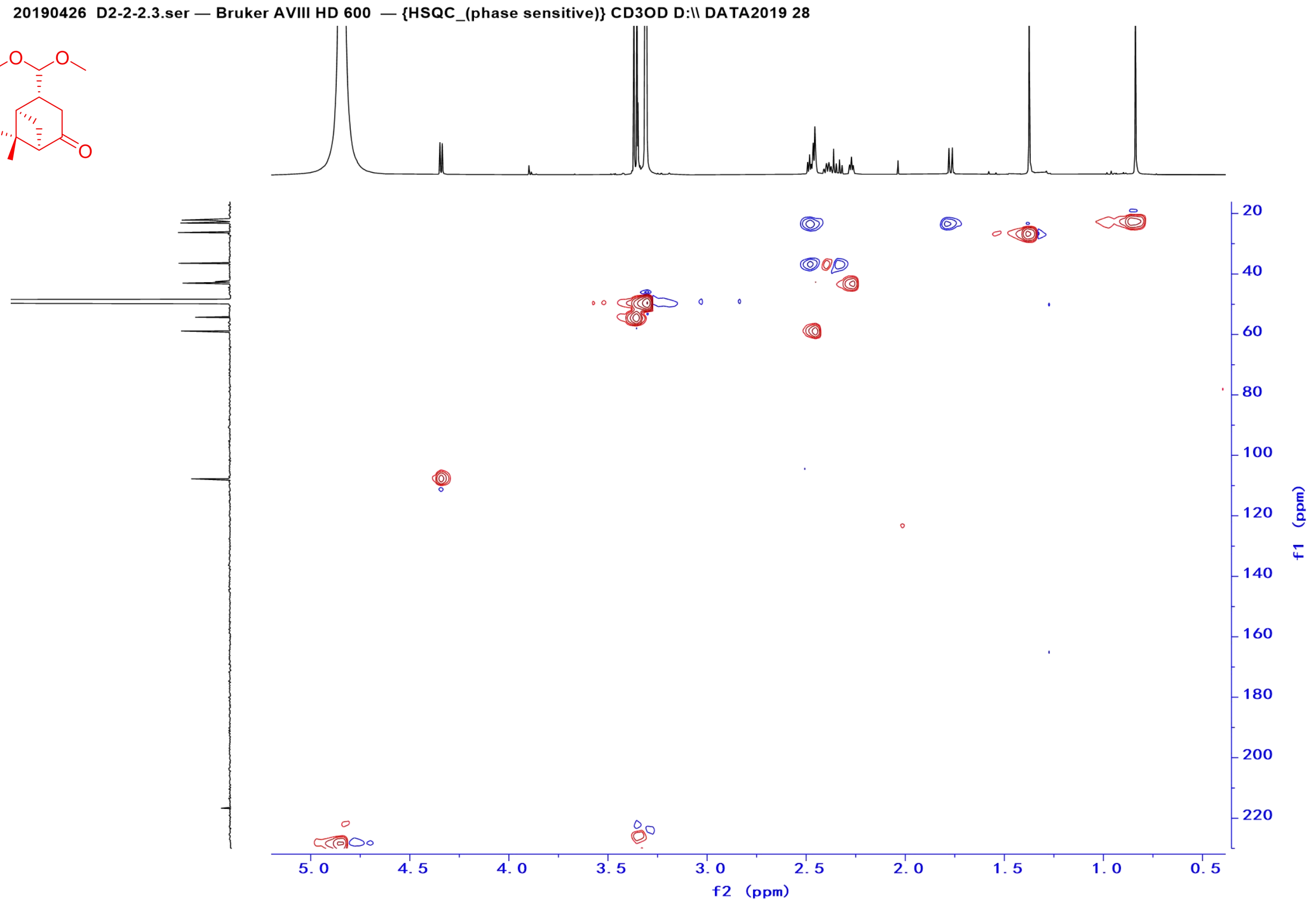

Figure S88. The HSQC Spectrum of Compound 10 in $\mathrm{MeOH}_{-} d_{4}(600 \mathrm{MHz})$ 
20190426 D2-2-2.4.ser - Bruker AVIII HD 600 - HMBC CD3OD D:II DATA2019 28
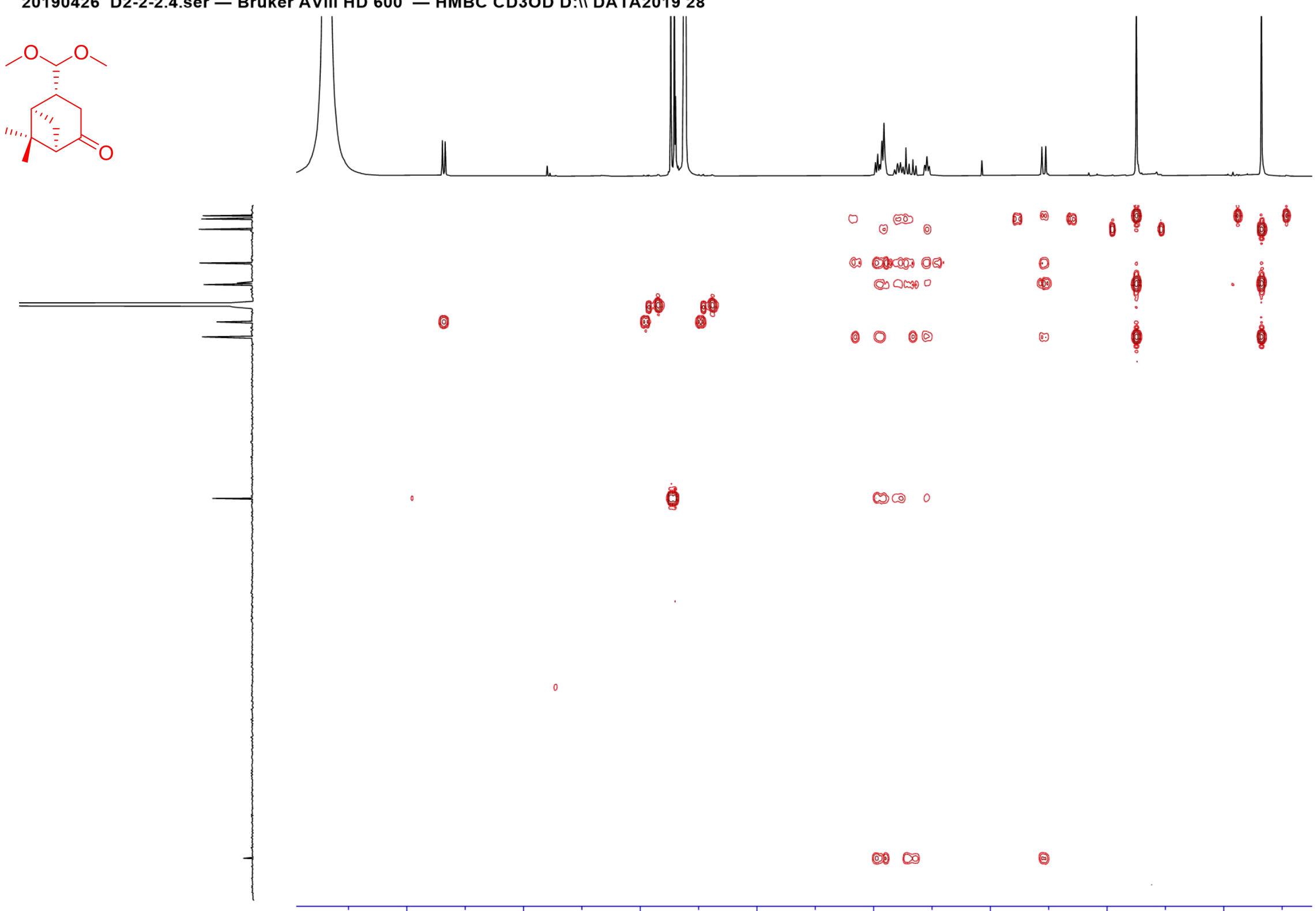

a.

(2) ๓

(1)

○๑@

(.)

?

20

웅

8

$\omega \infty$

$\infty$

둥

Figure S89. The HMBC Spectrum of Compound 10 in $\mathrm{MeOH}-d_{4}(600 \mathrm{MHz})$ 


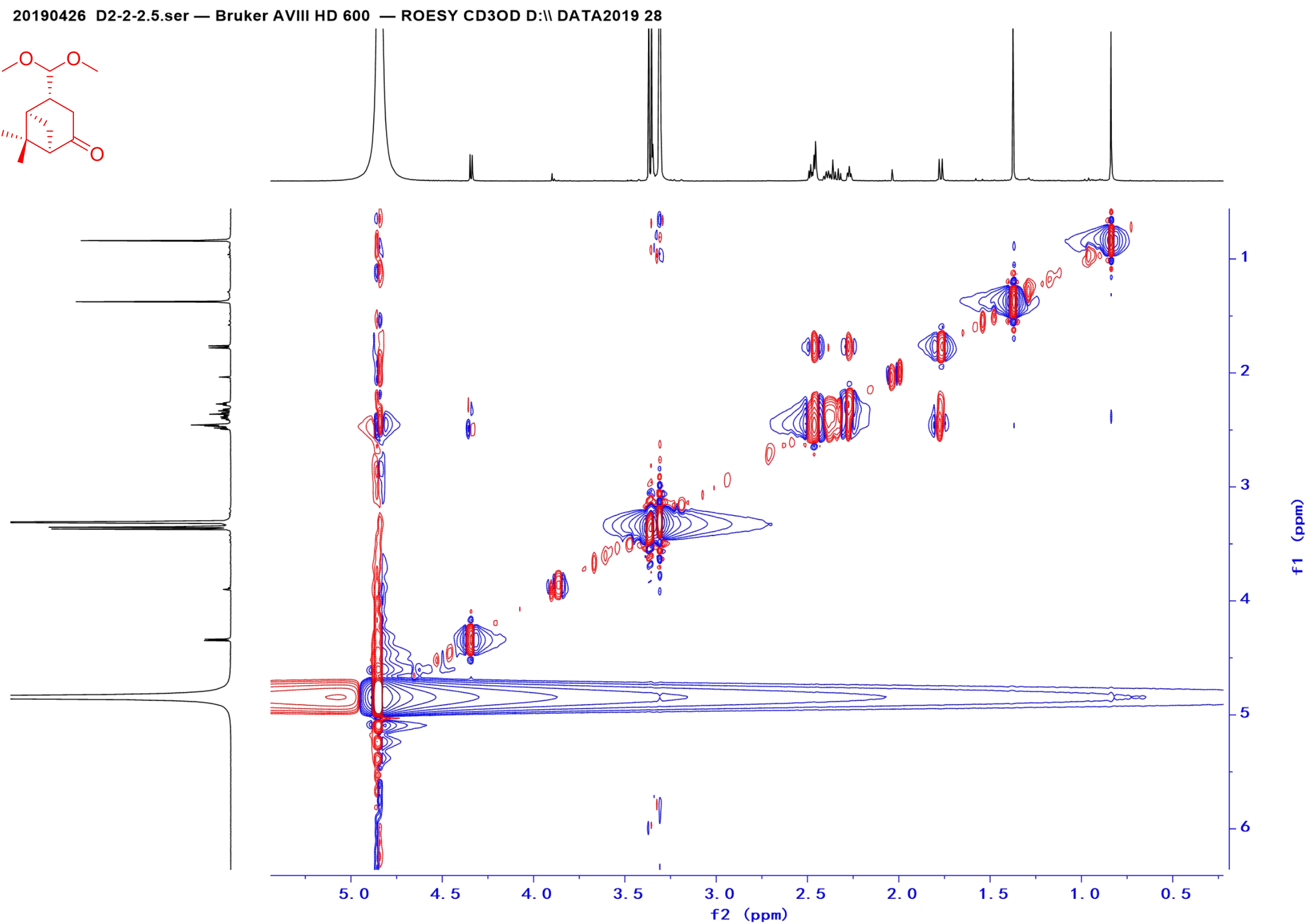

Figure S90. The NOESY Spectrum of Compound 10 in MeOH-d $(600 \mathrm{MHz})$ 


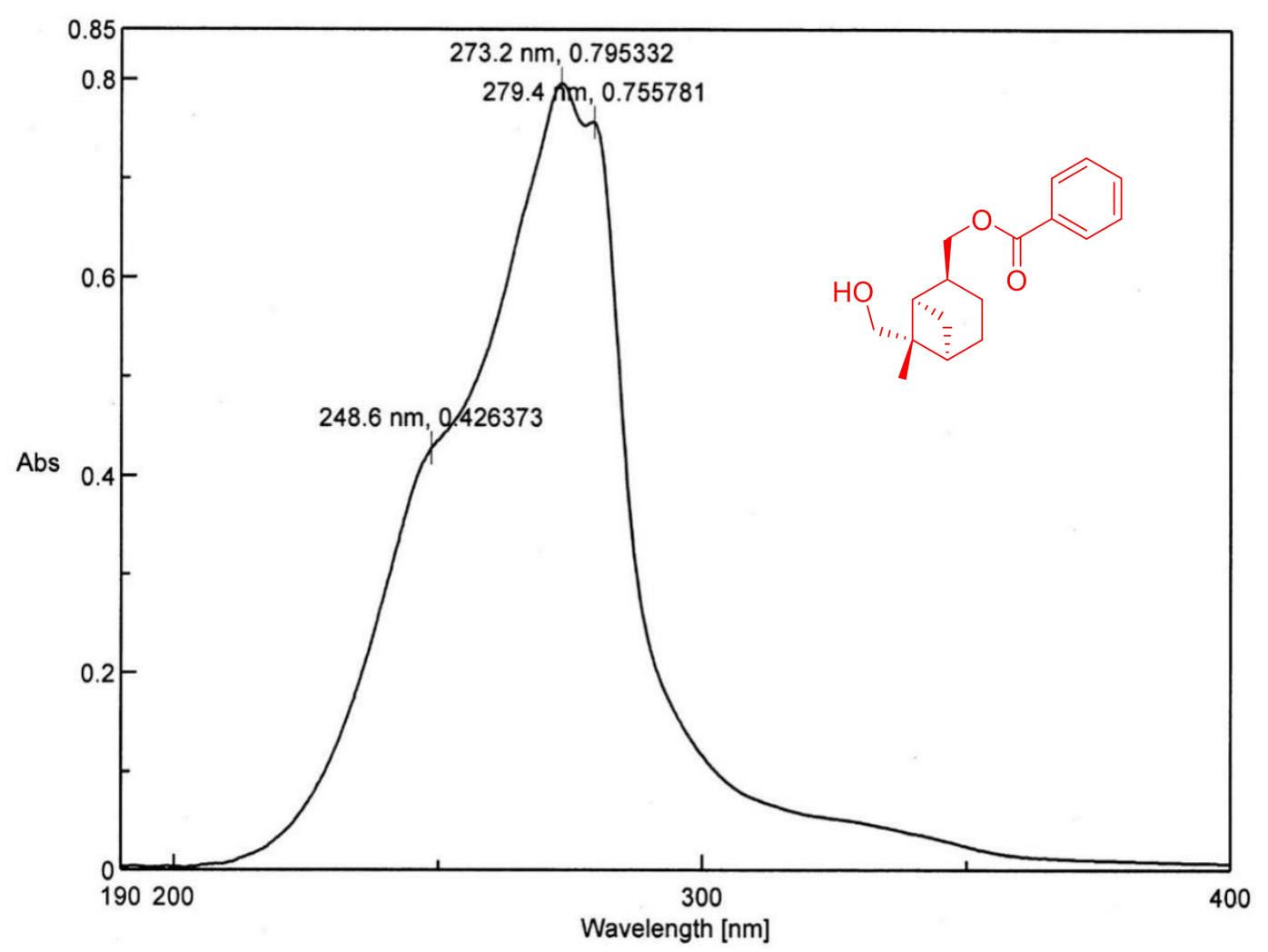

Figure S91. The UV Spectrum of Compound 11 in MeOH

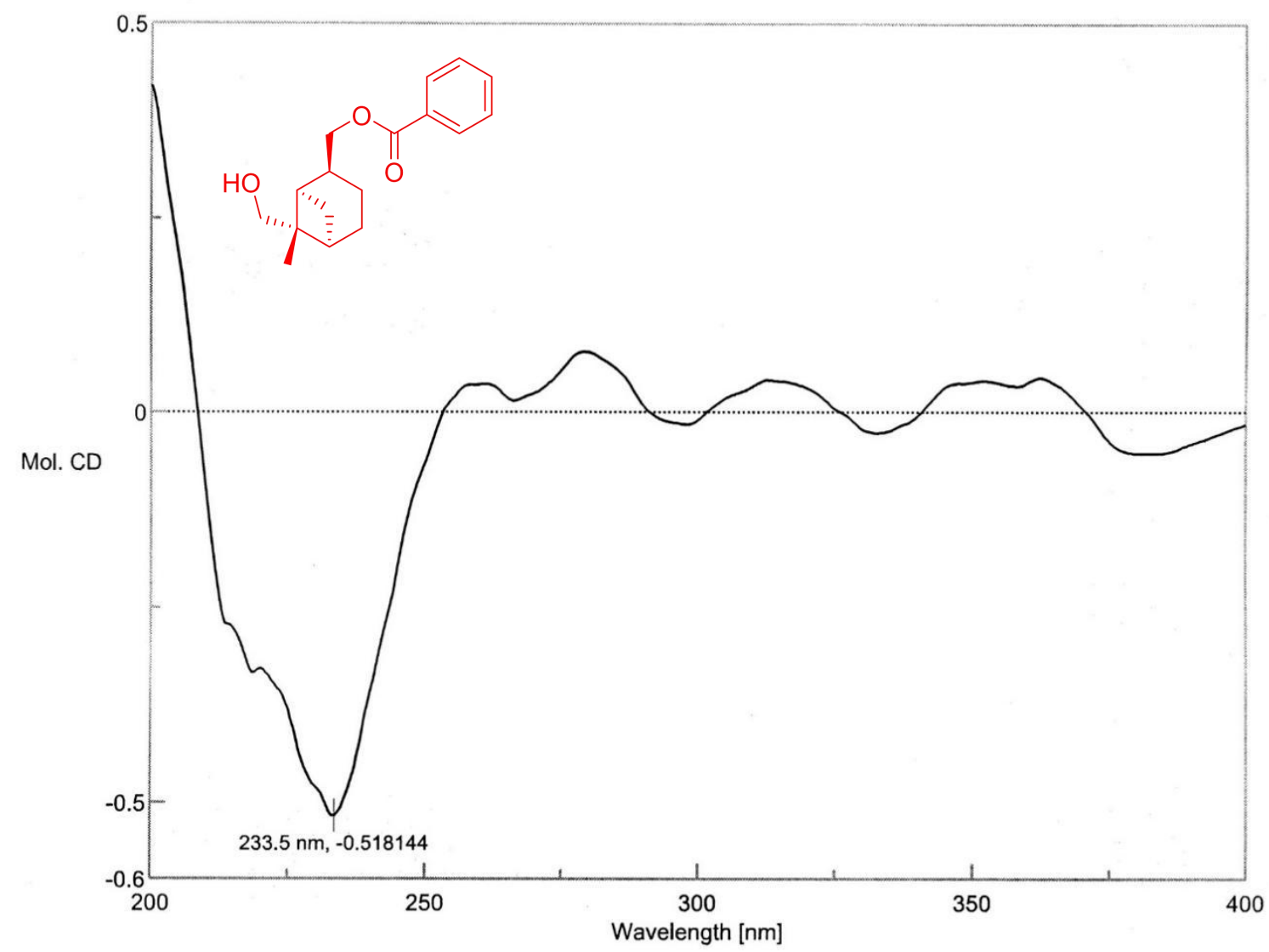

Figure S92. The CD Spectrum of Compound 11 in $\mathrm{MeOH}$ 
MS Formula Results: + Scan (7.853 min) Sub (2016031005.d)

\begin{tabular}{|c|c|c|c|c|c|c|c|c|c|c|c|c|c|c|}
\hline \multicolumn{2}{|r|}{$\mathrm{m} / \mathrm{z}$} & Ion & Formula & Abundance & & & & & & & & & & \\
\hline & 297.1467 & $(\mathrm{M}+\mathrm{Na})+$ & $\mathrm{C} 17 \mathrm{H} 22 \mathrm{Na}$ O3 & 570455.5 & & & & & & & & & & \\
\hline & Best & Formula (M) & Ion Formula & Score & Cross Sco & Mass & Calc Mass & Calc $\mathrm{m} / \mathrm{z}$ & Diff (ppm) & Abs Diff (ppm) & Mass Match & Abund Match & Spacing Match & DBE \\
\hline If & $\bar{v}$ & $\mathrm{C} 17 \mathrm{H} 22 \mathrm{O}$ & $\mathrm{C} 17 \mathrm{H} 22 \mathrm{NaO} 03$ & 99.67 & & 274.1575 & 274.1569 & 297.1461 & -2.29 & 2.29 & 99.86 & 99.81 & 99.11 & 7 \\
\hline + & $\Gamma$ & $\mathrm{C} 12 \mathrm{H} 22 \mathrm{~N} 2 \mathrm{O} 5$ & $\mathrm{C}_{2} \mathrm{H}_{22} \mathrm{~N} 2 \mathrm{Na} \mathrm{O} 5$ & \begin{tabular}{l|l}
95.15 \\
\end{tabular} & & 274.1575 & 274.1529 & 297.1421 & -16.98 & 16.98 & 92.66 & 96.21 & 98.86 & 3 \\
\hline . & $\Gamma$ & $\mathrm{C} 19 \mathrm{H} 18 \mathrm{~N} 2$ & $\mathrm{C} 19 \mathrm{H} 18 \mathrm{~N} 2 \mathrm{Na}$ & 84.24 & & 274.1575 & 274.147 & 297.1362 & -38.4 & 38.4 & 67.71 & 99.39 & 99.12 & 12 \\
\hline - & $\Gamma$ & $\mathrm{C} 16 \mathrm{H} 22 \mathrm{~N} 2 \mathrm{O} 2$ & $\mathrm{C} 16 \mathrm{H} 22 \mathrm{~N} 2 \mathrm{NaO} 2$ & 84.11 & & 274.1575 & 274.1681 & 297.1573 & 38.67 & 38.67 & 67.33 & 99.65 & 99.02 & 7 \\
\hline . & $r$ & $\mathrm{C} 21 \mathrm{H} 22$ & $\mathrm{C} 21 \mathrm{H} 22 \mathrm{Na}$ & 74.24 & & 274.1575 & 274.1722 & 297.1614 & 53.35 & 53.35 & 47.1 & 98.63 & 99.24 & 11 \\
\hline
\end{tabular}

Figure S93. The HR-mass Spectrum of Compound 11 in $\mathrm{MeOH}$

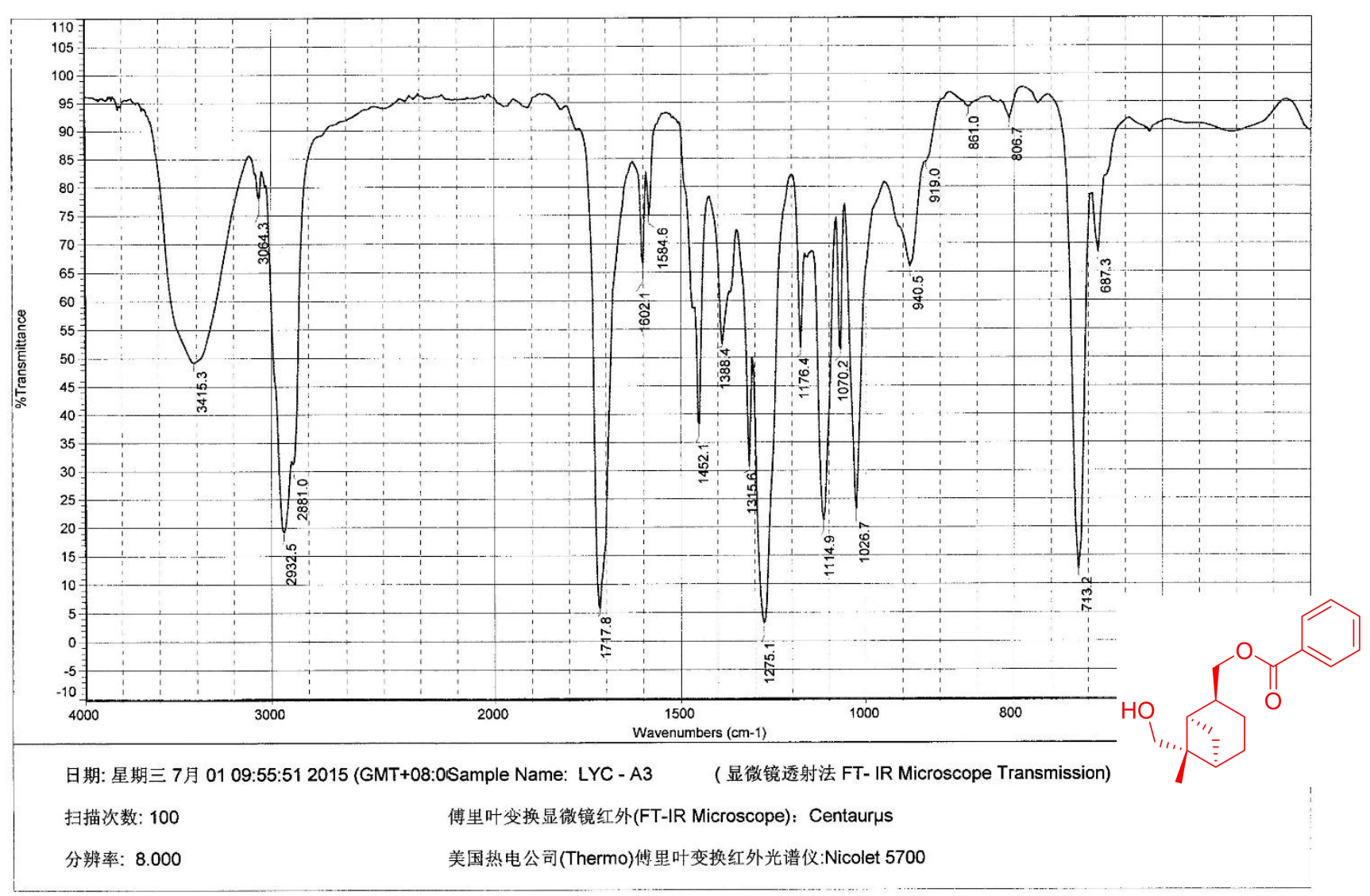

Figure S94. The IR Spectrum of Compound 11 


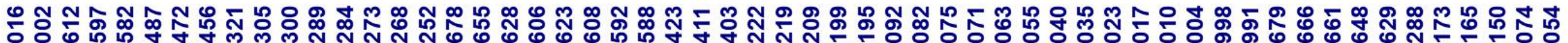

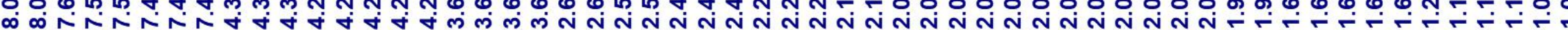

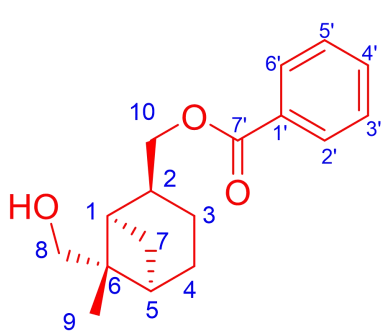

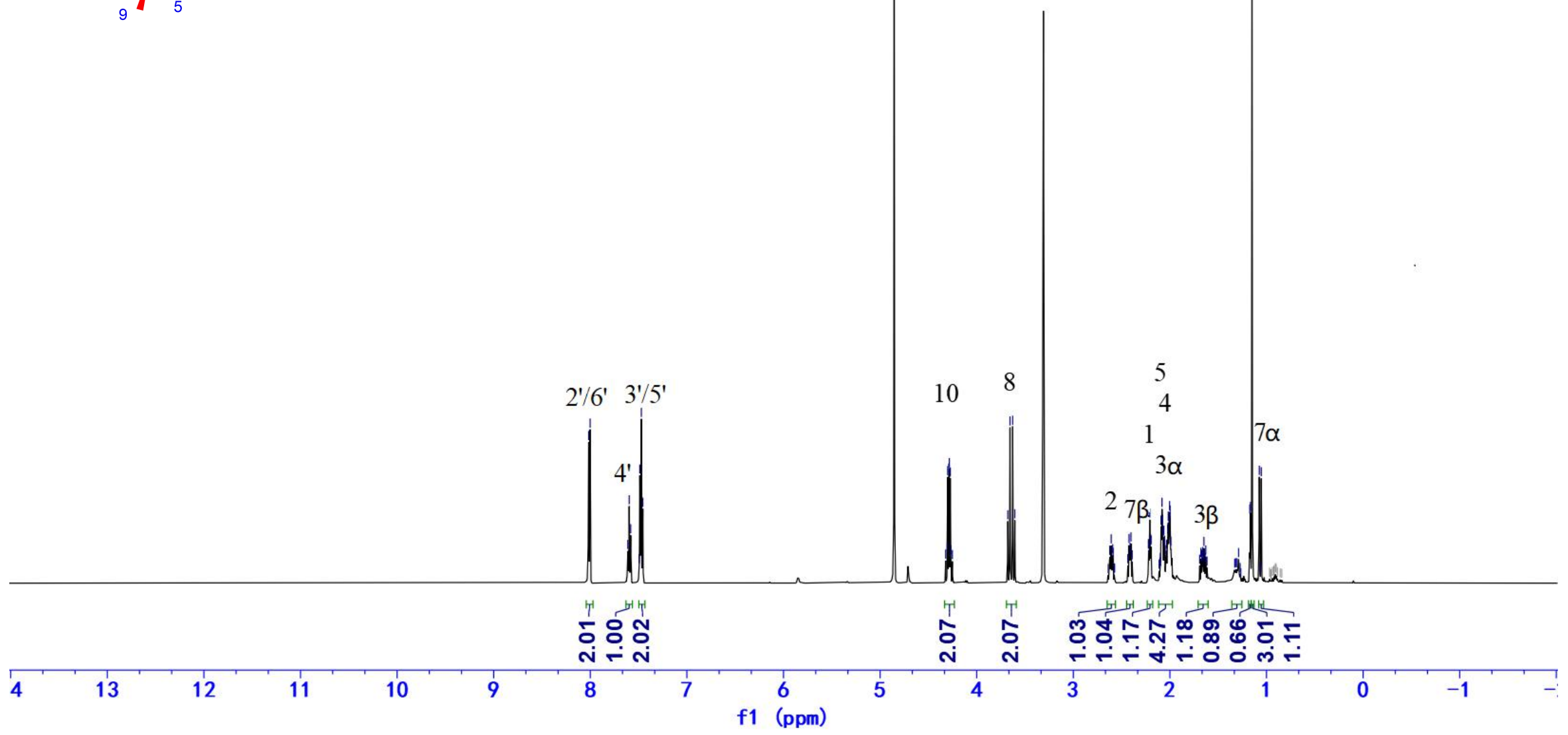

Figure S95. The ${ }^{1} \mathrm{H}$ NMR Spectrum of Compound 11 in $\mathrm{MeOH}_{-} d_{4}(500 \mathrm{MHz})$ 
CARBON_01 - DD2-500 LYC-A3 IN cd3od coldprobe-Probe -
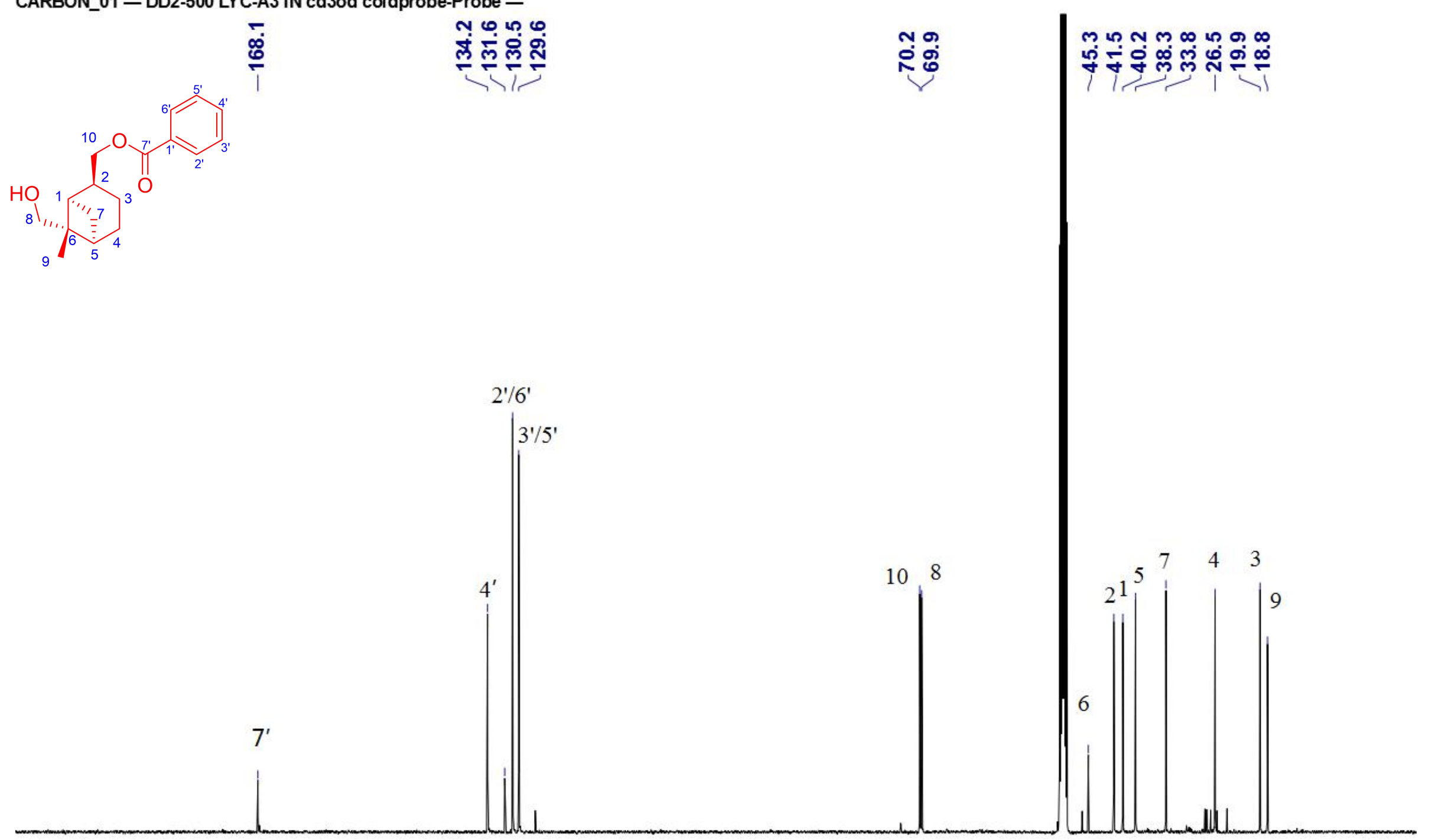

200

190180

$180 \quad 170$

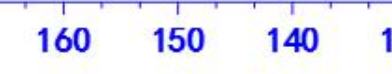

130120

$110 \quad 100 \quad 90$

80

70

$60 \quad 50$

40

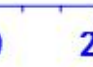

Figure S96. The ${ }^{13} \mathrm{C}$ NMR Spectrum of Compound 11 in $\mathrm{MeOH}-d_{4}(125 \mathrm{MHz})$ 


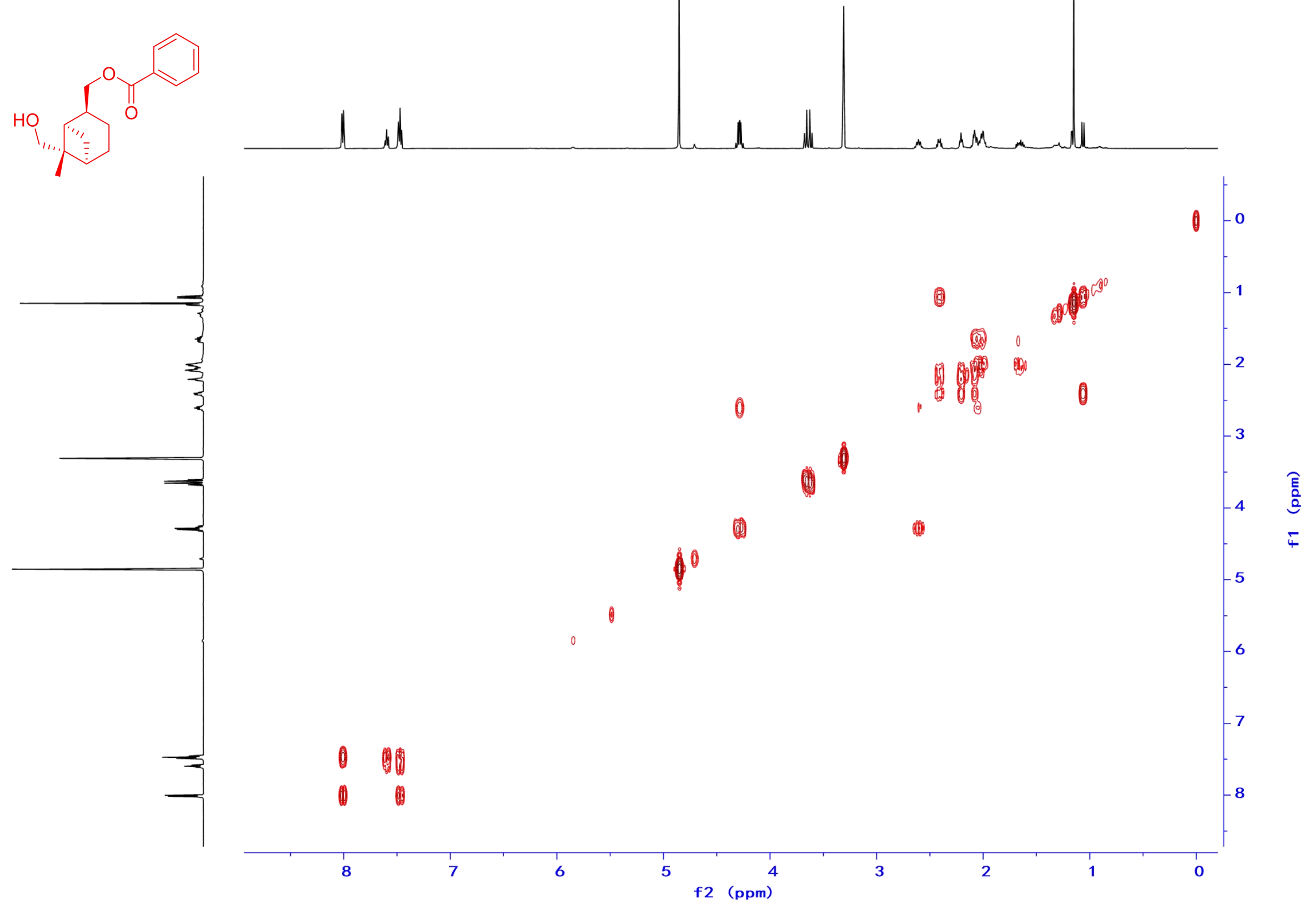

Figure S97. The ${ }^{1} \mathrm{H}-{ }^{1} \mathrm{H}$ COSY Spectrum of Compound 11 in $\mathrm{MeOH}-d_{4}(500 \mathrm{MHz})$ 
gHSQCAD_01 - DD2-500 LYC-A3 IN cd3od id-Probe -

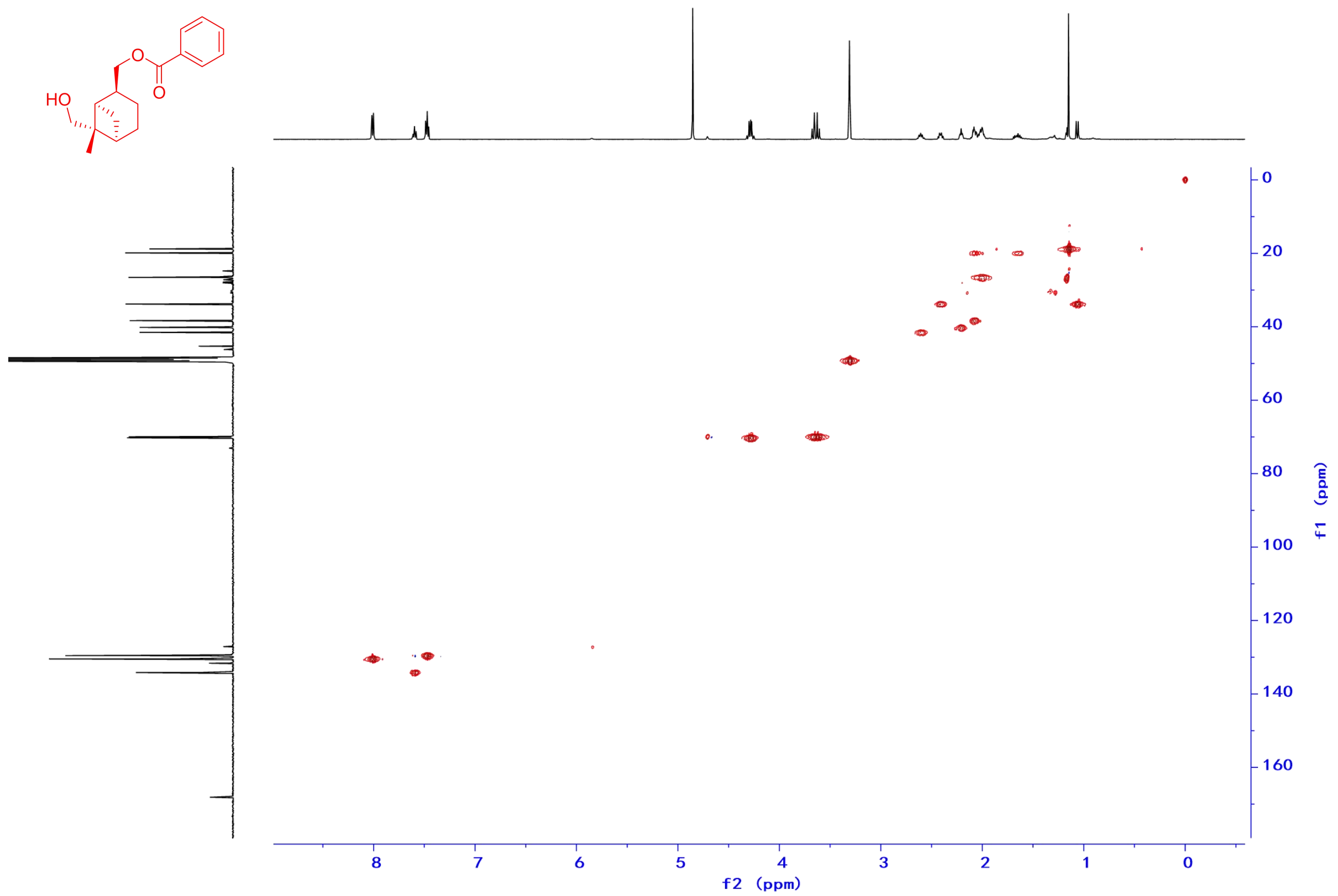

Figure S98. The HSQC Spectrum of Compound 11 in $\mathrm{MeOH}-d_{4}(500 \mathrm{MHz})$ 
gHMBCAD_01 - DD2-500 LYC-A3 IN cd3od id-Probe -

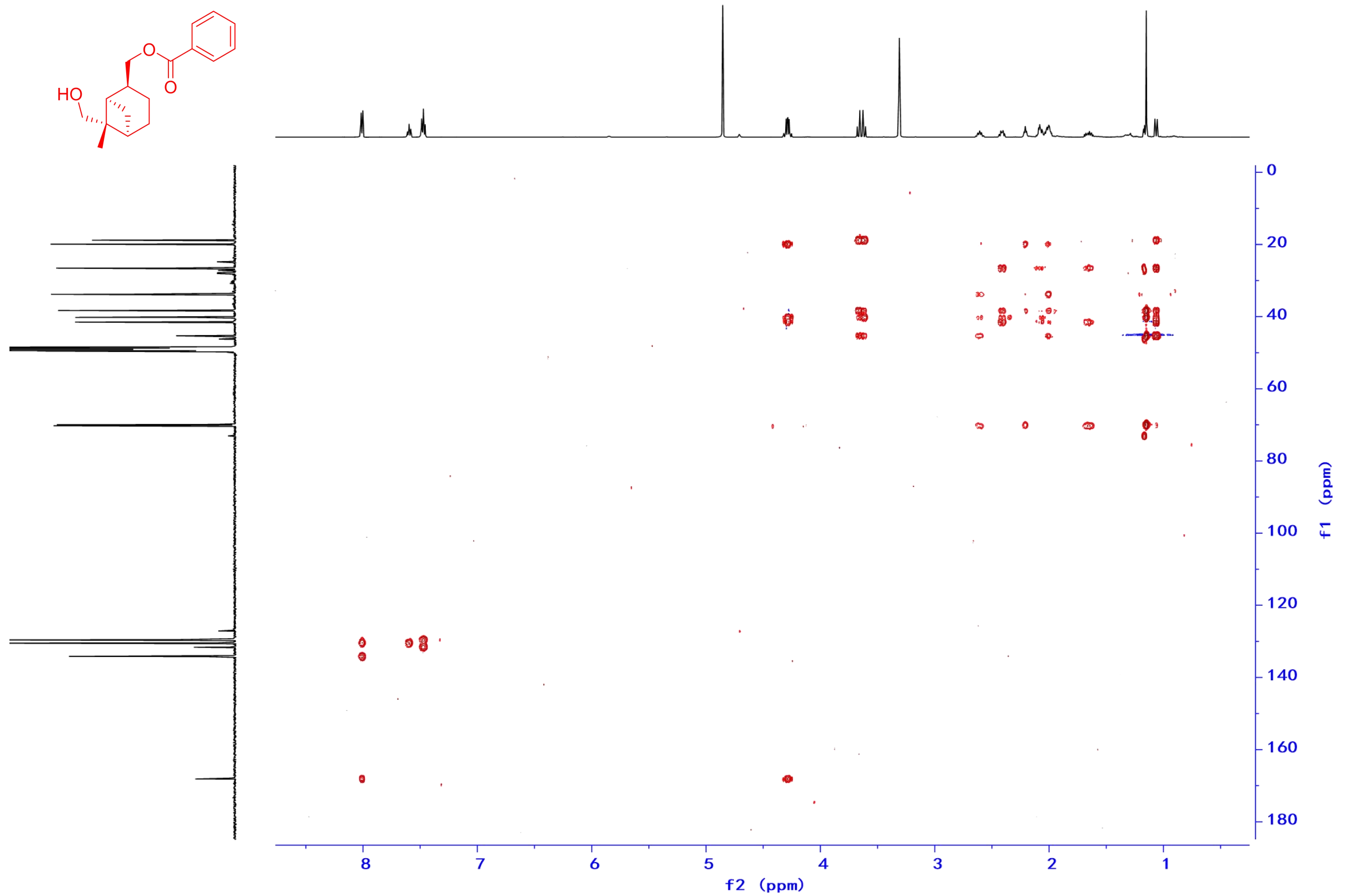

Figure S99. The HMBC Spectrum of Compound 11 in $\mathrm{MeOH}-d_{4}(500 \mathrm{MHz})$ 

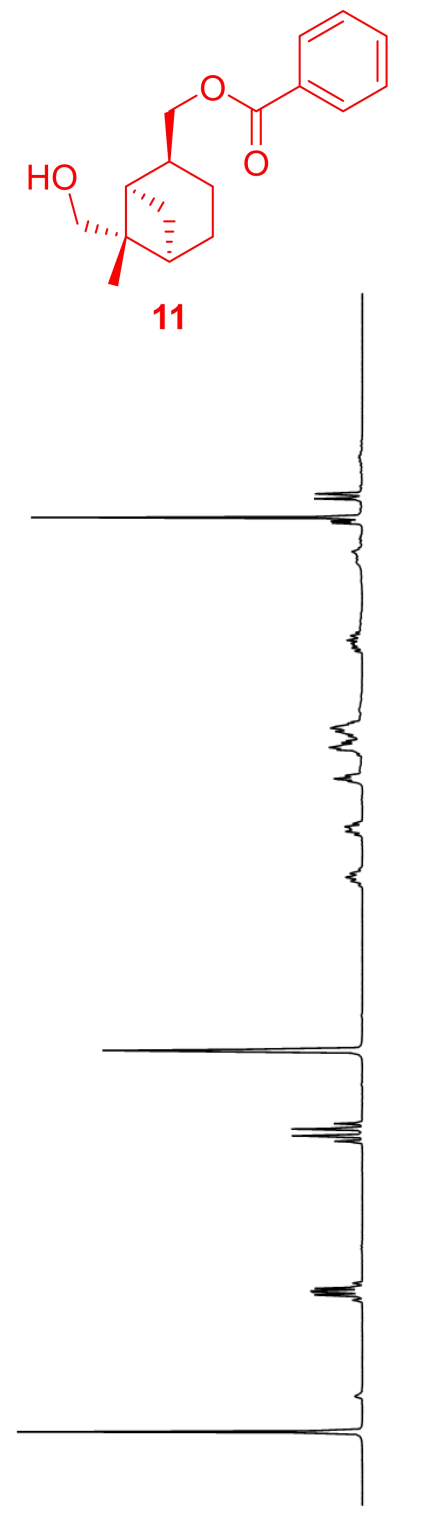$$
\text { (1) }
$$

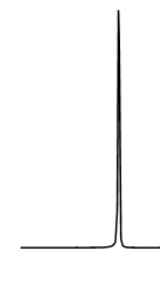

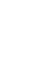

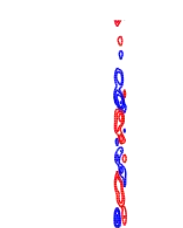

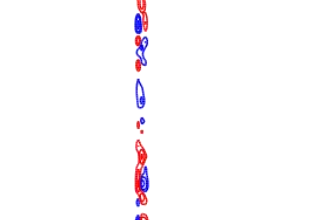

๑.

1900

(2)

(9)

要

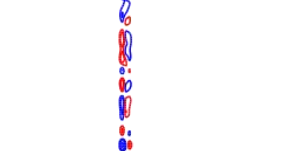

0

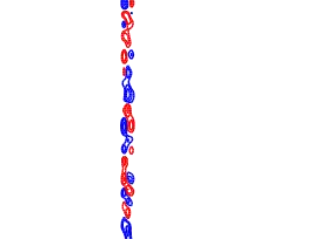$$
\frac{1}{5}
$$

5.0

$$
\text { (5) }
$$

- ชீ : ஊ

(-)

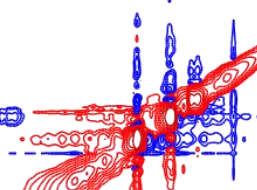

0.5

1. 0

1.5

2. 0

2. 5

$30 \quad$

Figure S100. The NOESY Spectrum of Compound 11 in $\mathrm{MeOH}-d_{4}(500 \mathrm{MHz})$ 


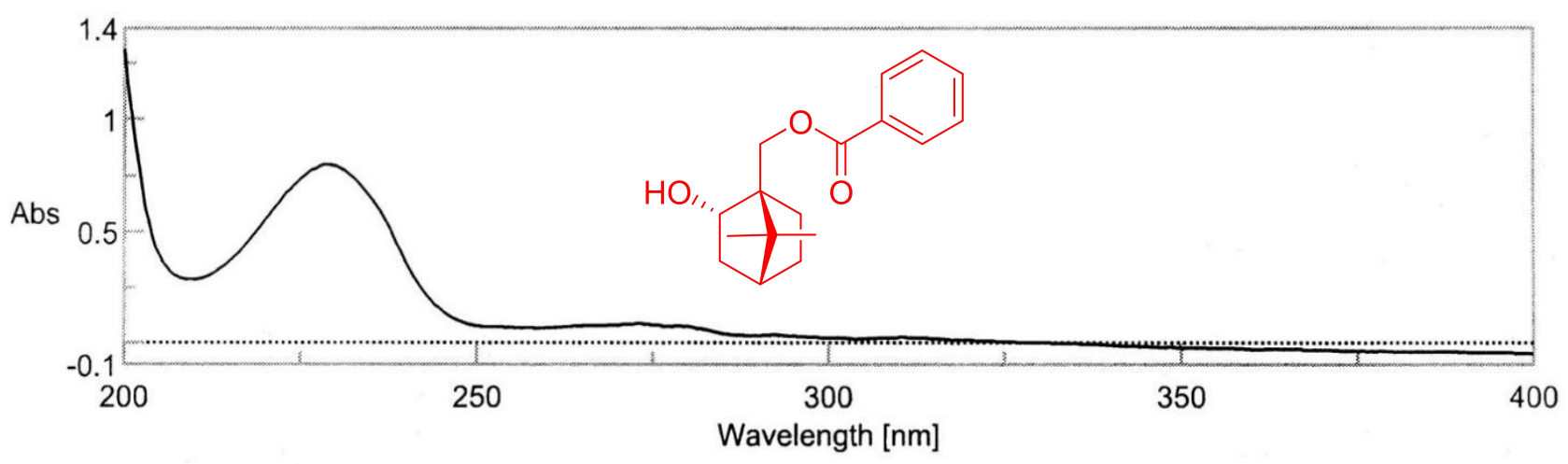

Figure S101. The UV Spectrum of Compound 12 in MeOH

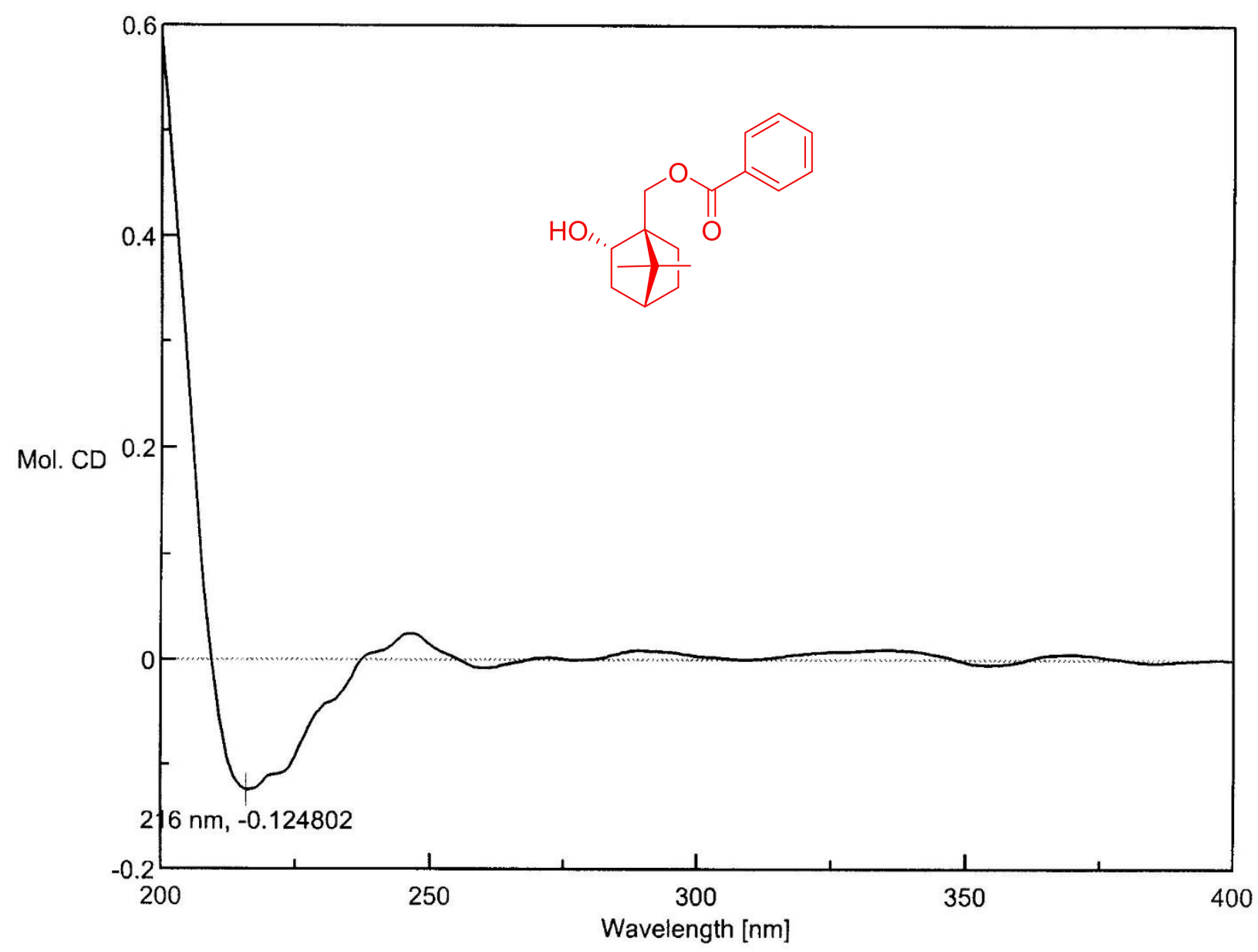

Figure S102. The CD Spectrum of Compound 12 in $\mathrm{MeOH}$ 
MS Formula Results: + Scan (7.805-8.192 min) Sub (2016031001.d)

\begin{tabular}{|c|c|c|c|c|c|c|c|c|c|c|c|c|c|c|}
\hline \multicolumn{2}{|r|}{$\mathrm{m} / \mathrm{z}$} & Ion & Formula & Abundance & & & & & & & & & & \\
\hline & 297.147 & $(\mathrm{M}+\mathrm{Na})+$ & $\mathrm{C} 17 \mathrm{H} 22 \mathrm{Na} \mathrm{O} 3$ & 116016.4 & & & & & & & & & & \\
\hline & Best & Formula (M) & Ion Formula & Score & Cross Sco & Mass & Calc Mass & Calc $\mathrm{m} / \mathrm{z}$ & Diff (ppm) & Abs Diff (ppm) & Mass Match & Abund Match & Spacing Match & DBE \\
\hline & $\bar{v}$ & $\mathrm{C} 17 \mathrm{H} 22 \mathrm{O} 3$ & $\mathrm{C} 17 \mathrm{H} 22 \mathrm{NaO}$ & 99.66 & & 274.1578 & 274.1569 & 297.1461 & -3.33 & 3,33 & 99.71 & 99.32 & 99.99 & 7 \\
\hline + & $\Gamma$ & $\mathrm{C}_{12} \mathrm{H}_{22} \mathrm{~N} 2 \mathrm{O} 5$ & $\begin{array}{l}\mathrm{C} 12 \mathrm{H} 22 \mathrm{~N} 2 \mathrm{Na} \text { O5 } \\
\end{array}$ & 95.84 & & 274.1578 & 274.1529 & 297.1421 & -18.01 & 18.01 & 91.78 & 99.18 & 99.95 & 3 \\
\hline + & $r$ & $\mathrm{C} 16 \mathrm{H} 22 \mathrm{~N} 2 \mathrm{O} 2$ & $\mathrm{C} 16 \mathrm{H} 22 \mathrm{~N} 2 \mathrm{NaO} 2$ & 84.98 & & 274.1578 & 274.1681 & 297.1573 & 37.64 & 37.64 & 68.75 & 99.54 & 99.97 & 7 \\
\hline - & $\Gamma$ & $\mathrm{C} 19 \mathrm{H} 18 \mathrm{~N} 2$ & $\mathrm{C} 19 \mathrm{H} 18 \mathrm{~N} 2 \mathrm{Na}$ & 83.1 & & 274.1578 & 274.147 & 297.1362 & -39.43 & 39.43 & 66.28 & 97.06 & \begin{tabular}{|c|}
99.98 \\
\end{tabular} & 12 \\
\hline & $r$ & C21 H22 & $\mathrm{C} 21 \mathrm{H} 22 \mathrm{Na}$ & 74.12 & & 274.1578 & 274.1722 & 297.1614 & 52.31 & 52.31 & 48.49 & 95.27 & 99.99 & 11 \\
\hline
\end{tabular}

Figure S103. The HR-mass Spectrum of Compound 12 in MeOH

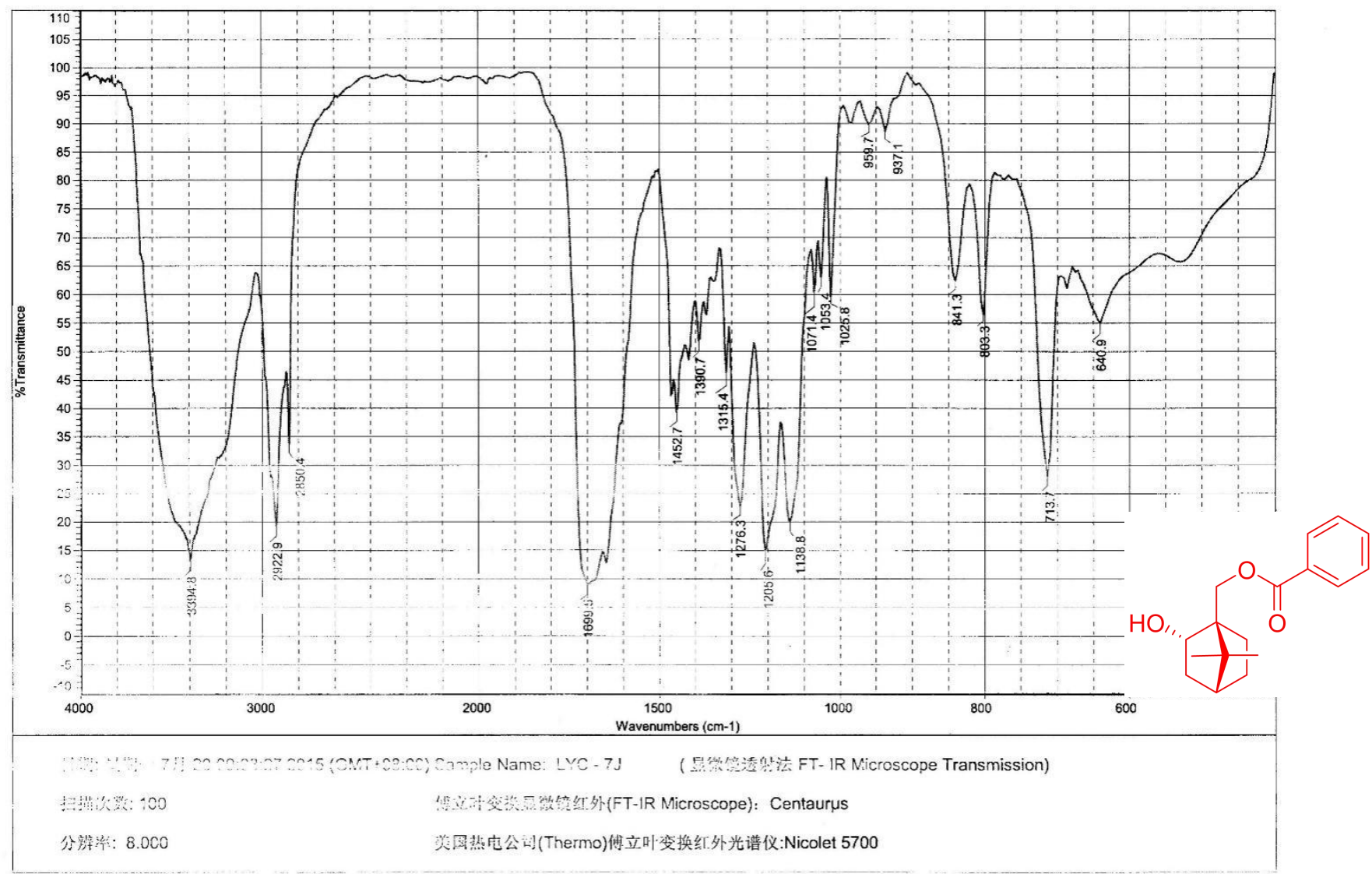

Figure S104. The IR Spectrum of Compound 12 

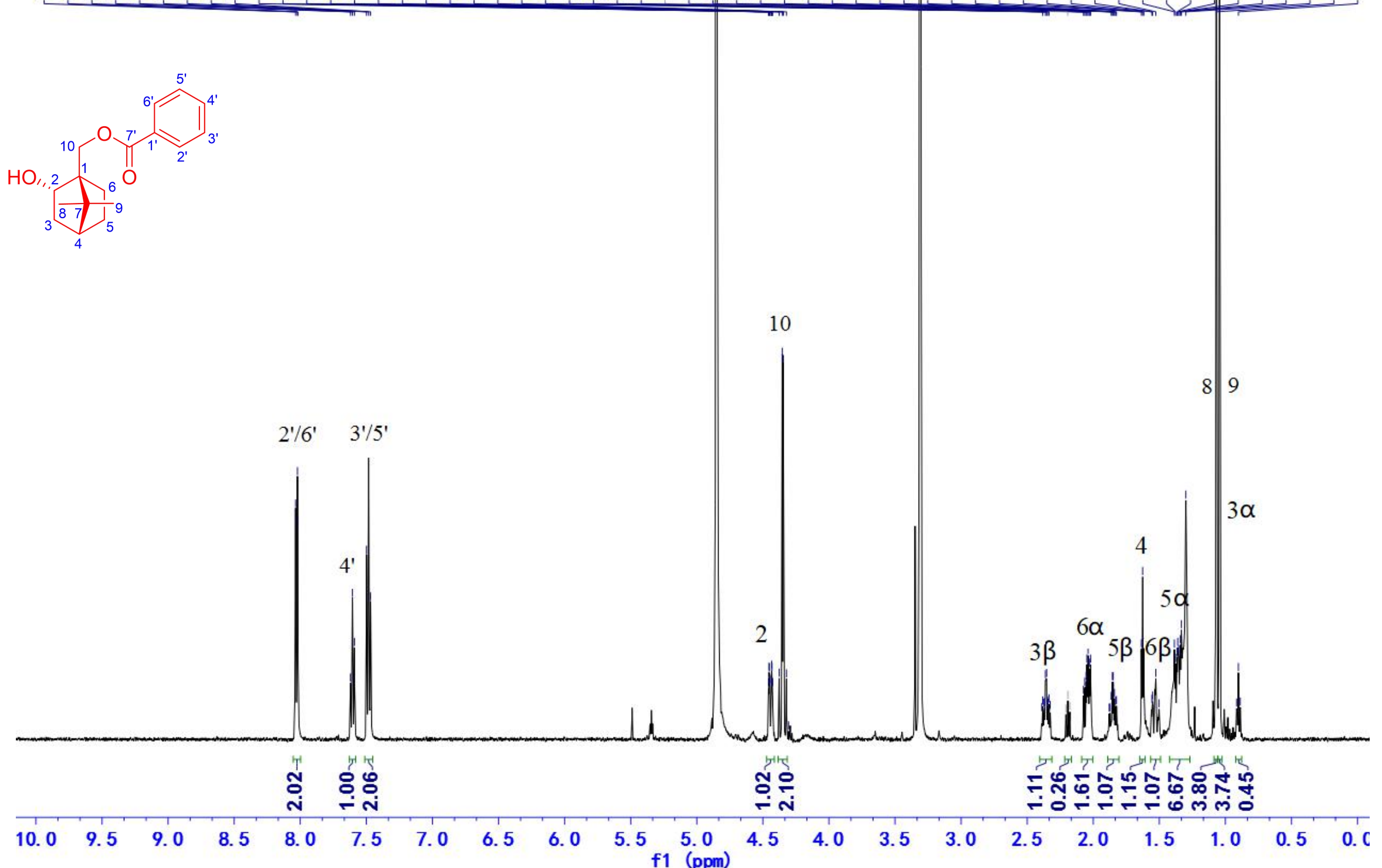

Figure S105. The ${ }^{1} \mathrm{H}$ NMR Spectrum of Compound 12 in $\mathrm{MeOH}_{-} d_{4}(500 \mathrm{MHz})$ 
CARBON_01 - DD2-500 LYC-7J IN cd3od sw-Probe -

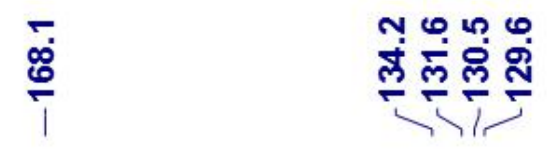

$$
\text { लं }
$$
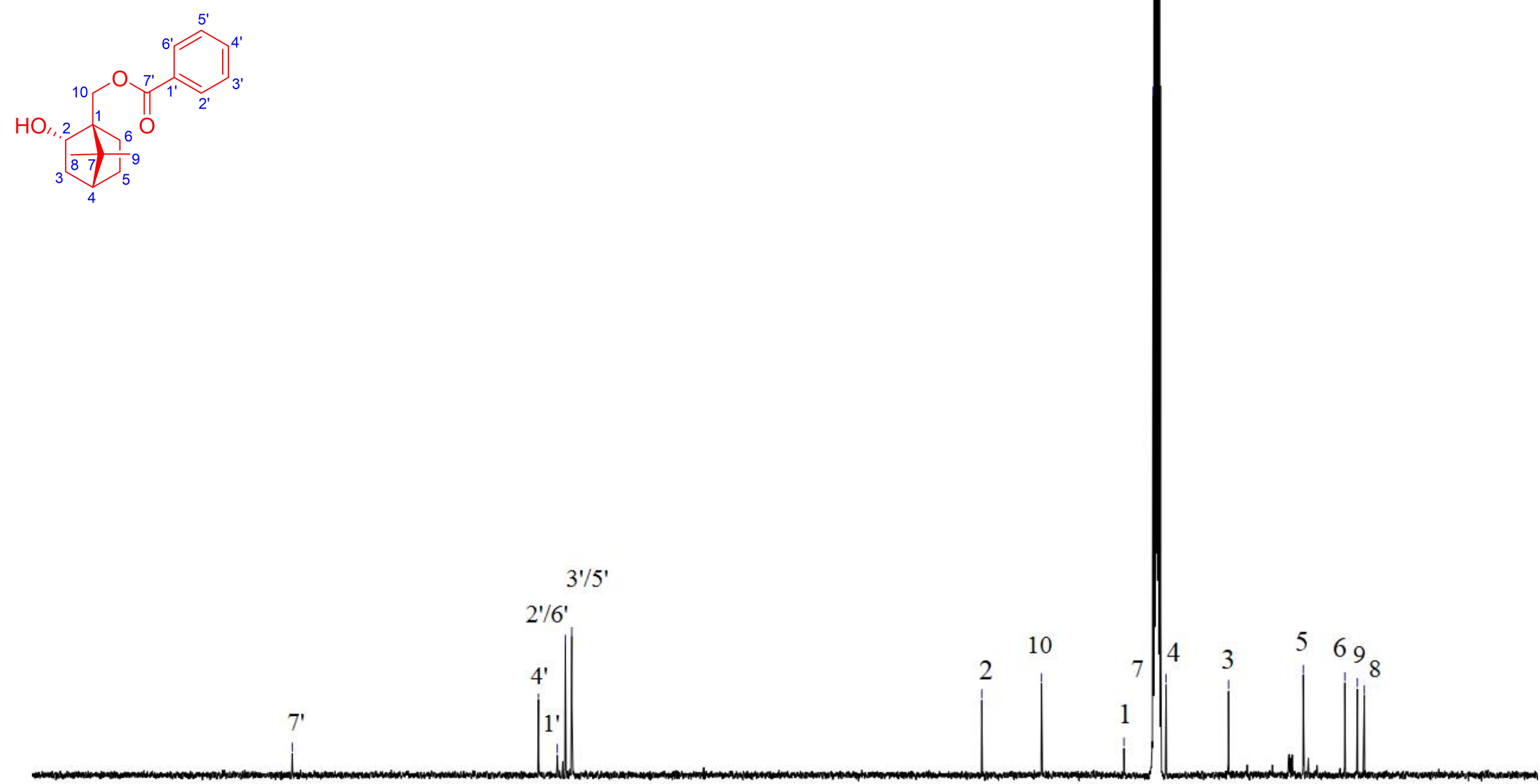

$170 \quad 160 \quad 150$

140

130

120

f1 (ppm)

Figure S106. The ${ }^{13} \mathrm{C}$ NMR Spectrum of Compound 12 in $\mathrm{MeOH}_{-} d_{4}(125 \mathrm{MHz})$ 
20160601 LYC-7J/2 — Bruker AVIIIHD 60020160601 — COSY_MQF CD3OD D:II DATA2016 30
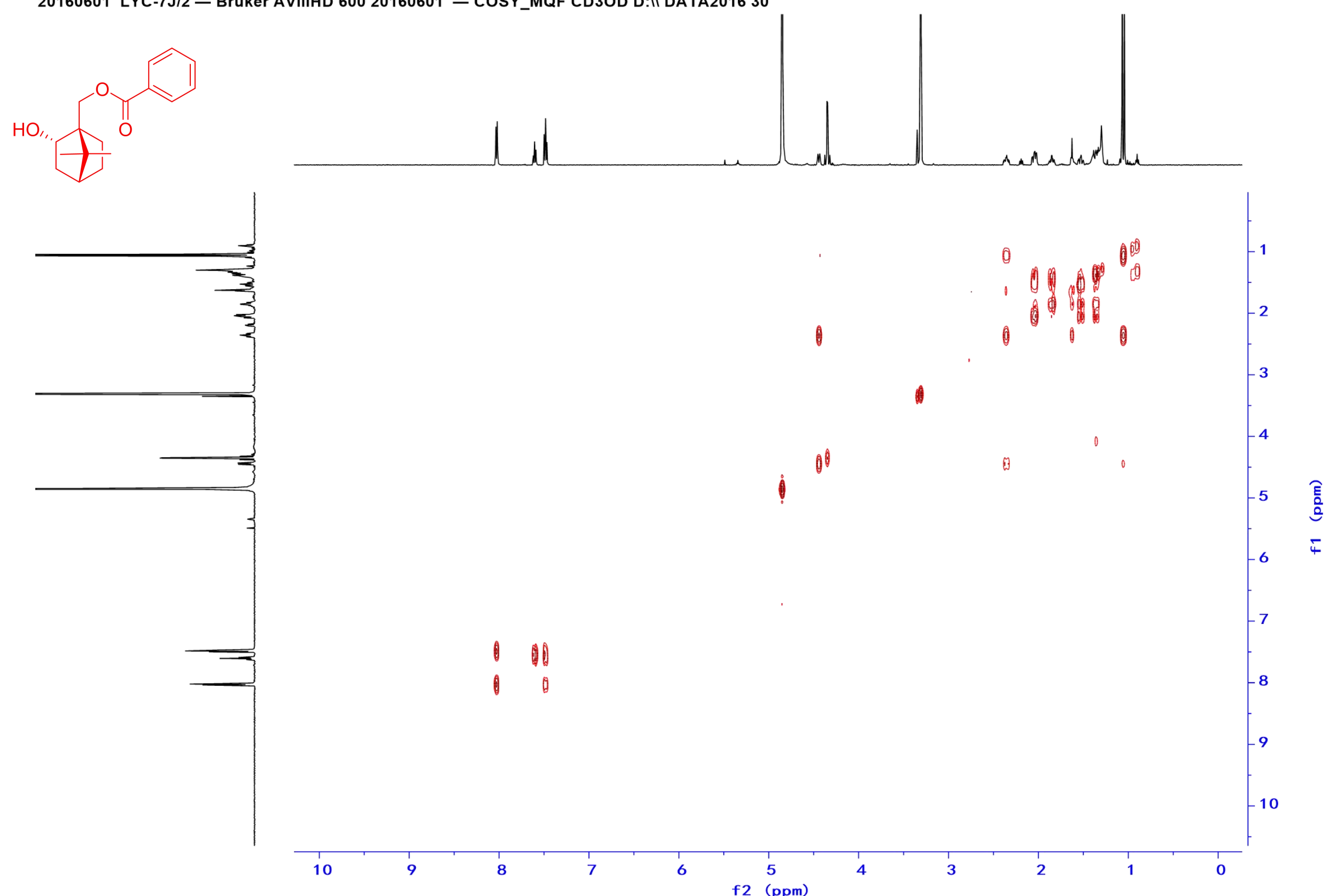

Figure S107. The ${ }^{1} \mathrm{H}-{ }^{1} \mathrm{H}$ COSY Spectrum of Compound 12 in MeOH-d $\mathrm{d}_{4}(500 \mathrm{MHz})$ 

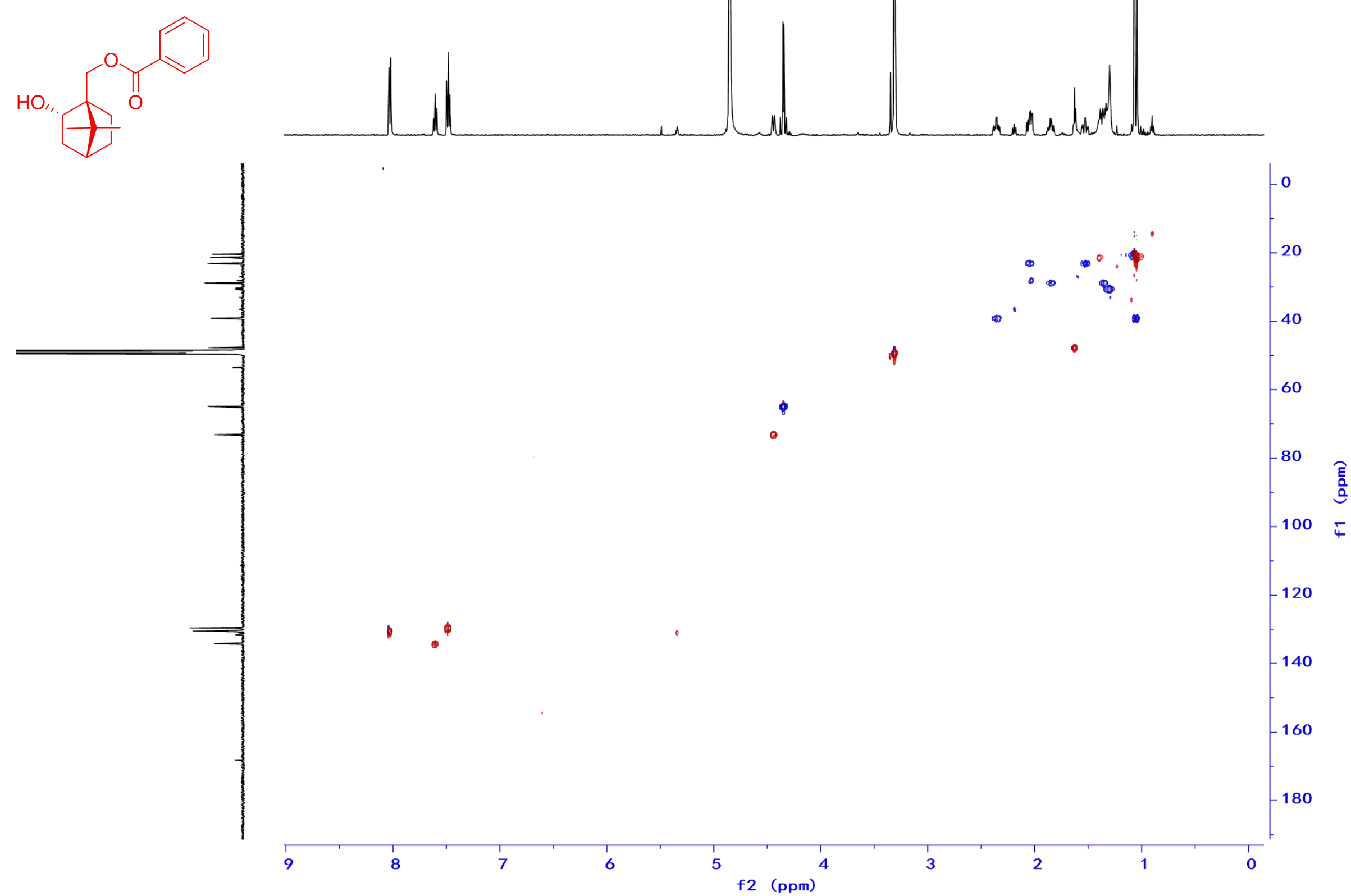

Figure S108. The HSQC Spectrum of Compound 12 in MeOH-d $(500 \mathrm{MHz})$ 


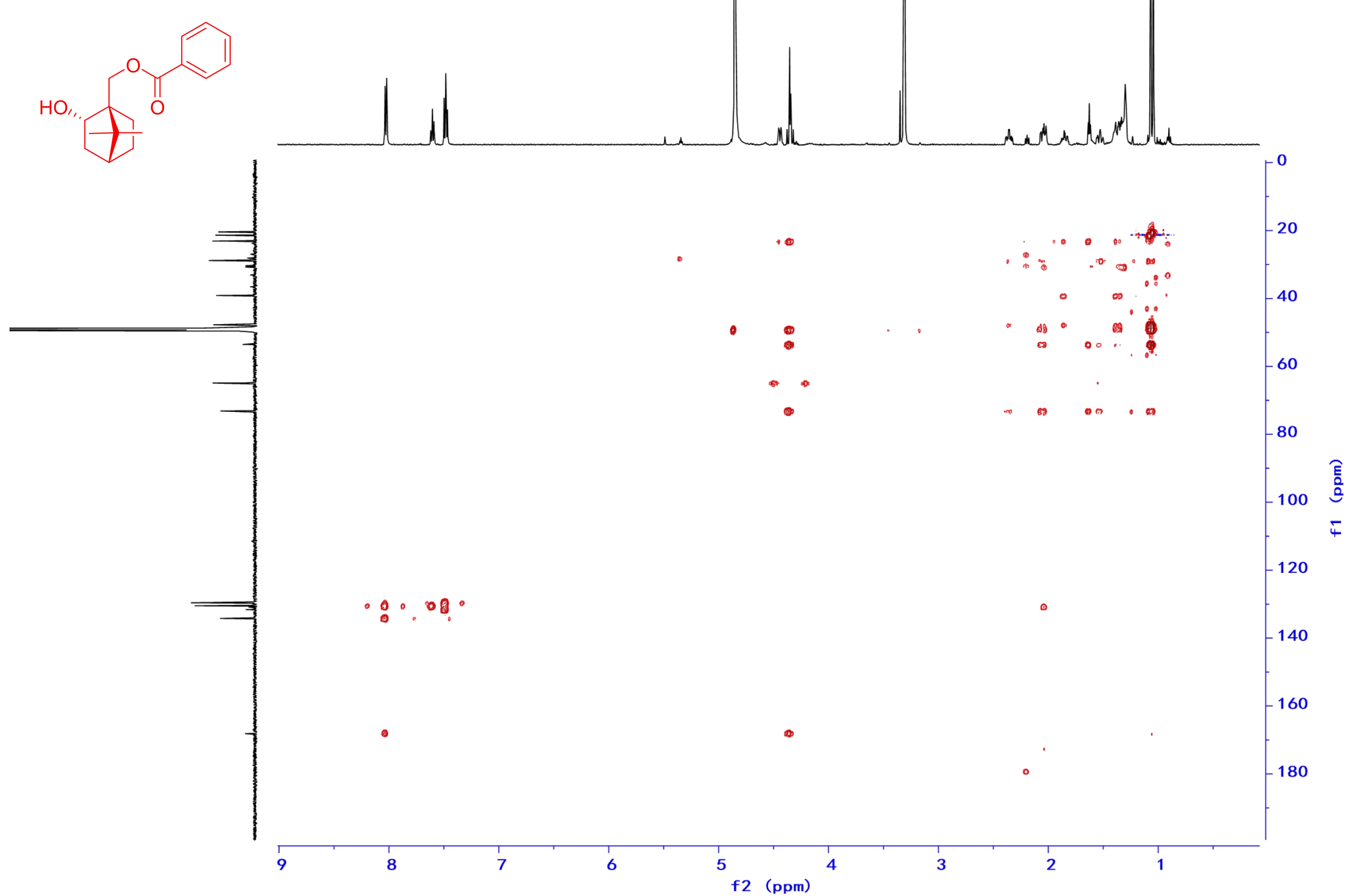

Figure S109. The HMBC Spectrum of Compound 12 in MeOH- $d_{4}(500 \mathrm{MHz})$ 
NOESY_01 - DD2-500 LYC-7J IN cd3od sw-Probe -

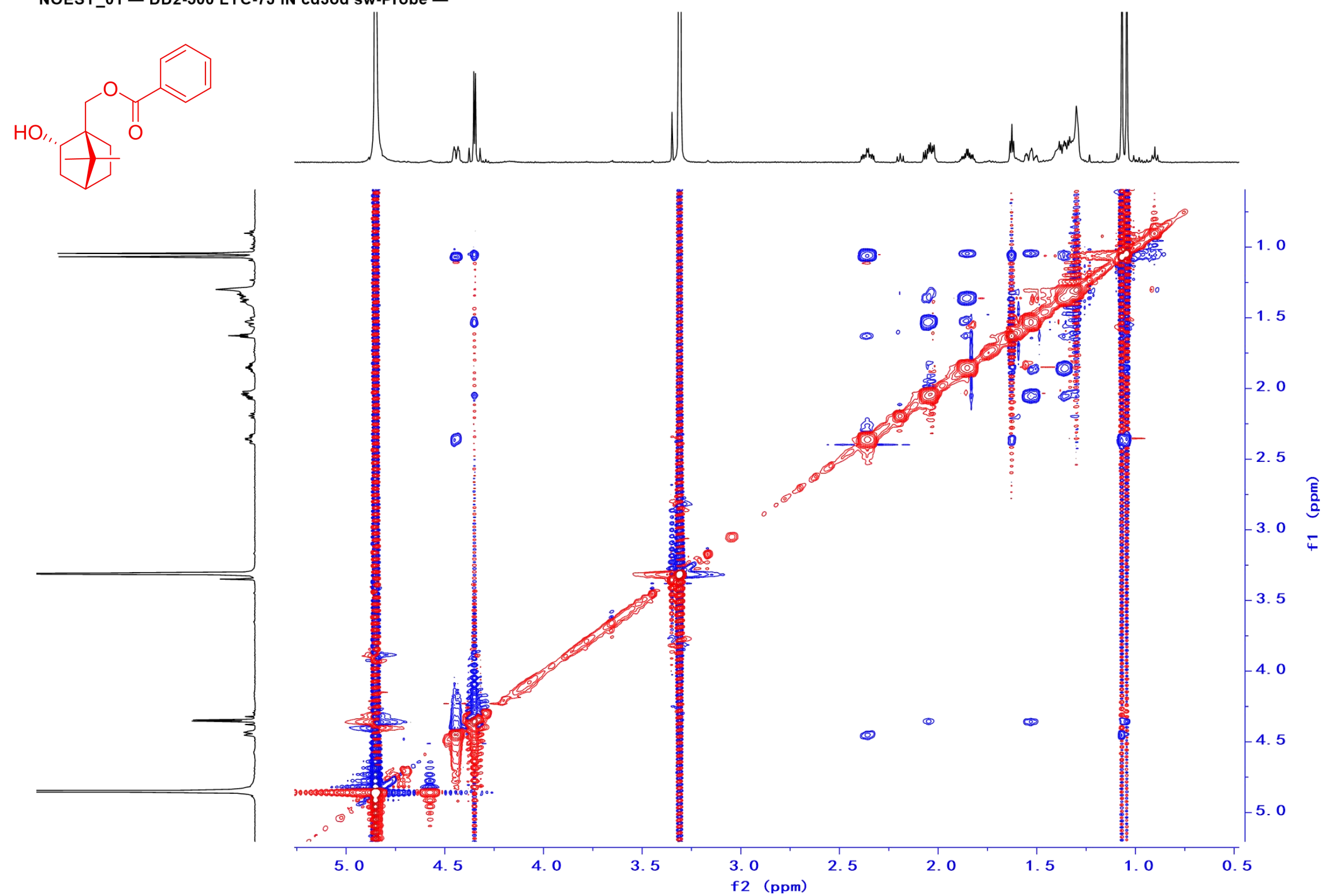

Figure S110. The NOESY Spectrum of Compound 12 in MeOH-d $(500 \mathrm{MHz})$ 


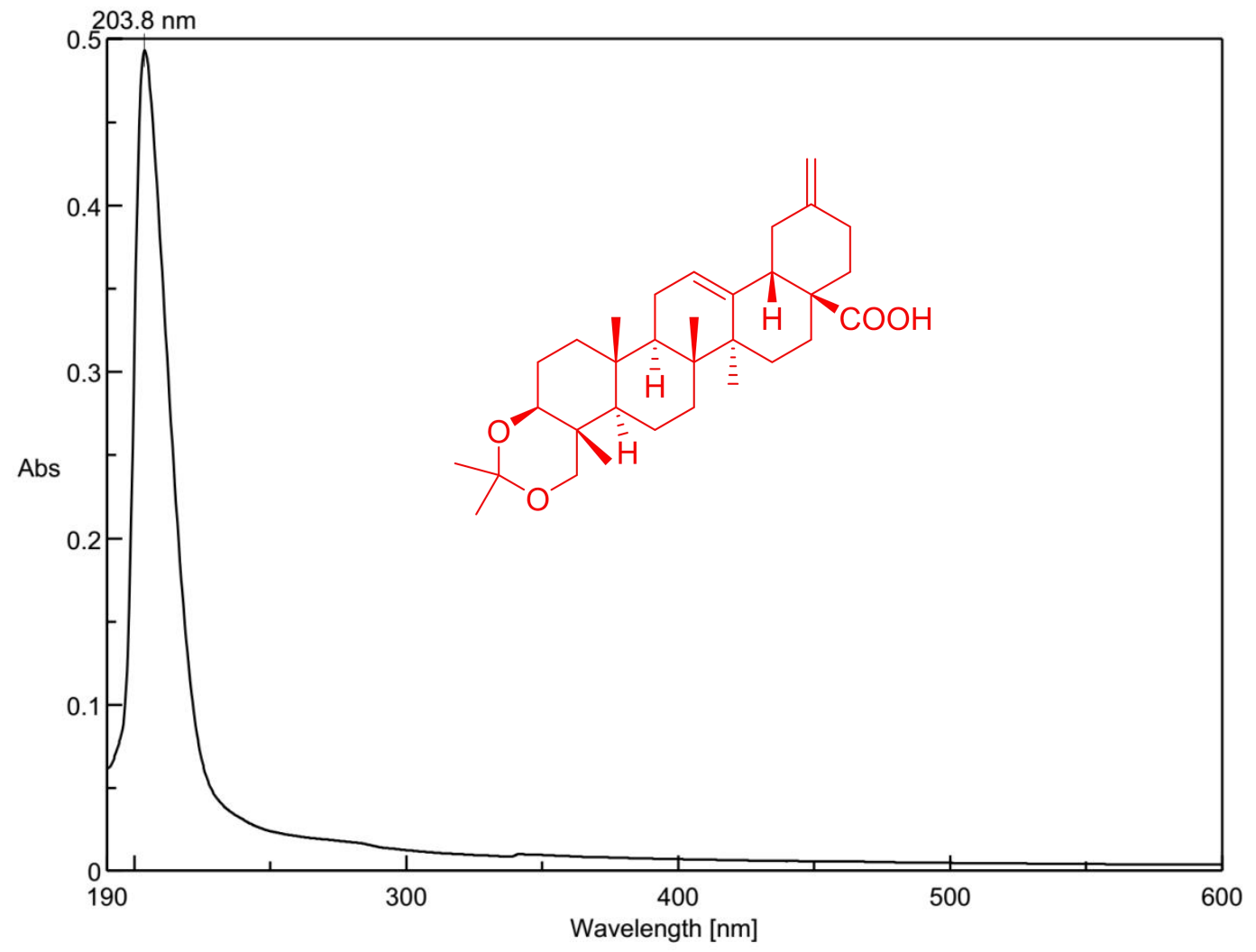

Figure S111. The UV Spectrum of Compound 26 in MeOH

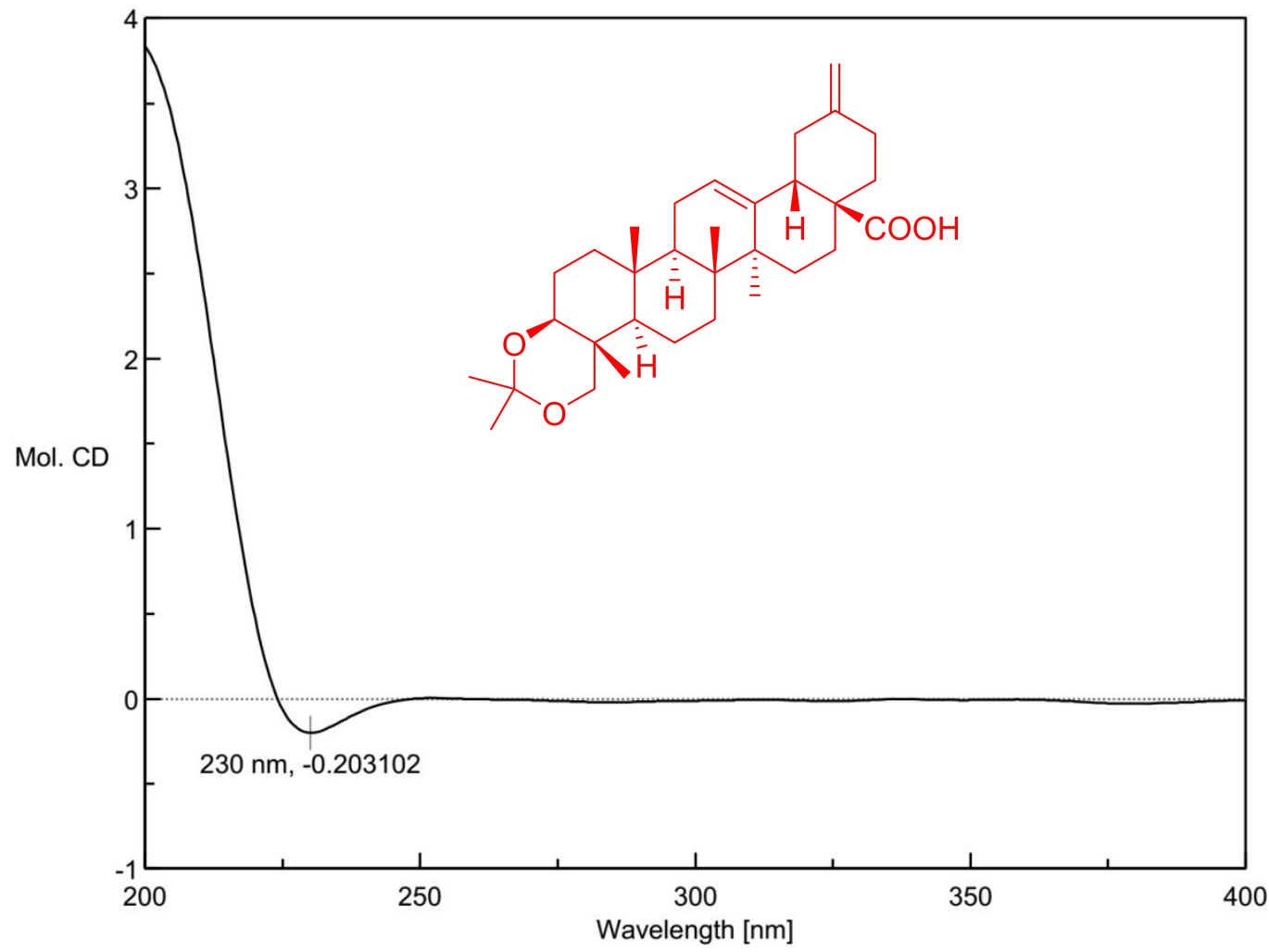

Figure S112. The CD Spectrum of Compound 26 in MeOH 


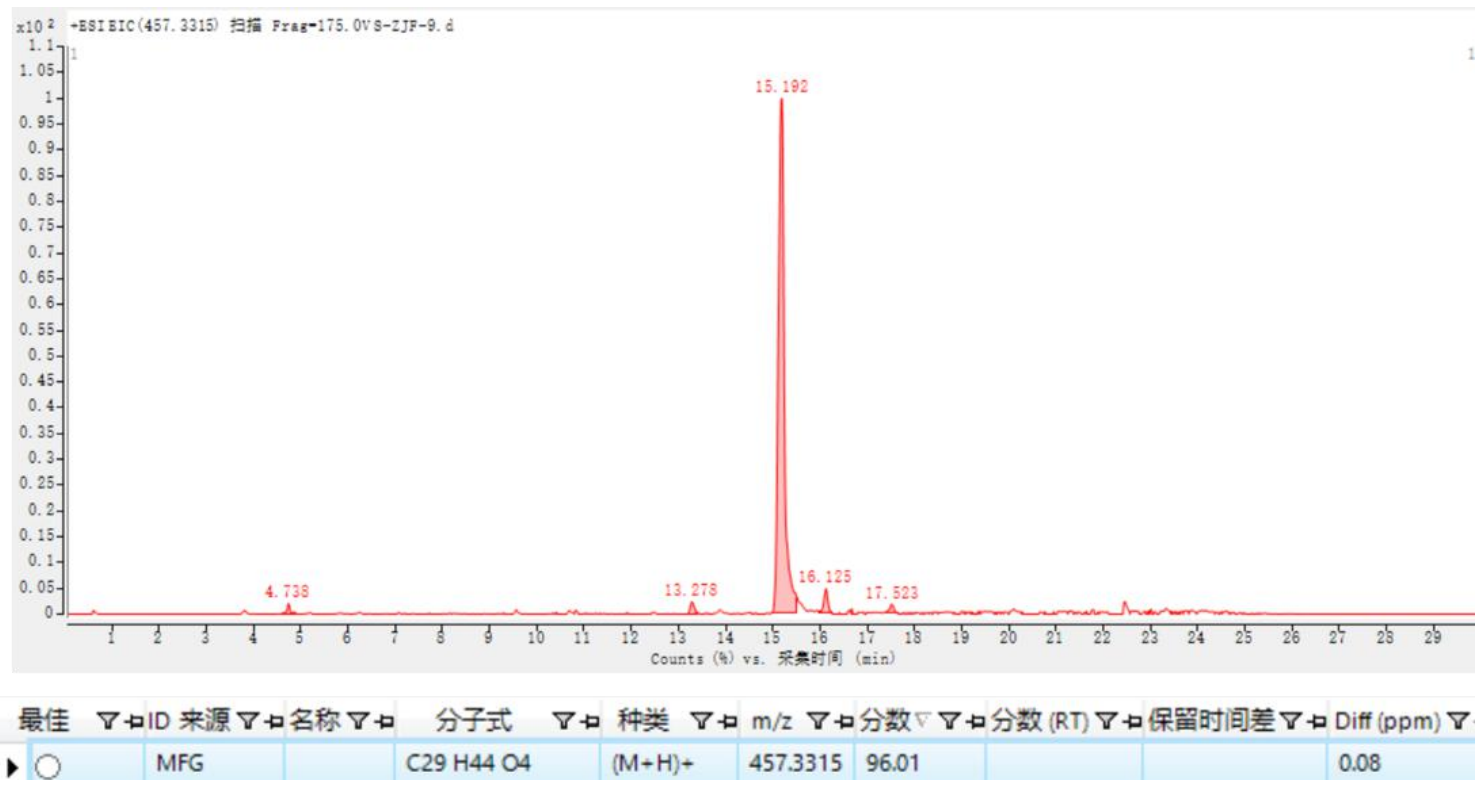

Figure S113. The HR-mass Spectrum of Compound 26 in MeOH

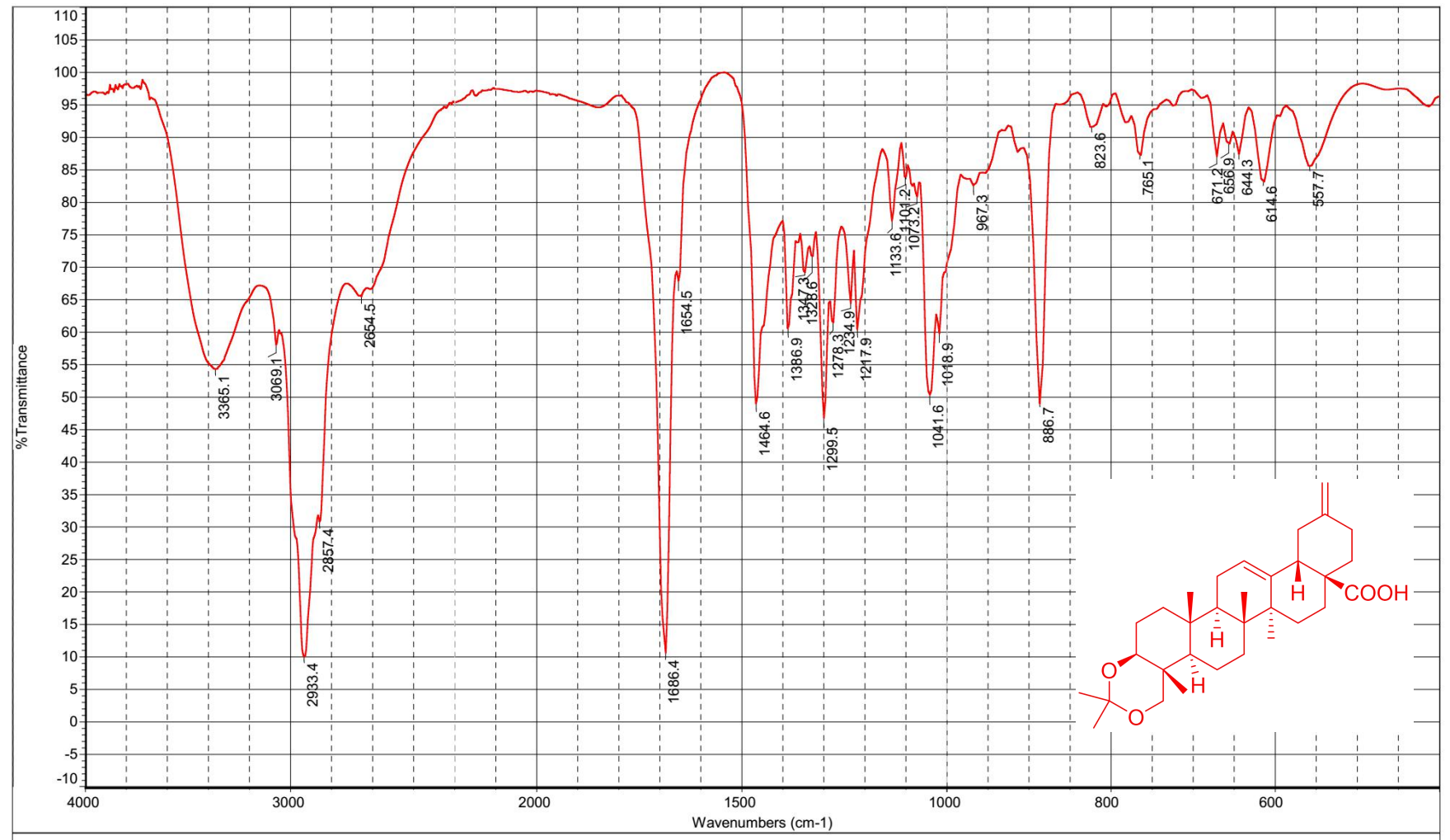

Figure S114. The IR Spectrum of Compound 26 
ZJF-S-ZJF-9.1.fid - ZJF-S-ZJF-9 1H NMR

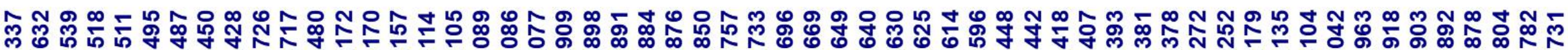

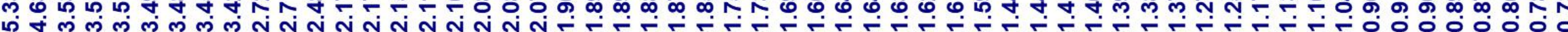

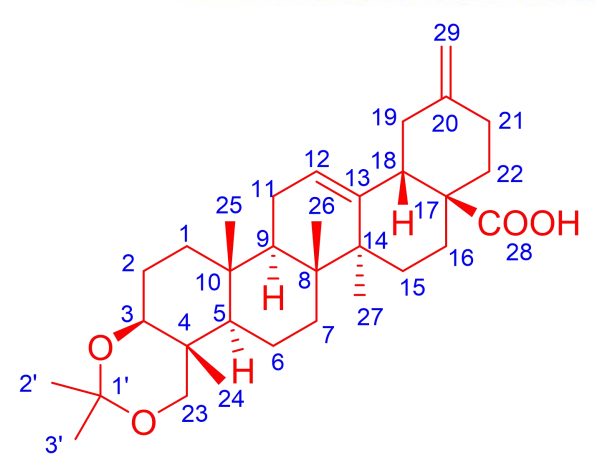

27

$16 \alpha, 7 \beta$

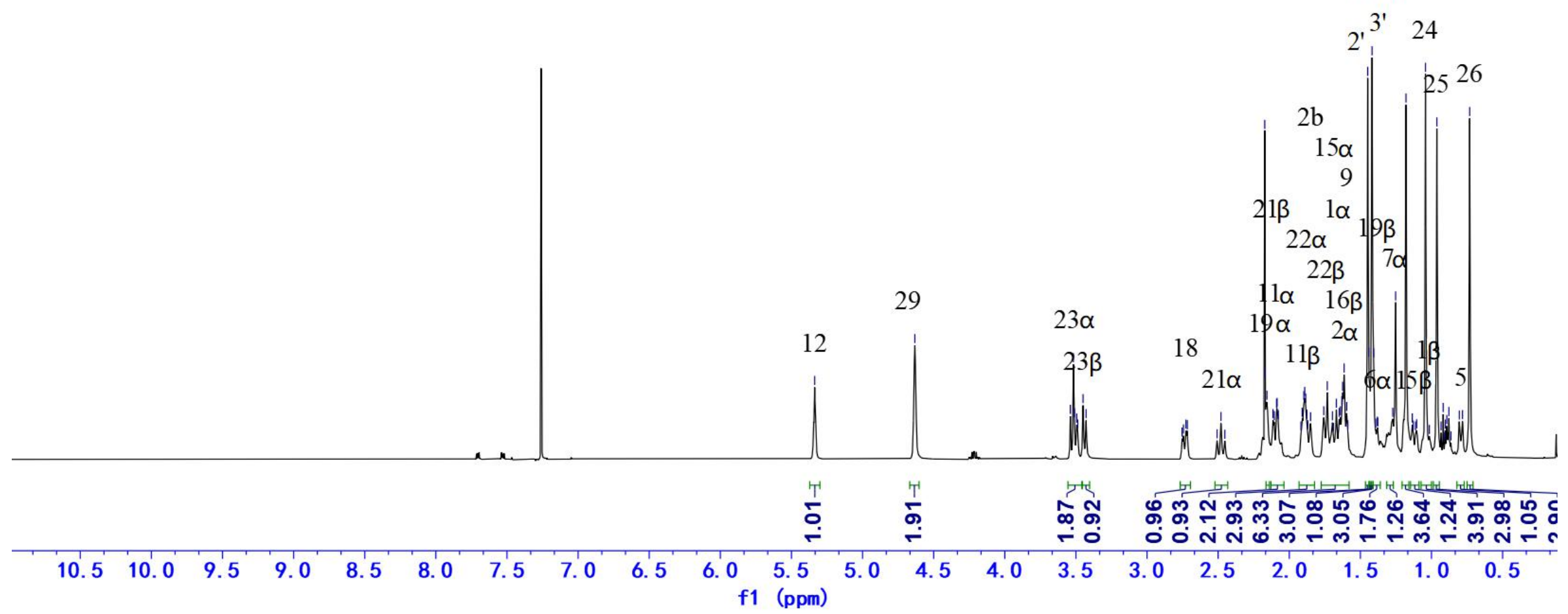

Figure S115. The ${ }^{1} \mathrm{H}$ NMR Spectrum of Compound 26 in $\mathrm{CD}_{3} \mathrm{Cl}(500 \mathrm{MHz})$ 

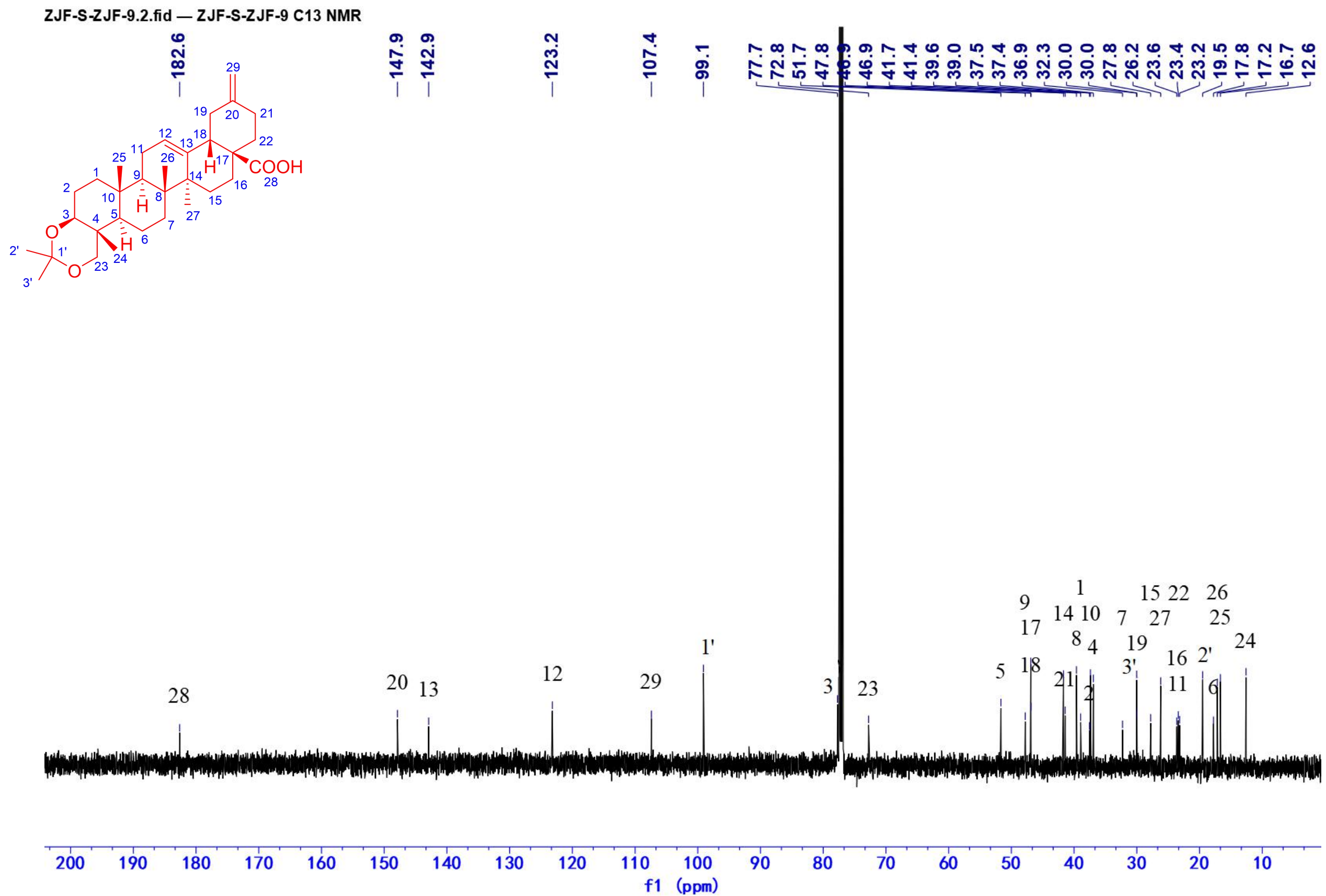

Figure S116. The ${ }^{13} \mathrm{C}$ NMR Spectrum of Compound 26 in $\mathrm{CD}_{3} \mathrm{Cl}(125 \mathrm{MHz})$ 


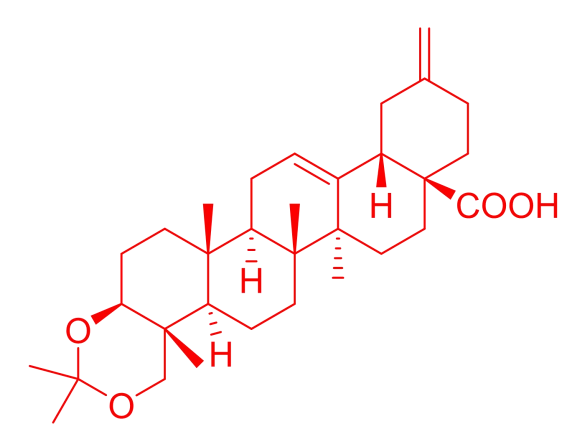

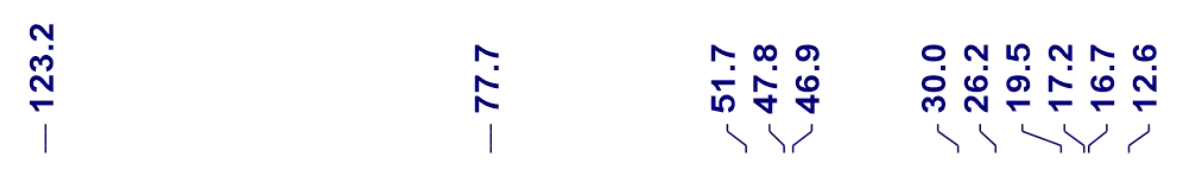

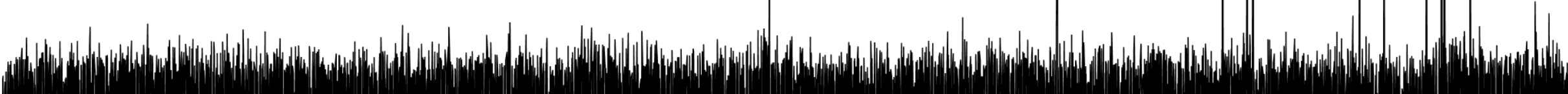

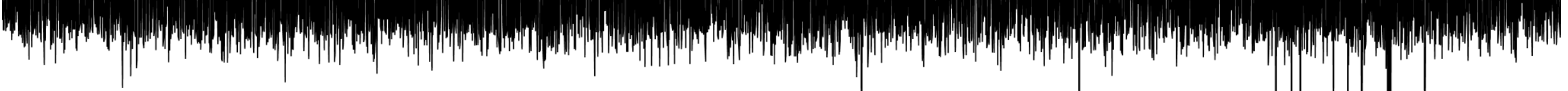

$\begin{array}{llllllllllllllll}240 & 230 & 220 & 210 & 200 & 190 & 180 & 170 & 160 & 150 & 140 & 130 & 120 & 1\end{array}$

Figure S117. The DEPT Spectrum of Compound 26 in $\mathrm{CD}_{3} \mathrm{Cl}(125 \mathrm{MHz})$ 
ZJF-S-ZJF-9.4.ser - ZJF-S-ZJF-9 1H 1H COSY

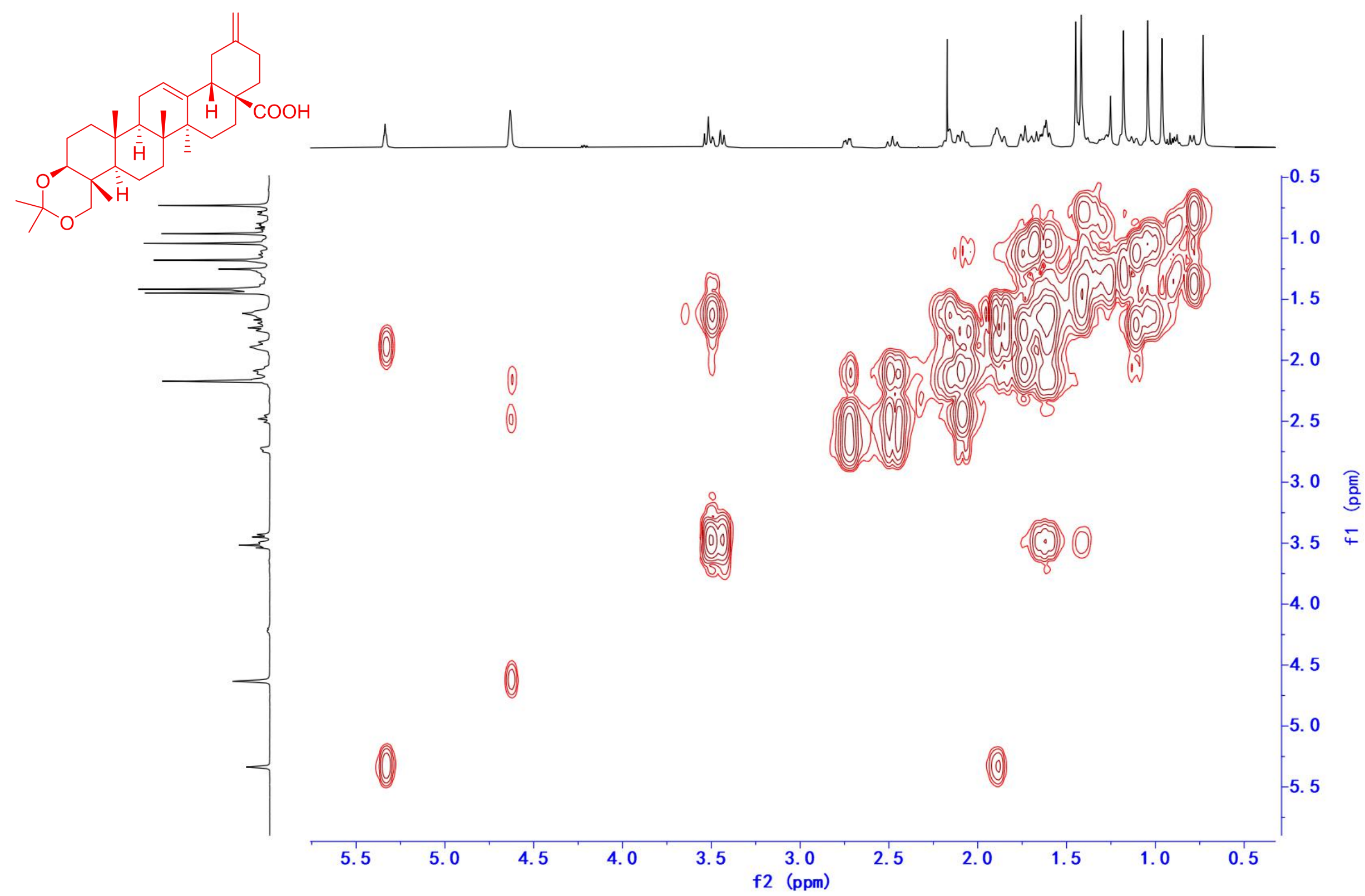

Figure S118. The ${ }^{1} \mathrm{H}-{ }^{1} \mathrm{H}$ COSY Spectrum of Compound 26 in $\mathrm{CD}_{3} \mathrm{Cl}(500 \mathrm{MHz})$ 
ZJF-S-ZJF-9.5.ser - ZJF-S-ZJF-9 HSQC

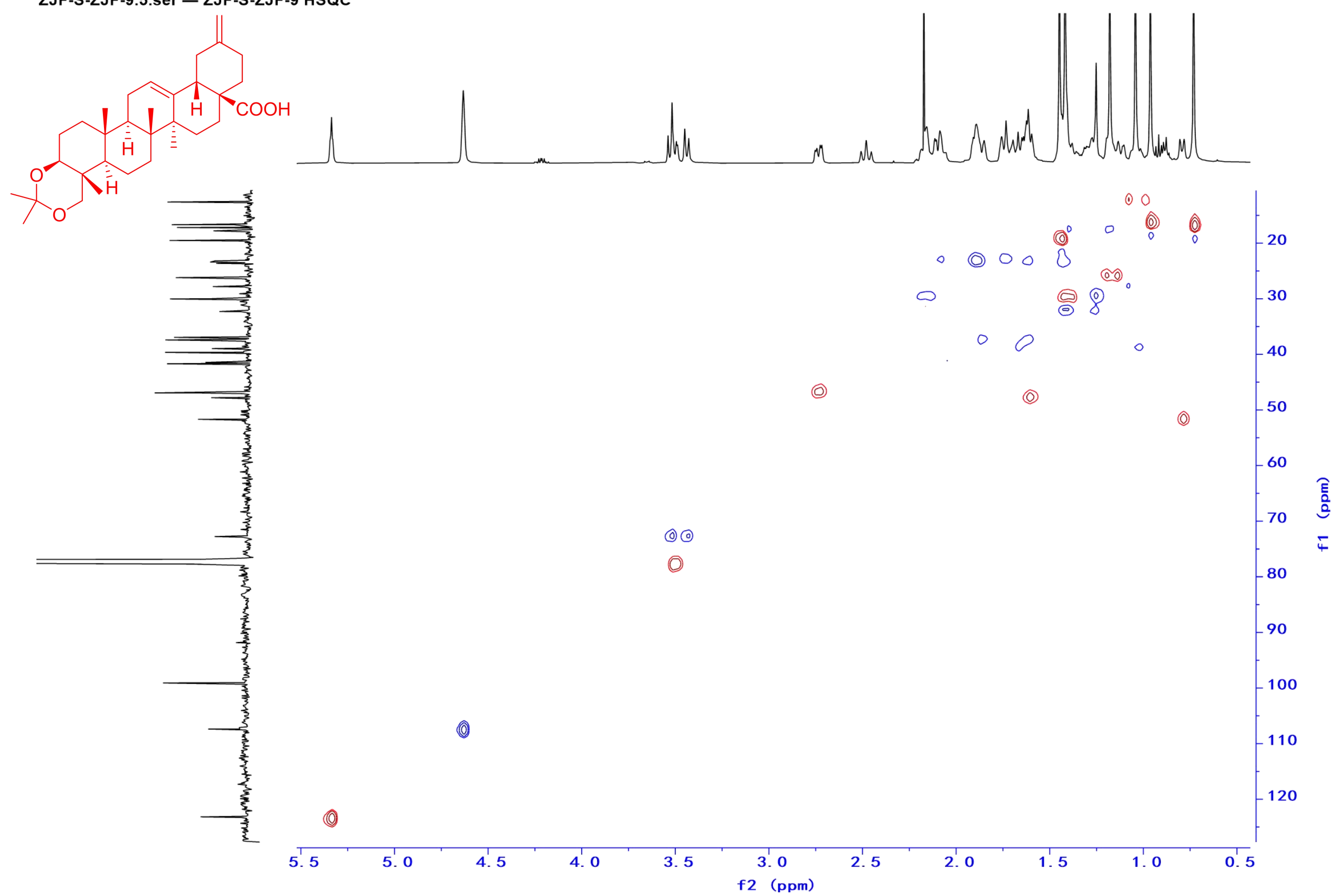

Figure S119. The HSQC Spectrum of Compound 26 in $\mathrm{CD}_{3} \mathrm{Cl}(500 \mathrm{MHz})$ 


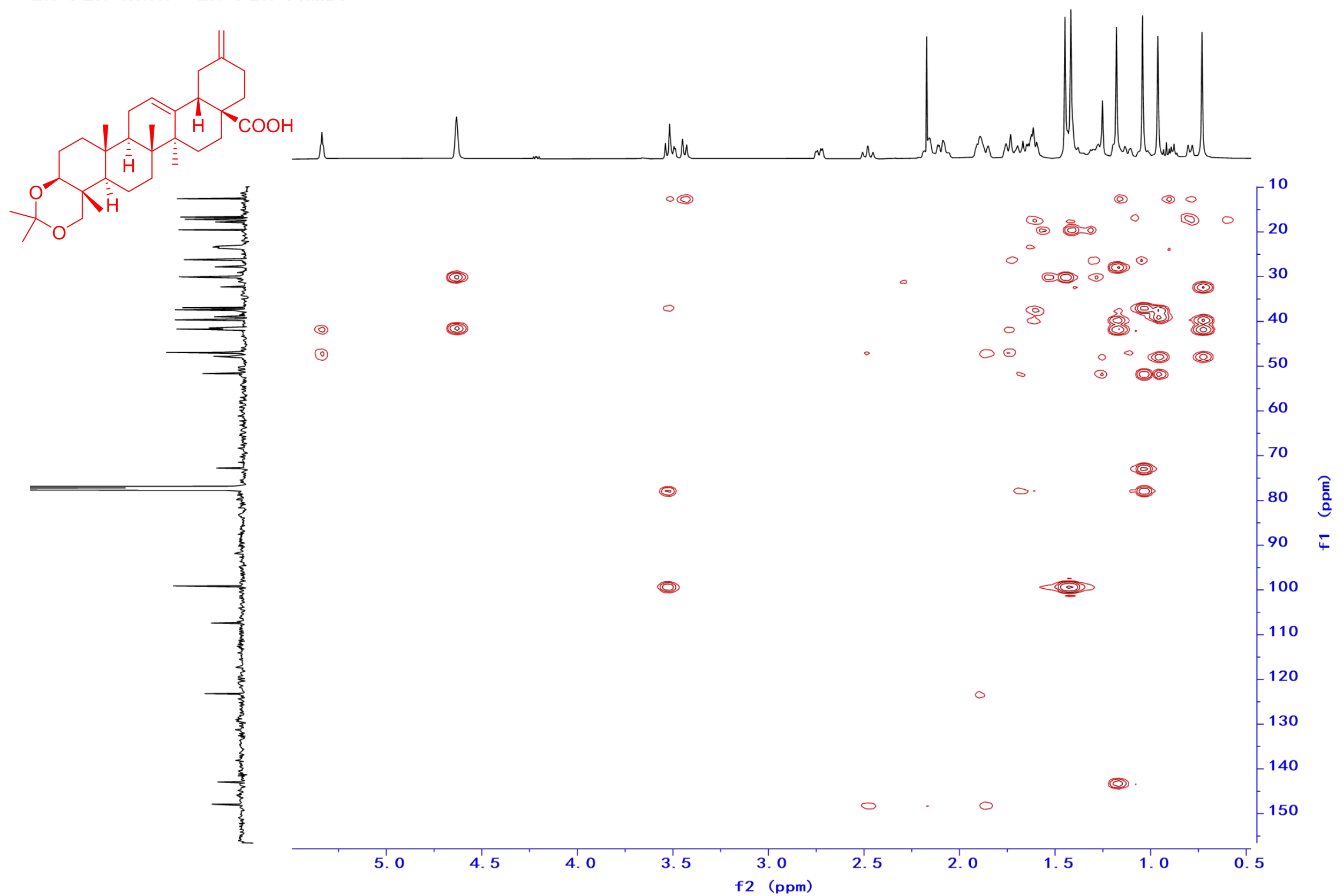

Figure S120. The HMBC Spectrum of Compound 26 in $\mathrm{CD}_{3} \mathrm{Cl}(500 \mathrm{MHz})$ 


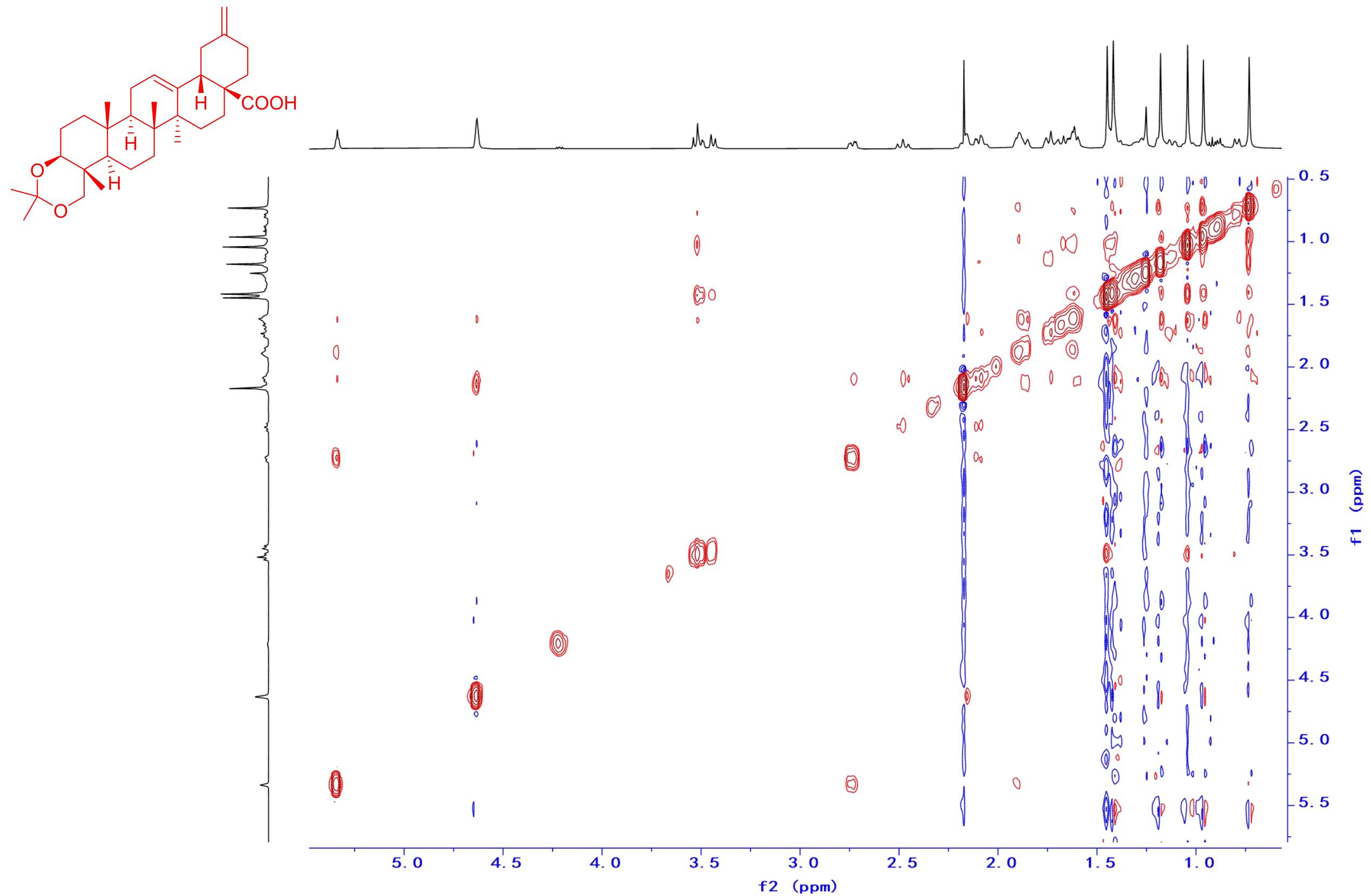

Figure S121. The NOESY Spectrum of Compound 26 in $\mathrm{CD}_{3} \mathrm{Cl}(500 \mathrm{MHz})$ 


\section{In silico prediction of ECD spectrum}

All calculations were performed using Gaussian 16. ${ }^{1}$ Conformation search using molecular mechanics calculations was performed in MOE (Molecular Operating Environment) 2015 with MMFF94s force field with $20 \mathrm{kcal} \mathrm{mol}^{-1}$ upper energy limit at best level. The conformers performed with the MOE 2015 software package were further optimized by using the TDDFT method at the B3LYP/6-31G (d, p) level, and the frequency was calculated at the same level of theory. For all optimized structures, vibrational spectra were calculated to ensure that no imaginary frequencies for energy minimum were obtained. The average values were obtained by the Boltzmann distributions, using the relative Gibbs free energies as weighting factors. The stable conformers were subjected to ECD calculation by the TDDFT method at the B3LYP/6-311G+ $(\mathrm{d}, \mathrm{p})$ level with the CPCM model in MeOH. ECD spectra of different conformers were simulated using SpecDis 1.71with a half-bandwidth of $0.3 \mathrm{eV},{ }^{2}$ and the final calculated ECD spectra were obtained according to the Boltzmann-calculated contribution of each con-former. The calculated ECD spectra were compared with the experimental data.

\section{Refferences.}

1. Gaussian 16, Revision A.03, M. J. Frisch, G. W. Trucks, H. B. Schlegel, G. E. Scuseria, M. A. Robb, J. R. Cheeseman, G. Scalmani, V. Barone, G. A. Petersson, H. Nakatsuji, X. Li, M. Caricato, A. V. Marenich, J. Bloino, B. G. Janesko, R. Gomperts, B. Mennucci, H. P. Hratchian, J. V. Ortiz, A. F. Izmaylov, J. L. Sonnenberg, D. Williams-Young, F. Ding, F. Lipparini, F. Egidi, J. Goings, B. Peng, A. Petrone, T. Henderson, D. Ranasinghe, V. G. Zakrzewski, J. Gao, N. Rega, G. Zheng, W. Liang, M. Hada, M. Ehara, K. Toyota, R. Fukuda, J. Hasegawa, M. Ishida, T. Nakajima, Y. Honda, O. Kitao, H. Nakai, T. Vreven, K. Throssell, J. A. Montgomery, Jr., J. E. Peralta, F. Ogliaro, M. J. Bearpark, J. J. Heyd, E. N. Brothers, K. N. Kudin, V. N. Staroverov, T. A. Keith, R. Kobayashi, J. Normand, K. Raghavachari, A. P. Rendell, J. C. Burant, S. S. Iyengar, J. Tomasi, M. Cossi, J. M. Millam, M. Klene, C. Adamo, R. Cammi, J. W. Ochterski, R. L. Martin, K. Morokuma, O. Farkas, J. B. Foresman, and D. J. Fox, Gaussian, Inc., Wallingford CT, 2016.

2. T. Bruhn, A. Schaumlöffel, Y. Hemberger, G. Pescitelli, SpecDis version 1.71, Berlin, Germany, 2017, http:/specdis-software.jimdo.com. 


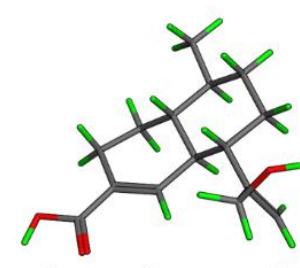

1-conformer 1

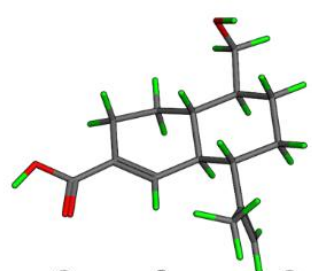

2-conformer 2

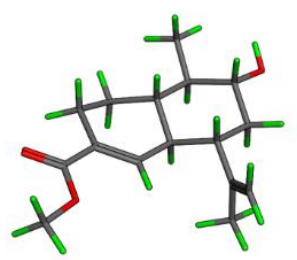

4-conformer 1

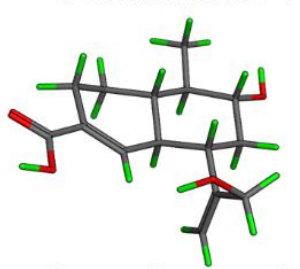

5-conformer 3

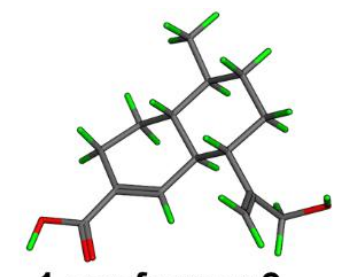

1-conformer 2

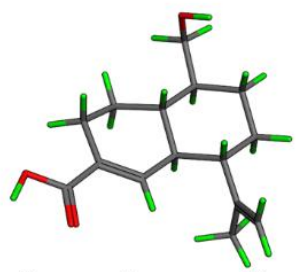

2-conformer 3

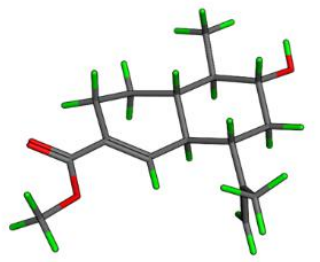

4-conformer 2

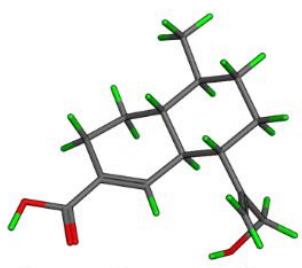

1-conformer 3

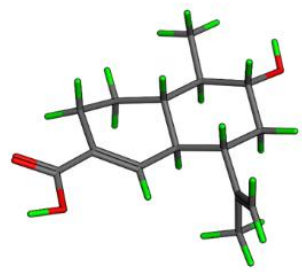

3-conformer 1

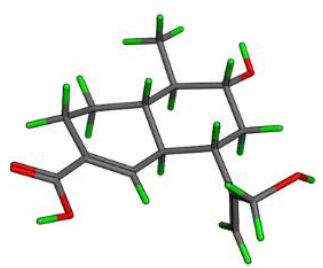

5-conformer 1

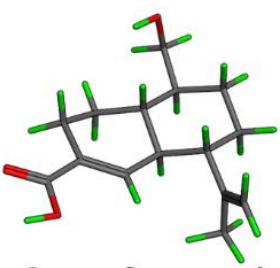

2-conformer 1

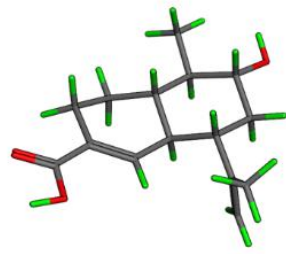

3-conformer 2

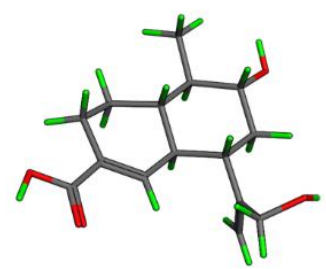

5-conformer 2

Figure S122. Low-energy Conformers of 1-5 in $\mathrm{MeOH}$

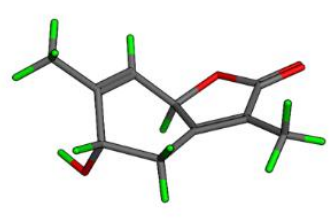

7-conformer 1

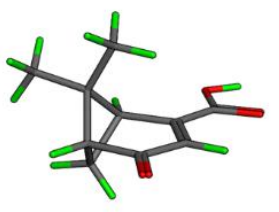

9-conformer 2

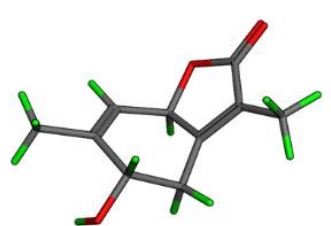

7-conformer 2

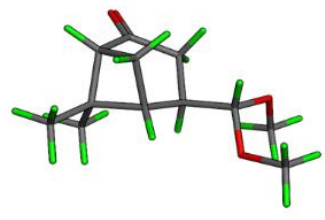

10-conformer 1

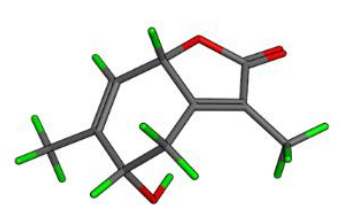

8-conformer 1

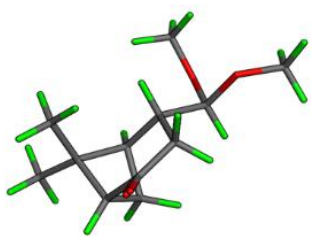

10-conformer 2

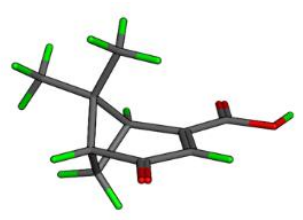

9-conformer 1

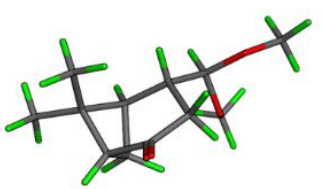

10-conformer 3

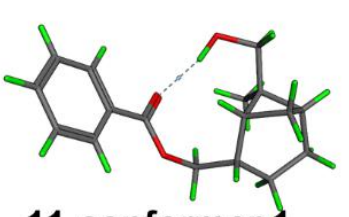

11-conformer 1

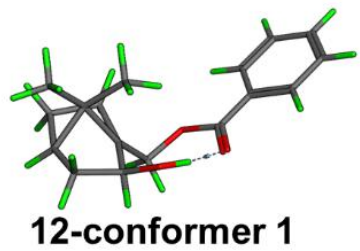

12-conformer 1

Figure S123. Low-energy Conformers of 7-12 in $\mathrm{MeOH}$ 


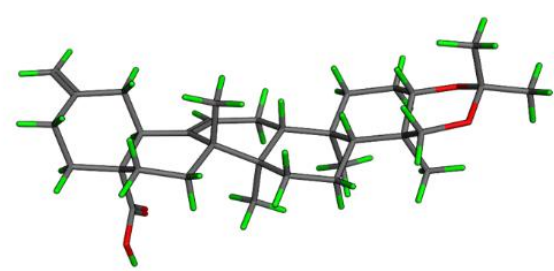

26-conformer 1

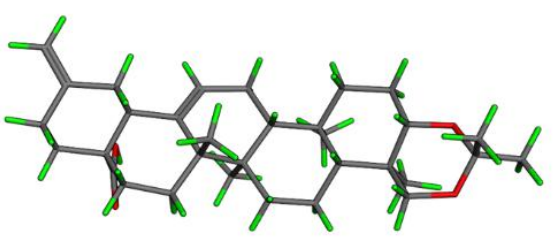

26-conformer 2

Figure S124. Low-energy Conformers of 26 in $\mathrm{MeOH}$

Table S1. Relative Energies, Equilibrium Populations, Extracted heats and weighting factors of the optimized conformers of 1-5, 7-12 and 26 at B3LYP/6-311+G(d,p) level in MeOH with PCM

\begin{tabular}{|c|c|c|c|c|c|}
\hline & Conformer & $\begin{array}{l}\text { Relative } \\
\text { Energies } \\
(\mathrm{kcal} / \mathrm{mol})\end{array}$ & $\begin{array}{l}\text { Equilibrium } \\
\text { Populations }\end{array}$ & $\begin{array}{l}\text { Extracted heats } \\
(\mathrm{kcal} / \mathrm{mol})\end{array}$ & $\begin{array}{l}\text { Boltzmann-calculated } \\
\text { contribution }(\%)\end{array}$ \\
\hline \multirow{4}{*}{1} & 1 & 0 & 0.566488367 & -810.7540875 & 0 \\
\hline & 2 & 0.40124696 & 0.287661470 & -810.7538160 & 64.68 \\
\hline & 3 & 0.83766931 & 0.137648574 & -810.7522632 & 35.32 \\
\hline & 1 & 0 & 0.317138599 & -810.7551857 & 48.72 \\
\hline \multirow[t]{2}{*}{2} & 2 & 0.05453676 & 0.289232517 & -810.7533952 & 15.64 \\
\hline & 3 & 0.22636622 & 0.216377698 & -810.7540376 & 35.64 \\
\hline \multirow{2}{*}{3} & 1 & 0 & 0.563825898 & -810.7600376 & 79.72 \\
\hline & 2 & 0.16441619 & 0.427118060 & -810.7587003 & 20.28 \\
\hline \multirow{3}{*}{4} & 1 & 0 & 0.416040206 & -850.0683802 & 81.28 \\
\hline & 2 & 0.045812536 & 0.385063557 & -850.0670320 & 18.72 \\
\hline & 1 & 0 & 0.299089009 & -886.0000824 & 34.65 \\
\hline \multirow{2}{*}{5} & 2 & 0.18405204 & 0.219179905 & -885.9995412 & 20.42 \\
\hline & 3 & 0.34520575 & 0.166953925 & -886.0003855 & 44.93 \\
\hline \multirow{2}{*}{7} & 1 & 0 & 0.567562022 & -614.1338724 & 0.9 \\
\hline & 2 & 0.16099747 & 0.432437978 & -614.1383070 & 99.1 \\
\hline 8 & 1 & 0 & 0.999986637 & -614.1384280 & 100 \\
\hline \multirow{2}{*}{9} & 1 & 0 & 0.608080616 & -614.1207607 & 70.27 \\
\hline & 2 & 0.26007891 & 0.391919384 & -614.1198746 & 29.73 \\
\hline \multirow{3}{*}{10} & 1 & 0 & 0.377160690 & -695.1496450 & 43.11 \\
\hline & 2 & 0.16968693 & 0.283180483 & -695.1497852 & 50.16 \\
\hline & 3 & 0.47312698 & 0.169626650 & -695.1479860 & 6.73 \\
\hline 11 & 1 & 0 & 0.789955155 & -886.9608809 & 100 \\
\hline 12 & 1 & 0 & 0.940813546 & -886.9765052 & 100 \\
\hline \multirow{2}{*}{26} & 1 & 0 & 0.580513415 & -1549.6159635 & 58.54 \\
\hline & 2 & 0.197291 & 0.416009598 & -1549.6156148 & 41.46 \\
\hline
\end{tabular}



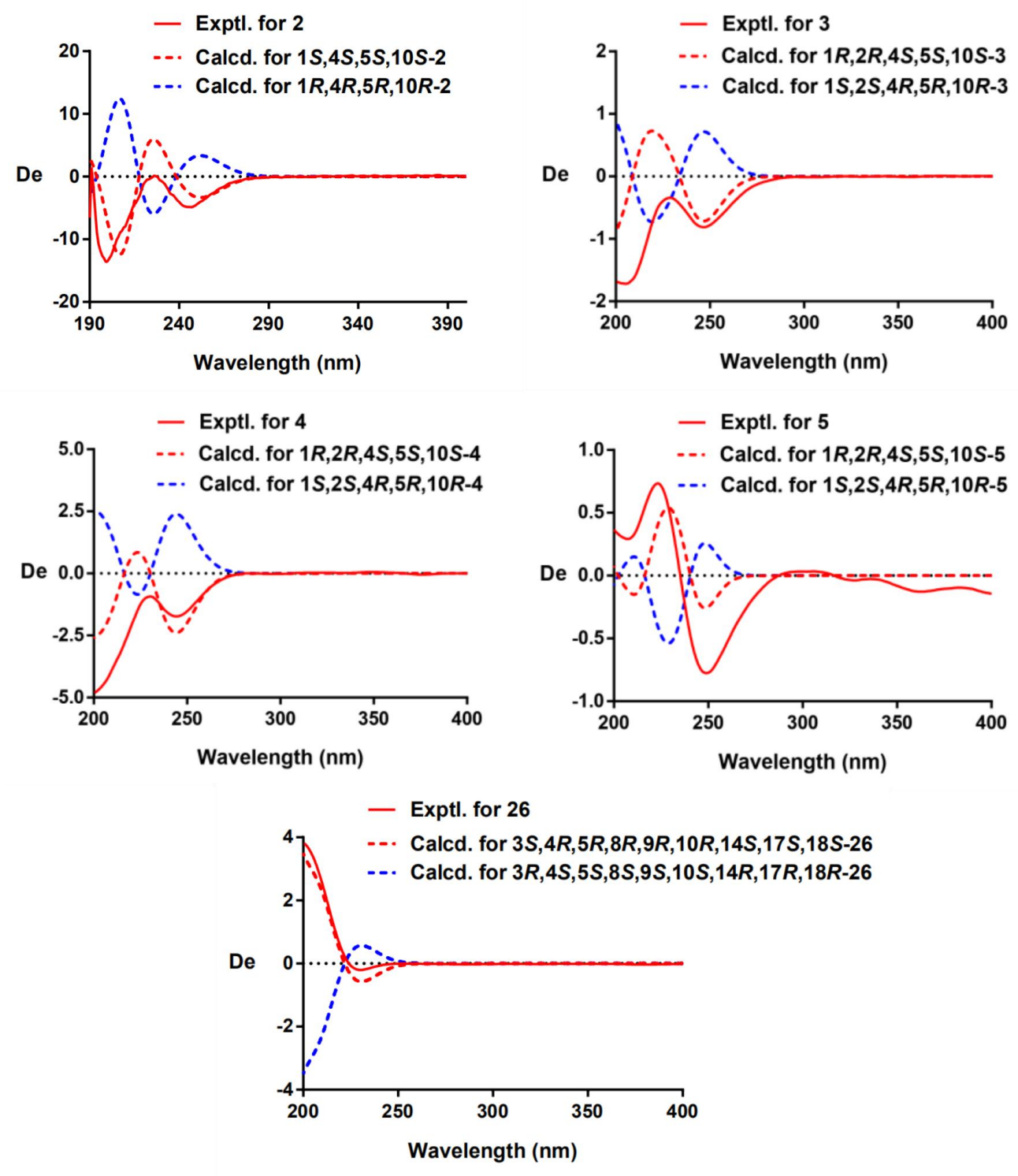

Figure S125. Experimental and calculated ECD data of compounds 2-5 and 26 


\section{General Experimental Procedures}

Melting points were obtained on a Boetius Micro Melting Point Apparatus. Optical rotations were measured on a Rudolph Research Autopol III automatic polarimeter. UV spectra were measured on a Cary 300 spectrometer. ECD spectra were recorded on a JASCO J-815 spectrometer. IR spectra were obtained on a Nicolet Impact 400 FT-IR Spectrophotometer. The NMR experiments were conducted on a Bruker spectrometer $\left(600 \mathrm{MHz}\right.$ for ${ }^{1} \mathrm{H}$ or $150 \mathrm{MHz}$ for $\left.{ }^{13} \mathrm{C}\right)$ or a Varian INOVA spectrometer $\left(500 \mathrm{MHz}\right.$ for ${ }^{1} \mathrm{H}$ or $125 \mathrm{MHz}$ for ${ }^{13} \mathrm{C}$ ) equipped with an inverse detection probe. HR-ESIMS data were acquired on an Agilent 6520 Accurate-Mass Q-TOFL CMS spectrometers (Agilent Technologies, Ltd., Santa Clara, CA, USA). Column chromatography (CC) was run using MCI gel (CHP20P), silica gel (100-200 or 200-300 mesh, Qingdao Marine Chemical Inc., China), and Sephadex LH-20 (Pharmacia Biotech AB, Uppsala Sweden). Analytical HPLC was performed with an Agilent HP 1260 using a Titank column (Guangzhou FLM Scientific Instrument Co., Ltd.) packed with $\mathrm{C}_{18}(250 \times 4.6 \mathrm{~mm}, 5 \mu \mathrm{m})$. HPLC separation was conducted on Waters HPLC equipment, namely, a Waters 600 pump, a Waters 600 controller, and Waters 2487 dual $\lambda$ absorbance detector, using the following columns: Shiseido Capcell Pak MGIII $\mathrm{C}_{18}(250 \times 4.6 \mathrm{~mm}, 5$ $\mu \mathrm{m})$, Waters XBridge ${ }^{\mathrm{TM}}$ Prep Shield $\mathrm{RP}_{18}(250 \times 10 \mathrm{~mm}, 5 \mu \mathrm{m})$, Welch Ultimate ${ }^{\circledR} \mathrm{XB}-$ Phenyl $(250 \times 10$ $\mathrm{mm}, 5 \mu \mathrm{m})$ and Welch Ultimate ${ }^{\circledR}$ XB-C8 $(250 \times 10 \mathrm{~mm}, 5 \mu \mathrm{m})$. All fluorescence-based assays were performed on a SpectraMax ${ }^{\circledR}$ iD3 Molecular Device. 
Table S2. The Inhibitory Activity of Fractions A-J Against hCEs

\begin{tabular}{lll}
\hline Fractions & \multicolumn{2}{c}{ Inhibition (\%) $10 \mu \mathrm{g} / \mathrm{mL}$} \\
& hCES1A 1 & hCES $2 \mathrm{~A} 1$ \\
\hline $\mathrm{A}$ & $\mathbf{6 7 . 1 9}$ & $\mathbf{5 9 . 7 9}$ \\
\hline $\mathrm{B}$ & $\mathbf{7 4 . 0 3}$ & $\mathbf{7 8 . 2 7}$ \\
\hline $\mathrm{C}$ & $\mathbf{6 4 . 6 4}$ & $\mathbf{9 2 . 0 2}$ \\
\hline $\mathrm{D}$ & $\mathbf{5 2 . 8 6}$ & $\mathbf{7 8 . 1 4}$ \\
\hline $\mathrm{E}$ & $\mathbf{3 7 . 1 1}$ & $\mathbf{7 1 . 9 5}$ \\
\hline F & $\mathbf{1 5 . 2 1}$ & $\mathbf{5 2 . 7 0}$ \\
\hline $\mathrm{G}$ & $\mathbf{2 . 9 9}$ & $\mathbf{5 8 . 8 8}$ \\
\hline $\mathrm{H}$ & $\mathbf{2 0 . 7 1}$ & $\mathbf{6 4 . 6 2}$ \\
\hline $\mathrm{I}$ & $\mathbf{1 3 . 2 8}$ & $\mathbf{5 3 . 3 1}$ \\
\hline J & $\mathbf{- 0 . 2 9}$ & $\mathbf{4 5 . 0 8}$ \\
\hline
\end{tabular}

Table S3. IC $\mathrm{IC}_{50}$ Values of 1, 6, 10, 11, 13-15, 18-20, 22, and 24-26 on hCES2A1

\begin{tabular}{clcl}
\hline compounds & $\mathrm{IC}_{50}(\mu \mathrm{M})$ & compounds & $\mathrm{IC}_{50}(\mu \mathrm{M})$ \\
\hline $\mathbf{1}$ & $5.1 \pm 0.44$ & $\mathbf{1 8}$ & $14.5 \pm 2.84$ \\
$\mathbf{6}$ & $3.8 \pm 0.53$ & $\mathbf{1 9}$ & $1.9 \pm 0.26$ \\
$\mathbf{1 0}$ & $6.3 \pm 0.58$ & $\mathbf{2 0}$ & $4.6 \pm 0.59$ \\
$\mathbf{1 1}$ & $8.2 \pm 0.91$ & $\mathbf{2 2}$ & $5.0 \pm 0.98$ \\
$\mathbf{1 3}$ & $10.2 \pm 1.39$ & $\mathbf{2 4}$ & $2.2 \pm 0.23$ \\
$\mathbf{1 4}$ & $16.8 \pm 2.79$ & $\mathbf{2 5}$ & $5.3 \pm 0.66$ \\
$\mathbf{1 5}$ & $5.8 \pm 1.10$ & $\mathbf{2 6}$ & $4.6 \pm 0.27$ \\
$\mathbf{L P A}$ & $1.20 \pm 0.10$ & & \\
\hline
\end{tabular}

Table S4. IC 50 Values of 18-26 on hCES1A1

\begin{tabular}{cc}
\hline compounds & $\mathrm{IC}_{50}(\mu \mathrm{M})$ \\
\hline $\mathbf{1 8}$ & $0.14 \pm 0.01$ \\
$\mathbf{1 9}$ & $2.12 \pm 0.12$ \\
$\mathbf{2 0}$ & $0.13 \pm 0.02$ \\
$\mathbf{2 1}$ & $0.26 \pm 0.04$ \\
$\mathbf{2 2}$ & $0.57 \pm 0.03$ \\
$\mathbf{2 3}$ & $0.37 \pm 0.04$ \\
$\mathbf{2 4}$ & $1.1 \pm 0.10$ \\
$\mathbf{2 5}$ & $2.3 \pm 0.21$ \\
$\mathbf{2 6}$ & $4.1 \pm 0.57$ \\
\hline
\end{tabular}

